${ }^{*}$ RMIS View/Frint Document Cover Sheet tow

This document was retrieved from the Documentation and Records Management (DRM) ISEARCH System. It is intended for Information only and may not be the most recent or updated version. Contact a Document Service Center (see Hanford Info for locations) if you need additional retrieval information.

Accession \#: D196022534

Document \#: SD-WM-RPT-210

Title/Desc:

PRELIMINARY LLW FEED STAGING PLAN

Pages: 202 


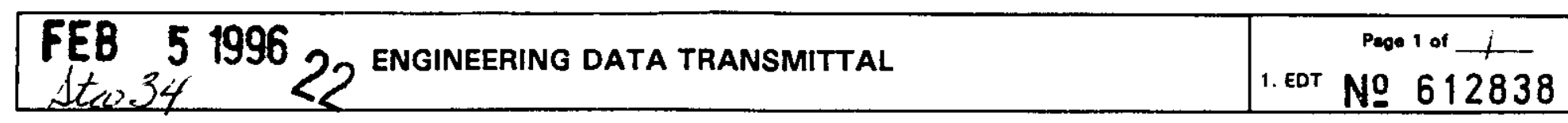

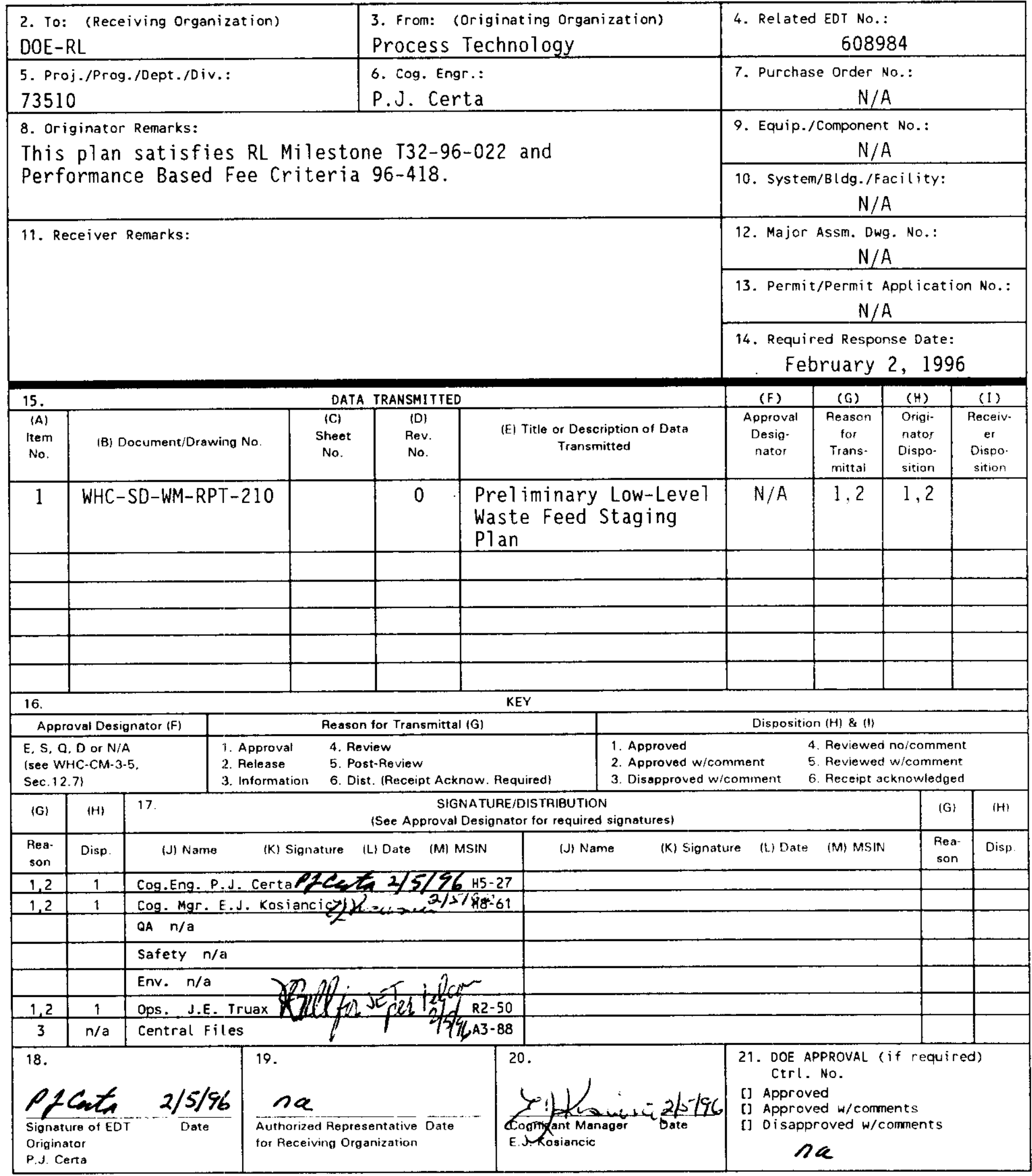

BD-7400-172-2 (04/94) GEF097 


\title{
PRELIMINARY LOW-LEVEL WASTE FEED STAGING PLAN
}

\author{
P.J. CERTA \\ C.M. MCCONVILLE \\ L.W. SHELTON \\ E.J. SLAATHAUG \\ WESTINGHOUSE HANFORD COMPANY, Richland. WA 99352 \\ U.S. Department of Energy Contract DE-AC06-87RL10930
EDT/ECN: 612838
Org Code: 73510
UC: 2020
Charge Code: 06129
B\&R Code: EW3130010
Total Pages: 202

Key Words: low-level waste, feed staging, double-shell tank (DST), supernate, private contractor, DST retrieval sequence, analysis, Phase I privatization, feed specifications, feed envelopes, Monte-Carlo, tank heels, tank inventory.

Abstract: A preliminary low-level waste feed staging plan is developed to support Phase I privatization efforts. Issues that potentially affect staging of DST supernate are identified as are recommended changes to the draft request for proposal.

TRADEMARK DISCLAIMER. Reference herein to any specific commercial product, process, or service by trade name, trademark. manufacturer, or otherwise, does not necessarily constitute or imply its endorsement, recommendation. or favoring by the United States Government or any agency thereof or its contractors or subcontractors.

Printed in the United States of America. To obtain copies of this document contact WHC/BCS Document Control Services. P.O. Box 1970. Mailstop H6-08. Richland WA 99352. Phone (509) 372-2420; Fax (509) 376-4989
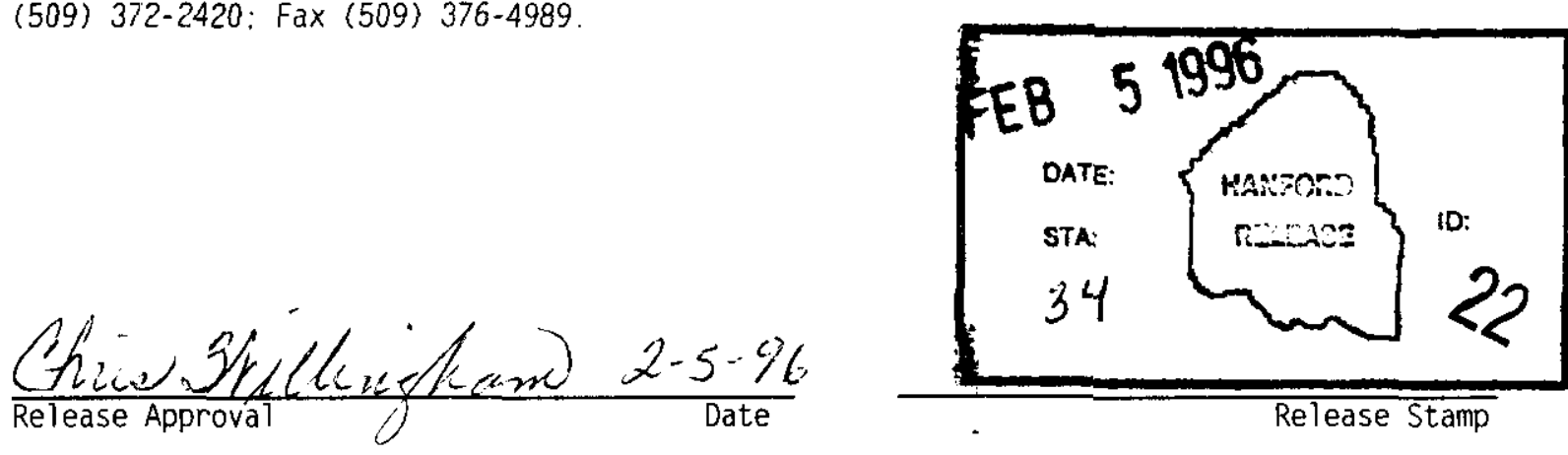

\section{Approved for Public Release}




\section{Preliminary Low-Level Waste Feed Staging Plan}

Prepared for the U.S. Department of Energy Office of Environmental Restoration and Waste Management

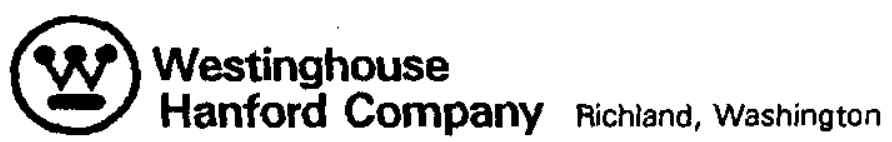

Manegement and Operations Contractor for the

U.S. Department of Energy under Contract DE-ACO6-87RL10930

Approved for Public Release 


\section{ACKNOWLEDGMENTS}

The author would like to thank the following Westinghouse Hanford Company contributors: E. J. Slaathaug for performing the heel mixing study; L. $W$. Shelton for the preparing the projected supernate inventories and the original spreadsheet used to assess the feed envelopes and double-shell tank supernate; C.M. McConville for reviewing and modifying the assessment spreadsheet and performing the assessments of the feed envelopes, double-and single-shell tank supernate and the staged feed batches; and J.N. Strode for performing the special operational waste volume projection. Considerable guidance concerning the interpretation of the draft request for proposal has been provided by K.D. Wiemers and W.G. Richmond (Pacific Northwest Laboratories), J.A. Voogd (Westinghouse Hanford Company) and R.A. Gilbert (DOE Richland Operations).

E.J. Slaathaug, L.W. Shelton, C.M. McConville and J.D. Galbraith have each written sections of this report.

M.A. Fouts for coordinating the production of this document and providing technical editing support and M.C. Newman for providing word processing support under less than optimal conditions (BCS Richland).

Additionally, the author is indebted to C.M. McConville and L.W. Shelton for the evenings and weekends they lost during the preparation of this report. 
WHC-SD-WM-RPT-210, Rev. 0

This page intentionally left blank. 


\section{EXECUTIVE SUMMARY}

A Preliminary Low-Level Waste Feed Staging Plan was prepared. The plan supports the Phase I privatization effort by providing recommendations that may influence the technical content of the final request for proposal, and the interface control documents for the turnover of two double-shell tanks (DST) to the private contractors for use as feed tanks and the transfer of supernate to these tanks. Additionally, the preliminary schedule of feed staging activities will be useful to both $\mathrm{RL}$ and the private bidders during the contract negotiation period. A revised feed staging plan will be issued in August 1996 reflecting anticipated changes in the request for proposal, resolution of issues identified in this report, and completion of additional work scope.

Highlights from the report are listed below. The remainder of the Executive Summary discusses them in more detail:

- A preliminary feed staging plan was prepared that delivers supernate containing a total of $9500 \mathrm{MT} \mathrm{Na}$ to the private contractors.

- A special Operational Waste Volume Projection (OWVP) suggests that there is sufficient DST tank space to support feed staging activities provided the SST retrieval sequence and schedule conform to the available DST space.

- A cursory review suggests that some of the waste compatibility rules may interfere with feed staging activities - further study is required.

- Two DSTs are needed for intermediate staging of feed prior to transfer to the private contractors feed tanks. Tanks 102-AP and 104-AP are proposed for this purpose.

- The draft RFP should be modified to increase the length of the second and third batches of feed.

- The heel remaining in the intermediate staging tanks and the private contractors feed tanks should be kept as small as possible when changing feed envelopes. 
- Seventy-five percent of the available DST supernate (Na mass basis) fits within the feed envelopes. This is not enough feed to supply the maximum order quantities, but meets the minimum order quantities.

- Modifications to the feed envelopes should be considered: remove most lower concentration limits; remove the physical property limits, especially $\mathrm{Spg}$; increase the upper $\mathrm{Na}$ concentration limit to minimize required dilution water; and express the limits as ratios to the $\mathrm{Na}$ concentration.

- About twenty percent of the composition data needed to classify DST supernate according to envelope was either not available or reported as "less than" values. Values of zero were assumed to enable the analysis to proceed.

- Solid-liquid equilibria was not considered in preparation of the preliminary feed staging plan.

A schedule was prepared to show the various feed staging transfers and other activities, including the private contractors' campaigns. The following table summarizes the campaigns for both private contractors: 
WHC-SD-WM-RPT-210, Rev. 0

\begin{tabular}{|l|r|r|r|r|}
\hline \multicolumn{3}{|c|}{ Summary of Supernate Delivered to the Private Contractors } \\
\hline \multirow{4}{*}{\begin{tabular}{l} 
Concept \\
\cline { 2 - 5 }
\end{tabular}} & Envelope & $\begin{array}{r}\text { Contractor 1 } \\
\text { (MT Na) }\end{array}$ & $\begin{array}{r}\text { Contractor 2 } \\
\text { (MT Na) }\end{array}$ & $\begin{array}{r}\text { Totals } \\
\text { (MT Na) }\end{array}$ \\
\cline { 2 - 5 } & $\mathrm{A}$ & 520 & 550 & 1070 \\
\cline { 2 - 5 } & $\mathrm{B}$ & 210 & 210 & 420 \\
\cline { 2 - 5 } & $\mathrm{C}$ & 190 & 220 & 410 \\
\hline Extension & $\mathrm{A}$ & 2620 & 2550 & 5170 \\
\cline { 2 - 5 } & Subtotal & 3540 & 3530 & 7070 \\
\cline { 2 - 5 } & $\mathrm{A}$ & 660 & 420 & 1080 \\
\hline \multirow{3}{*}{$\begin{array}{l}\text { By } \\
\text { Envelope }\end{array}$} & Subtotal & 490 & 860 & 1350 \\
\cline { 2 - 5 } & TOTAL & 4690 & 1280 & 2430 \\
\cline { 2 - 5 } & $\mathrm{A}$ & 3800 & 4810 & 9500 \\
\hline & $\mathrm{B}$ & 210 & 3520 & 7320 \\
\hline
\end{tabular}

A special OWVP was performed using assumptions similar to, but not identical with, those in this report. No SST retrieval (other than C-106) was assumed. This allowed the space available for SST retrieval as a function of time to be estimated. The results suggest that there is sufficient DST space to support feed staging activities if the SST retrieval is planned to fit within the remaining space.

The waste compatibility DOO rules were applied to the projected DST supernate and to the proposed staging schedule to identify potential problems. The proposed staging schedule conflicts to some degree with many of the rules in the waste compatibility DQO. Most of the conflicts are not specific to the proposed feed staging schedule. Some of the rules allow exceptions under specific 
conditions so that issues may be easily resolved; other rules may require further investigation or interpretation of policy. The rules that may present problems are: 1) Flammable Gas Accumulation, 2) TRU Segregation, 3) Heat Generation Rate, 4) Complexed Waste Segregation and 5) the Tank Waste Type.

Three feed staging strategies were studied using a Monte Carlo simulation. In this type of analysis, many variables are allowed to vary randomly within a specified range to account for uncertainty. The length of the feed outage (the time that the private contractors are waiting for feed from the M\&l contractor) and the amount of time available for contingencies (such as correcting out-ofspecification feed or delays that are a result of conflicting transfers) were used as performance measures. The analysis recommended that the alternative called Indirect Staging - ASAP be implemented over the Indirect Staging - When Notified and the Direct Staging alternatives.

In the Indirect Staging - ASAP alternative, retrieved DST supernate are transferred to an intermediate DST for staging prior to transfer to the private contractors' feed tanks. Tanks 102-AP and 104-AP are proposed for this purpose. Staging of each batch in the intermediate staging tanks begins as soon as the intermediate staging tank is available. Indirect Staging - When Notified is a variation in which intermediate staging is not started until RL receives the advance notice from the private contractor stating when feed will be needed. In Direct Staging, all staging transfers are made directly into the private contractors' feed tanks.

The Indirect Staging - ASAP alternative was successful in staging waste within the 60-day feed delivery window for $94 \%$ of the simulation cases. The median outage length was 13 days and 219 days were available for contingencies. Feed would be available $91 \%$ of the time, well within the allocated $80 \%$. If the 


\section{WHC-SD-WM-RPT-210, Rev. 0}

duration of the feed delivery window was reduced to 30 days, waste would be staged successfully for only $65 \%$ of the simulation cases.

The Indirect Staging - When Notified alternative was successful in staging waste within the 60-day feed delivery window for $53 \%$ of the simulation cases. The median outage length was 57 days and an unacceptable 4 days were available for contingencies. Feed would be available $78 \%$ of the time, just outside the allocated $80 \%$. If the duration of the feed delivery window was reduced to 30 days, waste would be staged successfully for only $25 \%$ of the simulation cases.

The Direct Staging alternative was successful in staging waste within the 60 -day feed delivery window for $27 \%$ of the simulation cases. The median outage length was 75 days and there was no time available for contingencies. Feed would be available $73 \%$ of the time, outside the allocated $80 \%$. If the duration of the feed delivery window was reduce to 30 days, waste would be staged successfully for only $1 \%$ of the simulation cases.

The relative performance of the three feed staging strategies in terms of time available for contingencies simply corresponds to the amount slack in the schedule. For a given deadline (the target ready-for-feed date), the sooner staging begins, the more slack is available.

Seven sensitivity cases and three parametric studies suggest that the recommended alternative, Indirect Staging - $A S A P$, is robust with respect to changing assumptions.

The feed staging study developed the following guidelines (these are not hard limits but require serious consideration): 
- The minimum scheduled campaign length (processing time) should be kept larger than 210 to 275 days to ensure sufficient contingency for restaging out-of-specification feed. This corresponds to a feed batch containing 400 to $500 \mathrm{MT} \mathrm{Na}$ at a 0.75 plant operating efficiency.

- The minimum scheduled campaign length (processing time) should be kept larger than 90 to 125 days to avoid increases in the length of the nominal outage. This corresponds to a feed batch containing 170 to $235 \mathrm{MT} N \mathrm{Na}$ at a 0.75 plant operating efficiency.

A Recommended Case was developed based upon these guidelines and other results from the sensitivity and parametric studies. This case requires modification of the draft RFP to permit the longer campaign lengths for the second and third feed batches (Envelope $\mathrm{B}$ and $\mathrm{C}$ ). For the Recommended Case, the Indirect Staging - ASAP alternative was successful in staging waste within the 60 -day feed delivery window for $100 \%$ of the simulation cases. The median outage length was 8 days and 249 days were available for contingencies. Feed would be available $94 \%$ of the time, well within the allocated $80 \%$. If the duration of the feed delivery window was reduced to 30 days, waste would be staged successfully for about $72 \%$ of the simulation cases.

A heel mixing study investigated the maximum heel that could remain in the intermediate feed staging tanks and the private contractors' feed tanks when switching over to a new feed envelope. To be conservative, the full range of waste composition permitted by the three feed envelopes were explored rather than limiting the analysis to estimated waste compositions. Switching from Envelope $B$ or $C$ to any other envelope requires as small a heel as is reasonable (about $0.1 \mathrm{ML}$ or about 10 inches of waste) to ensure that the new feed batch remains in the intended envelope. 
The projected DST supernate were classified according to envelope; in all, supernate from sixteen DSTs fit Envelopes A, B or C. Thirteen DSTs fit Envelope A, one fits Envelope B, and two fit Envelope C. The evaporator feed tank (102-AW) and product tank (106-AW) were not considered in this study. Tank 102-AW was projected to contain dilute evaporator feed and 106-AW was projected to contain only solids. The remaining ten DSTs did not fit any envelope and thus are excluded from use as feed. The quantity of available supernate that fit within the envelopes is $9500 \mathrm{MT} \mathrm{Na}$. This represents about $75 \%$ of the total available supernate (12600 MT Na). Supernate containing about $3100 \mathrm{MT} N \mathrm{Na}$ was excluded from the envelopes. Tanks 101-SY and 103-SY were included as part of the total available supernate, but not considered as viable feed since additional pretreatment (water wash as part of retrieval and first stage settle/decant) would be required to prepare them as feed for the private contractors.

In most cases, the excluded supernate would satisfy the feed envelopes if the lower concentration limits were removed. Other potential limit changes to both the upper and lower limits needed to fit the excluded supernate in the envelopes were identified.

There is sufficient sodium present in the DST supernate that meets feed envelope specifications to provide the minimum order quantities to both private contractors. However, there is not enough available sodium to meet the maximum order quantities, as shown in the following table: 
WHC-SD-WM-RPT-210, Rev. 0

\begin{tabular}{|c|c|c|c|}
\hline \multicolumn{4}{|c|}{$\begin{array}{l}\text { Comparison of Supernate Meeting Envelope Specifications with Minimum and } \\
\text { Maximum Order Quantities }\end{array}$} \\
\hline Envelope & $\begin{array}{l}\text { Minimum Order } \\
\text { Quantity } \\
\text { Total for two } \\
\text { Contractors } \\
\text { (MT Na) }\end{array}$ & $\begin{array}{l}\text { Available Feed } \\
\text { Total for two } \\
\text { contractors } \\
\text { (MT Na) }\end{array}$ & $\begin{array}{l}\text { Maximum Order } \\
\text { Quantity } \\
\text { Total for two } \\
\text { contractors } \\
\text { (MT Na) }\end{array}$ \\
\hline A & 5200 & 7400 & 13000 \\
\hline B & 200 & 400 & 2000 \\
\hline C & 200 & 1700 & 7400 \\
\hline Total & 5600 & 9500 & 22400 \\
\hline Excluded & na & 3100 & na \\
\hline $\begin{array}{l}\text { Grand } \\
\text { Total }\end{array}$ & na & 12600 & na \\
\hline
\end{tabular}

The estimated soluble fraction of waste present in the SSTs was classified according to envelope in case it was desired to process this fraction during Phase I. Twenty-five of the SSTs fit Envelope A. No SSTs fit Envelope B or C. The soluble $\mathrm{Na}$ inventory of the SSTs fitting Envelope $A$ is about 14,400 MT which represents about twenty-five percent of the soluble Na inventory for all SSTs.

This will be investigated further as part of the Confirmed LLW Feed Staging Plan in order to determine understand why only twenty-five percent of the soluble SST fraction fit the envelopes (e.g., envelope limits too restrictive, missing data in the estimated SST inventory).

${ }^{1}$ Discrepancies between this and the previous table are caused by a combination of round-off-error and the heels remaining in the intermediate staging tanks and the private contractors' feed tanks.

${ }^{2}$ The available $\mathrm{Na}$ has been reduced to reflect the portion remaining behind in the source tank heels. 
The projected DST supernate inventories are consistent with the TWRS Process Flowsheet (except when newer data is available), the latest revision of the Operational Waste Volume Projection, and the C-106 and NCAW consolidation plans. The NCRW plans were not available in sufficient detail for incorporation into the projected inventory. This, however, only affects supernate in a few tanks. Approximately twenty percent of the data needed to classify supernate according to envelope was either not available or reported as "less than" values. Data Quality Objectives should be prepared to 1) obtain this data and 2) address the sampling needs during feed staging activities.

Most of the DST supernate requires dilution with water in order to satisfy the envelope limits. Addition of water to supernate containing high concentrations of aluminate may cause gibbsite to precipitate (around three volume percent). This will probably returned by the private contractors as part of the Entrained Solids stream. The disposition of the gibbsite (if any is formed) has not been addressed since solid-liquid equilibria was not modeled. 
WHC-SD-WM-RPT-210, Rev. O

This page intentionally left blank. 


\section{CONTENTS}

EXECUTIVE SUMMARY

FIGURES $\ldots \ldots \ldots \ldots \ldots \ldots \ldots \ldots \ldots \ldots \ldots \ldots \ldots \ldots \ldots \ldots \ldots$

TABLES $\ldots \ldots \ldots \ldots \ldots \ldots \ldots \ldots \ldots \ldots \ldots \ldots \ldots \ldots \ldots \ldots \ldots \ldots i i$

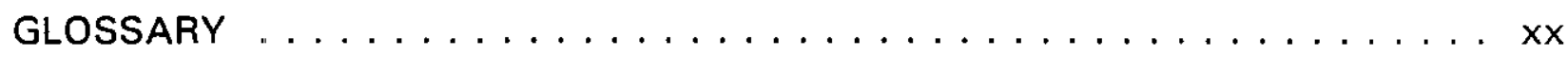

1. INTRODUCTION . . . . . . . . . . . . . . . . . 1-1

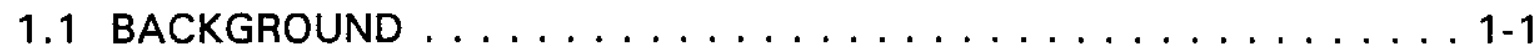

1.2 PURPOSE AND SCOPE $\ldots \ldots \ldots \ldots \ldots \ldots \ldots \ldots \ldots \ldots \ldots$

1.3 METHODOLOGY AND ORGANIZATION $\ldots \ldots \ldots \ldots \ldots \ldots \ldots$

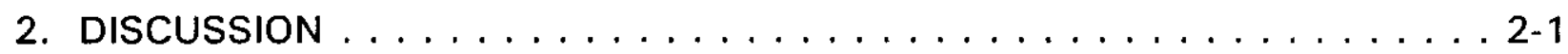

2.1 ASSUMPTIONS .................... $2-1$

2.2 FEED STAGING STRATEGY $\ldots \ldots \ldots \ldots \ldots \ldots \ldots \ldots \ldots \ldots \ldots \ldots .2-2$

2.2.1 Alternatives .................. 2-3

2.2 .2 Simulation Results . . . . . . . . . . . . 2-7

2.2 .3 Conclusions . . . . . . . . . . . . . . 2-10

2.3 PROJECTED DST WASTE INVENTORIES $\ldots \ldots \ldots \ldots \ldots \ldots \ldots$

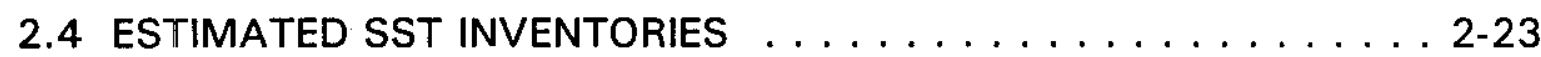

2.5 FEED ENVELOPE ASSESSMENT AND TANK CLASSIFICATION . . . 2-24

2.5.1 Feed Envelope Specifications . . . . . . . . . . . 2-24

2.5.2 Double-Shell Tank Supernate Classification . . . . . . . 2-27

2.5.3 Sensitivity of DST Classification Against Supernate Composition

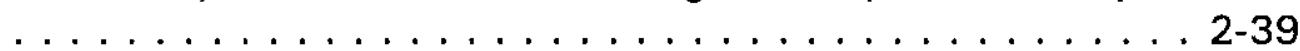

2.5 .3 SST Classification . . . . . . . . . . . . . 2-39

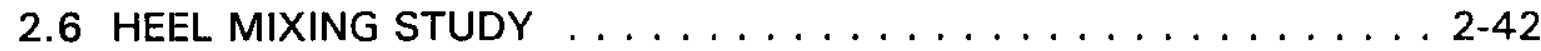

2.6.1 Calculation of Trial Waste Compositions . . . . . . . 2-42

2.6 .2 Results . . . . . . . . . . . . . . . . 2-43

2.6 .3 Conclusions . . . . . . . . . . . . . . . . 2-44

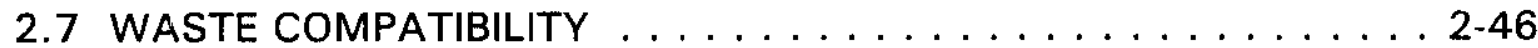

2.7.1 Criticality Decision Rule . . . . . . . . . . . . . 2-46

2.7.2 Flammable Gas Accumulation Decision Rule . . . . . . . 2-46

2.7 .3 Energetics . . . . . . . . . . . . . . . . 2-48

2.7.4 Corrosion Decision Rule . . . . . . . . . . . . . . . . 2-49

2.7.5 Watch List Tanks Decision Rule . . . . . . . . . . . . 2-49

2.7.6 TRU Segregation Rules . . . . . . . . . . . . . 2-50

2.7.7 Heat Generation Rate Rule . . . . . . . . . . . . . 2-51

2.7.8 Complexant Waste Segregation Rule . . . . . . . . . 2-52

2.7.9 Waste Pumpability Rule . . . . . . . . . . . . . 2-52 
2.7.10 Tank Waste Type . . . . . . . . . . . . . . . 2-52

2.7.11 High Phosphate Waste ............ 2-52

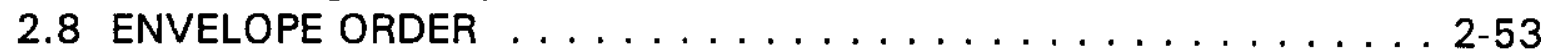

2.9 OPERATIONAL WASTE VOLUME PROJECTION $\ldots \ldots \ldots \ldots \ldots .2-53$

2.10 DST PROCESSING SEQUENCE $\ldots \ldots \ldots \ldots \ldots \ldots \ldots \ldots \ldots \ldots$

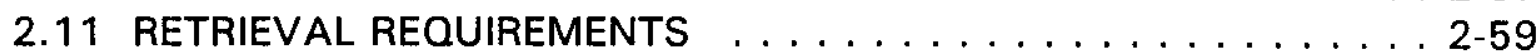

2.12 TRANSFER REQUIREMENTS . . . . . . . . . . . . 2-59

2.12 TANK ALLOCATION TO M\&I STAGING FUNCTIONS . . . . . 2-60

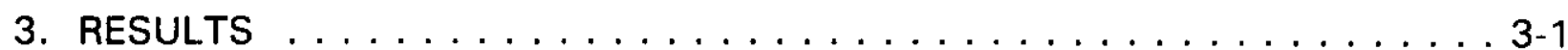

3.1 OPERATING SCENARIO . . . . . . . . . . . . . 3-1

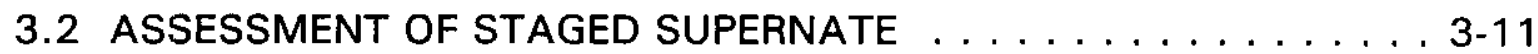

4. CONCLUSIONS ........................ 4-1

4.1 CONCLUSIONS ...................

4.2 RECOMMENDATIONS . . . . . . . . . . . . 4-1

4.3 ISSUES AND ACTIONS $\ldots \ldots \ldots \ldots \ldots \ldots \ldots \ldots \ldots \ldots \ldots$

4.3 STUDY CAVEATS $\ldots \ldots \ldots \ldots \ldots \ldots \ldots \ldots \ldots \ldots \ldots$

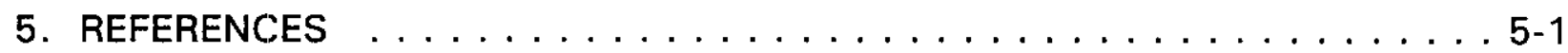

ASSUMPTIONS $\ldots \ldots \ldots \ldots \ldots \ldots \ldots \ldots \ldots \ldots \ldots \ldots \ldots \ldots$ Appendix A

FEED STAGING STRATEGY $\ldots \ldots \ldots \ldots \ldots \ldots$ Appendix B

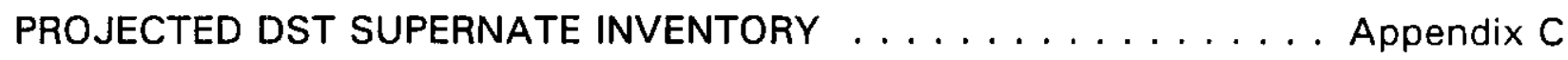

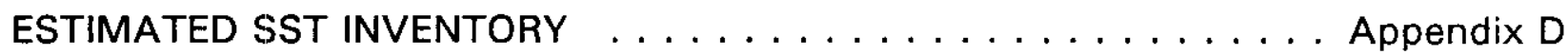

ESTIMATED COMPOSITION OF STAGED FEED $\ldots \ldots \ldots \ldots \ldots$ Appendix E 


\section{FIGURES}

Figure 1-1 - Influence and Data Flow Diagram $\ldots \ldots \ldots \ldots \ldots \ldots$ 1-4 Figure 2-1 - Direct Staging . . . . . . . . . . . . . . . . . 2-5

Figure 2-2 - Indirect Staging (both When Notified and ASAP) . . . . . . 2-5 Figure 2-3 - Timing of Alternative Feed Staging Strategies . . . . . . . . 2-6 Figure 2-4 - DST Supernate Classification and Assessment for Envelope A . 2-30 Figure 2-5 - DST Supernate Classification and Assessment for Envelope B . . 2-31 Figure 2-6 - DST Supernate Classification and Assessment for Envelope C . 2 2-32 Figure 2-7 - Retrieved SST "Supernate" Classification and Fit Assessment for

Envelope A . . . . . . . . . . . . . . . . . . 2-41

Figure 2-8 - Heel Mixing Study Results . . . . . . . . . . . . 2-45

Figure 2-9 - Operational Waste Volume Projection Case L9512A . . . . . . . 2-56

Figure 3-2 - Envelope A Staged Feed Assessment . . . . . . . . . . 3-12

Figure 3-3 - Envelope B Staged Feed Assessment . . . . . . . . . . . . 3-13

Figure 3-4 - Envelope C Staged Feed Assessment . . . . . . . . . . . 3-14 


\section{TABLES}

Table 1-1 - Deliverables . . . . . . . . . . . . . . . . . . . 1-2

Table 2-1 - Summary of Feed Staging Strategy Simulation Results . . . . . . . 2-9

Table 2-2 - Summary of DST Projections . . . . . . . . . . . . 2-13

Table 2-3 - Test 1 Envelope Specifications . . . . . . . . . . . . . . 2-26

Table 2-4 - Test 2 Technical Challenge Limits for Envelopes A and B . . . . 2 2-27

Table 2-5 - Intended DST Supernate Classification . . . . . . . . . . . . . 2-35

Table 2-6 - Hypothetical Constraint Adjustments . . . . . . . . . . . . . 2-36

Table 2-7 - Available Feed Summary . . . . . . . . . . . . . . . . . 2-37

Table 2-8 - DST Supernate Summary . . . . . . . . . . . . . . 2-38

Table 2 -9 - Estimated Supernate SpG . . . . . . . . . . . . . . 2-48

Table 2-10 - Estimated Supernate TRU Concentration $\ldots \ldots \ldots \ldots \ldots$ 2-51

Table 2-11 - DST Supernate Processing Sequence . . . . . . . . . . . . . 2-58 
WHC-SD-WM-RPT-210, Rev. 0

This page intentionally left blank. 


\section{GLOSSARY}

Acronym,

Abbreviation, or Term

ANN

Base Case

Baseline

Batch

CC

$C_{d}$

Constraint

Contingency

CP

CST

CSWL

DC

Direct Staging

\section{Explanation}

Aluminum Nitrate Nonahydrate

The set of assumptions around which an analysis is performed. Sensitivity studies are used to explore deviations from the base case.

The set of assumptions that have been officially incorporated into a program or project.

A discrete quantity of supernate transferred to the private contractor's feed tank for processing. One batch is processed completely (except for the heel) before another batch is provided.

Complexed Concentrate

Facility design capacity (the maximum instantaneous processing rate).

Constraints are external requirements imposed on a system.

In this analysis, contingencies refer to unplanned events that interfere with the staging of waste.

Concentrated Phosphate waste

Contractor Support Team

Complexed Salt-Well Liquor

Dilute Complexant Waste

A staging alternative in which all transfers, dilution, mixing, sampling, etc., take place in the private contractors' feed tanks.

Dilute Non-complexant waste

Dilute Phosphate waste

Data Quality Objective

Differential Scanning Calorimetry

Double-Shell Slurry Waste 
WHC-SD-WM-RPT-210, Rev. 0

Acronym,

Abbreviation, or Term

Explanation

DSSF

Double-Shell Slurry Feed Waste

DST

Double-Shell Tank

Enabling Assumption

An assumption made to permit continued analysis where information concerning a decision, constraint, or requirement is lacking.

Envelope

In this analysis, an Envelope is a set of limits that must be met by the supernate provided to the private contractors as feed.

Extension

Refers to the optional period during which RL may request the private contractors to process waste beyond the minimum quantities.

FAE

Feed Availability Efficiency. The fraction of the time that the approved feed is available in the private contractors' feed tanks.

FRD

Functions and Requirements Document.

FY

Fiscal Year (starting October 1)

HTCE

Indirect Staging ASAP

Historical Tank Contents Estimates

A variation on Indirect Staging. The waste transfers begin as soon as the intermediate staging tank is free (i.e., as soon as the previous feed batch is transferred to the private contractor).

Indirect Staging

A staging alternative in which waste is transferred to an intermediate staging tank for blending, dilution, adjustment, mixing, and sampling before decant/transfer to the private contractors' feed tanks.

Indirect Staging A variation on Indirect Staging. The waste transfers When Notified begin after notification is received from the private contractors.

ISSTRS

Initial Single-Shell Tank Retrieval System

LANL

Los Alamos National Laboratories

LAW

Low-Activity Waste

LLW

Low-Level Waste 
WHC-SD-WM-RPT-210, Rev. 0

Acronym,

Abbreviation, or Term

M\&l

ML

MT

NCAW

NCSWL

OSD

Outage

OWVP

PBFC

Phase 1

Phase II

POE

Privatization

Proof-of-Concept

PT
Explanation

Management and Integration

Million Liters

Metric Ton

Neutralized Cladding Removal Waste

Non-Complexed Salt-Well Liquor

Operating Specification Document

In this analysis, outage refers to the time period during which no feed is available in a private contractor's feed tank.

Operational Waste Volume Projection

Performance Based Fee Criteria

The first portion of TWRS Privatization during which a proof-of-concept demonstration is preformed and additional feed is processed using relatively smallscale processing facilities.

The final portion of the TWRS Privatization during which full-scale production facilities are operated.

Plant Operating Efficiency. Ratio of the facility's average throughput (after adjusting for reduced rate operation, startup, and shutdown transients and all plant outages planned or otherwise, except for lack of feed) to the design capacity.

A business strategy in which private contractors provide the capital for building plants and treating waste. The private contractors assume much of the financial and technical risk.

The first part of Phase I B during which the minimum quantities of waste are processed to demonstrate that privatization is viable from technical, regulatory, and financial aspect.

TRU Solids from Plutonium Finishing Plant operations. 
WHC-SD-WM-RPT-210, Rev. 0

Acronym,

Abbreviation, or Term

Requirement

Explanation

Requirements are internal limits that are imposed on a system.

RFP

Request for Proposal

RL

U.S. Department of Energy, Richland Operations Office

Simplifying

An assumption made to make calculations or analysis

Assumption easier.

SL

Slurry pipeline

SN

Supernate pipeline

SpG

Specific Gravity

SST

Single-Shell Tank

TGA

Thermal Gravimetric Analysis

TIC

Total Inorganic Carbon

TLM

Tank Layer Model

TOC

Total Organic Carbon

TOE

Total Operating Efficiency

TRU

Transuranic

TWRS

Tank Waste Remediation System

USQ

Unreviewed Safety Question

W-151

241-AZ-101 Waste Retrieval System Project

W-211

DST Initial Retrieval System Project

W-314

Waste Transfer System Upgrades Project

W-320

241-C-106 Retrieval Systems Project

WHC

Westinghouse Hanford Company 
WHC-SD-WM-RPT-210, Rev. 0

This page intentionally left blank. 


\section{INTRODUCTION}

\subsection{BACKGROUND}

The mission of the Tank Waste Remediation System (TWRS) is "to store, treat, and immobilize highly radioactive Hanford Waste (current and future tank waste and the encapsulated cesium and strontium) in a safe, environmentally sound, and cost-effective manner. The mission includes retrieval, pretreatment, immobilization, interim storage and disposal, and tank closure" (WHC 1995a).

The U.S. Department of Energy, Richland Operations Office (RL), is pursuing a new business strategy for remediation of Hanford Site tank waste. This strategy, commonly called privatization, involves hiring private contractors to perform the TWRS functions on a pay-for-product basis. During Phase I, the technical, regulatory, and financial viability of the privatization concept will be demonstrated by processing a portion of the waste stored in the double-shell tank (DST) system. DST supernate would be provided to two private contractors for pretreatment and immobilization into a low-activity waste (LAW) product. Optionally, pretreated solids would be processed by one of the two private contractors into a high-level waste (HLW) product. The scope of Phase II is being defined by RL.

RL has issued a draft Request for Proposal (RFP), which solicits bids for the Phase I portion of TWRS Privatization (DOE-RL 1995a). The intent is to issue the final RFP in February 1996 and to award contracts by August 1996.

\subsection{PURPOSE AND SCOPE}

Westinghouse Hanford Company (WHC) has been asked to prepare a LLW Feed Staging Plan to support Phase I privatization. This work is covered by the LLW Feed Staging Plan activity (Kirkbride 1995). Deliverables are shown in Table 1-1. This report satisfies the third deliverable, which is a Performance Based Fee Criteria (PBFC).

The management and integration (M\&l) contractor is required to provide the two Phase I LAW private contractors with the appropriate quantities of feed of a specified composition at the proper times. The purpose of this report is to develop a preliminary plan for the delivery of this feed to the private contractors. The report also to identifies issues that need to be resolved in order to prepare the Confirmed LLW Feed Staging Plan. 
Table 1-1 - Deliverables

\begin{tabular}{|l|l|l|l|l|}
\hline Deliverable & Activity & $\begin{array}{l}\text { Milestone } \\
\text { Type }\end{array}$ & $\begin{array}{l}\text { Control } \\
\text { Number }\end{array}$ & $\begin{array}{l}\text { Completion } \\
\text { Date }\end{array}$ \\
\hline $\begin{array}{l}\text { Issue Feed Staging } \\
\text { Feasibility Study }\end{array}$ & L1W02742A & DOE-RL & T32-96-020 & $\begin{array}{l}11 / 1 / 95 \\
\text { (completed) }\end{array}$ \\
\hline $\begin{array}{l}\text { Issue Draft Preliminary } \\
\text { Feed Staging Plan }\end{array}$ & L1W02744A & WHC Key & T32-96-021 & $\begin{array}{l}1 / 15 / 96 \\
\text { (completed) }\end{array}$ \\
\hline $\begin{array}{l}\text { Issue Preliminary Feed } \\
\text { Staging Plan }\end{array}$ & L1W02746A & DOE-RL & T32-96-022 & $2 / 15 / 96$ \\
\cline { 2 - 5 } & PBFC & $96-418$ & $2 / 5 / 96$ \\
\hline $\begin{array}{l}\text { Confirmation of } \\
\text { Preliminary Feed } \\
\text { Staging Plan }\end{array}$ & L1W02748A & DOE-RL & T32-96-023 & $8 / 15 / 96$ \\
\hline
\end{tabular}

The basic scope of this report includes projecting waste inventories to the beginning of staging activities, assessing the viability of the feed envelopes, recommending a feed staging strategy, preparing an operating scenario, and identifying issues and future work that must be resolved in order to prepare the preliminary plan to be included in the Confirmed LLW Feed Staging Plan.

\subsection{METHODOLOGY AND ORGANIZATION}

Figure 1-1 is an influence and data flow diagram for this analysis. It depicts the influences that have been considered and shows which elements of the study are affected. This diagram can be used as a road map since it is cross-referenced to the various sections in the report.

Section 2.1 highlights the major assumptions used in this report. The complete set of assumptions is listed in Appendix $A$ along with their basis. When appropriate the assumptions are discussed further and issues identified.

Section 2.2 (details in Appendix B) recommend sa feed staging strategy and provides guidelines concerning feed batch size and campaign length. Three feed staging strategies were compared primarily in terms of timing. The length of the feed outage (the time that the private contractors are waiting for feed from the $M \& l$ contractor) and the amount of time available for contingencies (such as correcting out-of-specification feed or delays that are a result of conflicting transfers) were used as performance measures. A Monte Carlo simulation is used 
to account for uncertainty in the major variables. In this type of analysis, many variables are allowed to vary randomly within a specified range rather than remain fixed. Sensitivity studies and parametric analysis were used to explore the effects of changing assumptions upon the recommended staging strategy.

The DST supernate inventories are projected to near the start of staging activities in Section 2.3. Estimated inventories of the soluble fraction of SST waste after retrieval are documented in Section 2.4. Projected supernate is then classified according to feed envelope as is the soluble portion of retrieved SST waste (Section 2.5).

Next, a heel mixing study is performed (Section 2.6). This study estimates the maximum heel that may remain in the intermediate feed staging tanks and the private contractors' feed tanks when switching envelopes. The study used a Monte Carlo approach to explore the full range of compositions belonging to each envelope.

A cursory review of the waste compatibility DQO was performed to identify potential problems that could affect feed staging transfers (Section 2.7). The decision rules were executed for the projected supernate compositions and when appropriate, the staged feed compositions.

The envelope order provided by the draft RFP was reviewed (Section 2.8).

A special Operational Waste Volume Projection (OWVP) was performed to better understand tank space issues during Phase I of privatization (Section 2.9). The purpose of this OWVP was to confirm that there is sufficient tank space for staging feed during Phase 1. The OWVP also estimates the amount of SST solids that may be retrieved during Phase I. This was done by estimating the DST space made available as a function of time if no SST retrieval (other than 106-C) takes place.

A processing sequence for DST supernate was prepared using tradeable and non-tradeable criteria (Section 2.10). Using this sequence, a schedule of feed staging and processing activities for both private contractors was prepared (Section 3.1). The composition of the staged supernate was compared with the envelope limits (Section 3.2). 
WHC-SD-WM-RPT-210, Rev. 0

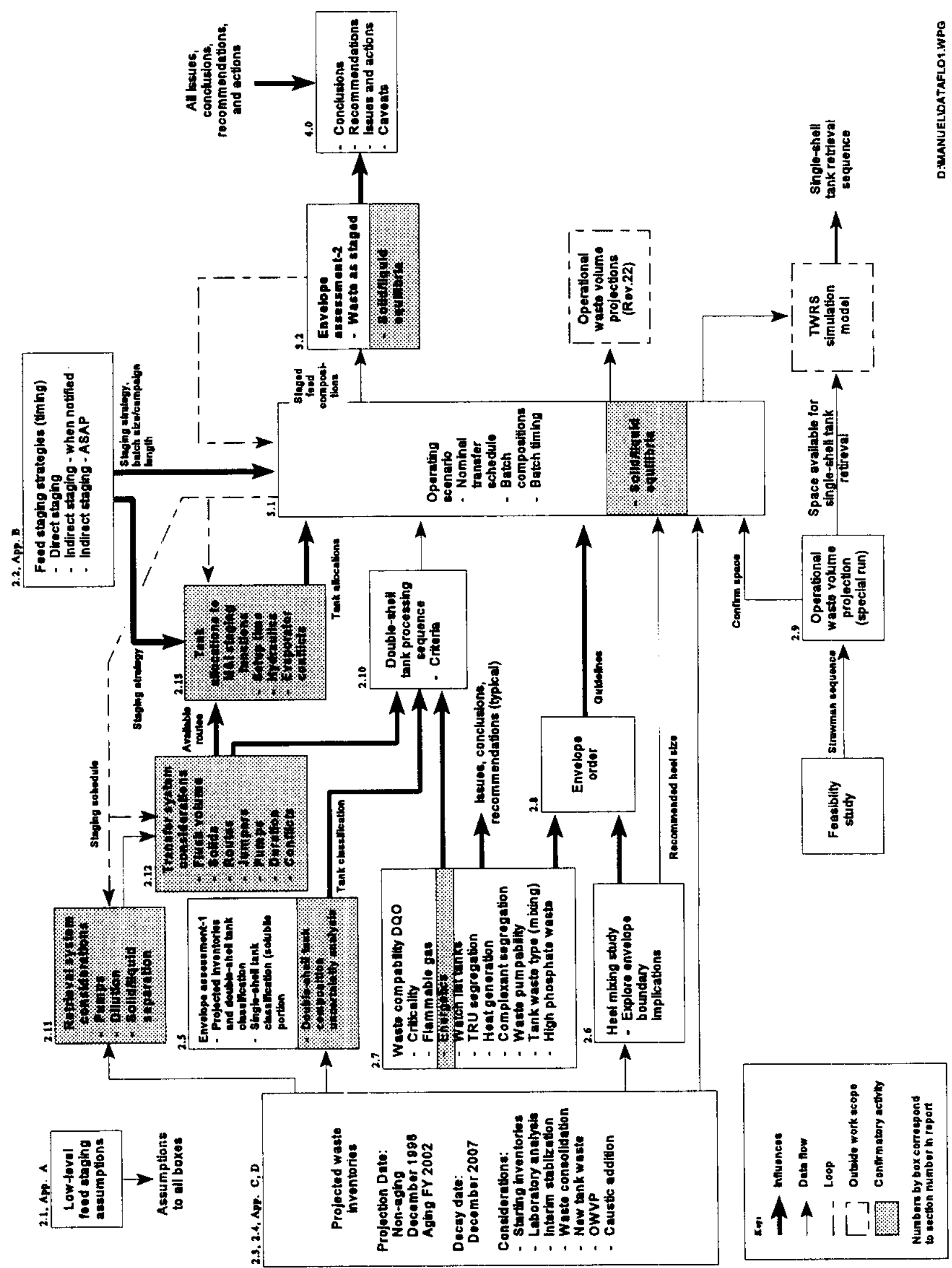

Figure 1-1 - Influence and Data Flow Diagram 


\section{DISCUSSION}

\subsection{ASSUMPTIONS}

All of the major assumptions are documented in Appendix $A$ along with a their basis, a discussion and related issues. Other 'lower-level' technical assumptions are documented at the point of use. The more important assumptions are listed below:

- The functional flow block diagram derived from the TWRS Function and Requirernents Document defines the interfaces and overall sequence of activities involved with feed staging.

- The overall schedule is provided by the draft RFP. The proof-of-concept demonstration begins June 1, 2002 and ends June 1, 2007. The extension period begins when the minimum order quantities have been processed and ends June 1, 2011.

- The envelope order and initial batch sizes are provided by the CST since the draft RFP is not understandable. The envelope order and corresponding batch sizes for one private contractor are: $\mathrm{A}$ : $600 \mathrm{MT}-5 \%,+15 \%$; $\mathrm{B}:>100$ MT; C: > $100 \mathrm{MT}$; $A$ : until minimum order quantity is reached; $A, B$, or $C$ : in any order until maximum order quantities are reached.

- The minimum and maximum order quantities and the minimum batch size is provide by the draft RFP.

- The private contractors must provide 30 to 90 days notice in advance of the ready-for-feed date. The $M \& l$ contractor must begin delivery of feed no earlier than the ready-for-feed date and complete delivery no later than 60 days after the ready-for-feed date. This requirement was provided by the CST since the draft RFP was not understandable.

- Tanks 106-AP and 108-AP are turned over to the private contractors containing the first feed batches on or before June 1, 2002.

- Facility processing rates are estimated using the minimum order quantities over the 5-year proof-of-concept demonstration. It was necessary to allocate the $60 \%$ total operating efficiency (TOE) into a facility attribute (plant operating efficiency or POE; $75 \%$ ) and a system attribute (feed availability efficiency or FAE; $80 \%$ ). This critical assumption needs to be formally controlled and allocated using the system engineering process. 
- High-level waste will be processed from June 1, 2002 though June 1, 2007. The minimum order quantity is $190 \mathrm{MT}$ of waste oxides (excluding $\mathrm{Na}$ and Si).

- The feed specification envelopes are provided in the draft RFP. The "Test 2" $\mathrm{PO}_{4} \cdot$ limit is corrected according to direction provided by the CST. The physical property limits are ignored (they are either redundant or in the case of SpG would exclude almost all of the waste).

- The Waste Compatibility Program and DOO define permissible transfers of waste within the DST system (Fowler 1995a and 1995b).

- The DST supernate inventories will be projected to December 31, 1998 for non-aging waste tanks and FY 2002 for the aging waste tanks. The starting values are consistent with the TWRS Flowsheet Inventory; however, the most recent sample data is used whenever possible. The projections are consistent with the latest formal Operational Waste Volume Projection (OWVP) (Koreski and Strode 1995). Supernate in 102-AW and 106-AW was not estimated.

- Solid-liquid equilibria is ignored. Entrained solids are not tracked, although provisions are made for dealing with them.

- For planning purposes, it is assumed that the "Entrained Solids" and "Strontium and TRU" streams from both LAW private contractors are combined and stored in a single DST. The volume of this stream is $8 \%$ of the original feed volume (5 $\mathrm{M} \mathrm{Na}$, nominal).

\subsection{FEED STAGING STRATEGY}

Three alternative feed staging strategies were analyzed. The strategies were compared in terms of the median length of outage required for feed staging, the median time available for contingencies (such as correcting a bad feed batch or working around scheduling conflicts), the robustness of the strategy against changes in assumptions, the fraction of successful cases, and an estimated feed availability efficiency. The analysis assumed that staging activities for each private contractor were independent.

A mathematical model was built that relates these measures to the durations of the underlying activities (e.g., transfer setup time). The durations used by the model are not point estimates. They either span a range of values or are calculated from parameters that span a range of values. For example, the time required to setup a transfer can vary from about 1 to 60 days depending on the complexity of the transfer, weather conditions, competition for resources, or 
interference with other activities. A Monte Carlo simulation was used to address this aspect (stochastic nature) of feed staging.

Seven sensitivity studies were performed to test the robustness of the decision against the assumed activities and their durations. Three parametric studies also were performed to examine the nominal behavior of the three staging strategies and to identify restrictions on the campaign length (batch size). A recommended case was developed using the results of the sensitivity and parametric studies.

The complete analysis is presented in Appendix B. The remainder of this section shows the alternative feed staging strategies that were considered, their timing, and a summary of the results and conclusions.

\subsubsection{Alternatives}

Three alternative staging strategies were analyzed. They are Direct Staging, Indirect Staging - When Notified, and Indirect Staging - ASAP. In the Direct Staging alternative (Figure 2-1), all transfers are made directly into the private contractors' feed tank. Transfers can not begin until the previous batch of supernate in the private contractor's feed tank has been processed. In both Indirect Staging variants (Figure 2-2), all transfers are made into an intermediate staging tank, then transferred into the private contractors' feed tank. In the Indirect Staging - When Notified strategy, transfers begin when notification from the private contractor is received; however, the final transfer into the private contractor's feed tank can not begin until the previous batch of supernate in the private contractor's feed tank has been processed. In the Indirect Staging - ASAP strategy, transfers begin as soon as the intermediate feed staging tank is emptied; however, the final transfer into the private contractor's feed tank can not begin until the previous batch of supernate in the private contractor's feed tank has been processed.

Figure 2-3 shows the timing of the three strategies in relation to the timing requirements derived from the draft RFP. The private contractor must provide between 30 and 90 days notice in advance of the ready-for-feed date. The M\&l contractor must deliver this feed within the 60-day window after the ready-forfeed date.

The Direct Staging alternative was given a slight advantage by allowing the first transfer to be set up in advance of the anticipated start date for the actual transfer. In some cases, the transfer lines would need to remain unavailable for other use until the transfer is ready to start. The other two alternatives were not given this advantage. 
The time available for contingencies was defined so that it primarily represents the time available to correct for out-of-specification feed batches. This time can be used to correct for other problems as well. For Direct Staging, the contingency is the time remaining within the feed delivery window after the approved feed is available. The duration between the setup of the primary transfer (T1s) and the remaining activities (TX) is excluded since (1) it is not know at this time if the waste is in specification and (2) the transfer set-up time distribution already includes allowance for pump failures.

The contingency for both Indirect Staging alternatives consists of two parts. Part 1 is the time available between the time when waste has been staged in the intermediate staging tanks and the ready-for-feed date. Part 2 is the time remaining within the feed delivery window after approved feed is delivered. 
WHC-SD-WM-RPT-210, Rev. 0

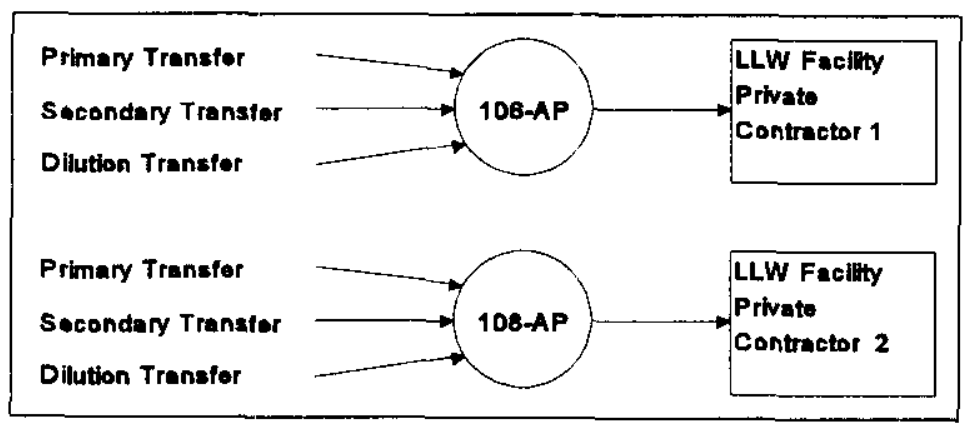

Figure 2-1 - Direct Staging

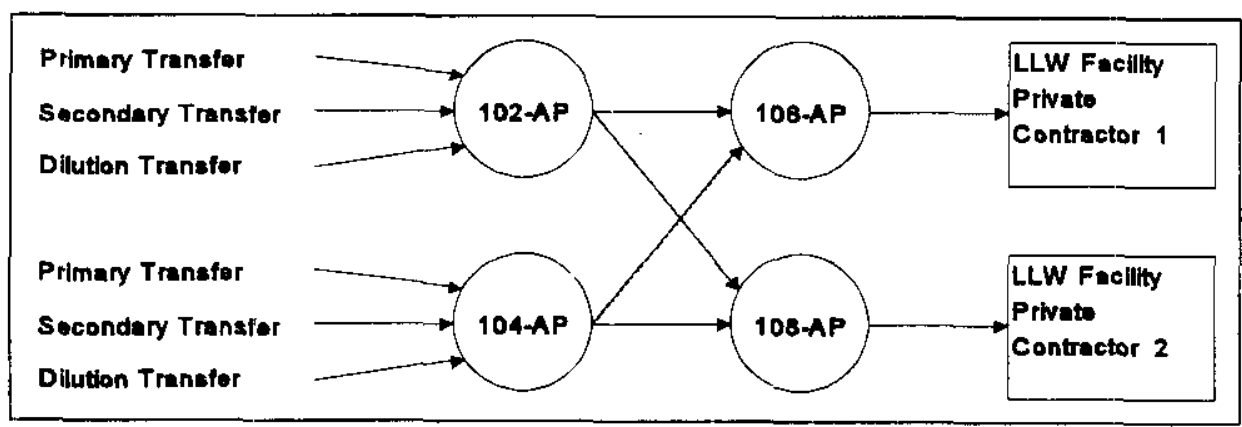

Figure 2-2 - Indirect Staging (both When Notified and ASAP) 
WHC-SD-WM-RPT-210, Rev. 0

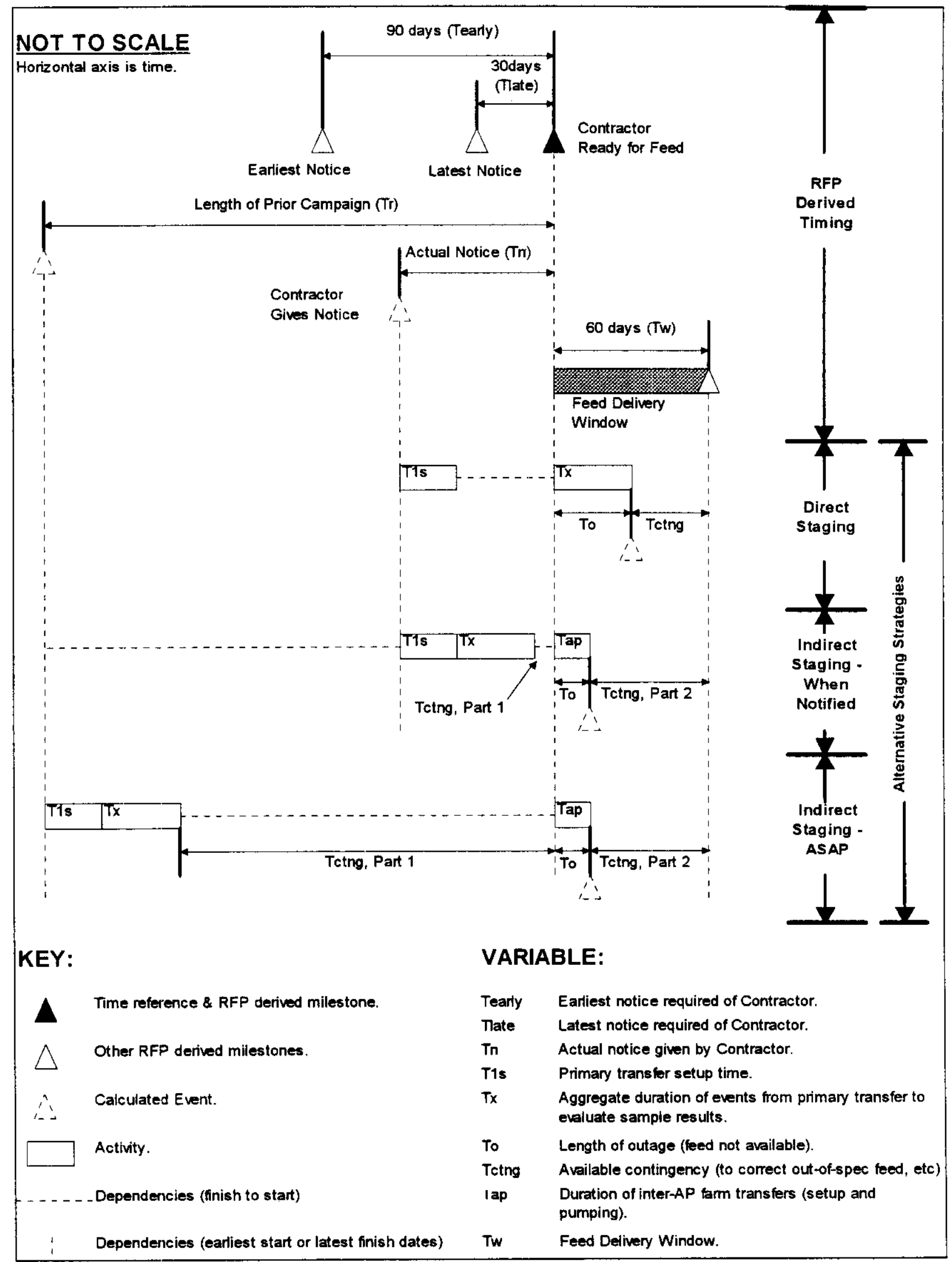

Figure 2-3 - Timing of Alternative Feed Staging Strategies 


\subsubsection{Simulation Results}

Table 2-1 compares the Monte Carlo simulation results for the three alternative feed staging strategies. Strategies are compared in terms of their median length of outage, median time available for contingencies, percent of successful simulation cases, and estimated feed availability efficiency.

The base case results show that Direct Staging is successful for only $27 \%$ of the simulation cases with a median outage of 75 days, no time for contingencies, and a $0.77 \mathrm{FAE}$. For most cases, this does not satisfy the timing requirements imposed by the draft RFP or the allocated 0.80 FAE.

Indirect Staging - When Notified is successful for $53 \%$ of the simulation cases with a median outage of 57 days, 4 days for contingencies, and a 0.81 FAE. For most cases, this does not satisfy the timing requirements imposed by the draft RFP, however the allocated 0.80 FAE is satisfied.

Indirect Staging - ASAP is successful for $94 \%$ of the simulation cases with a median outage of 13 days, 213 days for contingencies, and a 0.91 FAE. Most cases satisfy the timing requirements, provide a generous amount of time for contingencies, and exceed the allocated $0.80 \mathrm{FAE}$.

The cumulative distribution of the length of outage and available contingency for the base case results (See Appendix B) were used to estimate the effect of reducing the feed delivery window (Tw). If $T w=T 0=30$ days, then approximately $65 \%$ of the Indirect Staging - ASAP cases are successful.

Sensitivity Case 1 (all case definitions are in Appendix B) is a bounding case in which there is no mixing, sampling, analysis, evaluation, settling, or secondary transfers. The purpose is to see if the strategy decision is sensitive to these assumptions. The performance of all three strategies improved with Direct Staging showing the greatest improvement. All three strategies were similar in median outage, percent of successful cases and FAE. However, Indirect Staging - ASAP performed significantly better with 282 days of contingency available versus 54 days for Direct Staging and 72 days for Indirect Staging - When Notified.

Sensitivity Case 2 is a less aggressive version of Sensitivity Case 1 where there is no sampling, analysis, or evaluation. Results are similar to those from Sensitivity Case 1.

Sensitivity Case 3 reduces the maximum transfer setup time for the final staging transfer (inter AP-farm) from 60 days to 30 days to determine if there are drivers to implement such a change. Jumpers would need to be configured to avoid pit work and reduce the chance of transfer conflicts (perhaps by installation of valve manifolds). Spare pumps and critical equipment would need to be 
available on short notice with the capability to change them out (the Long Length Contaminated Equipment Removal System can speed-up pump replacement). These changes would, at the least, favorably change the shape of the setup time distribution. The performance of Direct Staging remained the same as expected since Direct Staging does not use this transfer. The performance of Indirect Staging - When Notified improves slightly. The performance of Indirect Staging ASAP improves from $94 \%$ successful simulation cases to $99 \%$.

Sensitivity Case 4 eliminates the dilution and secondary transfers and mixing time. This tests sensitivity of the three staging strategies to a potential envelope modification that permits higher $\mathrm{Na}$ concentrations. The performance of all staging strategies improve slightly.

Sensitivity Cases 5 and 6 set the medians of all random variables to either their most favorable (Case 5) or least favorable (Case 6) values. The purpose is to verify that the assumed shape of the distributions are not artificially forcing the recommended feed staging strategy. These test distributions are not meant to represent a realistic case. In Case 5, the Indirect Staging - ASAP performs significantly better than both Direct Staging and Indirect Staging - When Notified. This is the same behavior seen in the base case. In Case 6, all strategies perform similarly (very poorly).

Sensitivity Case 7 increases the minimum campaign length and batch size according to the guidelines developed from the parametric studies (See Appendix B). In Case 7, performance of all strategies improved slightly.

The Recommended Case was similar to Sensitivity Case 7; however, the final transfer setup time (Taps) was reduced from 60 to 50 days according to the observations in the parametric studies (See Appendix B). This resulted in nearly $100 \%$ of the simulation cases for the Indirect Staging - ASAP strategy being successful. The median outage was 9 days, 222 days was available for contingencies, and the estimated FAE was 0.93 . 


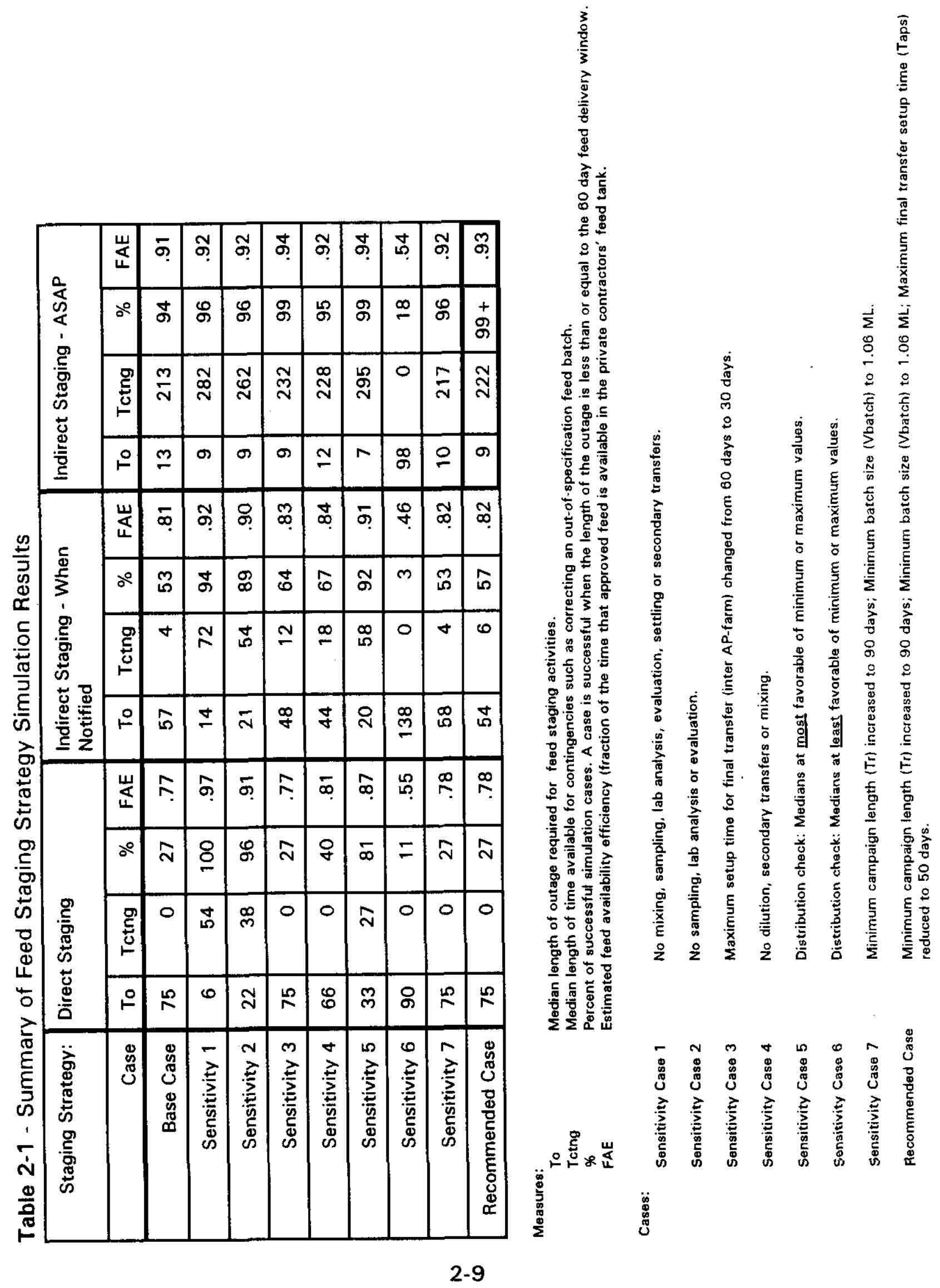




\subsubsection{Conclusions}

- Indirect Staging - ASAP is the recommended staging strategy. It can consistently meet the RFP timing requirements and provides sufficient contingency (nominal 213 days) for conflicting transfers and restaging or adjustment of waste to correct an out-of-specification feed batch including clean out of problematic quantities solids.

- Direct Staging performs poorly with base case assumptions. It fails most of the time and nominally provides little or no contingency. A bounding sensitivity study showed that elimination of all activities other than the primary transfer and dilution transfer allows it to successfully stage waste in the allocated time. However, only a nominal $\mathbf{5 4}$ days of contingency are available, which is not sufficient to restage out-of-specification waste.

- The performance of the Indirect Staging - ASAP strategy is degraded by short duration campaigns (processing time). The following guidelines will maintain reasonable values of contingency and outage:

- The minimum scheduled campaign length should be kept larger than about 200 to 275 days to ensure that sufficient contingency for restaging waste is maintained. This corresponds to a feed batch containing about 400 to $500 \mathrm{MT} N \mathrm{Na}$ at a 0.75 POE.

- The minimum scheduled campaign length should be kept larger than 90 to 120 days to avoid increases in the nominal outage. This corresponds to a feed batch containing about 170 to $225 \mathrm{MT} \mathrm{Na}$ at a $0.75 P O E$.

- The performance of the Indirect Staging - ASAP strategy is also sensitive to the maximum setup time for the final staging transfer (Taps). A slight decrease of Taps (from 60 days to 50 days) combined with increased campaign length, results in nearly $100 \%$ of the simulation cases being successful. Therefore, the location and connectivity of DSTs allocated as intermediate feed staging tanks need to be considered to provide minimal setup transfers and reduce the potential for conflicting transfers. Methods for reducing the setup time for the final staging transfer should be investigated such as installation of valve manifolds in the diversion boxes and pump pits and procuring the Long Length Contaminated Equipment Removal System (which will expedite replacement of pumps). 
- Each intermediate feed staging tank will require the capability to meet the following criteria:

- add dilution water

- $\quad$ mix and sample the waste

- $\quad$ transfer the supernate and solids (if the solids content and composition is acceptable) to the private contractors' feed tanks

- decant and transfer the supernate to the private contractors' feed tanks leaving all or some of the solids behind

- transfer the entire tank's contents (excluding the heel) if the waste is out-of-spec and must be moved out of the way for later disposition.

- remove solids that are a problem because of either their quantity or their composition.

\subsection{PROJECTED DST WASTE INVENTORIES}

The projected double-shell tank (DST) supernatant inventories in Appendix C are derived from three principal sources of information: sample data, historical transaction sheets, and the Operational Waste Volume Projection model (OWVP) (Koreski and Strode 1995). The most recent sample analyses were used to provide a starting point for the projections. The historical transactions sheets that were obtained for this study recorded all transfers of waste from the early 1980's to July 1995. The sheets were used to project the inventories from the sample data through July 1995. Finally, the assumptions in the OWVP were used to project estimates of future waste volume for most tanks. The OWVP projects DST volumes to May 1997, which is the endpoint given in the OWVP for most tanks. The compositions for tanks involved in consolidation of aging waste, which are 101-AY, 102-AY, 101-AY, and 102-AZ, were projected to FY 2002 in accordance with the OWVP.

The starting inventories are basically the same as those prepared earlier for the CST to support privatization (Shelton 1995). They also are consistent with the estimates used in the TWRS Process Flowsheet (Orme 1995) except in cases where new data superseded older material. Specifically, more recent supernate analyses for tanks 107-AN, 108-AP, 102-AY, 101-AZ, and 102-AZ were used. Values reported as less than values in the various characterization reports were not included for this study. Data was either not available or reported as less than values for about twenty percent of the projected inventories on a component-bycomponent and tank-by-tank basis and treated as zero. Also, waste streams were 
not reconciled to obtain charge balances; only the reported concentrations from the laboratory were used to derive initial inventories.

Contained in the historical transaction sheets are volumes transferred, and sources and destinations of various waste streams. Included among these transactions are the receipt of waste from pumping of saltwell liquids from SSTs, wastes received from routine operations and decommissioning of facilities, waste from evaporator operations, and other transfers that take place between the DSTs.

Two average saltwell liquid compositions, one for complexed (CSWL) and the other for non-complexed (NCSWL) saltwell liquids were used (WHC 1995). The compositions of facility wastes were taken primarily from waste profile sheets that are used to assess waste compatibility.

The projections in the OWVP represent the best source of complete information regarding future activity in the DST system. Even so, some of the assumptions in the OWVP will change as events unfold. Equipment failures, waste incompatibilities, tank space restrictions, and safety concerns are a few examples of how current strategies may require revision in order to complete the mission.

Enough information regarding volumes of facility waste streams, streams resulting from interim stabilization, evaporator operations, and tank-to-tank transfers is in the OWVP to project future waste volumes. In tandem with initial composition estimates, an approximate composition matrix can be developed for the DST system. The reliability of the compositions for each tank depends on the date on which a tank was sampled, the number of transactions associated with that tank, and the reliability of the compositions for all the streams involved in each transfer. Older sample data may misrepresent the composition of a tank because factors such as in-tank evaporation and hydroxide depletion can cause the precipitation of some metals, particularly aluminum and chromium. And of course, a tank that has not received waste since the last sample date will have a more reliable composition than tanks that have been involved in multiple transfers. Qualifiers were assigned to express the confidence level $(H=h i g h, M=$ medium, $L=$ low) for each tank's composition. These qualifiers are summarized along with other general tank information in Table 2-2. The difference between the projected total volume and the projected supernate volume represents the volume of solids in the tank. 
Table 2-2 - Summary of DST Projections

\begin{tabular}{|c|c|c|c|c|c|}
\hline TANK & $\begin{array}{l}\text { CURAENT } \\
\text { WASTE TYPE }\end{array}$ & $\begin{array}{l}\text { PROJECTED } \\
\text { WASTE TYPE }\end{array}$ & $\begin{array}{l}\text { PROJECTED } \\
\text { SUPERNATANT } \\
\text { VOLUME (L) } \\
\end{array}$ & $\begin{array}{l}\text { PROJECTED } \\
\text { TOTAL VOLUME } \\
\text { (L) }\end{array}$ & $\begin{array}{l}\text { QUALITY OF } \\
\text { PROJECTION }\end{array}$ \\
\hline AN-101 & $D N$ & DSSF & $3.68 \mathrm{E} 6$ & $3.68 \mathrm{E} 6$ & $M$ \\
\hline$A N-102$ & $\mathrm{CC}$ & $\mathrm{CC}$ & $3.95 \mathrm{E} 6$ & 4.29E6 & $\mathrm{H}$ \\
\hline$A N-103$ & DSS & DSS & $3.62 \mathrm{E} 6$ & $3.62 \mathrm{E} 6$ & $\mathrm{H}$ \\
\hline AN-104 & DSSF & DSSF & $3.02 \mathrm{E} 6$ & $3.02 E 6$ & $M$ \\
\hline$A N-105$ & DSSF & DSSF & 4.09E6 & $4.09 E 6$ & $M$ \\
\hline$A N-106$ & $D N$ & $\mathrm{CC}$ & 4.47EG & $4.53 \mathrm{E} 6$ & $L$ \\
\hline$A N-107$ & $\mathrm{CC}$ & $\mathrm{CC}$ & $3.68 \mathrm{E} 6$ & 4.19E6 & $\mathrm{H}$ \\
\hline AP-101 & DSSF & DSSF & $3.39 \mathrm{E} 6$ & 3.39E6 & $M$ \\
\hline$A P-102$ & $\mathrm{CP}$ & $\mathrm{CP}$ & $4.16 \mathrm{E} 6$ & $4.16 \mathrm{E} 6$ & $\mathrm{H}$ \\
\hline AP-103 & DN & DN & $1.02 E 5$ & $1.02 \mathrm{E} 5$ & $\mathrm{H}$ \\
\hline AP-104 & DN & DN & $4.23 E 6$ & 4.23E6 & $M$ \\
\hline AP-105 & DSSF & $\mathrm{DC}$ & $7.56 \mathrm{E} 4$ & $7.56 \mathrm{E} 4$ & $\dot{L}$ \\
\hline AP- 106 & DN & DSSF & $3.03 E 6$ & $3.03 \mathrm{E} 6$ & $L$ \\
\hline AP- 107 & DN & $\mathrm{DN}$ & $1.17 \mathrm{E} 5$ & 1.17E5 & $\mathrm{M}$ \\
\hline AP. 108 & DN & DN & $3.10 \mathrm{E} 6$ & $3.10 \mathrm{E} 6$ & $\mathrm{~L}$ \\
\hline AW-101 & DSSF & DSSF & $3.94 \mathrm{E} 6$ & $4.26 \mathrm{E} 6$ & $\mathrm{H}$ \\
\hline$A W-102$ & $\mathrm{~N} / \mathrm{A}$ & N/A & N/A & N/A & $\mathrm{N} / \mathrm{A}$ \\
\hline$A W-103$ & NCRW & NCRW & $5.41 \mathrm{E5}$ & $1.91 \mathrm{E} 6$ & $\mathrm{~L}$ \\
\hline$A W-104$ & DN & DN & $5.68 \mathrm{E} 5$ & $1.25 \mathrm{E} 6$ & $M$ \\
\hline$A W-105$ & NCRW & NCRW & $4.31 E 6$ & $5.43 \mathrm{E} 6$ & $\underline{L}$ \\
\hline$A W-106$ & N/A & N/A & N/A & $N / A$ & $\mathrm{~N} / \mathrm{A}$ \\
\hline AY- 101 & $D C$ & DN & $1.48 \mathrm{E} 6$ & $1.79 \mathrm{E} 6$ & $\mathrm{M}$ \\
\hline$A Y-102$ & DN & DN & $2.98 \varepsilon 6$ & $3.10 \mathrm{E} 6$ & $M$ \\
\hline$A Z-101$ & NCAW & NCAW & $2.95 \mathrm{E} 6$ & $2.99 \mathrm{E} 6$ & $\mathrm{H}$ \\
\hline$A Z-102$ & NCAW & DN & 2.67E6 & $3.71 E 6$ & $M$ \\
\hline SY-101 & $\mathrm{CC}$ & $\mathrm{CC}$ & $6.81 E 4$ & $4.20 E 6$ & $\mathrm{H}$ \\
\hline $5 Y-102$ & PFP & PFP & $1.40 \mathrm{E} 5$ & $2.09 E 5$ & $L$ \\
\hline SY-103 & $\mathrm{CC}$ & $\mathrm{CC}$ & $6.43 E 5$ & $2.82 \mathrm{E} 6$ & $\underline{L}$ \\
\hline SY-101TOT & $\mathrm{CC}$ & $\mathrm{CC}$ & $7.37 E 6$ & $7.37 E 6$ & $\mathrm{H}$ \\
\hline SY-103TOT & $\mathrm{CC}$ & $\mathrm{CC}$ & 5.40E6 & $5.40 \mathrm{E} 6$ & $\underline{L}$ \\
\hline
\end{tabular}


The inventory estimates were developed in Excel 5.0'. Flush volumes for cleaning out transfer lines and waste volume reduction factors in the evaporator were determined implicitly by simply making tank volumes consistent with the volumes reported in the OWVP.

The following is a brief description of the assumptions used to develop the projected supernatant inventory for each DST. References for the data, the date when the sample was taken, and a synopsis of the activity, past and future, are included for each tank:

101-AN

Reference: Internal Memo, M. J. Sutey to S. D. Godfrey, "Waste Compatibility Assessment of Tank 241-AN-101 with Tanks 241 $B X-110$ and 241-BX-111," August 3, 1993.

Supernate samples were taken from 101-AN on April 19, 1993. 101-AN contains dilute non-complexed (DN) wastes and is the receiver for NCSWL from 200 East Area. It had received 2.31E6 L of saltwell liquid by June 1995. The OWVP assumed that $3.60 \mathrm{E} 6 \mathrm{~L}$ of waste would be transferred from 101-AN to 104-AW in the first quarter of FY 1996.

101-AN will continue its role as SWL receiver and over 2.38E6 L of NCSWL should be pumped in by the end of FY 1998. Because the assumed composition for NCSWL is based on a weighted average, the confidence level for this tank is medium.

102-AN

Reference: Internal memo from D. L. Herting to J. M. Jones, "Characterization of Supernate Samples from Tank 102-AN," December 28, 1994.

Supernate samples were taken from 102-AN on October 21, 1994. 102-AN is designated as a complexed concentrate (CC) tank. The OWVP assumes that 102-AN will remain static through FY 1998. However, the hydroxide concentration in 102-AN $(0.24 \mathrm{M})$ is not in compliance with the minimum corrosion limit of $0.3 \mathrm{M}$. To bring the tank in compliance would require an addition of $1.89 \mathrm{E} 4 \mathrm{~L}$ of $50 \mathrm{wt} \% \mathrm{NaOH}$. This projection assumes that 7.57E $6 \mathrm{~L}$ of caustic will be added to bring the hydroxide concentration to $0.6 \mathrm{M}$ because this is the concentration needed to place.102-AN in Envelope C.

${ }^{1}$ Excel is a trademark of Microsoft Corporation, Redmond, Washington. 
The confidence level for 102-AN is high.

103-AN

Reference: WHC-SD-TI-543, Radionuclide and Chemical Inventories for the Double-Shell Tanks, July 30, 1993.

The sample from 103-AN was taken around February 1990. 103-AN stores double-shell slurry (DSS). No activities are planned for 103-AN prior to final retrieval.

The confidence level for 103-AN is high.

104-AN

Reference: WHC-SD-WM-TI-528, Revision 1, Grout Treatment Facility Waste Feed Projections, February 1994.

Starting inventories are based on estimates made for 104-AN from 242-A Evaporator post-run samples taken before transfer of evaporator bottoms to 104-AN and 105-AN. 104-AN is a DSSF tank.

There have been no transfers associated with 104-AN since the last sample date. No activities are planned for $104-\mathrm{AN}$ prior to final retrieval.

Because the tank was not sampled directly, the confidence level for this tank is medium.

105-AN

Reference: WHC-SD-WM-TI-528, Revision 1, Grout Treatment Facility Waste Feed Projections, February 1994.

Starting inventories are based on estimates made for AN-105 from 242-A Evaporator post-run samples taken before transfer of evaporator bottoms to 104-AN and 105-AN. 105-AN is a DSSF tank.

There have been no transfers associated with 105-AN since the last sample date. No activities are planned for $105-\mathrm{AN}$ prior to final retrieval.

Because the tank was not sampled directly, the confidence level for this tank is medium. 
106-AN

Reference: WHC-SD-WM-TI-528, Revision 1, Grout Treatment Facility Waste Feed Projections, February 1994.

Samples were taken from 106-AN on April 12, 1989. Between September 9 and September 13,1994, 1.51E6 L of dilute complexed waste from 106-AW, which is the evaporator receipt tank, were transferred to 106-AN. Future plans include sending the partially concentrated waste back to the evaporator. Approximately six months later, 106-AN is scheduled to receive CC waste from the evaporator and then will be designated as such. It was assumed that this waste will be a blend of waste from 105-AP, 107-AP, 104-AW, 105-AW, and the DC waste that was originally in 106-AN.

106-AN is scheduled to be the receiver for CSWL pumped from 200 West Area tanks via 102-SY through the cross-site transfer line. Because the average CSWL Na concentration is expected to be $12 \mathrm{M}$ (WHC 1995), it was assumed that this waste will not be concentrated any further.

The confidence level for this tank's projected inventory is low.

107-AN

Reference: Internal Memo, D. L. Herting to K. G. Carothers, "Characterization of Sludge Samples form Tank 241-AN-107," July 21, 1994.

Samples were taken from 107-AN on May 13, 1994. 107-AN is a CC tank. The only activity planned for this tank is an addition of $1.89 \mathrm{E} 5 \mathrm{~L}$ of caustic to bring the hydroxide concentration within the corrosion limits.

The confidence level for this tank is high.

101-AP

Reference: $\quad$ WHC-SD-WM-ER-357, Tank Characterization Report for DoubleShell Tank 241-AP-101, September 6, 1994.

Samples were taken from 101-AP on July 20, 1993. At that time, 101-AP was a DN tank. A series of transfers involving receipts of waste from 108-AP and transfers to the evaporator feed tank and 107-AP already have occurred. The last transfer was the receipt of DSSF from 105-AP during the last quarter of FY1995 so that 101-AP is now a DSSF tank.

A relatively large number of transactions are associated with 101-AP. But the compositions of the waste transferred are fairly well understood. For these reasons the confidence level for this tank is medium. 
Reference: $\quad$ WHC-SD-WM-ER-357, Tank Characterization Report for DoubleShell Tank 241-AP-101, September 6, 1994.

Tank 102-AP was last sampled on April 30, 1993 and no transfers have occurred since then. It is filled with concentrated phosphate (CP) waste. No transfers are expected to take place with this tank through FY1997.

The confidence level for this tank is high.

103-AP

Reference: WHC-SD-WM-ER-359 Revision 0, Tank Characterization Report for Double-Shell Tank 241-AP-103, September 6, 1994.

Tank 103-AP was last sampled on November 25, 1991. Most of the DN waste in 103-AP was sent to the evaporator in May 1994 leaving only $1.02 \mathrm{E5} \mathrm{L}$ of waste behind. This tank has been designated as one of two non-aging spare tanks and will remain so through FY 1997.

The confidence level for this tank is high.

104-AP

Reference: WHC-SD-TI-543 Revision 0, Radionuclide and Chemical Inventories for the Double-Shell Tanks, July 30, 1993.

Samples were taken from 104-AP on June 1, 1988. 104-AP, a DN tank, will continue to receive DN wastes from 102-SY. This DN waste originates from facility operations in the 200 West Area. It is assumed that 104-AP will be filled and emptied with DN waste several times between now and FY 1998.

The compositions of the dilute wastes from facility operations in 200 West Area are based on average compositions reported in the waste profile sheets. These average compositions are believed to adequately represent the waste that leaves those facilities. However, because of the fairly large number of transactions involved, the confidence level assigned to this tank is medium.

105-AP

Reference: WHC-SD-WM-ER-360, Tank Characterization Report for DoubleShell Tank 241-AP-105, September 13, 1994.

Tank 105-AP was last sampled on March 14, 1993. At that time, the waste was classified as DSSF. During the last quarter of FY 1995, most of the contents of 105-AP were transferred to 101-AP. Supernatant from 101-AY is scheduled to be transferred to 105-AP before being sent to the evaporator. 
105-AP will become the receiver of CSWL pumped from 200 East Area after 101-AY, which has been the receipt tank for CSWL waste, becomes dedicated to aging waste consolidation in FY 1996.

Because of the large number of transfers projected for AP-105, the confidence level is low.

106-AP

Reference: WHC-SD-WM-ER-361, Tank Characterization Report for DoubleShell Tank 241-AP-106, September 6, 1994.

Samples were taken from 106-AP on March 16 and 17, 1993. In May 1995, most of the DN waste in 106-AP was transferred to 108-AP for eventual concentration in the evaporator. The OWVP then assumes that 106-AP will be refilled with DN waste, which will be transferred to the evaporator feed tank in the first quarter of FY 1997. After that, 106-AP is assumed to receive DSSF from the evaporator. An average composition of this waste was defined by blending all the waste streams assumed to be concentrated during that time period.

The confidence level for this tank is low.

107-AP

Reference: $\quad$ WHC-SD-WM-ER-362, Tank Characterization Report for DoubleShell Tank 241-AP-107, September 6, 1994.

Tank 107-AP was sampled on August 1, 1993. It contained DN waste. Historical transactions include the receipt of dilute wastes from 101-AP and 103-AW. Virtually all the waste in 107-AP will be transferred to the evaporator and, at that time, the tank will become a spare tank.

The confidence level for this tank is medium.

108-AP

Reference: WHC-SD-WM-DP-065, Analysis and Characterization of DoubleShell Tank 241-AP-108, November 11, 1994.

The last sample from 108-AP was taken in March 1994. 108-AP is a DN tank. Historical transaction records show transfers of waste from 106-AP and 105-AW. This waste eventually will be pumped to the evaporator feed tank. 108-AP also will temporarily store the supernatant in $102-A Z$ before it is concentrated.

Because the bulk of the waste in 108-AP at the end of the projection will come from 102-AZ supernatant, the confidence level for this tank is high. 
WHC-SD-WM-RPT-210, Rev. 0

101-AW

Reference: WHC-SD-TI-543, Radionuclide and Chemical Inventories for the Double-Shell Tanks, July 30, 1993.

Samples from 101-AW were taken on June 28, 1990. 101-AW is filled with DSSF. The tank is expected to remain idle through FY 1998.

The confidence level for 101-AW is high.

\section{2-AW}

102-AW is the evaporator feed tank. Because it is being filled and emptied so often, it is too difficult to project any inventory estimates. Therefore, none will be given. The OWVP shows that 102-AW is expected to contain about $4 \mathrm{ML}$ of dilute evaporator feed.

103-AW

Reference: Internal Memo, J. S. Schofield to S. L. Barker, "Estimation of Neutralized Current Acid Waste And Neutralized Cladding Removal Waste Constituents," July 18,1991.

103-AW contains Neutralized Cladding Removal Waste (NCRW). The solids in 103-AW and 105-AW, the other NCRW tank, are considered TRU solids. The beginning composition is based partly on data from the core samples taken in June 1989. The core sample data was reconciled by J. S. Schofield in 1991 using flowsheets and chemical usage data. This reconciliation of the 1989 core sample data is the basis for the starting inventory.

In October, 1994 about half of the supernatant in 103-AW was transferred to 107-AP. Future plans include the consolidation of the TRU solids in 103-AW, 105 AW, and 102-SY into 103-AW beginning in the first quarter of FY 1999. Since a consolidation plan has not yet been developed, a post-consolidation inventory estimate was not attempted for these three tanks.

The confidence level on the pre-consolidated composition of 103-AW is high. However, because the post-consolidation compositions will be significantly different, the confidence level is considered low.

\section{4-AW}

Reference: WHC-SD-WM-ER-453, Revision 0, Tank Characterization Report for Double-Shell Tank 241-AW-104, July 13, 1995.

The sample from 104-AW was taken November 27, 1994. 104-AW is a DN tank. The waste was scheduled to be transferred to the evaporator in November 
1995. 104-AW will temporarily store dilute wastes from 101-AN, B Plant, and the 300 Laboratory before being sent to the evaporator feed tank. By May 1997, 104-AW will hold a small volume of DN waste.

Because of the uncertainty involved with the compositions of the waste added to 104-AW and the number of transfers, the confidence level is medium.

105-AW

Reference: Internal Memo, J. S. Schofield to S. L. Barker, "Estimation of Neutralized Current Acid Waste And Neutralized Cladding Removal Waste Constituents," July 18,1991.

As in the case of 103-AW, 105-AW is a NCRW tank whose composition is based on a reconciliation of the January, 1986 and July, 1986 core sample data. Since 1986, 105-AW has received over 8.71E5 $\mathrm{L}$ of dilute wastes from PUREX. In December, 1994, 2.88E6 L were transferred to 108-AP. 105-AW will continue to receive DN waste from PUREX and there will be periodic transfers of waste from $105-A W$ as it fills up. low.

Because of the large number of transfers, the confidence level for this tank is

\section{6-AW}

106-AW is the evaporator receipt tank. Because it is being filled and emptied so often, it is too difficult to project any inventory estimates. Therefore, none will be given. The OWVP shows that this tank is empty except for a solids heel.

\section{1-AY}

Reference: WHC-SD-WM-TI-578, Revision 0, 101-AY, 102-AY, \& 106-C Data Compendium, August 19, 1993.

The sample from 101-AY was taken on July 20, 1988. 101-AY is designated as a dilute complexed (DC) tank. Since 1988, approximately $3.41 \mathrm{E} 5 \mathrm{~L}$ of CSWL, 5.68E4 L of dilute laboratory waste, and 3.79E4 L of DN waste from $B$ Plant were added to 101-AY. Virtually all of the supernatant in 101-AY was scheduled to be transferred to 105-AP in the first quarter of FY 1996.

As part of the aging waste consolidation plan, 101-AY will next receive the supernatant from 101-AZ and the concentrated supernatant in 102-AZ, which is assumed to have been previously stored in 108-AP. The blended AZ supernatant will finally be transferred to 101-AZ in FY 2002 after the neutralized current acid waste (NCAW) solids have been consolidated in 102-AZ.

Finally, 101-AY, according to the aging waste consolidation plan, will receive the leachate and washes from the pretreatment of NCAW in FY 2002. 
Projecting liquid compositions for the aging waste consolidation plan includes estimating the amount of solids that will be dissolved during water and caustic washing. The assumptions for dissolution of NCAW and 106-C sludge are based on actual laboratory data for those tanks or, in the case of the caustic washing of 106-C, on data taken from the caustic washing of 103-C, which is a waste type similar to the waste in $106-\mathrm{C}$.

The aging waste tanks and the other wastes involved in aging waste consolidation have all been well characterized so that the confidence level for these wastes is high. However, the process involves many transfers and assumptions on sludge washing were needed even though these assumptions rest on laboratory data. Because of these factors, the confidence level for 101-AY is medium.

102-AY

Reference: WHC-SD-ER-454 Rev. 0, Tank Characterization Report for DoubleShell Tank 241-AY-102, July 6, 1995.

The samples from 102-AY were taken in June, 1994. 102-AY is a DN tank. Laboratory waste was added to 102-AY in FY 1995. As part of the aging waste consolidation plan, the supernatant in AY-102 will be transferred to 101-AZ. Then in FY 1997, the retrieved waste for 106-C will be transferred to 102-AY. This slurry will be transferred to 101-AZ in FY 1997 and then the leachate and washes from the pretreatment of 106-C solids will be transferred to 102-AY in FY 1998.

The confidence level for this tank is medium.

101-AZ

Reference: WHC-SD-WM-ER-410, Rev. 0, Tank Characterization Report for Double-Shell Tank 241-AZ-101, July 24, 1995.

The samples from 101-AZ were taken on March 3, 1995. 101-AZ is a NCAW tank. The supernatant in 101-AZ will be transferred to 101-AY in FY 1995. The supernatant from 102-AY will be used to sluice the solids in 101-AZ to $A Z-102$. Then, 101-AZ will be used to wash the sludge from 106-C in FY 1997. After the washed C-106 slurry is transferred to 102-AZ, 101-AZ will receive the blended 101-AZ and 102-AZ supernatant that were being held in 101-AY.

The confidence level for this tank is high since its ending inventory should be comprised mostly of aging waste supernatant that are well characterized.

102-AZ

Reference: WHC-SD-WM-ER-411, Rev. 0-A, Tank Characterization Report for Double-Shell Tank 241-AZ-102, December 8, 1995. 
The samples from 102-AZ were taken on February 23, 1995. 102-AZ is a NCAW tank. The supernatant in 102-AZ is assumed to be transferred to 108-AP for temporary storage before being sent to the evaporator feed tank. 102-AZ will be used for the water and caustic washing of NCAW sludge. The leachate and wash solutions will be decanted to the evaporator feed tank and the washed 106-C slurry will be combined with the washed NCAW solids in 102-AZ. After settling, the supernatant in 102-AZ principally will be the liquid used to transfer the 106-C washed solids.

The confidence level for this tank is medium.

101-SY

Reference: WHC-SD-Ti-543, Revision 1, Radionuclide and Chemical Inventories for the Double-Shell Tanks, July 30, 1993.

The samples from 101-SY were taken on May 1, 1991. 101-SY is a CC tank. No transfer activities for 101-SY were assumed by OWVP. Two compositions are shown for 101-SY. The first set is similar to the other tanks; it represents supernatant data and supernatant volumes only. However, it is unlikely that the supernatant in these 101-SY will ever be retrieved separate from the slurry layers. The slurry, or convective layer as it is commonly called, in 101-SY is constantly being mixed to mitigate hydrogen gas generation. For these reasons, a second data set is included with a "TOT" suffix. This composition represents the soluble portion of the total inventory of 101-SY and is a more likely LAW facility feed source term. Retrieval water is included in this estimate. The compositions used for the second data set were taken from the soluble compositions provided in the TWRS flowsheet (Orme 1995).

The soluble composition in the TWRS. Flowsheet (Orme 1995) was generated using water wash data for 101-SY (Herting 1994). The wash factors from this reference probably comprise the largest uncertainty in the 101-SY estimates. Even so, the confidence level for both the supernatant-only and combined soluble compositions are high.

102-SY

Reference: WHC-SD-EM-ER-366, Revision 0, Tank Characterization Report for Double-Shell Tank 241-SY-102, June 6, 1995.

The sample from 102-SY was taken on March 10, 1994. 102-SY contains TRU solid waste primarily from the Plutonium Finishing Plant (PFP) and is considered the only PFP tank. Since the last sampling event, 102-SY has received NCSWL and DN waste from the 222 Laboratory. In July 1995, much of the supernatant in 102-SY was transferred to AP-104. 102-SY will be the receiver for DN wastes from 200 West Area facilities and NCSWL/CSWL from saltwell pumping operations in 200 West Area. 
The issue of mixing CSWL with TRU waste is being addressed since complexed wastes and TRU solids have traditionally been segregated to prevent complexing of the transuranic into solution. OWVP assumes that CSWL will be pumped into 102-SY without prior retrieval of the TRU solids in order to meet Tri-Party Agreement milestones concerning completion of interim stabilization. This study assumes that the retrieval of TRU solids is accelerated in order to transfer the CSWL to 102-SY. The CSWL and DN wastes sent to 102-SY are assumed to be transferred separately to 200-East Area tanks through the crosssite transfer line.

The confidence level for 102-SY is low.

\section{3-SY}

Reference: Internal Memo from B. M. Mauss to D. K. Steiner, "Laboratory Analysis of 103-SY Sample," October 29, 1985.

The sample from 103-SY was taken around July 1, 1985. Since that time, the only waste transferred to $103-S Y$ has been about $4.69 E 5 \mathrm{~L}$ of SWL from the 200 West Area.

As in the case of 101-SY, two compositions are shown, one for the supernatant and the other for the combined slurry. Again, retrieval water is included in the combined slurry inventory. The combined slurry composition is the more valid composition to use since a mixing pump is likely to be installed in 103-SY for retrieval purposes. The slurry composition is the soluble composition found in Orme 1995. The amounts assumed to be soluble in 103-SY are not based on actual laboratory data, but rather on basic knowledge of the chemistry of complexed waste.

Because the sample from 103-SY was taken over 10 years ago and the soluble composition is not based on laboratory data, the confidence level for this tank is low.

\subsection{ESTIMATED SST INVENTORIES}

Estimated SST inventories will be used in Section 2.5.3 to identify which SSTs, if retrieved, could supply feed to the LAW private contractors during Phase I. There are no plans at this time to process the soluble portion of retrieved SST waste during Phase 1.

The tank-by-tank inventory estimates for SSTs are based on the Historical Tank Content Estimates (HTCE) produced by Los Alamos National Laboratories (LANL) (Brevick, 1994). LANL has used tank transaction records and a set of defined waste types to produce a Tank Layer Model (TLM) that predicts tank 
WHC-SD-WM-RPT-210, Rev. 0

compositions by identifying the different waste layers that were added to a tank and assigning a composition for the individual layers from the defined waste type list (Agnew, 1994).

In order to separate the waste into soluble and insoluble fractions, the bulk inventory estimates in the HTCE were first partitioned into saltcake/sludge fractions. This was accomplished by summing the saltcake layers separate from the sludge layers as determined by the TLM. Mass weighted average sludge washing factors, obtained from sludge washing experiments of core samples from 27 SSTs, were applied to the sludge fractions, while the saltcake was assumed to be $99 \%$ soluble for all components.

Finally, the HTCE component totals (with the exception of aluminum) were normalized to make them consistent with the Hanford Environmental Impact Statement (EIS) (Boomer, et. al., 1993). For components not listed in the EIS, TRAC totals were used (ibid). The normalization was done because the differences between the two inventory estimates have not yet been reconciled by Hanford Site authorities. The HTCE estimate for total aluminum was adopted temporarily because in an independent study by G.W. Borsheim, the aluminum estimate agreed closely with the HTCE (Borsheim, 1994).

The confidence level for the soluble portion of the SST inventories is low for several reasons. First, the HTCE have not been verified and revisions of the estimates are in progress. Secondly, the normalization of the HTCE adds further uncertainty and furthermore, the mass weighted average sludge washing factors assuredly do not reflect in all cases the solubility of sludge in the SSTs.

\subsection{FEED ENVELOPE ASSESSMENT AND TANK CLASSIFICATION}

Three waste envelopes, entitled A, B, and C, have been defined in the draft RFP for feed to the LAW private contractors. The three envelopes include differing maximum and minimum waste component limits to make each envelope exclusive from the others and to present a technical challenge to the contractors. This section assesses the feasibility of potential feed fitting within Envelopes A, B, and $C$ as defined in the draft RFP (DOE-RL 1995a).

\subsubsection{Feed Envelope Specifications}

Envelope A represents waste that will test the production capacity and fission product removal efficiency of the plants while producing a final product in which the waste loading will be limited by sodium. Envelope $B$ addressed the same treatment objectives as Envelope $A$ but will produce a final product in which the waste loading will be limited by minor component concentrations and/or require a Cs DF greater than 1000 . Envelope $C$ represents waste with organic 
complexing agents that may interfere with ${ }^{90} \mathrm{Sr}$ and/or TRU decontamination, thus requiring demonstration of organic destruction or some other acceptable mitigation technology (McKee et.al. 1995).

The envelope specifications are divided into 2 parts, entitled "Test 1 " and "Test 2" for this report. Envelopes A and B require the DST waste to pass both Test 1 and Test 2, while Envelope $C$ requires the DST waste to meet only the Test 1 specifications.

\section{Test 1}

The Test 1 specifications for Envelopes A, B, and C are listed in Table 2-3. The specifications reflect those listed in the Draft RFP (DOE-RL 1995a), with the exception of the physical property limits and the limits listed for $\mathrm{Al}(\mathrm{OH})_{4}$, $\mathrm{Cr}(\mathrm{OH})_{4}$, and $\mathrm{CO}_{3}$. Physical property limits were not considered in this study. The draft RFP limits listed for $\mathrm{Al}, \mathrm{Cr}$, and TIC were modified to correspond with the available tank waste inventory tables as explained in the footnotes of Table 2-3. The major differences among the three envelope specifications are that Envelopes $B$ and $C$ have a minimum radionuclide limit while Envelope A does not; Envelopes $A$ and $B$ have a maximum TOC limit of $10 \mathrm{~g} / \mathrm{L}$, which is equal to the minimum TOC limit for Envelope $C$.

\section{Test 2}

The Test 2 specifications for Envelopes $A$ and $B$ are listed in Table 2-4. The specifications reflect those listed in the Draft RFP except for the $\mathrm{PO}_{4}$ limit which has been changed to $44 \mathrm{~g} / \mathrm{L}$ based on advice from the CST. The limits are based on a $7 \mathrm{M} \mathrm{Na}$ feed and a $20 \mathrm{wt} \% \mathrm{Na}_{2} \mathrm{O}$ silicate glass. The concentrations of minor components were calculated for a hypothetical glass product at $20 \mathrm{wt} \% \mathrm{Na}_{2} \mathrm{O}$ loading. As shown in Table 2-4, the Test 2 limits serve as a discriminator between envelopes $A$ and $B$, making it impossible for a waste type to fit in both envelopes. If the DST waste component concentrations are less than all the limits listed, it can be concluded the waste does not fit in envelope B. If any component exceeds the concentrations listed, it can be concluded the waste does not fit in Envelope A. 
Table 2-3 - Test 1 Envelope Specifications

\begin{tabular}{|c|c|c|c|c|c|c|}
\hline \multirow{2}{*}{$\begin{array}{l}\text { Chemical } \\
\text { Analyte: }\end{array}$} & \multicolumn{2}{|c|}{ Envelope A } & \multicolumn{2}{|c|}{ Envelope $B$} & \multicolumn{2}{|c|}{ Envelope C } \\
\hline & $\begin{array}{c}\text { Minimum } \\
\text { Limit } \\
\text { (g/L) }\end{array}$ & $\begin{array}{c}\text { Maximum } \\
\text { Limit } \\
(\mathrm{g} / \mathrm{L})\end{array}$ & $\begin{array}{c}\text { Minimum } \\
\text { Limit } \\
\text { (g/l) }\end{array}$ & $\begin{array}{c}\text { Maximum } \\
\text { Limit } \\
\text { (g/L) }\end{array}$ & $\begin{array}{c}\text { Minimum } \\
\text { Limit } \\
(\mathrm{g} / \mathrm{L})\end{array}$ & $\begin{array}{l}\text { Maximum } \\
\text { Limit } \\
(\mathrm{g} / \mathrm{L})\end{array}$ \\
\hline Al(OH) 4 & 0 & 123 & 0 & 123 & 0 & 123 \\
\hline $\mathrm{Ba}$ & $\mathrm{NE}$ & 0.1 & $\mathrm{NE}$ & 0.1 & $\mathrm{NE}$ & 0.1 \\
\hline $\mathrm{Ca}$ & NE & 5 & NE & 5 & $\mathrm{NE}$ & 5 \\
\hline Cd & NE & 0.1 & $\mathrm{NE}$ & 0.1 & NE & 0.1 \\
\hline $\mathrm{Cl}$ & 0 & 9 & 0 & 22 & 0 & 9 \\
\hline $\mathrm{Cr}(\mathrm{OH}) 4$ & 0 & 5.77 & 0 & 11.6 & 0 & 5.77 \\
\hline$F$ & 0 & 12 & 0 & 36 & 0 & 12 \\
\hline Fe & NE & 1 & $\mathrm{NE}$ & 1 & $\mathrm{NE}$ & 1 \\
\hline $\mathrm{Hg}$ & NE & 0.02 & NE & 0.02 & NE & 0.02 \\
\hline$K$ & 0 & 50 & 0 & 50 & 0 & 50 \\
\hline $\mathrm{La}$ & NE & 0.08 & $\mathrm{NE}$ & 0.08 & $\mathrm{NE}$ & 0.08 \\
\hline $\mathrm{Na}$ & 69 & 160 & 69 & 160 & 69 & 160 \\
\hline $\mathrm{Ni}$ & NE & 1 & NE & 1 & NE & 1 \\
\hline $\mathrm{NO} 2$ & 10 & 120 & 10 & 120 & 10 & 120 \\
\hline $\mathrm{NO} 3$ & 5 & 200 & 5 & 200 & 5 & 200 \\
\hline $\mathrm{OH}$ & 4 & 70 & 4 & 70 & 4 & 70 \\
\hline $\mathrm{Pb}$ & NE & 1 & NE & 1 & NE & 1 \\
\hline PO4 & 0 & 25 & 0 & 88 & 0 & 25 \\
\hline 504 & 0 & 7 & 0 & 26 & 0 & 7 \\
\hline $\cos$ & 0 & 75 & 0 & 75 & 0 & 75 \\
\hline TOC & 0 & 10 & 0 & 10 & 10 & 40 \\
\hline$U$ & NE & 2 & NE & 2 & NE & 2 \\
\hline$(\mathrm{Na}+\mathrm{K})$ & NE & $7 \mathrm{Mol} / \mathrm{L}$ & NE & $7 \mathrm{Mol} / \mathrm{L}$ & NE & $7 \mathrm{Mol} / \mathrm{L}$ \\
\hline Radionuclido & $\begin{array}{l}\text { Minimum } \\
\text { Limit cif }\end{array}$ & $\begin{array}{l}\text { Maximum } \\
\text { Limit CilL }\end{array}$ & $\begin{array}{l}\text { Minimum } \\
\text { Limit } \mathrm{Ci} / \mathrm{L}\end{array}$ & $\begin{array}{l}\text { Maximum } \\
\text { Limit Cill }\end{array}$ & $\begin{array}{l}\text { Minimum } \\
\text { Limit Ci/L }\end{array}$ & $\begin{array}{l}\text { Maximum } \\
\text { Limit Ci/L }\end{array}$ \\
\hline TRU & NE & $8.11 E-5$ & 2.7E-8 & $8.11 E-5$ & 2.7E-8 & $5.41 E-4$ \\
\hline Cs-137 & NE & $8.11 \mathrm{E}-1$ & 2.7E-2 & 5.41 & $2.7 \mathrm{E}-2$ & $8.11 \mathrm{E}-1$ \\
\hline $\mathrm{Sr}-89 / 90$ & NE & $1.08 E-2$ & 2.7E-5 & $1.08 \mathrm{E}-2$ & $2.7 \mathrm{E}-5$ & $8.11 \mathrm{E}-2$ \\
\hline Tc-99 & NE & $1.35 \mathrm{E}-3$ & 2.7E-5 & $1.35 \mathrm{E}-3$ & $2.7 \mathrm{E}-5$ & $1.35 \mathrm{E} \cdot 3$ \\
\hline \multicolumn{7}{|c|}{ 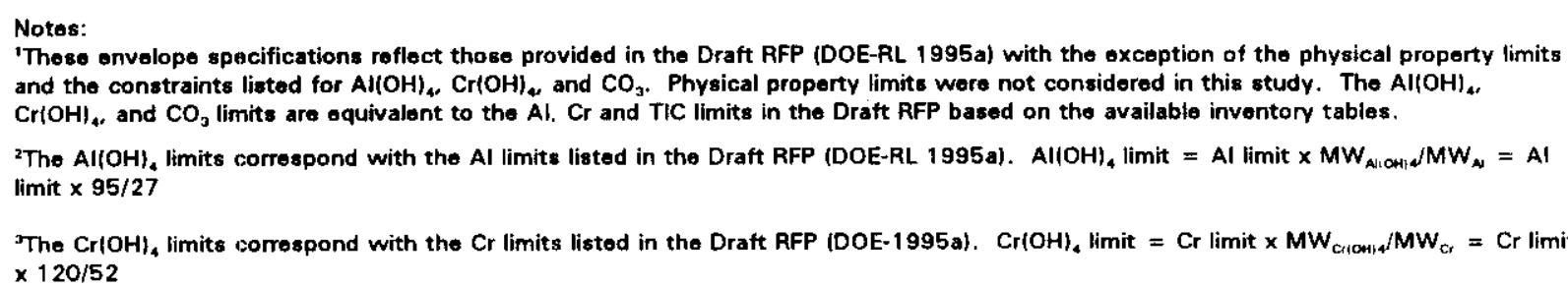 } \\
\hline
\end{tabular}


Table 2-4 - Test 2 Technical Challenge Limits for Envelopes A and B

\begin{tabular}{|l|l|l|}
\hline $\begin{array}{l}\text { Chemical } \\
\text { Analyte }\end{array}$ & $\begin{array}{l}\text { NOT Envelope B } \\
\text { (If all of the following conditions are } \\
\text { met for 7 M Na feed, the waste does } \\
\text { NOT fit in Envelope B) }\end{array}$ & $\begin{array}{l}\text { NOT Envelope A } \\
\text { (If any of the following conditions is } \\
\text { met for 7M Na feed, the waste does } \\
\text { NOT fit in Envelope A) }\end{array}$ \\
\hline $\mathrm{Cl}$ & $<11 \mathrm{~g} / \mathrm{L}$ & $>11 \mathrm{~g} / \mathrm{L}$ \\
\hline $\mathrm{Cr}(\mathrm{OH}) 4$ & $<8.6 \mathrm{~g} / \mathrm{L}$ & $>8.6 \mathrm{~g} / \mathrm{L}$ \\
\hline $\mathrm{F}$ & $<11 \mathrm{~g} / \mathrm{L}$ & $>11 \mathrm{~g} / \mathrm{L}$ \\
\hline $\mathrm{PO4}$ & $<44 \mathrm{~g} / \mathrm{L}$ & $>44 \mathrm{~g} / \mathrm{L}$ \\
\hline $\mathrm{SO} 4$ & $<6.6 \mathrm{~g} / \mathrm{L}$ & $>6.6 \mathrm{~g} / \mathrm{L}$ \\
\hline Cs137 & $<1.3 \mathrm{Ci} / \mathrm{L}$ & $>1.3 \mathrm{Ci} / \mathrm{L}$ \\
\hline "The PO4 feed concentration limit is listed as $4.6 \mathrm{~g} / \mathrm{L}$ in the draft RFP. The limit was changed to 44 \\
$\mathrm{~g} / \mathrm{L}$ based on direction from the CST.
\end{tabular}

\subsubsection{Double-Shell Tank Supernate Classification}

The feed envelopes are compared to the projected DST supernate inventories (Section 2.3) to satisfy the following objectives:

1) to classify the DST supernate according to envelope

2) to determine whether dilution or concentration is required

3) to estimate how easily the waste fits within its corresponding envelope.

Twenty-six of the twenty-eight DST supernate inventories were compared to the Test 1 and Test 2 limits (see Tables 2-3 and 2-4) to determine the envelope classification. Two DSTs (102-AW, 106-AW) are assumed to be evaporator feed/receipt tanks and were not included in this study. The waste in tanks SY101 and SY-103 will probably be retrieved as a mixture of supernatant and solids, rather than supernatant only. The inventories for tanks SY-101 and SY-103, therefore, represent the soluble portion of the total tank inventories after adding retrieval water and are designated as 101-SY-TOT and 103-SY-TOT.

Figures 2-4, 2-5, and 2-6 were constructed for envelopes A, B, and C, respectively, to summarize the results of the classification tests. The charts satisfy the 3 objectives listed above by showing how easily each DST fits into an envelope (if at all), and whether the DST waste requires concentration or dilution to fit. 
Figures 2-4, 2-5, and 2-6 were constructed by comparing the DST supernatant chemical component concentrations $(\mathrm{g} / \mathrm{l})$ and radionuclide concentrations $(\mathrm{Ci} / \mathrm{l})$ to the constraints listed in Tests 1 and 2 . For Test 1 , the inventory concentrations were divided by the maximum and minimum constraints listed in Table 2-2. These ratios are designated $\mathrm{C} / \mathrm{C}_{\max }$ and $\mathrm{C} / \mathrm{C}_{\min }$ where $\mathrm{C}=$ projected concentration, $\mathrm{C}_{\max }=$ maximum Test 1 limit, and $\mathrm{C}_{\min }=$ minimum Test 1 limit. The DST passes Test 1 if the smallest of the $C / C_{\min }$ ratios is greater than the largest of the $\mathrm{C} / \mathrm{C}_{\max }$ ratios (i.e., $\left[\mathrm{C} / \mathrm{C}_{\min }\right]_{\min }>\left[\mathrm{C} / \mathrm{C}_{\max }\right]_{\max }$ ). The Test 2 limits are simpler, since they are invariant with respect to dilution or concentration. The projected concentrations are normalized to $7 \mathrm{M} \mathrm{Na}$ and compared with the Test 2 limits. If the DST passes Tests 1 and 2 for an envelope, a bar is plotted on the corresponding envelope chart with the bar ends representing $\mathrm{C} / \mathrm{C}_{\max }$ (lower end) and $\mathrm{C} / \mathrm{C}_{\min }$ (upper end). A bar appears on each envelope as follows:

- A bar appears on an Envelope A chart if Envelope A Test 1 shows that $\left[\mathrm{C} / \mathrm{C}_{\min }\right]_{\min }>\left[\mathrm{C} / \mathrm{C}_{\max }\right]_{\max }$ and Test 2 produces a "NOT Envelope B" result.

- A bar appears on an Envelope B chart if the Envelope B Test 1 shows that $\left[\mathrm{C} / \mathrm{C}_{\min }\right]_{\min }>\left[\mathrm{C} / \mathrm{C}_{\max }\right]_{\max }$ and Test 2 produces a "NOT Envelope $\mathrm{A}$ " result.

- A bar appears on the Envelope $\mathrm{C}$ chart if Envelope $\mathrm{C}$ Test 1 shows that $\left[\mathrm{C} / \mathrm{C}_{\min }\right]_{\min }>\left[\mathrm{C} / \mathrm{C}_{\max }\right]_{\max }$

The location of the bar on the chart shows whether the supernate will require concentration or dilution to fit within the envelope. The $x$-axis represents the volume ratio $\left(\mathrm{V} / \mathrm{V}_{0}\right)$, which is a ratio of the final $\mathrm{DST}$ supernate volume to its original volume. The $V / V_{0}$ ratio is equivalent to the $C / C_{\max }$ and $C / C_{\min }$ ratios. Values of $V / V_{0}$ greater than one mean that the DST supernate waste requires dilution to fit in the envelope. Likewise, values less than one mean that the DST supernatant requires concentration to fit in the envelope. If the bar crosses $V / V_{o}=1$, the DST supernatant does not require any dilution or concentration to fit in the envelope.

The length of the bar shows how easily the DST waste fits within the envelope constraints. The measure of "fit" is the ratio of the V/Vo at the right side of the bar to V/Vo at the left side. Keeping this in mind, the longer the bar the easier the fit (IF a log scale where used, the length of the bars would be directly comparable as the measure of "fit"). If the bar is very short, it is unlikely the waste will fit once the projected DST supernate inventory uncertainties are considered.

The first two limiting components are shown next to the ends of each bar with their numerical value of $V / V_{0}$. For the component values on the left side of 
each bar, V/ $V_{0}$ equals the projected DST supernate concentration divided by the maximum limits listed in Table 2-3. For the component values on the right side of each bar, V/ $\mathrm{V}_{0}$ represents the DST supernate concentration divided by the minimum limits listed in Tables 2-3. The first limiting component is shown immediately next to the bar, and the second limiting component is shown further away from the ends of the bar. 
WHC-SD-WM-RPT-210, Rev. 0

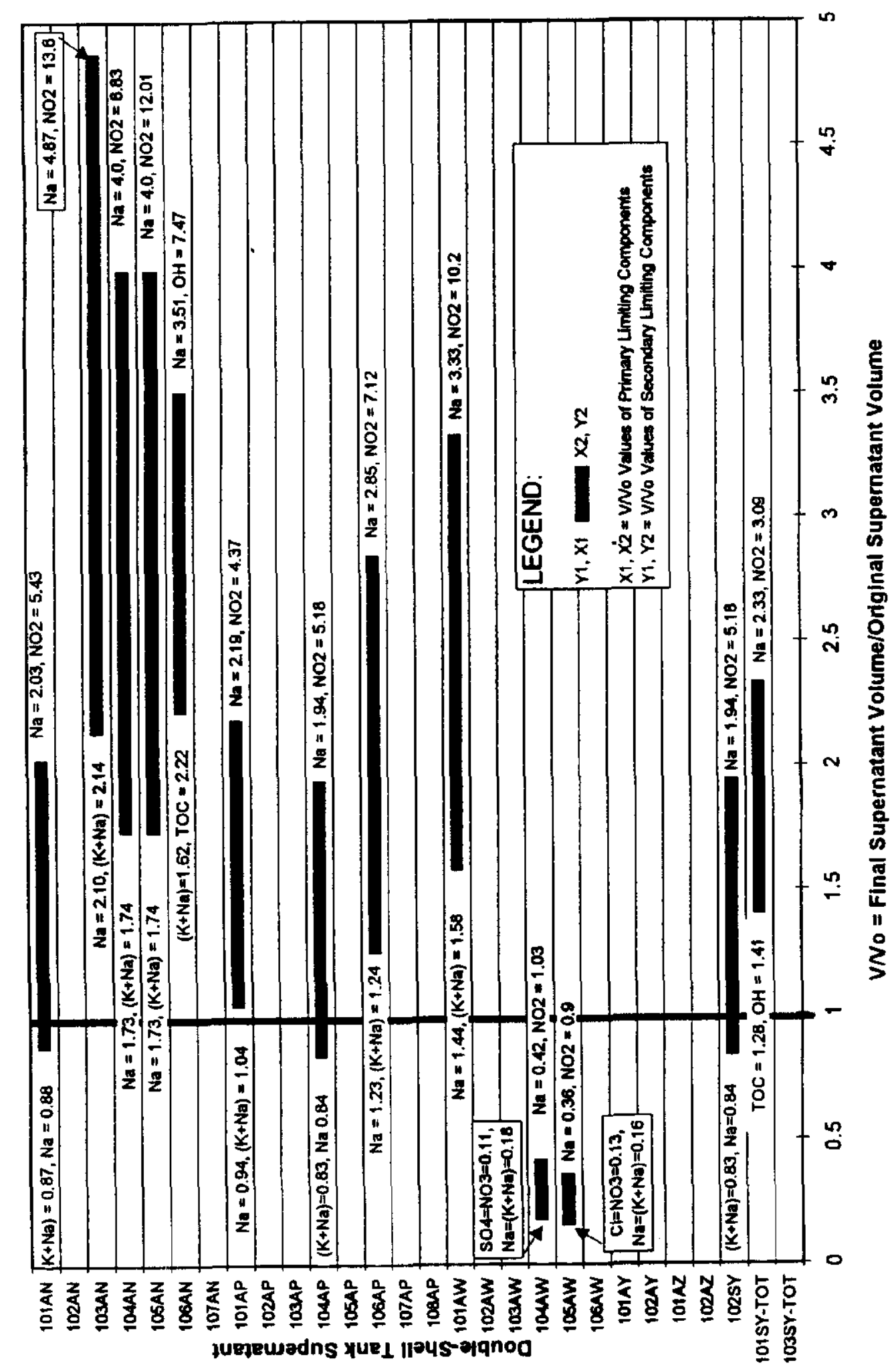


WHC-SD-WM-RPT-210, Rev. 0

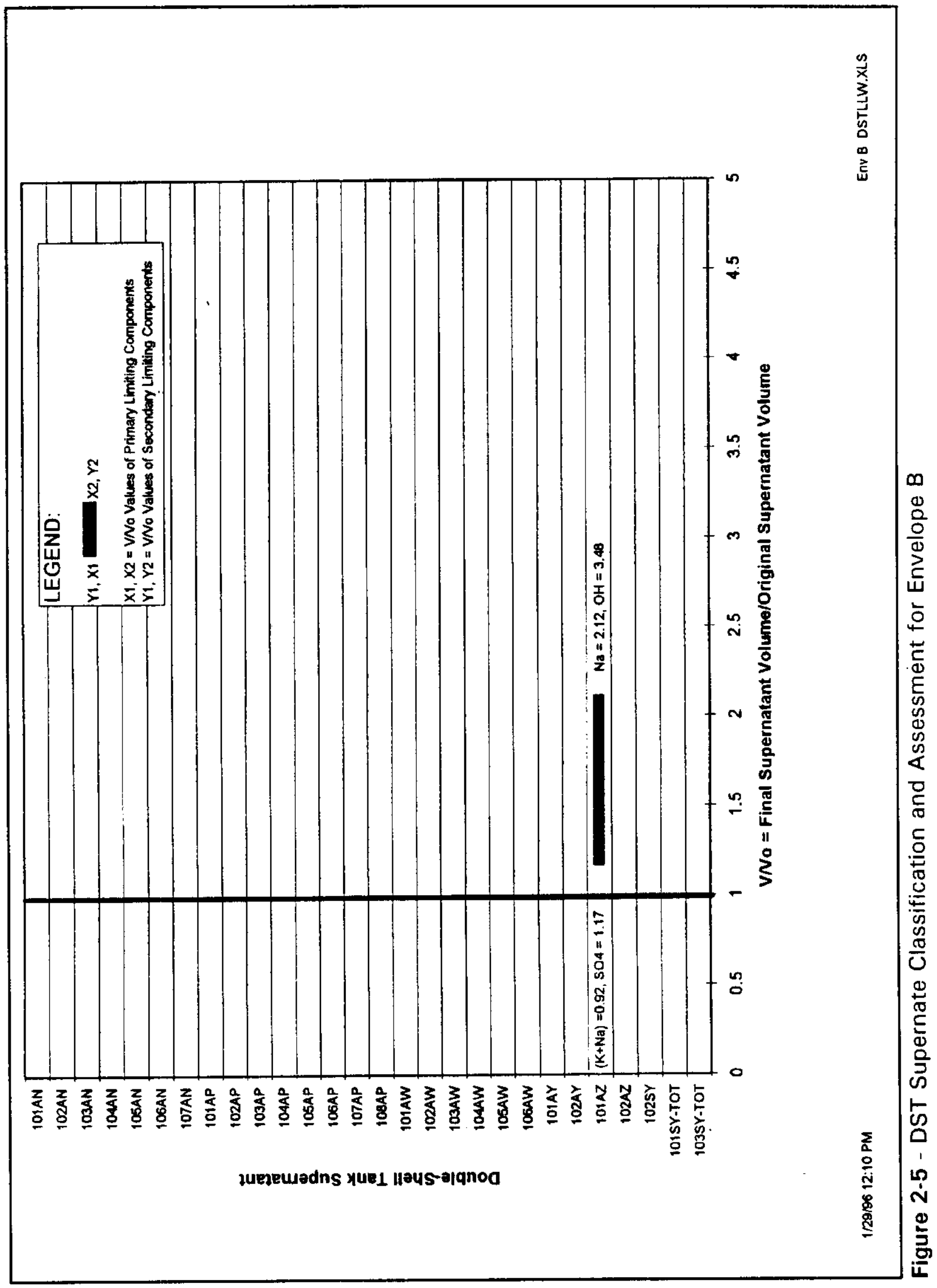


WHC-SD-WM-RPT-210, Rev. 0

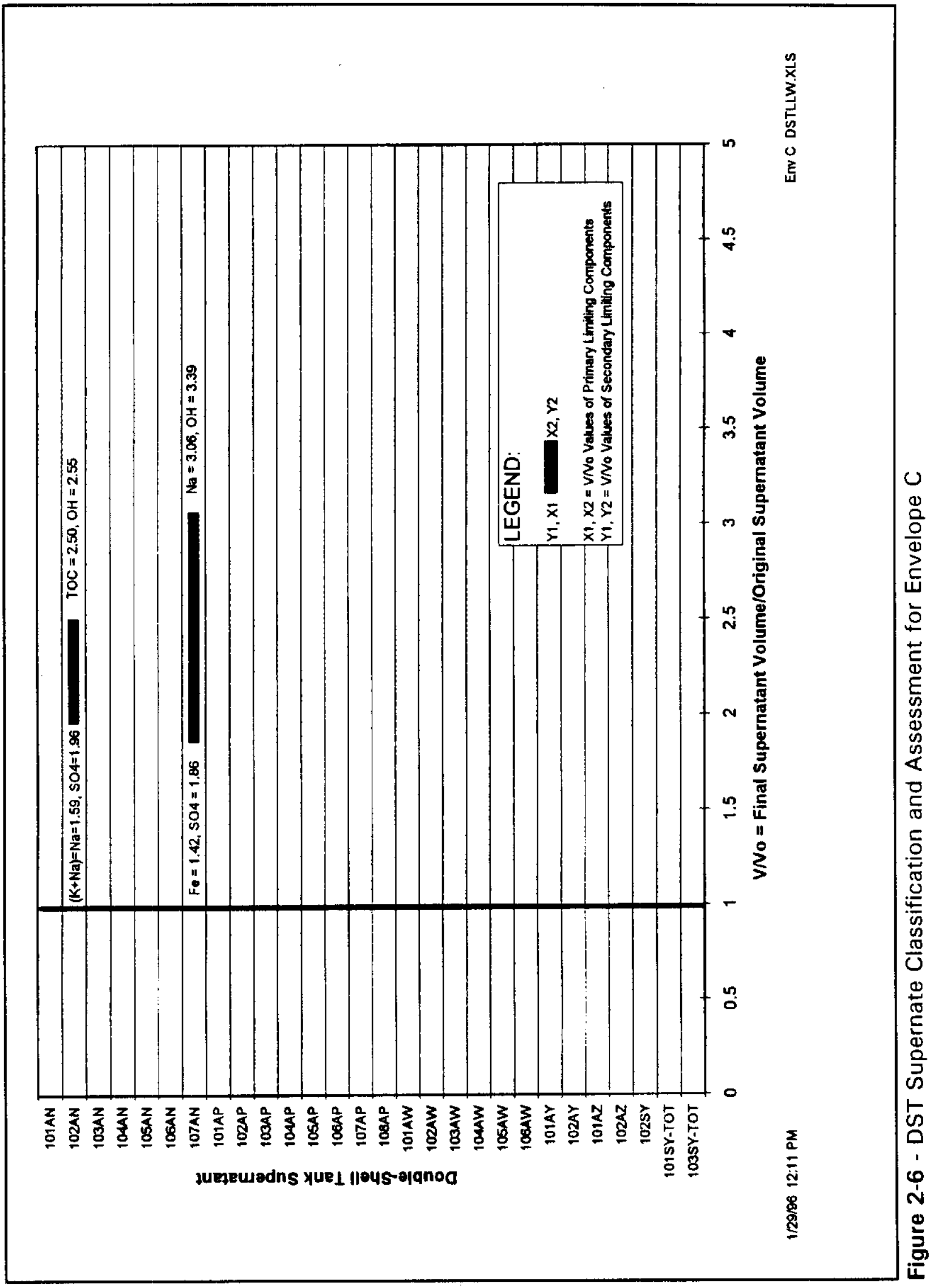


The following observations can be drawn from Figure 2-4, Envelope A:

- Supernate from thirteen DSTs (101-AN, 103-AN, 104-AN, 105-AN, 106-AN, 101-AP, 104-AP, 106-AP, 101-AW, 104-AW, 105-AW, 102SY, 101-SY-TOT) fit within Envelope A.

- Supernate from three DSTs (101-AN, 104-AP, 102-SY) fit within Envelope $A$ without requiring dilution or concentration.

- Supernate from two DSTs (104-AW, 105-AW) will require concentration down to less than half their original volume in order to fit within Envelope A. To avoid unnecessary evaporator operation, the supernate from 105-AW will be used to dilute more concentrated waste. Tank $104-\mathrm{AW}$ is not being targeted for feed do to its small $\mathrm{Na}$ inventory of $16 \mathrm{MT}$.

- $\quad$ Supernate from eight DSTs (103-AN, 104-AN, 105-AN, 106-AN, 101AP, 106-AP, 101-AW, 101-SY-TOT) will require dilution to more than twice their original volume in order to fit within Envelope $A$.

The following observations can be drawn from Figure 2-5, Envelope B:

- $\quad$ Supernate from one DST (101-AZ) fits within Envelope B.

- Supernate from 101-AZ will require dilution to 1.2 to 2 times its original volume to fit within Envelope B.

The following observations can be drawn from Figure 2-6, Envelope $\mathrm{C}$ :

- Supernate from two DSTs (102-AN, 107-AN) fit within Envelope C.

- Supernate from 102-AN and 107-AN will require dilution to approximately 2 to 3 times their original volume in order to fit within Envelope C.

Based on PNL-10584, nineteen DSTs were tentatively classified as belonging to Envelopes A, B, or C (Weimers 1996). Table 2-5 lists the intended envelope assignments, whether the supernate fits the intended envelope, and if applicable, the constraints preventing the supernate from fitting its intended envelope.

Figures 2-4, 2-5, and 2-6 show that supernate from sixteen of the twenty-six DSTs assessed fit within Envelopes A, B, or C. The supernate from ten DSTs not 
fitting within Envelopes A, B, or C were studied to determine the most practical envelope assignment for each DST (i.e., envelope assignments requiring only slight modifications to the constraints).

By considering the intended DST envelope classifications (Table 2-5) and the DST supernate inventories, hypothetical envelope assignments were provided for 7 of the 10 remaining DSTs (102-AP, 108-AP, 103-AW, 101-AY, 102-AY, 102-AZ, 103-SY-TOT). The projected waste inventories indicate that supernate from three DSTs (103-AP, 105-AP, and 107-AP) contain too little Na to be of concern.

The hypothetical envelope assignments are listed below in Table 2-6 along with the required adjustments to the envelope constraints. The constraint adjustments are not recommended changes. They are being provided so that the CST can investigate whether minor adjustments to the limits are feasible and/or necessary.

Table 2-7 shows that total sodium present in each of the three envelopes satisfies the minimum requirements proposed in the Draft RFP. However, there is not enough sodium available to supply the maximum order quantities.

Table 2-8 summarizes all the characteristics of the supernatant in all 28 DSTs. The DSTs are listed in alphanumeric order with their corresponding envelope classification, projected waste type, flammable gas USO status, watch list status, total MT Na in each DST, projected supernatant volume in each DST, and the SpG of the supernatant in each DST. 
WHC-SD-WM-RPT-210, Rev. 0

Table 2-5 - Intended DST Supernate Classification

\begin{tabular}{|c|c|c|c|}
\hline $\begin{array}{l}\text { Intended } \\
\text { Envelope }\end{array}$ & DST & $\begin{array}{c}\text { Does DST Fit } \\
\text { Intended Envelope? } \\
(\mathrm{Y} / \mathrm{N})\end{array}$ & $\begin{array}{l}\text { Constraints Preventing DST from } \\
\text { Fitting Intended Envelope }\end{array}$ \\
\hline \multirow[t]{12}{*}{ A } & 101-AN & Y & N/A \\
\hline & 103-AN & $\mathrm{Y}$ & $N / A$ \\
\hline & 104-AN & $Y$ & N/A \\
\hline & 105-AN & Y & $N / A$ \\
\hline & 101-AP & $\mathrm{Y}$ & $N / A$ \\
\hline & 102-AP & $\mathrm{N}$ & Does not pass Test 2 for Envelope A \\
\hline & 103-AP & $\mathrm{N}$ & $\begin{array}{l}\text { Projected tank waste inventory contains too } \\
\text { little } \mathrm{Na}\end{array}$ \\
\hline & 105-AP & $N$ & $\begin{array}{l}\text { Projected tank waste inventory contains too } \\
\text { little } \mathrm{Na}\end{array}$ \\
\hline & 106-AP & $\mathrm{Y}$ & N/A \\
\hline & 108-AP & $\mathrm{N}$ & Does not pass Test 2 for Envelope A \\
\hline & 101-AW & Y & $N / A$ \\
\hline & $\begin{array}{l}\text { 102-SY- } \\
\text { TOT }\end{array}$ & Y & N/A \\
\hline \multirow[t]{4}{*}{ B } & 106-AN & $\mathrm{N}$ & Fits in Envelope A rather than B \\
\hline & 107-AP & $\mathrm{N}$ & $\begin{array}{l}\text { Projected tank waste inventory contains too } \\
\text { little } \mathrm{Na}\end{array}$ \\
\hline & 106-AW & $\mathrm{N}$ & Not Assessed in this study \\
\hline & $101-A Z$ & $Y$ & N/A \\
\hline \multirow[t]{3}{*}{ C } & 102-AN & $Y$ & $\mathrm{~N} / \mathrm{A}$ \\
\hline & 107-AN & Y & N/A \\
\hline & $\begin{array}{l}\text { 103-SY- } \\
\text { TOT }\end{array}$ & $\mathrm{N}$ & Does not pass Test 1 for Envelope $C$ \\
\hline
\end{tabular}


Table 2-6 - Hypothetical Constraint Adjustments

\begin{tabular}{|c|c|c|c|}
\hline $\begin{array}{l}\text { Hypothetical } \\
\text { Envelope } \\
\text { Assignment }\end{array}$ & DST & $\begin{array}{l}\text { Required Constraint Adjustments } \\
\text { for Hypothetical Assignments }\end{array}$ & $\begin{array}{l}\text { Basis for } \\
\text { Hypothetical } \\
\text { Envelope } \\
\text { Assignment }\end{array}$ \\
\hline \multirow[t]{2}{*}{ A } & 102-AY & $\begin{array}{l}\text { Remove Envelope A Test } 1 \text { minimum } \mathrm{NO}_{2} \\
\text { and } \mathrm{NO}_{3} \text { limits }\end{array}$ & $\begin{array}{l}\text { Test } 2 \text { result }=\text { "Not } \\
\text { Envelope B" }\end{array}$ \\
\hline & $\begin{array}{l}\text { 103-SY- } \\
\text { TOT }\end{array}$ & $\begin{array}{l}\text { Increase Envelope A Test } 1 \text { maximum } \\
\text { limits as listed below: } \\
\mathrm{Cr}(\mathrm{OH})_{4}=7 \mathrm{~g} /(\text { from } 5.77 \mathrm{~g} / \mathrm{l}) \\
\mathrm{Na}=165 \mathrm{~g} /(\text { from } 160 \mathrm{~g} / \mathrm{l}) \\
(\mathrm{Na}+\mathrm{K})=7.5 \mathrm{M} \text { (from } 7 \mathrm{M}) \\
\text { Remove Envelope A Test } 1 \text { minimum } \mathrm{NO}_{2} \\
\text { limit }\end{array}$ & $\begin{array}{l}\text { Test } 2 \text { result }=\text { "Not } \\
\text { Envelope } B ", \text { TOC } \\
\text { content does not meet } \\
\text { minimum Envelope C } \\
\text { limit }\end{array}$ \\
\hline \multirow[t]{5}{*}{$B$} & $102-A P$ & $\begin{array}{l}\text { Remove Envelope B Test } 1 \text { minimum }{ }^{137} \mathrm{Cs} \\
\text { limit }\end{array}$ & $\begin{array}{l}\text { Test } 2 \text { result }=\text { "Not } \\
\text { Envelope A" }\end{array}$ \\
\hline & 108-AP & $\begin{array}{l}\text { Remove Envelope B Test } 1 \text { minimum } \mathrm{OH} \\
\text { and TRU limits } \\
\text { Decrease Envelope B Test } 1 \text { minimum } \mathrm{Na} \\
\text { limit to } 50 \mathrm{~g} / \mathrm{l} \text { (from } 69 \mathrm{~g} / \mathrm{l} \text { ) }\end{array}$ & $\begin{array}{l}\text { Test } 2 \text { result }=\text { "Not } \\
\text { Envelope } A "\end{array}$ \\
\hline & 103-AW & $\begin{array}{l}\text { Remove Envelope B Test } 1 \text { minimum } \mathrm{NO}_{2} \text {, } \\
{ }^{90} \mathrm{Sr},{ }^{99} \mathrm{Tc} \text {, and TRU limits } \\
\text { Decrease Envelope B Test } 1 \text { minimum } \mathrm{Na} \\
\text { limit to } 30 \mathrm{~g} / \mathrm{l} \text { (from } 69 \mathrm{~g} / \text { ) }\end{array}$ & $\begin{array}{l}\text { Test } 2 \text { result }=\text { "Not } \\
\text { Envelope } A "\end{array}$ \\
\hline & $101-\mathrm{AY}$ & $\begin{array}{l}\text { Remove Envelope B Test } 1 \text { minimum } \mathrm{NO}_{3} \text {, } \\
\mathrm{NO}_{2},{ }^{\circ} \mathrm{Sr} \text {, and TRU limits } \\
\text { Decrease Envelope B Test } 1 \text { minimum } \mathrm{Na} \\
\text { limit to } 30 \mathrm{~g} / 1 \text { (from } 69 \mathrm{~g} / \text { ) }\end{array}$ & $\begin{array}{l}\text { Test } 2 \text { result }=\text { "Not } \\
\text { Envelope } A "\end{array}$ \\
\hline & $102-A Z$ & $\begin{array}{l}\text { Remove Envelope B Test } 1 \text { minimum } \mathrm{NO}_{2} \text {, } \\
{ }^{\circ} \mathrm{S} r \text {, and TRU limits } \\
\text { Decrease Envelope B Test } 1 \text { minimum } \mathrm{Na} \\
\text { limit to } 65 \mathrm{~g} / \text { (from } 69 \mathrm{~g} / \text { ) }\end{array}$ & $\begin{array}{l}\text { Test } 2 \text { result = "Not } \\
\text { Envelope } A "\end{array}$ \\
\hline
\end{tabular}


Table 2-8 - DST Supernate Summary

\begin{tabular}{|c|c|c|c|c|c|c|c|c|}
\hline $\begin{array}{l}\text { Supernate } \\
\text { Source }\end{array}$ & Envolope & $\begin{array}{l}\text { Projectod } \\
\text { Waste } \\
\text { Type' }\end{array}$ & $\begin{array}{l}\text { Flammablo } \\
\text { Gas USQ }\end{array}$ & $\begin{array}{l}\text { Watch } \\
\text { List }^{3}\end{array}$ & $\begin{array}{c}\mathrm{Na}^{+} \\
\text {in } \\
\text { Supernato } \\
\text { (MT) }\end{array}$ & $\begin{array}{c}\text { Projected } \\
\text { Supernate } \\
\text { Volume } \\
\text { (L) }\end{array}$ & $\begin{array}{l}\mathrm{Na}^{+} \\
\text {(M) }\end{array}$ & $\mathrm{SpG}^{4}$ \\
\hline $101 \mathrm{AN}$ & A & DSSF & & & $5.34 \mathrm{E} 2$ & $3.68 \mathrm{E} 6$ & 6.32 & 1.31 \\
\hline 102AN & $\mathrm{C}$ & $\mathrm{CC}$ & & & $1.0 \mathrm{E} 3$ & $3.95 \mathrm{E} 6$ & 11.0 & 1.37 \\
\hline 103AN & A & DSSF & $Y$ & $Y$ & $1.22 \mathrm{E} 3$ & $3.62 \mathrm{E} 6$ & 14.6 & 1.50 \\
\hline 104AN & $\bar{A}$ & DSSF & $Y$ & $Y$ & $8.34 \mathrm{E} 2$ & $3.02 \mathrm{E} 6$ & 12.0 & 1.46 \\
\hline 105AN & A & DSSF & $Y$ & $\mathbf{Y}$ & $1.18 \mathrm{E} 3$ & $4.29 \mathrm{E} 6$ & 12.0 & 1.46 \\
\hline 106AN & $A$ & $\mathrm{CC}$ & & & $1,08 \mathrm{E} 3$ & 4.47E6 & 10.5 & 1.37 \\
\hline 107AN & $\mathrm{C}$ & $\mathrm{CC}$ & & & $7.78 \mathrm{E} 2$ & $3.68 \mathrm{E} 6$ & 9.19 & 1.33 \\
\hline 101AP & A & DSSF & & & $5.11 \mathrm{E2}$ & $3.39 \mathrm{E} 6$ & 6.56 & 1.32 \\
\hline 102AP & & $\mathrm{CP}$ & & & $4.24 \mathrm{E} 2$ & $4.16 \mathrm{E} 6$ & 4.43 & 1.21 \\
\hline 103AP & & DN & & & $5.43 E-1$ & $1.02 \mathrm{E} 5$ & 0.23 & 1.01 \\
\hline 104AP & A & DN & & & $5.67 \mathrm{E} 2$ & $4.23 \mathrm{~EB}$ & 5.83 & 1.29 \\
\hline 105AP & & DC & & & $1.54 \mathrm{E} 1$ & $7.56 \mathrm{E} 4$ & 8.87 & 1.32 \\
\hline 106AP & A & DSSF & & & $5.95 \mathrm{E} 2$ & 3.03E6 & 8.55 & 1.38 \\
\hline 107AP & & $\mathrm{DN}$ & & & $9.83 E-1$ & 1.17E5 & 0.37 & 1.01 \\
\hline 108AP & & DN & & & $1.60 \mathrm{E} 2$ & $3.10 \mathrm{E} 6$ & 2.25 & 1.10 \\
\hline $101 \mathrm{AW}$ & A & DSSF & $Y$ & $Y$ & $9.06 \mathrm{E} 2$ & $3.94 \mathrm{E} 6$ & 10.0 & 1.51 \\
\hline 102AW & \multicolumn{8}{|c|}{ Not Assessed } \\
\hline 103AW & & NCRW & & & $1.87 \mathrm{E} 1$ & $5.41 \mathrm{ES}$ & 1.5 & 1.04 \\
\hline 104AW & A & DN & $\mathrm{Y}$ & & $1.64 \mathrm{E} 1$ & $5.68 \mathrm{E} 5$ & 1.26 & 1.07 \\
\hline 105AW & A & NCRW & & & $1.08 \mathrm{E} 2$ & $4.31 \mathrm{E} 6$ & 1.09 & 1.06 \\
\hline $106 \mathrm{AW}$ & \multicolumn{8}{|c|}{ Not Assessed } \\
\hline 101AY & & $\mathrm{Cc}$ & $Y$ & & 4.99E1 & $1.48 \mathrm{E} 6$ & 1.47 & 1.05 \\
\hline 102AY & & DN & & & $2.86 \mathrm{E} 2$ & $2.98 \mathrm{E} 6$ & 4.17 & 1.14 \\
\hline 101AZ & B & NCAW & & & $4.31 \mathrm{E2}$ & $2.95 \mathrm{E} 6$ & 6.35 & 1.27 \\
\hline $102 \mathrm{AZ}$ & & NCAW & & & $1.79 \mathrm{E} 2$ & $2.67 \mathrm{EG}$ & 2.91 & 1.11 \\
\hline $102 S Y$ & A & PFP & & & $1.88 \mathrm{E}$ & $1.40 E 5$ & 5.83 & 1.29 \\
\hline 101SY-TOT & A & $\mathrm{CC}$ & & $Y$ & $1.19 E 3$ & $7.37 E 6$ & 7 & 1.36 \\
\hline 103SY-TOT & & $\mathrm{CC}$ & & $Y$ & $8.7 \mathrm{E2}$ & $5.40 \mathrm{E} 6$ & 7 & 1.31 \\
\hline \multicolumn{9}{|c|}{$\begin{array}{l}\text { Notes: } \\
{ }^{1} \text { DST waste types are discussed in Section } 2.3 \text {. } \\
{ }^{2} \text { Tanks With a Flammable Gas USO - information obtained verbally from W.B. Barton, } 1 / 12 / 96 \text {. } \\
{ }^{3} \text { Watch List Tanks obtained from Tank Farm Surveillance and Waste Status Summary Report for } \\
\text { September } 1995 \text { (Hanlon } 1995 \text { ). } \\
{ }^{4} \mathrm{SpG} \text { estimates are discussed in Section } 2.7 .2 \text {. } \\
{ }^{5} 102-\mathrm{AW} \text { and } 106-\mathrm{AW} \text { are assumed to be evaporator feed/receipt tanks with varying inventories, and } \\
\text { were therefore not included in this study. } \\
\text { It is unlikely that supernate alone can be retrieved from } 101-\mathrm{SY} \text { and } 103-\mathrm{SY} \text {. The entire contents of } \\
\text { tanks } 101-\mathrm{SY} \text { and } 103-\mathrm{SY} \text { will probably be retrieved as a mixture of supernate and solids. The } \\
\text { supernate labeled } 101 \mathrm{SY}-\mathrm{TOT} \text { and } 103 \mathrm{SY} \text {-TOT represent the soluble fraction these tanks after adding } \\
\text { retrieval water. }\end{array}$} \\
\hline
\end{tabular}




\subsubsection{Sensitivity of DST Classification Against Supernate Composition}

A sensitivity analysis is outside the scope of the Preliminary LLW Feed Staging Plan. The intention is to perform a sensitivity analysis as part of the work scope in the Confirmed LLW Feed Staging Plan. The sensitivity analysis would determine the effect each component has on the supernate's envelope classification. Knowing which component limits are significant or insignificant would provide a basis for adjusting the envelope constraints. The results of the sensitivity analysis would also be used as input to the Privatization DOO.

\subsubsection{SST Classification}

The same process used to classify DSTs according to envelope was also applied to the SSTs. The purpose of this exercise was to determine which SSTs, if retrieved during Phase 1, could provide feed to the LAW private contractors. The SST compositions represent the soluble fraction after retrieval. Sufficient retrieval water has been added to bring the $[\mathrm{Na}]$ to $5 \mathrm{M}$ or the concentration of insoluble solids to 10 weight percent (whichever requires more water). The soluble portion of twenty-five SSTs satisfy Envelope A limits. None satisfied Envelopes B or C. The results are shown in Figure 2-7 for Envelope A. Tanks not belonging to Envelope $A$ are not shown.

Figure 2-7 shows that twenty-three SSTs fit within the Envelope A constraints. The total soluble Na inventory of the Envelope A SSTs is $14,400 \mathrm{MT}$ which represents about $25 \%$ of the total soluble Na SST inventory.

The following conclusions can be drawn from Figure 2-7:

- Twenty-five SSTs fit within the Envelope A constraints. They are 103A, 101-AX, 102-BY, 102-S, 103-S, 105-S, 106-S, 108-S, 109-S, 104SX, 106-SX, 102-U, 103-U, 105-U, 106-U, 107-U, 108-U, 109-U, $111-$ $U, 201-U, 202-U, 203-U$ and 204-U.

- The Initial Single-Shell Tank Retrieval (ISSTRS) project and the Initial SST Retrieval Sequence and Blending Strategy should consider that waste from SSTs NOT appearing on Figure 2-7 will not meet any of the envelope specifications. If retrieved, the soluble portion of the tanks not fitting within the envelope specifications must remain in the DST system until Phase II or be blended with other waste to meet the limits.

- Fourteen SSTs (101-AX, 102-S, 103-S, 105-S, 106-S, 108-S, 109-S, 103-U, 105-U, 106-U, 107-U, 108-U, 109-U, and 111-U) fit within Envelope $A$ without requiring dilution or concentration. 
- Tank 102-BY is probably not a good choice for feed due to its narrow bar length.

- Four SSTs (201-U, 202-U, 203-U, and 204-U) will require concentration down to at least half their original volume in order to fit within Envelope A. Although not verified, these tanks probably contain mostly insoluble sludge.

- Four SSTs (103-A, 104-SX, 106-SX and 102-U) will require dilution to approximately 1.5 times their original volume to fit within Envelope A. 
WHC-SD-WM-RPT-210, Rev. 0

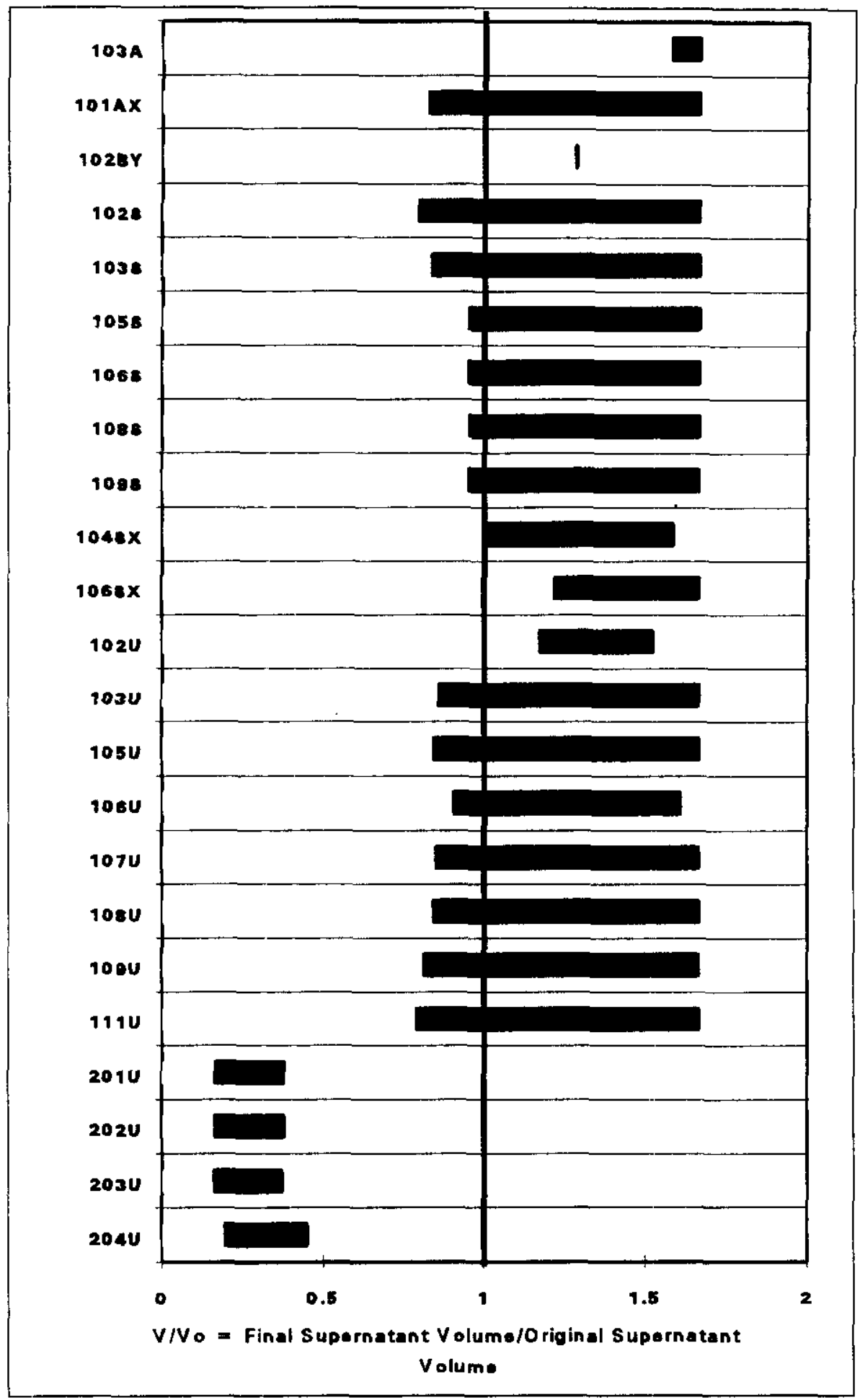

Figure 2-7 - Retrieved SST "Supernate" Classification and Fit Assessment for Envelope A 


\subsection{HEEL MIXING STUDY}

The purpose of this study is to examine the effect that the heel remaining in the private contractors' feed staging tank has when switching envelopes. The basic question is: what is the minimum volume of waste from one envelope that can be mixed with the heel from a different envelope so that the resulting mixture belongs to the first envelope?

Six mixing scenarios were explored, each corresponding to one of the six permutations of envelopes: $A \rightarrow B, A \rightarrow C, B \rightarrow A, B \rightarrow C, C \rightarrow A$ and $C \rightarrow B$. A MonteCarlo simulation was used to generate trial waste compositions bounded by the various envelope limits.

\subsubsection{Calculation of Trial Waste Compositions}

The methodology described below explores the full range of the envelopes without regard to actual waste composition or charge balances. The range of compositions explored will be broader than that exhibited by the actual waste.

The general approach used randomly generated compositions with uniform distributions for each component. For each component and envelope, the range (maximum Test 1 limit - minimum Test 1 limit) was multiplied by a uniformly distributed random number between 0 and 1 and added to the minimum limit (See Table 2-3). This procedure was done for all the analytes and radionuclides with the following exceptions:

\section{All Envelopes}

For all envelopes the $[\mathrm{Na}]+[\mathrm{K}]<=7 \mathrm{M}$. The $[\mathrm{Na}]$ is calculated using the uniform distribution (since the upper bound $[160 \mathrm{~g} / \mathrm{l}]$ is equal to $7 \mathrm{M}$ ). The $[K]$ is then calculated using a uniform distribution with the lower [K] Test 1 limit and temporary upper limit. This temporary upper limit is the lessor of the maximum [K] Test 1 limit and the $7 \mathrm{M}$ - [Na] difference.

\section{Envelope A}

The definition for $A$ requires that a hypothetical silicate glass made from this waste will be limited in waste oxide loading only by $\mathrm{Na}$, not by any minor component. The definition also requires that the required $C s$ DF be less than 1000. The maximum $\mathrm{g} / \mathrm{l}$ (and $\mathrm{Bq} / \mathrm{l}$ ) concentrations at $7 \mathrm{M} \mathrm{Na}$ for the minor components and $\mathrm{Cs}$ are given in the Test 2 limits (Table 2-4). From this a maximum ratio of grams (or $\mathrm{Bq}$ ) of each minor component to grams of $\mathrm{Na}$ can be calculated. This result gives the maximum permitted ratio for each minor component. The calculated [Na] from "All Envelopes" is then 
multiplied by the maximum permitted ratio to yield an adjusted minor component upper limit. A temporary upper limit is then calculated for each minor component as the lessor of the minor component upper Test 1 limit (Table 2-3) and the newly calculated adjusted maximum limit. Each minor component concentration is then determined using a uniform distribution with the Test 1 lower limit and the temporary upper limit.

\section{Envelope B}

The definition for Envelope $B$ requires that at least one of the Test 2 limits be exceeded (Table 2-4). First the concentrations of each component are calculated with a uniform distribution using the Test 1 limits. If none of the minor component concentrations exceed the glass solubility limits (Test 2), then the minimum [Cs] is set so that the calculated value will meet or exceed its limit (Test 2). Because the minor component upper Test 1 limits in Envelope $B$ are much greater than the calculated solubility limits (Test 2), forcing the Cs concentration to satisfy the Test 2 limits does not occur an inordinate number of times.

\section{Calculation of Volume of Added Waste}

The volume of waste (first envelope) that needs to be added to the heel (second envelope) to meet all constraints for the desired envelope (first envelope) is calculated in two parts. All calculations are performed as a volume ratio of Added Waste (or Feed) to Heel $(F / H)$.

First, the maximum F/Hs needed to meet the upper limit and/or the lower Test 1 limit for each component are calculated. Then the F/Hs for the minor components (and Cs) are calculated. For Envelope A, F/Hs are calculated to ensure that all concentrations are less than the minor component (and Cs) limits given in Test 2. The limiting $\mathrm{F} / \mathrm{H}$ for the minor components is then set to the maximum of these values. For Envelope $B$ the $F / H s$ are calculated so that each minor component (and Cs) meets or exceeds the minor component Test 2 limits. However, unlike Envelope $A$, the limiting minor component $F / H$ for Envelope $B$ is set to the minimum calculated value. For Envelope $C$ the minor component Test 2 limits do not apply and the value is set to 0 . The overall $F / H$ for each scenario is then set to the maximum of the three values.

\subsubsection{Results}

The spreadsheet is used to calculate 500 overall $\mathrm{F} / \mathrm{H}$ ratios for each of the six mixing scenarios using different heel and feed compositions each time. The calculated $\mathrm{F} / \mathrm{H}$ ratios were converted to maximum tank heel (in inches of waste) by 
fixing the $\mathrm{F}+\mathrm{H}$ at the maximum tank volume (416") used in this analysis. The results were sorted and plotted.

Figure 2-8 shows the maximum heel of one envelope that may be mixed with waste of another envelope and satisfy the second envelope's constraints.

Relatively large volumes of Envelope $A$ may remain in the heel and still be able to consistently switch to Envelopes B or C. Only small amounts of Envelope B or C may be left behind as heel if a switch to any other envelope is to consistently succeed. With a minimum operating heel of ten inches of waste assumed in this study, only $80 \%$ of these cases $(B \rightarrow A, B \rightarrow C, C \rightarrow A$ and $C \rightarrow B)$ are successful. As the heel increases the fraction of successful cases drops sharply.

The intermediate feed staging tanks (if used) will generally contain a heel of similar composition to that in the private contractors tanks. The volumes of these two heels are additive. An envelope switch will effectively pickup 20 inches of heel further reducing (to about $70 \%$ ) the fraction of successful envelope switches for the troublesome cases $(B \rightarrow A, B \rightarrow C, C \rightarrow A$ and $C \rightarrow B)$.

It must be understood that the waste compositions used in this study explore the full range of envelope compositions. For example, there are some instances where Envelope $\mathrm{B}$ waste with a high $\left[\mathrm{PO}_{4}\right]$ is mixed with Envelope $\mathrm{A}$ waste near the upper $\left[\mathrm{PO}_{4}\right]$ limit. Large $\mathrm{F} / \mathrm{H}$ ratios result since this is like diluting "100" with "0.999" to get a mixture that is less than "1". Actual waste is expected to have a more restricted range and may permit larger heels on a case by case basis. What is important is the sharp dependence of successful cases on the heel, not the exact fraction of successful cases.

\subsubsection{Conclusions}

As a guideline, reduce the number of the following envelope switches when possible: $B \rightarrow A, B \rightarrow C, C \rightarrow A$ and $C \rightarrow B$.

The private contractors' feed tank should contain only minimal heels of Envelope $\mathrm{B}$ or $\mathrm{C}$ whenever an envelope change will occur. A reasonable value for this heel appears to be 10 inches of waste.

The intermediate feed staging tanks should contain only minimal heels of Envelope $\mathrm{B}$ or $\mathrm{C}$ whenever an envelope change will occur. A reasonable value for this heel appears to be 10 inches of waste.

The $\mathrm{M} \& \mathrm{l}$ contractor is required to deliver waste of the proper envelope, not to insure that the resulting mixture in the private contractors feed tank remains in the limit. None-the-less, it is prudent that the M\&l's waste staging plan accounts for the heels to avoid tainting a batch of waste. 
The basis for the presence of multiple, non-zero, minimum limits is not fully explained by the draft RFP or by McKee (McKee, et.al. 1995). Minimum limits should only be present if needed to define the envelopes; the envelope definitions should not double as a nominal waste description.

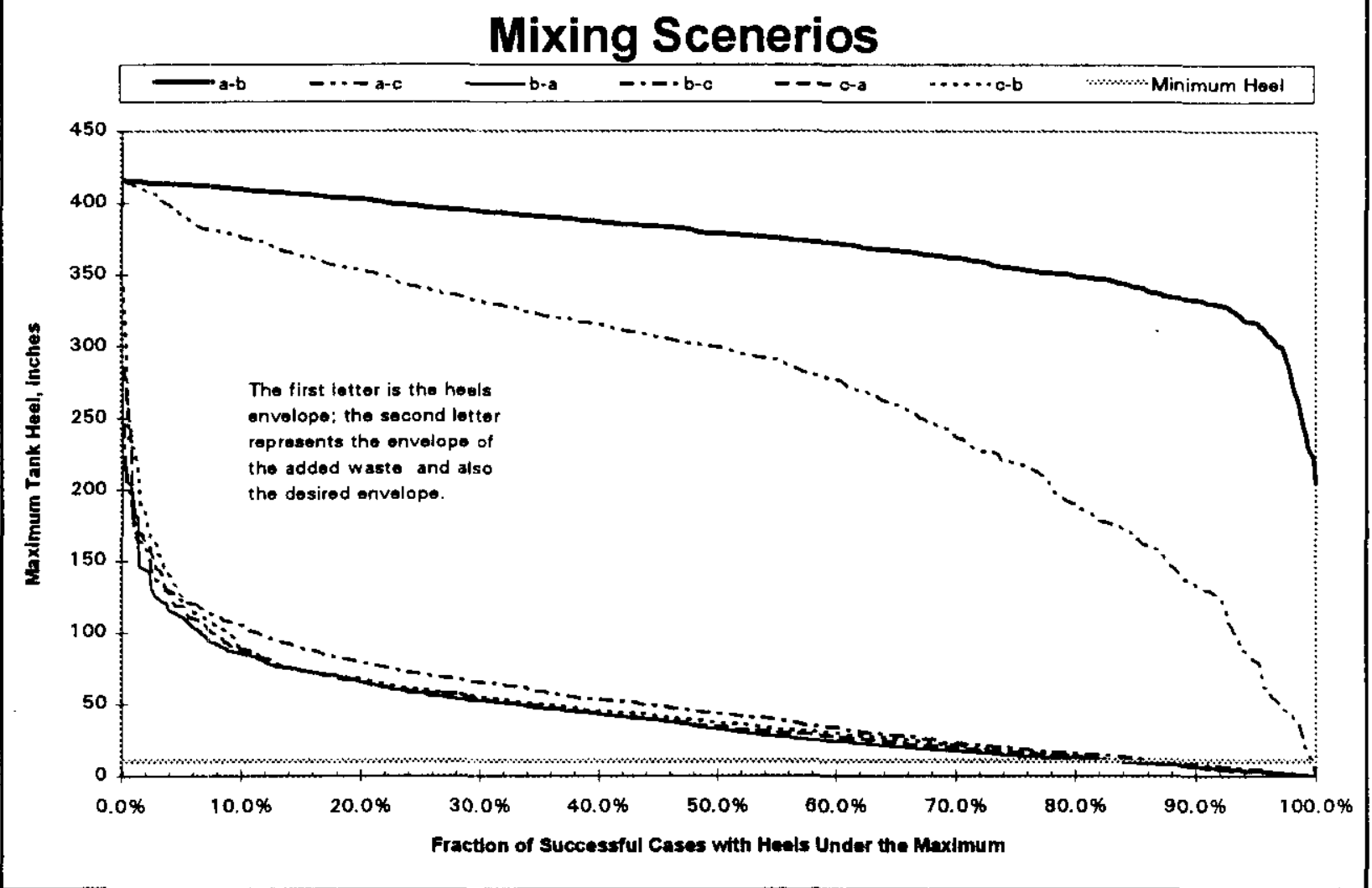

Figure 2-8 - Heel Mixing Study Results 


\subsection{WASTE COMPATIBILITY}

Prior to transfer of waste within the DST system (transfer is being used in the general sense and is not limited to the definition of 4.2.1.3 Transfer Managed Tank Wastel, a series of decision rules must be reviewed. These rules are documented in Fowler 1995a and 1995b and consolidate requirements from many sources. These rules, or there successors will need to be verified prior to each staging transfer. The discussions in the following sections are a cursory review that attempt to identify potential problems that may interfere with the staging of feed.

\subsubsection{Criticality Decision Rule}

The rule for when the Pu inventory ${ }^{1}$ in the destination tank is less than $10 \mathrm{Kg}$ will be satisfied if the total Pu in the transfer is less than $15 \mathrm{~g}$ or the $[\mathrm{Pu}]$ in the source waste is less than $0.013 \mathrm{~g} / \mathrm{L}$ (there are other ways to satisfy the criticality rule that are not being addressed here).

A reviev of the projected inventories for tanks 102-AP, 104-AP, 106-AP and 108-AP show the estimated Pu inventory to be near zero. A review of the projected supernate inventories for each DST show that the maximum estimated equivalent $[\mathrm{Pu}]$ to be $0.001 \mathrm{~g} \mathrm{Pu} / \mathrm{l}$ and the maximum equivalent quantity of $\mathrm{Pu}$ in any single transfer (not including entrained solids) is about $4400 \mathrm{~g} \mathrm{Pu}$.

Therefore, the criticality decision rule should not interfere with or otherwise influence staging of Phase I DST supernate unless entrained solids (which were not projected) contain significant quantities of Pu.

\subsubsection{Flammable Gas Accumulation Decision Rule}

If the SpG of the source tanks is less than 1.3 or the weighted mean SpG of the resulting blend is less than or equal to 1.41 , then the transfer may proceed. The operative rule will require that the $\mathrm{SpG}$ of the source tank be less or equal to 1.41 since most staging transfers will transfer the waste into a nearly empty tank. It is not desirable to add the dilution water until the waste is actually transferred. This is to avoid an out-of-specification feed batch if the expected volume of waste is not transferred.

The SpG of the projected supernate was estimated using the following relationship (Agnew 1994) and assuming that the reference density is $1.00 \mathrm{~g} / \mathrm{cm}^{3}$ :

\footnotetext{
${ }^{1} \mathrm{Pu}$ inventory is calculated using Pu equivalents as defined in WHC 1994a.
} 


$$
\begin{array}{r}
\rho=1+0.2\left(a[A /]^{2}+b[A /]+c[N a]^{2}+d[N a]+e\left[N O_{2}\right]^{2}+\right. \\
\left.f\left[\mathrm{NO}_{2}\right]+g\left[\mathrm{NO}_{3}\right]^{2}+h\left[\mathrm{NO}_{3}\right]+i[\mathrm{OH}]^{2}+j[\mathrm{OH}]\right)
\end{array}
$$

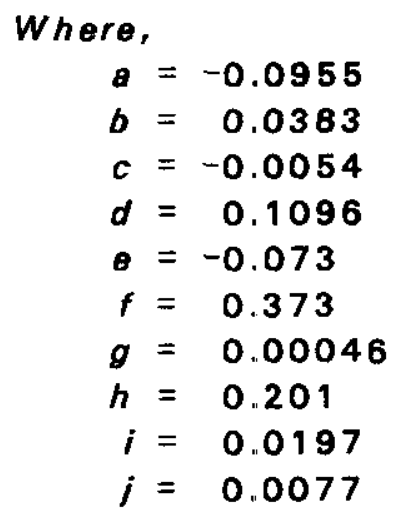

Density is in $\mathrm{g} / \mathrm{cm}^{3}$.

A/l concentrations are molarity.

The estimated supernate SpG of five of the tanks exceed the $1.41 \mathrm{SpG}$ limit. Four of these (103-AN, 104-AN, 105-AN and 101-AW) belong to the feed envelopes. Table 2-9 shows the estimated SpGs - tanks not belonging to any of the three feed envelopes have been shaded. The maximum SpG of the staged feed batches is 1.31 (Appendix E), which is acceptable. This rule permits a detailed technical evaluation for waste exceeding the $\mathrm{SpG}$ limit. It is prudent to perform this evaluation early enough to avoid impacts with feed staging activities. 
Table 2-9 - Estimated Supernate SpG

\begin{tabular}{|c|c|c|c|}
\hline \multicolumn{2}{|l|}{ Tanks above limit } & \multicolumn{2}{|l|}{ Tanks below limit } \\
\hline Tank & Estimated $S p G$ & Tank & Estimated $\mathrm{SpG}$ \\
\hline 103-AN & 1.50 & 101-AN & 1.31 \\
\hline 104-AN & 1.46 & 102-AN & 1.37 \\
\hline $105-\mathrm{AN}$ & 1.46 & 106-AN & 1.37 \\
\hline 101-AW & 1.51 & 107-AN & 1.33 \\
\hline \multirow[t]{19}{*}{ 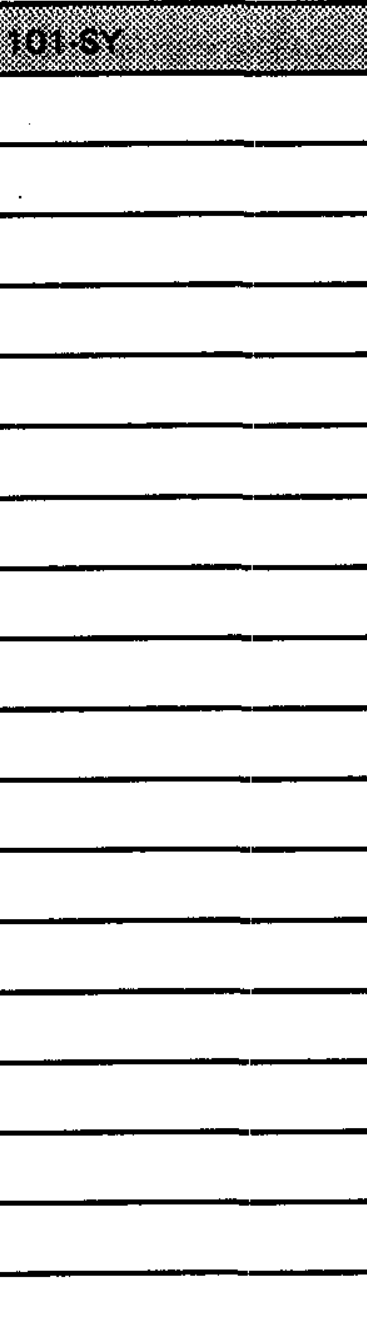 } & (1) & 101-AP & 1.32 \\
\hline & & 102.88 & 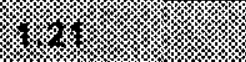 \\
\hline & & 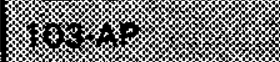 & $(1.310$ \\
\hline & & 104-AP & 1.29 \\
\hline & & 18.5 .8 & 3. \\
\hline & & 106-AP & 1.38 \\
\hline & & 107.78 & 1.82 \\
\hline & & (6) & 18 \\
\hline & & 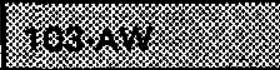 & 1.80 \\
\hline & & 104-AW & 1.07 \\
\hline & & 105-AW & 1.06 \\
\hline & & 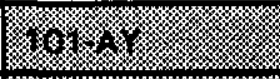 & 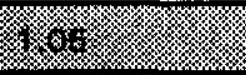 \\
\hline & & 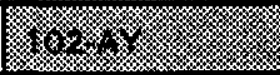 & 3.14 \\
\hline & & 101-AZ & 1.27 \\
\hline & & $\sqrt{30} \cdot 2.2$ & 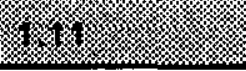 \\
\hline & & 102-SY & 1.29 \\
\hline & & 101-SY (total) & 1.36 \\
\hline & & 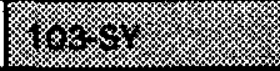 & $\sqrt{3.8}$ \\
\hline & & $100.5 \% 1.0 .01$. & 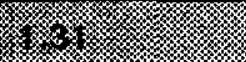 \\
\hline
\end{tabular}

\subsubsection{Energetics}

The waste must have no separable organic and the source and destination tanks must have endotherm in excess of exotherms. A separable organic phase 
has not been observed in any of the DSTs. The energetics of the system are dependent on the organic speciation. A prediction of DSC and TGA behavior from the projected inventories is not recommended. Barring the unexpected presence of a separable organic phase, this rule should not present any problems with staging of DST supernate.

\subsubsection{Corrosion Decision Rule}

The decision rule provides three sets of relationships between $\left[\mathrm{NO}_{2}{ }^{-}\right],\left[\mathrm{NO}_{3}{ }^{-}\right]$ and $\left[\mathrm{OH}^{-}\right]$that must be satisfied (the $\left[\mathrm{OH}^{-}\right]$is relaxed when the temperature is less than $167^{\circ} \mathrm{F}$ ). The set in use depends upon the $\left[\mathrm{NO}_{3}{ }^{-}\right]$. All of the projected supernate compositions satisfy the decision rule with the expectation of 102-AY. The $\left[\mathrm{NO}_{2}{ }^{-}\right]$for $102-\mathrm{AY}$ was projected as $0.01 \mathrm{M}$ which is slightly lower than the operative limit of $0.011 \mathrm{M}$ - this is within the noise level of the projections. The predicted staged waste compositions in Appendix $\mathrm{C}$ also satisfy the corrosion specifications (solid/liquid equilibria has not been considered). If significant quantities of solids precipitate during staging, chemical additions may required to prevent the precipitation or maintain waste within the corrosion specifications.

This rule should not interfere with feed staging plans, but may influence chemical additions.

\subsubsection{Watch List Tanks Decision Rule}

This rule restricts the transfer of waste into a watch list tank without DOE approval. Staging of DST supernate does not require transfer of waste inte current watch list tanks.

Currently, six DSTs are on the watch list. They are 103-AN, 104-AN, 105-AN, 101-AW, 101-SY and 103-SY. The supernate from all but 101-SY is used for Envelope A feed.

Currently, eight DSTs are associated with a flammable gas unreviewed safety question (USO). These tanks are 101-SY, 103-SY, 101-AW, 104-AW, 103-AN, 104-AN, 105-AN and 101-AY. For all practical purposes, these tanks are treated as if they were on the watch list. Supernate from tanks 101-AW, 104AW, 103-AN, 104-AN and 105-AN is used for Envelope A feed.

It may be prudent to determine if the watch list designation travels with waste staged from watch list tanks, thus classifying the intermediate staging tanks and the private contractors' feed tanks as watch list tanks. 
Additionally, the status of the USQ should be reviewed to understand fand plan to avoid) potential impacts on feed staging activities.

\subsubsection{TRU Segregation Rules}

This rule requires that waste with a $[T R U] \geq 100 \mathrm{nCi} / \mathrm{g}$ be transferred to a TRU storage tank. Otherwise the waste must be transferred to a non-TRU tank unless an analysis demonstrates that TRU segregation will not be jeopardized.

The [TRU] for the projected supernate was estimated by:

$$
[T R U] \approx \frac{\sum \text { Inventory }}{V \rho\left(1000 \mathrm{~cm}^{3} / /\right)}\left(10^{\circ} \mathrm{nCi} / \mathrm{Ci}\right)
$$

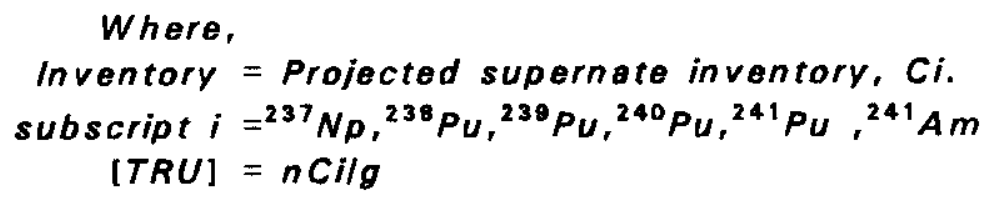

The estimated [TRU] exceeded the rule limit for five tanks (102-AN, 107-AN, 103-AW, 101-AY and 102-AZ), the rest were within the limit. Table 2-10 shows the estimated [TRU] - tanks not belonging to any of the three feed envelopes have been shaded.

Staging of supernate from 102-AN and 107-AN (Envelope $\mathrm{C}$ ) will require an analysis that determines that TRU segregation will not be jeopardized. 
Table 2-10 - Estimated Supernate TRU Concentration

\begin{tabular}{|c|c|c|c|}
\hline \multicolumn{2}{|c|}{ Tanks above limit } & \multicolumn{2}{|l|}{ Tanks below limit } \\
\hline 102-AN & $100+$ & 101-AN & 0.1 \\
\hline 107-AN & 300 & 103-AN & 3. \\
\hline 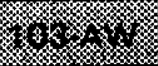 & 10 & 104-AN & 9. \\
\hline 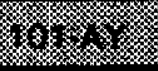 & 8 & $105-A N$ & 9. \\
\hline \multirow[t]{19}{*}{$10+2$} & 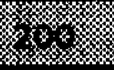 & 106-AN & 15. \\
\hline & & (3) & 88 \\
\hline & & 102,1 & 62 \\
\hline & & 103-AP & 0.02 \\
\hline & & 104-AP & 0.001 \\
\hline & & 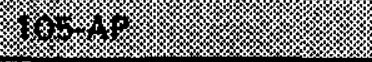 & $(-22$ \\
\hline & & 106-AP & 0.00002 \\
\hline & & 10728 & 0.08 \\
\hline & & 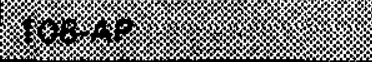 & $0.0 \%$ \\
\hline & & 101-AW & 2. \\
\hline & & 104-AW & 0.2 \\
\hline & & 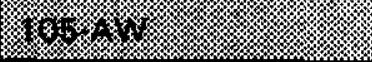 & (8) \\
\hline & & 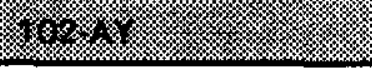 & (2) \\
\hline & & $101-A Z$ & 15. \\
\hline & & $102.8 \%$ & 85 \\
\hline & & 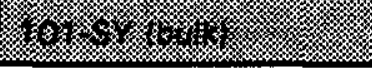 & 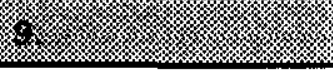 \\
\hline & & 102-SY & 0.001 \\
\hline & & 103-SY & 1.5 \\
\hline & & 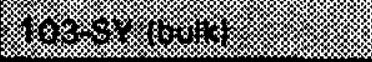 & (2) \\
\hline
\end{tabular}

All concentrations are in units of $\mathrm{nCi} / \mathrm{g}$.

\subsubsection{Heat Generation Rate Rule}

This rule requires that the heat generation rate in AP-Farm and AW-Farm (AW-Farm is an alternate location for intermediate staging tanks) must be less than $70,000 \mathrm{BTU} / \mathrm{hr}$. 
The heat generation rates for all projected supernate inventories were less than $70,000 \mathrm{BTU} / \mathrm{hr}$ with the exception of $101-\mathrm{AZ}$ at $90,000 \mathrm{BTU} / \mathrm{hr}$. This waste fits into Envelope $B$ as is (no dilution or concentration required). Although the heat generation limit will be satisfied if the 101-AZ supernate is split between both intermediate staging tanks, this complicates the staging of Envelope $B$ waste and may cause the following outage to exceed 60 days (the short campaign length can not be compensated for by prestaging Envelope $C$ in the other intermediate staging tank). This limit should be examined and, if possible, raised. Otherwise, the staging plan will be revised to comply with the existing limit.

\subsubsection{Complexant Waste Segregation Rule}

This rule requires transfer of complexant waste to a complexant waste receiver tank. This rule is problematic and will require that an exception be made to enable the staging of Envelope $C$ feed since waste meeting Envelope $C$ limits is classified as complexant waste.

\subsubsection{Waste Pumpability Rule}

The rule requires that $\mathrm{N}_{\mathrm{Re}}$ for the transfer line be greater than or equal to 20,000 and the volume percent solids less than or equal to 30 . This rule has not yet been evaluated for the feed staging transfers and is part of the scope necessary to confirm the LLW Feed Staging Plan.

\subsubsection{Tank Waste Type}

The rule provides a compatibility matrix for mixing of wastes of different types. The matrix must be followed to the extent practicable. In order to successfully stage DST supernate, this rule must permit mixing a heel of "incompatible" waste with the feed being staged. A heel of Envelope C waste (CC) can not be mixed with Envelope A waste (most often DSSF/DSS). A heel of Envelope B waste (mostly NCAW) can not be mixed with CC or DSSF/DSS. A heel of $\mathrm{CP}$

(CP is currently in 102-AP) can not be mixed with DSSF/DSS or CC.

Generally, this rule prevents switching waste Envelopes unless "to the extent practicable" permits mixing of an "incompatible" heel. The interpretation and intent of this rule should be documented well in advance of feed staging activities. If technically justified, an exception should be provided.

\subsubsection{High Phosphate Waste}


This rule prevents mixing waste with $\left[\mathrm{PO}^{-3}\right]>0.1 \mathrm{M}$ with waste containing a $\left[\mathrm{Na}^{+}\right]>8 \mathrm{M}$. The projected supernate composition of the waste in 102-AP contains a $\left[\mathrm{PO}^{-3}\right]$ of $0.122 \mathrm{M}$. The initial batch of waste staged in 102-AP was selected to have a $\left[\mathrm{Na}^{+}\right]<8 \mathrm{M}$ and thus avoid challenging this rule. This may not always be possible.

The interpretation and intent of this rule should be documented well in advance of feed staging activities. If technically justified, an exception should be provided.

\subsection{ENVELOPE ORDER}

The envelope order provided by Assumption ? appears to be workable provided the following is met:

- The potential waste compatibility issues identified in Section 2.7 are resolved.

- The intermediate staging tanks and the private contractors' feed staging tanks are emptied to near the assumed 10-inch minimum operating heel as recommended in Section 2.6.

- As a guideline, the number of times that waste envelopes are switched should be kept as small as practicable.

\subsection{OPERATIONAL WASTE VOLUME PROJECTION}

Section 2.3 explained how the most recent operational waste volume projection (OWVP) was used with sample and historical transfer data for projecting the volumes and compositions of the DSTs to the start of staging activities (Koreski and Strode 1995). The results from this OWVP case (and two other cases examiried in the same report) showed that DST space was tight from FY 1998 to FY 2002, a period critical for staging DST supernate.

The assumptions used by alternative acquisition strategy (privatization) case examined by this OWVP were similar to those used in this preliminary LLW feed staging plan. The primary exceptions, due to changes in the privatization plans, are as follows:

- Phase I processing ran from FY 2002 to FY 2009 rather than the current dates of June 1, 2002 to June 1, 2011. 
- Direct Staging was used rather than the now recommended Indirect Staging ASAP.

- The SST retrieval schedule/sequence introduced insoluble solids earlier and faster than desired. This schedule/sequence was based on retrieval sequence and blending work that was in progress at the time the OWVP assumptions were prepared. The completed report concluded that the preliminary SST retrieval sequence (which was similar to the sequence used by the OWVP) will require modification to reduce the amount of insoluble solids retrieved before HLW Vitrification begins (Certa 1995d)

To better understand the tank space issues during Phase I, a special OWVP was performed (Strode 1996). Assumptions not related to SST retrieval sequence or Privatization are the same as in Koreski and Strode 1995.

- $\quad$ DST supernate staging used the Indirect - ASAP staging strategy with 102$\mathrm{AP}$ and 104-AP designated as the intermediate staging tanks.

- The straw man staging sequence and dilution ratios from the feasibility study (Certa et al. 1995b) were used; the timing was accelerated to correspond to the assumed work off rate of (POE) $C_{d}$. An exception was that all supernate from 106-AN and 107-AN was pretreated at once to free up useable tank space. The preliminary staging plan does process all of 106-AN in consecutive batches, however 107-AN was forces to be split over several years.

- Beyond the feed provided by the straw man staging sequence, waste was diluted to a nominal $5 \mathrm{M} \mathrm{Na}$ in the intermediate staging tanks and then worked off at a nominal $3 \mathrm{Mgal} / \mathrm{year}$.

- No SST waste (other than 106-C) was retrieved. The purpose of this was to estimate the space available for SST waste retrieval as a function of time. This information will help with the modification of the Preliminary Retrieval Sequence (which will then be called the Initial Retrieval Sequence).

The results of the special OWVP (Strode 1996) suggest that DST supernate can be successfully staged during Phase I within existing DST tank space using the Indirect Staging - ASAP strategy, provided that SST retrieval be tailored to fit in the remaining tank space (Figure 2-9). The intermediate staging tanks (102-AP and 104-AP) are available in FY 2000 after waste is transferred to other DSTs. The private contractors' feed tanks become available for staging activities in FY 2001.

The next routine OWVP (Revision 22) will use the Preliminary SST Feed Staging Plan as one source of assumptions as will the TWRS Simulation Model, 
WHC-SD-WM-RPT-210, Rev. 0

which is being updated to support the selection of the Initial SST Retrieval Sequence. 
WHC-SD-WM-RPT-210, Rev. 0

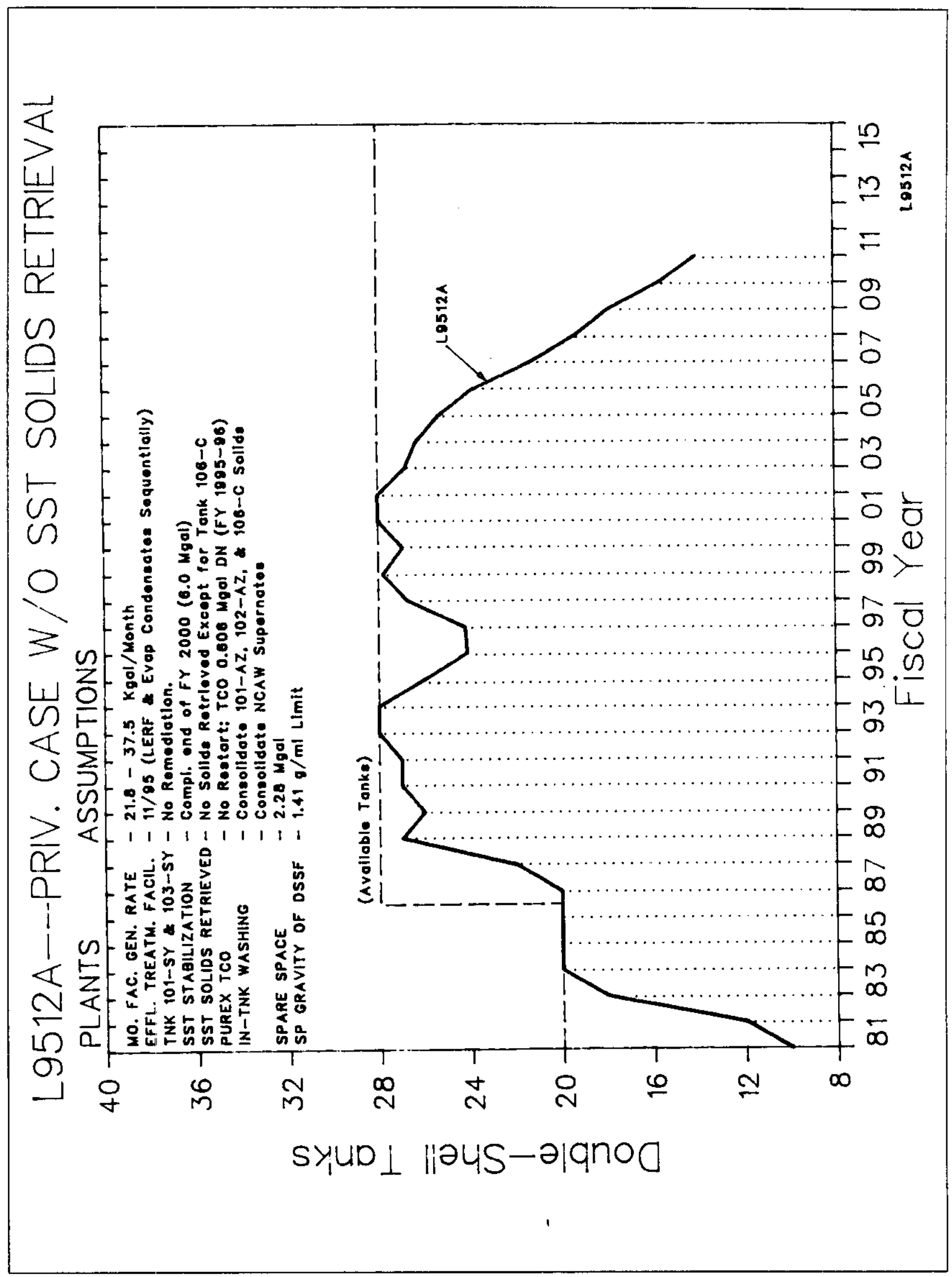

Figure 2-9 - Operational Waste Volume Projection Case L9512A 


\subsection{DST PROCESSING SEQUENCE}

The following criteria were used to establish the order that DST supernate is provided to the private contractors; the first group of criteria were considered non-tradable, the second group was considered tradeable:

\section{Non-tradable}

- The waste must belong to the proper envelope.

- The minimum order quantities of Na must be satisfied.

- Free up an AN-Farm DST early for use as a receiver tank by the Initial SST Retrieval Project.

\section{Iradeable}

- The required (scheduled) amounts of $\mathrm{Na}$ in each batch must be provided.

- Avoid "tank-hopping". Finish emptying a DST promptly.

- Avoid staging tanks with low quality projections early.

- $\quad$ Process dilute waste as soon as possible.

- Dilute with dilute waste when convenient, rather than dilution water.

- Avoid switching Envelopes.

Table 2-11 shows one plausible sequence based on the above criteria. The target $V / V_{0}$ was obtained from Figures 2-4, 2-5 and 2-6. The minimum $V / V_{0}$ was increased by about 0.5 units to provide a margin for error. If the resulting diluted volume required slightly more than 2.0 tanks $(4.33 \mathrm{ML}$ per tank, adjusted for heel and reduced upper liquid-level limit), the margin was reduced. Otherwise, an additional batch would be made with the excess.

The batch numbers in the two Private Contractor columns show which DST provides feed for each contractor. The first batch is numbered 1 , the second 2 and so on. If a number appears in both contractors' columns, the waste from that tank provides feed to each contractor. If two numbers appear for a given contractor, the supernate is split into additional batches. Tanks 102-SY and 104-AW were not scheduled since they contain insufficient $\mathrm{Na}$ (less than $90 \mathrm{MT}$ ) and their projected inventories will most likely change before they can be processed. 
WHC-SD-WM-RPT-210, Rev. 0

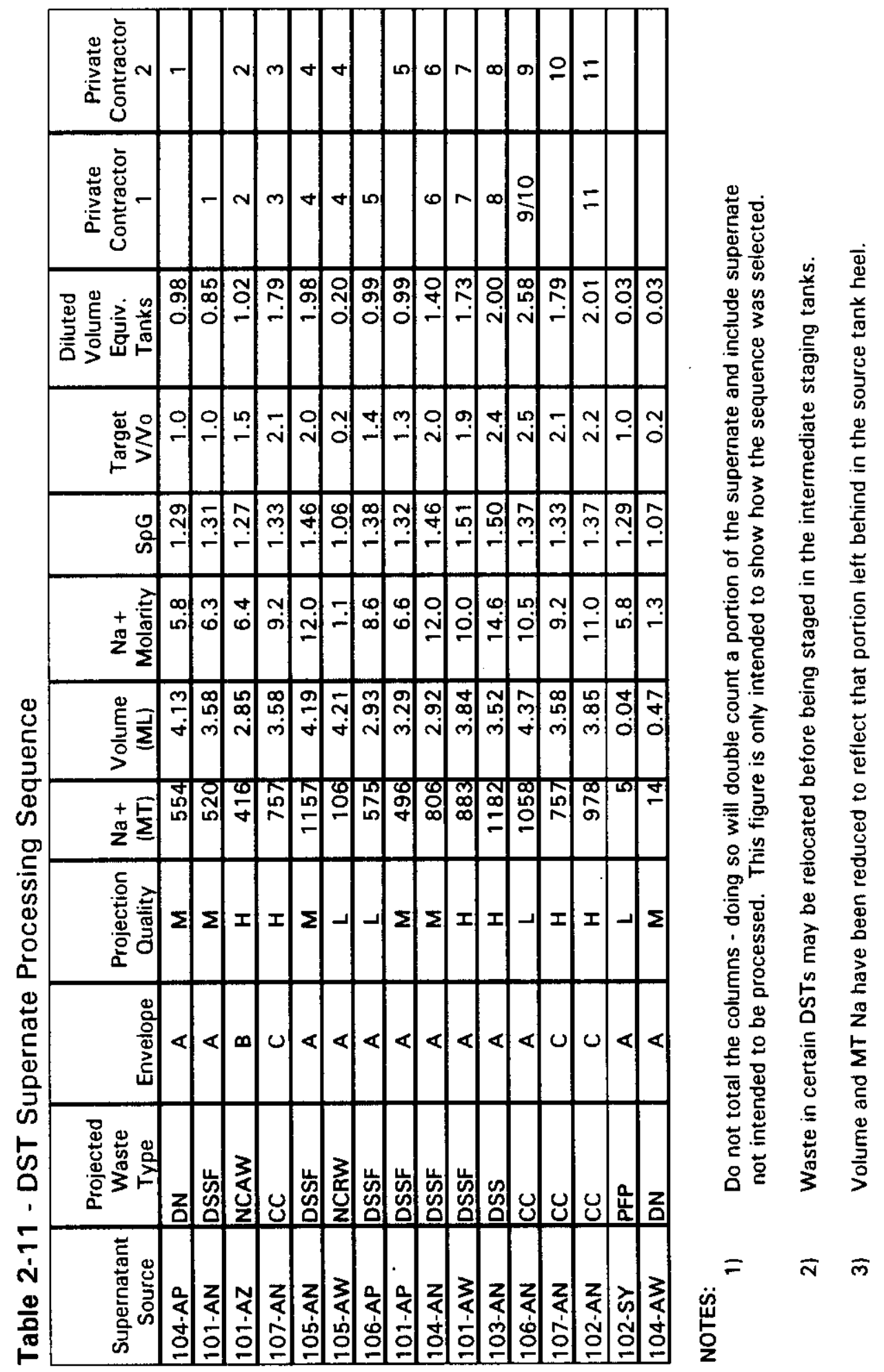




\subsection{RETRIEVAL REQUIREMENTS}

Retrieval of supernate from the A-Farm complex DSTs required the capability to provide a coarse solid-liquid separation. This will probably be accomplished using decant/transfer pumps with a flex and float mechanism. This approach has been used with success in past operations. Candidate decant-transfer systems include those designed for Projects W-151, W-211, and W-320.

Individual DSTs will need to be evaluated on a case-by-case basis to identify the required upgrades (equipment installation) for each tank. This work is outside the scope of the Preliminary LLW Feed Staging Plan and will be documented as part of the Confirmed LLW Feed Staging Plan.

\subsection{TRANSFER REQUIREMENTS}

The existing waste transfer system for the A-Farm Complex (200 East DSTs) consists of underground transfer lines, valve pits, diversion boxes, sluice pit, and pump pits. Portions of the waste transfer systems date back to the early operating years for Hanford. There are also newer systems that have been installed in the AN, AW, AP, AY, and AZ tank farms when they were constructed.

The current system is made up of nominal 2-in. and 3-in. transfer lines. The 2-in. lines are referred to as Slurry Lines (SL), and 3-in. lines are referred to as Supernate Lines (SN). It is assumed that the supernate transfers to the private contractors' feed tanks will be made through the SN lines since this will allow for a higher transfer rates $(\mathrm{gpm})$ than using SL lines. It is feasible to transfer supernate through the SL lines if needed to avoid conflicts with HLW feed staging transfers.

An issue that requires further evaluation is transfers from the $A N$ tank farm. Existing transfer lines from AN to the AX-A \& B valve pits are 2-in, which may limit the transfer rate. This issue is being investigated by Project $W-314$ Tank Farm Upgrades.

The A-Complex transfer system will need to be evaluated to recommend system upgrades (if any) to support staging of DST supernate and other concurrent activities. This work is outside the scope of the Preliminary LLW Feed Staging Plan and will be documented as part of the Confirmed LLW Feed Staging Plan.

The feasibility study (Certa et al.1995b) documented potential transfer routes from each of the DSTs into the intermediate staging tanks and the private contractors feed tanks. 


\subsection{TANK ALLOCATION TO M\&I STAGING FUNCTIONS}

The use of intermediate staging tanks was recommended in Section 2.2. It is desirable for the intermediate staging tanks to be located near the private contractors' feed tanks. By minimizing distance of the final staging transfers, the potential for conflicts with other ongoing tank farm activities such as 242-A Evaporator operation and SST retrieval is reduced. The intermediate staging tanks will require mixing capability, decant capability and the capability to add dilution water. The dilution water may require chemical adjustments depending upon the resolution of the issue in Assumption A1.8.6 (Appendix A) "Waste Mass-Balance Calculations".

Tanks 102-AP and 104-AP meet the above criteria. Tank 102-AP was modified for the Grout Program and currently has an agitation system (inoperative mixer pump) and a new transfer pump pit. It is recommended that the AP-104 tank receive similar modifications. The Grout Program began the modifications but the effort was stopped prior to completion, because of the cancellation of the Grout Program.

The allocation of a tank(s) to receive the "Entrained Solids" and "Strontium/TRU" streams from the private contractors requires a better estimate composition and volume of the streams is prepared. Approximately $76 \mathrm{ML}$ of feed are provided to the private contractors. Using the assumptions in A1.7.11 (Appendix A), the volume of the returned streams is about $6 \mathrm{ML}$ (1.5 DSTs).

The final allocation of the intermediate staging tanks and private contractors' return $\operatorname{tank}(s)$ is outside the scope of the Preliminary LLW Feed Staging Document. This allocation will be documented as part of the Confirmed LLW Feed Staging Document. 


\section{RESULTS}

\subsection{OPERATING SCENARIO}

The results of the feed staging study in Appendix B were used to establish a preliminary planning basis for preparing the schedule that describes the operating scenario. This operating scenario provides a starting point for further assessment of DST allocation and space availability and the demands placed upon the transfer system. The durations for activities in the schedule were taken from the Base Case simulation results - values near the medians were used. The Recommended Case results can not be used until supporting changes in the draft RFP are made. The planning basis is as follows:

- Primary transfers take a total of 20 days per transfer.

- Secondary transfers take a total of 20 days per transfer.

- Dilution water transfers take a total of 4 days per transfer.

- Final staging transfers take a total of 10 days per transfer.

- Only one staging transfer (including dilution water) is permitted at a time.

- Mixing, sampling, settling, analysis, and evaluation take a total of 70 days per intermediate staging tank.

- Waste is processed by the private contractors at $(P O E) C_{d}=1.875 \mathrm{MT} \mathrm{Na}$ per day.

The staging transfers that are needed to implement the DST supernate processing sequence in Table 2-10 are shown in Figure 3-1. Summary results are shown in the Executive Summary.

Tanks 102-AP and 104-AP become available for staging transfers in FY 2000; Tanks 106-AP and 108-AP become available at the start of FY 2001 (Strode 1996). The later date is used as the start of feed staging activities.

Waste interfering with the staging of feed was relocated. Waste from 102-AP was transferred to 103-AP; and waste from 106-AP was transferred to 107-AP; waste from 108-AP was transferred to 102-AW for evaporator feed staging. Evaporator plans should attempt to have these tanks already empty at the start of feed staging activities. 
Tank 104-AP already contains the first feed batch (Envelope A) for one contractor. The other contractors' first feed batch (Envelope A) becomes available when waste is transferred from 101-AN to 102-AP. Waste from 101-AN is permitted to be transferred on top of the high phosphate heel left behind in 102-AP. Waste in both tanks is mixed, sampled, evaluated, and then transferred to 106-AP and 108-AP. No dilution is required.

The second feed batch (Envelope B) for both contractors is staged in 102-AP. Although this exceeds the heat generation rate limit as discussed in Section 2.7.7, prestaging of the second and third feed batches is desired to compensate for their short campaign lengths. It is anticipated that the heat generation rate limit will have been successfully raised to accommodate this transfer. If not, the Preliminary LLW Feed Staging Plan will be changed (as part of the Confirmed LLW Feed Staging Plan work scope) to reflect this requirement. Waste is mixed, sampled, and evaluated, then is transferred to 106-AP and 108-AP immediately after the first batch of feed is processed.

The third feed batch (Envelope C, 107-AN) for both contractors is staged in 104-AP. Waste is diluted, mixed, sampled, and evaluated, then is transferred to 106-AP and 108-AP immediately after the second batch of feed is processed. Since 107-AN is not emptied, its space is considered segregated for storage of CC waste only.

Scheduling the second and third feed batches was complicated by the short campaign lengths that resulted from the quantity and time constraints. If the size of these batches was increased to a nominal $400 \mathrm{MT}$, feed staging would be simpler and tank space could be made available faster. Envelope limit changes are also required so that additional supernate fits Envelope B. The RFP will require changes to permit full batches of Envelope $B$ and $C$ for the second and third batches (and corresponding reduction in Envelope A during the proof-of-concept period).

Another disadvantage to prestaging Envelopes $B$ and $C$ as was done above is that the intermediate feed staging tanks each contain feed for both contractors. If one contractor falls behind schedule, prestaged feed for that contractor may interfere with the staging activities for the other contractor. This would require transfer of this feed into another DST for temporary storage. This tradeoff can be eliminated by permitting longer campaign lengths for the second and third feed batches or accepting the risk of exceeding the 60 day feed delivery window.

Additional batches of feed from Envelope A are stagged in 102-AP and 104AP each time these tanks are emptied. Dilute supernate is used in lieu of dilution water when possible (the fourth feed batch for both contractors). Supernate from 106-AN would require 2.6 tanks for storage after dilution and had to be split into three batches resulting in less than optimal batch sizes. 
WHC-SD-WM-RPT-210, Rev. 0

Envelope $C$ supernate was staged after all available Envelope $A$ supernate was processed. First, the remaining supernate in tank 107-AN was used as feed. Then, supernate from 102-AN was staged. 
WHC-SD-WM-RPT-210, Rev. 0

This page intentionally left blank. 


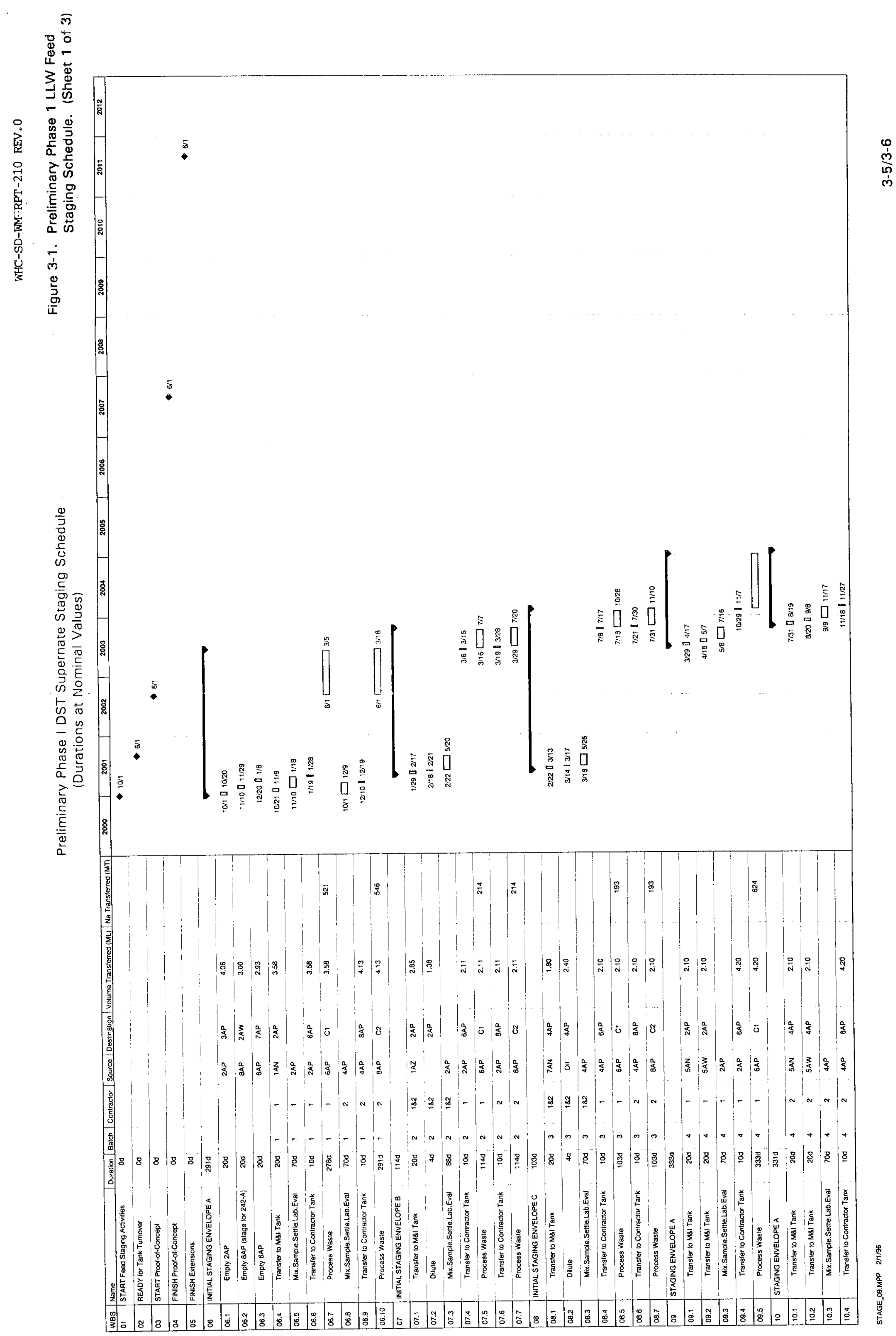




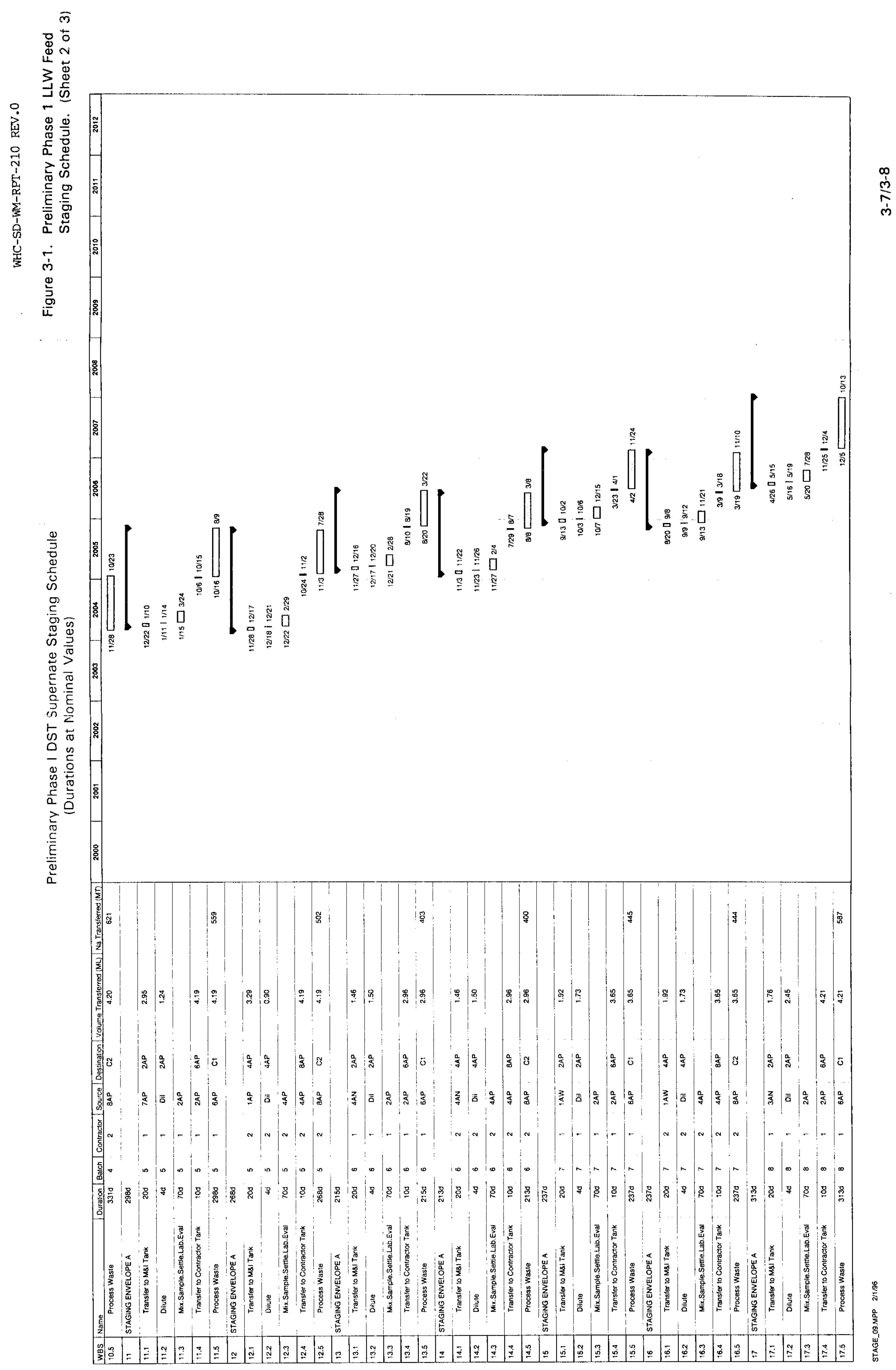




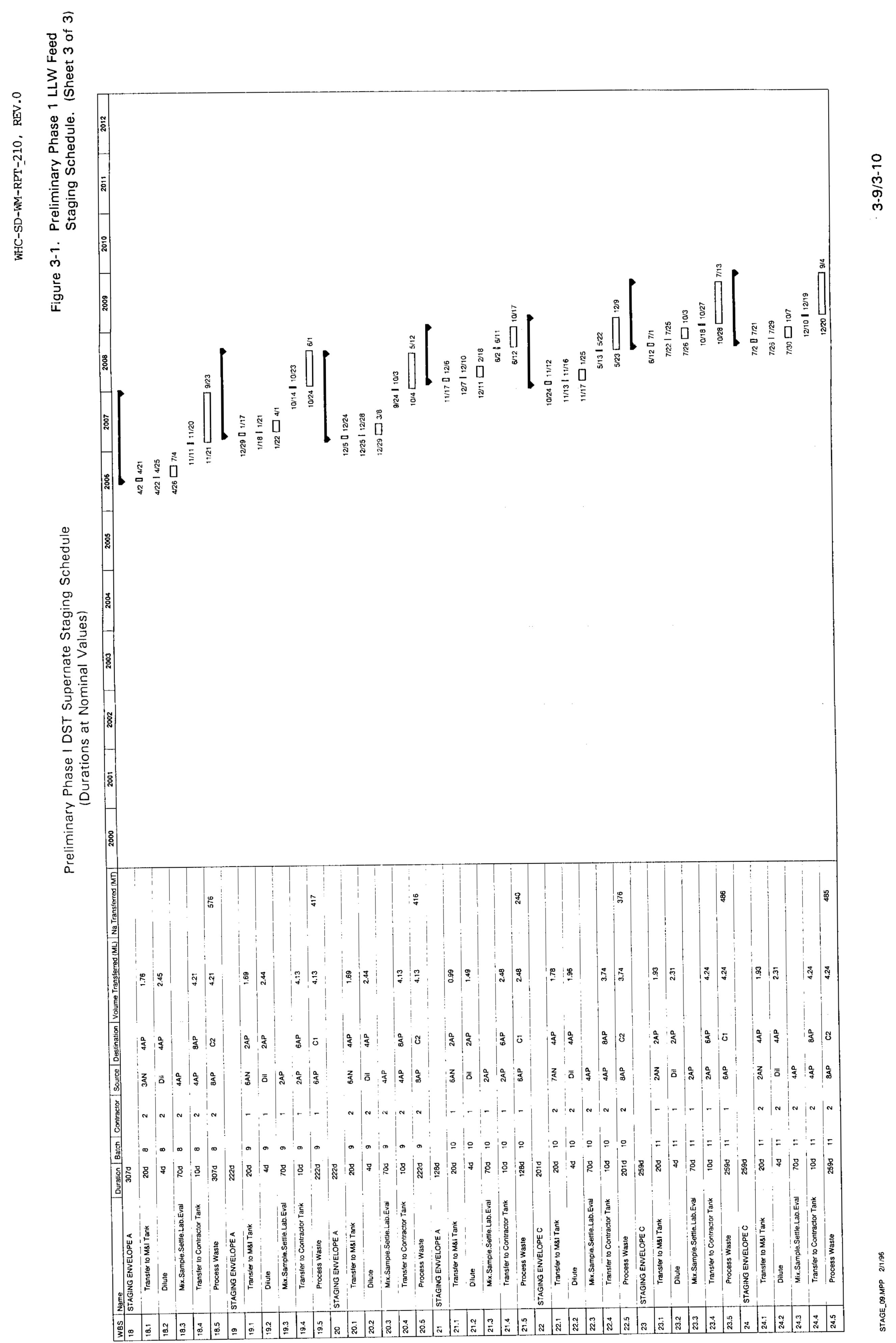


WHC-SD-WM-RPT-210, Rev. 0

\subsection{ASSESSMENT OF STAGED SUPERNATE}

The estimated composition and $\mathrm{SpG}$ of the supernate as staged in the private contractors' feed tanks are shown in Appendix E. These compositions were compared with the three feed envelopes and were shown to satisfy the appropriate limits (Figures 3-2, 3-3 and 3-4). The compositions satisfy the corrosion rule and the SpGs satisfy the flammability rule.

Feed batch 9 for Contractor 2 satisfies both Envelope $A$ and $C$ limits depending upon the amount of dilution water added. This is only of significance if the envelopes were intended to be mutually exclusive and invariant with respect to dilution and concentration. 

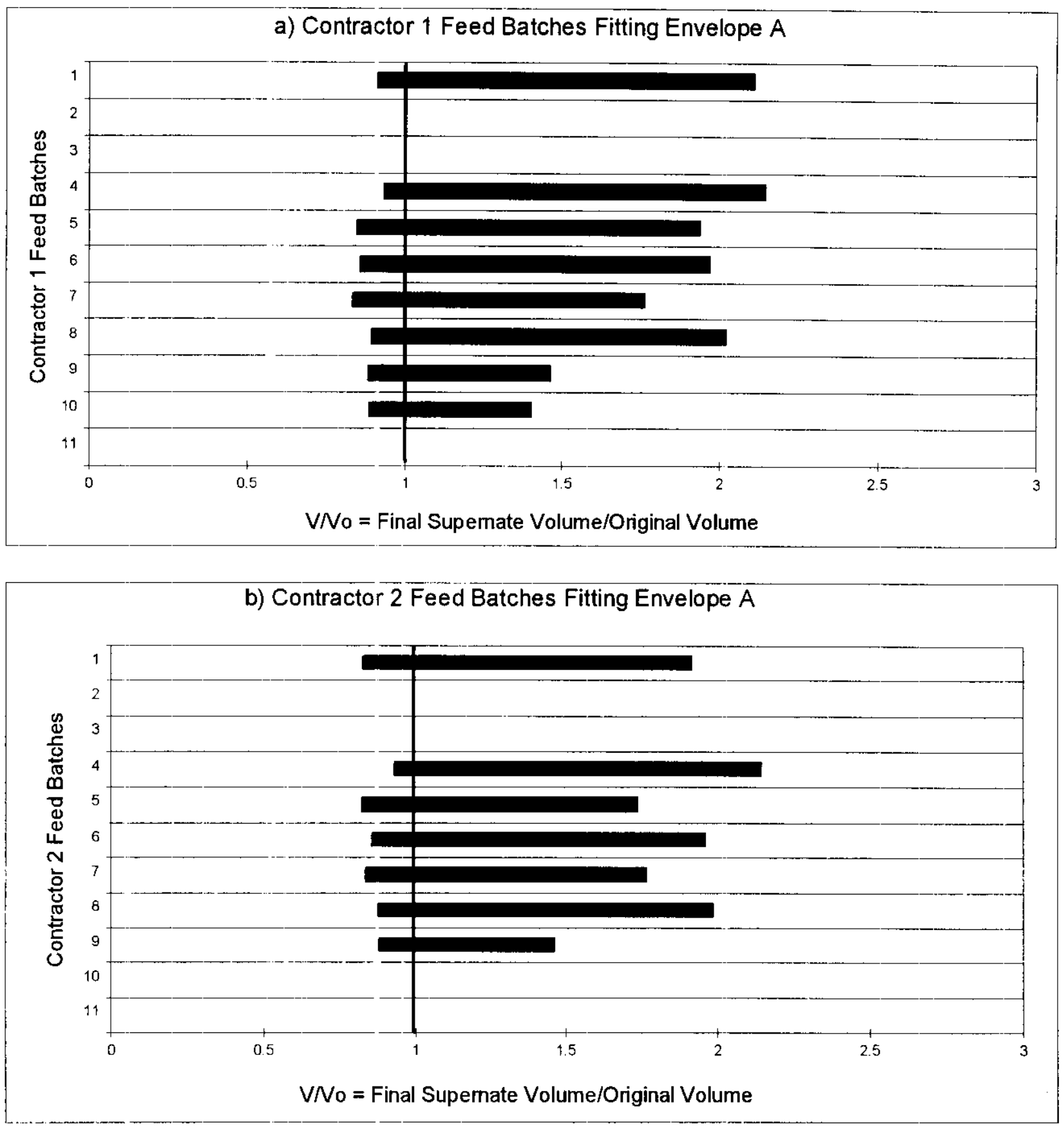

Figure 3-2 - Envelope A Staged Feed Assessment 


\section{WHC-SD-WM-RPT-210, Rev. 0}
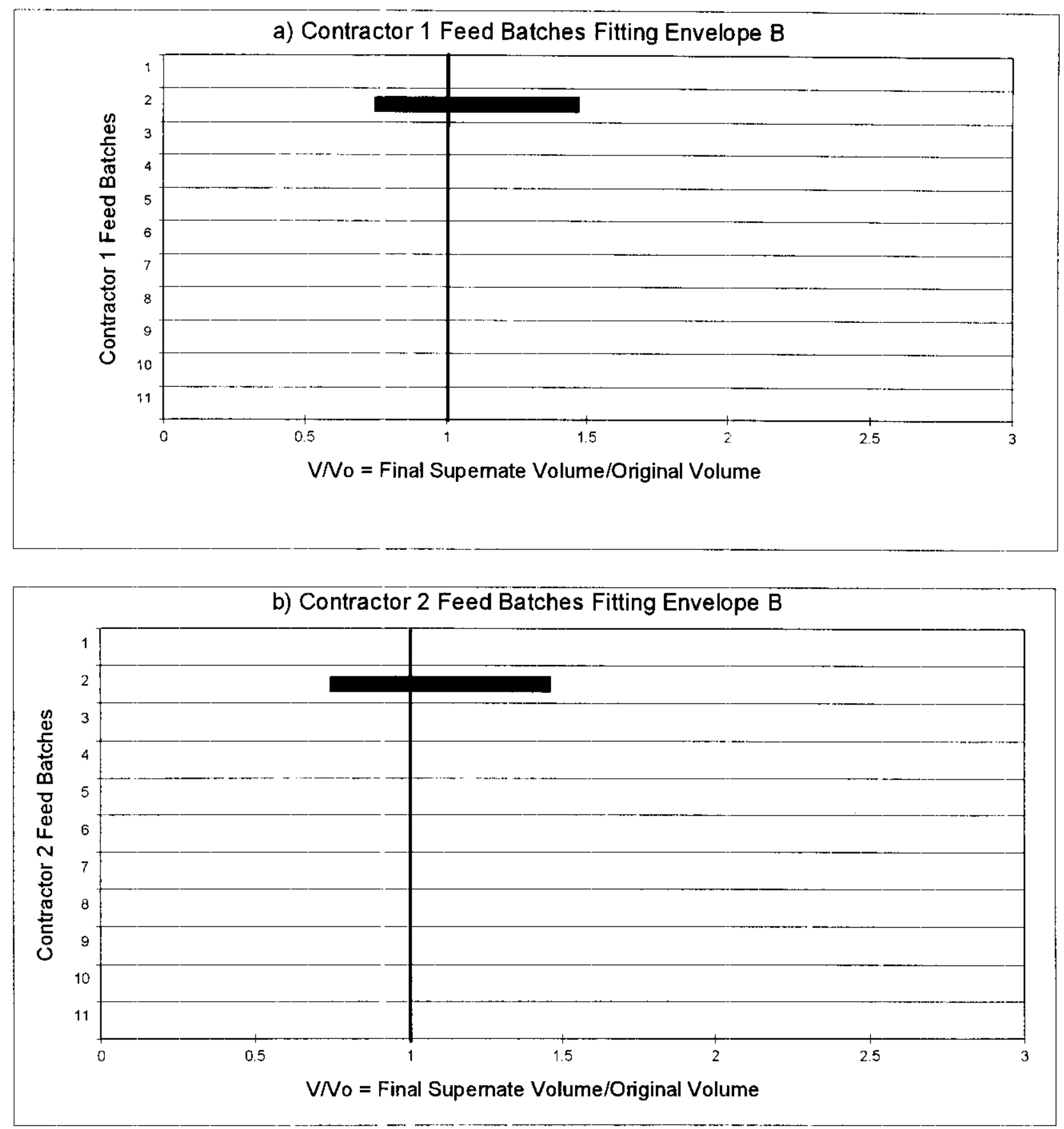

Figure 3-3 - Envelope B Staged Feed Assessment 

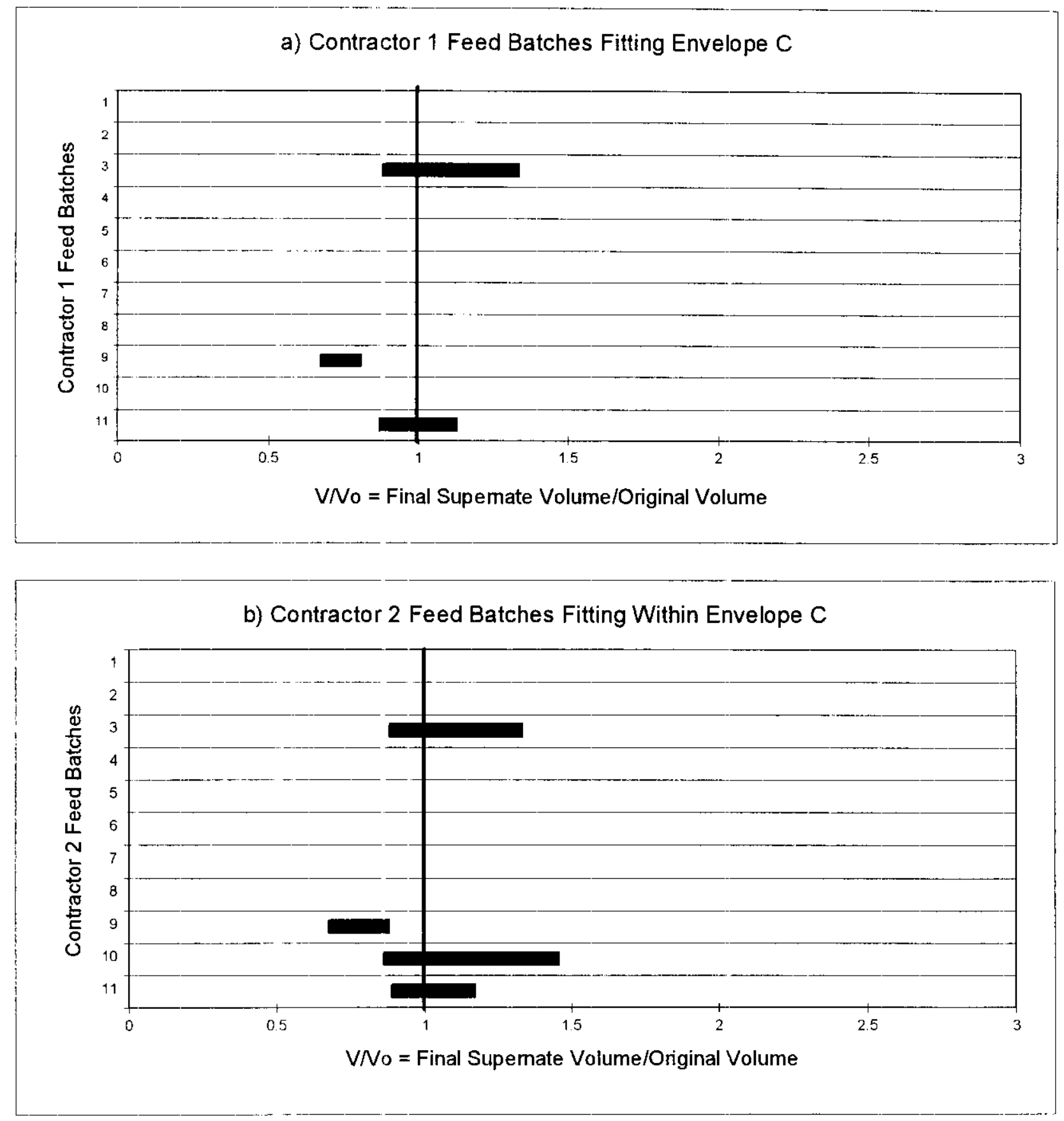

Figure 3-4 - Envelope C Staged Feed Assessment 


\section{CONCLUSIONS}

\subsection{CONCLUSIONS}

The Indirect Staging - ASAP strategy is recommended over Indirect Staging When Notified and Direct Staging.

The performance of the Indirect Staging - ASAP staging strategy can be significantly improved if the minimum campaign length is kept larger than 90 days and the maximum setup time for the final staging transfer is kept below 50 days.

The special OWVP performed for this study suggests that there is sufficient tank space to implement the Indirect - ASAP feed staging strategy.

The heels that remain in the intermediate staging tanks and in the private contractors' staging tanks should each be kept to a minimum. As a guideline, the maximum heel should be about $0.1 \mathrm{ML}$ (10 inches of waste). In practice, a slightly larger value may be used since 10 inches also corresponds to the assumed heel left behind by a transfer/decant pump.

\subsection{RECOMMENDATIONS}

The draft RFP should be modified to provide more flexibility in sizing feed batches during the proof-of-concept demonstration (June 1, 2002 to June 1, 2007) as follows:

The size of the first batch of supernate (Envelope A) should be reduced from $600 \mathrm{MT} \mathrm{Na}(-5 \%,+15 \%)$ to about $500 \mathrm{MT} \mathrm{Na}$. The addition of dilution water to bring the retrieved supernate into specification increases its volume. This makes it difficult to fit supernate containing $600 \mathrm{MT}$ of $\mathrm{Na}$ into a single batch. Consider permitting the first batch to contain "greater than or equal to $500 \mathrm{MT} \mathrm{Na"} \mathrm{to} \mathrm{allow} \mathrm{additional} \mathrm{flexibility} \mathrm{in} \mathrm{staging.}$

The draft RFP specifies that the size of the second and third batches of supernate (Envelope $\mathrm{B}$ and $\mathrm{C}$ ) is greater than or equal to $100 \mathrm{MT} \mathrm{Na}$ for each envelope and private contractor. However, $2800 \mathrm{MT}$ of $\mathrm{Na}$ (2600 MT Na from Envelope A) must be provided to each private contractor during the five-year proof-of-concept demonstration. At a $60 \% \mathrm{TOE}$, this would take just over 5 years to stage and process. Additional supernate from Envelopes $B$ and $C$ can not be processed without reducing the minimum order quantity of Envelope A. Because of the complicated trade-offs, it is inappropriate to provide specific recommendations on this issue. Some areas to consider are (1) delaying the end date for the proof-of-concept, (2) reducing the minimum 
order quantity for Envelope $A$ and $(3)$ increasing the size of the second and third feed batches.

Many of the envelope limits (most of the lower Test 1 limits and physical property limits) appear to be an attempt to provide a nominal waste description rather than an essential part of the envelope. Consider removing these limits whenever possible. If necessary, provide nominal feed compositions separately from the envelope limits.

The SpG of the staged supernate ranges from 1.17 to 1.31 . These are considerably less than the specified 1.3 to $1.6 \mathrm{SpG}$ in the three feed envelopes. Consider adjusting or eliminating these limits.

Consider increasing the upper $\mathrm{Na}$ limit so that feed requires minimal dilution by the M\&l. The private contractors can dilute the feed if necessary as part of their processes.

In this system, $\mathrm{Na}$ appears to be the key component. It is convenient to express the concentration of other components as ratios to the $\mathrm{Na}$ concentration. Concentrations are then invariant with respect to water addition/removal. This is also the preferred method when dealing with glass.

Consider the specific hypothetical limit changes discussed in Section 2.5.2. 
WHC-SD-WM-RPT-210, Rev. 0

\subsection{ISSUES AND ACTIONS}

The following are issues and actions that need to be resolved or otherwise dispositioned before issuing the Confirmed LLW Feed Staging Plan:

A decision needs to be made to accept the recommended staging strategy (Indirect Staging - ASAP).

The waste compatibility issues raised in Section 2.7 need to be investigated in more depth and if valid, resolved. Guidance needs to be provided for incorporation into the Confirmed LLW Feed Staging Plan.

Two DSTs need to be allocated for use as intermediate staging tanks.

Process flowsheets need to be prepared based on the staged feed compositions to provide realistic estimates of the composition and quantity of the 'Entrained Solids' and 'Strontium and TRU' streams that will be returned to the DST system from the private contractors. This information is needed to allocate one or more DSTs and to support planning of DST use.

The upgrades to the intermediate feed staging tanks that are required to support feed staging (decant pumps, mixing capability, sample capability) need to be identified.

The transfer system upgrades (jumper/valve configurations) need to be identified. These upgrades are required to support feed staging by minimizing the setup time for the final staging transfer and the potential for conflicting transfers.

A DOO addressing the sampling needs in the intermediate feed staging tanks during Phase I needs to be prepared, reviewed, and approved.

Approximately $20 \%$ of the data needed to classify waste according to envelopes was missing or reported as "less than" and assumed to be zero.

Total Operating Efficiency (TOE) should be controlled and allocated by the system engineering process. It is critical that a consistent basis be used for separating the system attribute (FAE) from the private contractors facility attribute $(\mathrm{POE}) \mathrm{C}_{\mathrm{d}}$.

There is not enough feed meeting the envelope specifications to supply the the maximum order quantities in the draft RFP. Consider adjusting these quantities or changing the envelope limits to increase the available feed. 


\subsection{STUDY CAVEATS}

This study is based on projected DST supernate inventories. Changes to these inventories can significantly affect classification of tanks according to envelope and, thus, the availability of feed during Phase I. Approximately $20 \%$ of the data needed to classify waste according to envelopes was missing or reported as "less than" and assumed to be zero. The sensitivity of the classification to waste composition will be explored as part of the Confirmed LLW Feed Staging Plan.

Many significant assumptions were provided informally by the CST or by making enabling assumptions, where required. These are highlighted in Secion 2.1 and documented in Appendix A.

The proposed staging schedule conflicts to some degree with some of the waste compatibility rules (see Section 2.7 ). The rules that may present problems are: 1) Flammible Gas Accumulation Decision Rule, 2) TRU Segregation Decision Rule, 3) Heat Generation Rate Decision Rule, 4) Complexed Waste Segregation Decision Rule and 5) the Tank Waste Type Decision Rule.

The next revision (Revision 22) of the OWVP will need to verify that there is sufficient tank space for staging feed to the private contractors along with all other demands being placed on the DST storage system.

The numerical results of the Monte Carlo simulation used for the feed staging study should not be applied out-of-context. The results show the relative performance of the candidate strategies, identify important parameters and the ranges for which staging activities can be consistently successful. However, the use of these numerical values of the measures in an absolute sense requires distributions that more accurately capture real-world behavior than the simple distributions used in the analysis. 


\section{REFERENCES}

Agnew, S.F. and J.G. Watkin, 1994, Estimation of Limiting Solubilities for lonic Species in Hanford Waste Tank Supernates, LA-UR-94-3590, Los Alamos National Laboratory, October 1994.

Barton, W.B., 1996, cc:Mail to J.P. Sloughter et al., Re[2]: Privatization, Watch List Tank Waste, January 10, 1996, Westinghouse Hanford Company, Richland Washington.

Certa, P.J., 1995a, Meeting Minutes, LLW Feed Staging Study Discussion, (NO Brown, R.A. Gilbert, K.D. Wieners, T.O. Wood attending), September 25, 1995, Westinghouse Hanford Company, Richland Washington.

Certa, P.J., L.W. Shelton, and D.A. Burbank, 1995b, Low-Leve/ Waste Feed Staging Feasibility Study, November 1, 1995; transmitted under cover of letter, Feed Staging Feasibility Study, J.O. Honeyman to W.J. Taylor, 9555908, Westinghouse Hanford Company, Richland Washington.

Certa, P.J., 1995c, Vendor Return Assumptions for OWVP, December 7, 1995 (unpublished calculations), Westinghouse Hanford Company, Richland Washington.

Certa, P.J., 1995d, Preliminary Retrieval and Blending Strategy, WHC-SD-WM-RFP-167, Rev. 0, September 1995, Westinghouse Hanford Company, Richland Washington.

DOE-RL, 1995a, TWRS Privatization Request for Proposals, Solicitation Number DE-RP06-96RL13308, Draft, November 1995.

Frank, D.D., 1996, TWRS Requirements Management System Browser, RMSD.MDB Data Time Stamp January 3, 1996 @ 4:00:26pm.

Foster, J.L., 1996, cc:Mail to P.J. Certa, Verify Assumptions for Preliminary LLW Feed Staging Plan, January 8, 1996, Westinghouse Hanford Company, Richland Washington.

Fowler, K.D., 1995a, Data Quality Objectives for Tank Farms Waste Compatibility Program, WHC-SD-WM-DQO-001, Rev. 1, April 1995, Westinghouse Hanford Company, Richland Washington. 
Fowler, K.D., 1995b, Tank Farm Waste Compatibility Program, WHC-SD-WMOCD-015, Rev. 1, April 1995, Westinghouse Hanford Company, Richland Washington.

Garfield, J.S., 1995, Privatization Cost Estimate, letter to D.L. Vieth, letter number 9551934, May 1, 1995, Westinghouse Hanford Company, Richland Washington.

Hanlon, D.M., 1995, Waste Tank Summary Report for Month Ending September 30, 1995, WHC-EP-0182-90, December 1995.

Hendrickson, D.W., T.L. Welsh, and D.M. Nguyen 1993, Hanford Grout Disposal Program Campaign 102 Feed Characterization and Test Plan, WHC-SD-WM-TP-136, Rev. O, February 1993, and ECN 16396, December 1993, Westinghouse Hanford Company, Richland Washington.

Herting, D.L., 1994, Internal Memo from D. L. Herting to G. D. Johnson, Chemical Composition of Tank 101-SY Solids, July 11, 1994, Westinghouse Hanford Company, Richland Washington.

Herting, D.L., 1996a, cc:Mail to P.J. Certa, Re[2]: Dilution Water $p H$ Requirements, January 9, 1996, Westinghouse Hanford Company, Richland Washington.

Kirkbride, R.A., 1995, Schedule Activity Planning Form, LLW Feed Staging Plan, Activity Numbers L1W02742-2748, October 3, 1995.

Koreski, G.M. and J.N. Strode, 1995, Operational Waste Volume Projection, WHC-SD-WM-ER-029, Rev. 21, September 1995, Westinghouse Hanford Company, Richland Washington.

Kruger, A.A., 1996, cc:Mail to P.J. Certa, Verify Assumptions for Preliminary $L L W$ Feed Staging Plan, January 8, 1996, Westinghouse Hanford Company, Richland Washington.

LSW, 1995, Background for TWRS Privatization, World Wide Web, http://twins.pnl.gov:8001/twrs_rfp/background.htm, November 17, 1995, ?.

McKee R.W., G.S. Anderson, M.M. King, W.W. Schulz, and T.W. Wood, 1995, Low Activity Waste Envelopes for Phase I of the Hanford Tank Waste Remediation System Privatization Project, PNL-10854, Pacific Northwest National Laboratory, Richland, Washington.

Orme, R.M. 1995, TWRS Process Flowsheet, WHC-SD-WM-TI-613 Rev. 1, August 1995, Westinghouse Hanford Company, Richland Washington. 
Shelton, L.W., 1995, Internal Memo from L. W. Shelton to J. P. Sloughter, Revised Supernate/Sludge Compositions for Double-Shell Tanks, August 22, 1995.

Strode, J.N. 1996, letter to PJ Cera, Requested Special Waste Volume Projection-New Privatization Case Without SST Solids Retrieval, 74A10-96-013, January 18, 1996, Westinghouse Hanford Company, Richland Washington.

WHC 1994a, Nuclear Criticality Safety Manual, WHC-CM-4-29, Release 6, Westinghouse Hanford Company, Richland, Washington.

WHC 1995a, Tank Waste Remediation System Functions and Requirements Document, WHC-SD-WM-FRD-020, Draft Revision E, December 1995, Westinghouse Hanford Company, Richland, Washington.

WHC 1995, Waste Volume Reduction Factors for Potential 241-A Evaporator Feed, WHC-SD-WM-TI-690 Rev. O, May 3, 1995, Westinghouse Hanford Company, Richland Washington.

Wiemers, K.D., 1995a, cc:Mail to P.J. Certa, Re: Feed Envelopes - Solids Questions, September 29, 1995, Westinghouse Hanford Company, Richland Washington.

Wiemers, K.D., 1995b, cc:Mail to P.J. Certa, Re: Clarification of Draft TWRS Privatization RFP, November 28, 1995, Westinghouse Hanford Company, Richland Washington.

Wiemers, K.D. 1996, FAX to P.J. Certa, Double-Shell Tanks Segregated by Envelopes Based on the TWRS Flowsheet Inventory, January 5, 1996, Westinghouse Hanford Company, Richland Washington. 
WHC-SD-WM-RPT-210, Rev. 0

This page intentionally left blank. 
WHC-SD-WM-RPT-210, Rev. O

\section{APPENDIX A - ASSUMPTIONS}


WHC-SD-WM-RPT-210, Rev. 0

This page intentionally left blank.

A-ii 
WHC-SD-WM-RPT-210, Rev, 0

CONTENTS

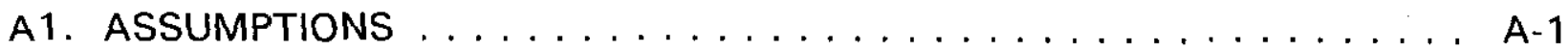

A1.1 FUNCTIONS AND INTERFACES $\ldots \ldots \ldots \ldots \ldots \ldots$ A-1

A 1.2 CONSTRAINTS FROM FRD $\ldots \ldots \ldots \ldots \ldots \ldots \ldots \ldots$ A-4

A 1.3 REQUIREMENTS FROM FRD . . . . . . . . . . . A A-4

A1.3.1 DST Volumes - Maximum Liquid Levels . . . . . . . . . A-4

A1.3.2 DST Volumes - Minimum Tank Heel . . . . . . . . . . A A-4

A1.3.3 Phase I - Feedstock to LLW Immobilization . . . . . . . . A-4

A1.3.4 Phase I-Storage Capacity . . . . . . . . . . A A-5

A1.3.5 Transfer of Feed Tanks . . . . . . . . . . . A A-5

A1.3.6 Waste Compatibility . . . . . . . . . . . . A-5

A1.4 REQUIREMENTS FROM RFP . . . . . . . . . . . A-6

A1.4.1 Target Feed - Composition . . . . . . . . . . A-6

A 1.4.2 Schedule - LAW Proof of Concept Demonstration . . . . A-6

A 1.4.3 Feed Quantities - DST Supernate Order Quantities .... A A-7

A1.4.4 Feed Quantities - Minimum DST Supernate Batch Size . A-7

A 1.4.5 Interfaces - Feed Staging Tank Allocation . . . . . . . A A-7

A.1.4.6 Interfaces - "Entrained Solids" . . . . . . . . . . . . A A-7

A 1.4.7 Interfaces - "Strontium and TRU" . . . . . . . . . A-8

A 1.5 CST REQUIREMENTS . . . . . . . . . . . . . . A A-8

A 1.5.1 Target Feed - Composition $\mathrm{PO}_{4}$ Exception . . . . . . . A A-8

A1.5.2 Target Feed - Composition . . . . . . . . . . . A A-8

A 1.5.3 Target Feed - Intra/Inter Contractor Batch Homogeneity A-8

A1.5.4 Number of LAW Treatment Facilities . . . . . . . . A A-9

A1.5.5 Design Basis - Facility Processing Rates . . . . . . . . A A-9

A1.5.6 Feed Schedule - Protocol - Private Contrator Notice ... A-9

A1.5.7 Feed Sequence . . . . . . . . . . . . . A-10

A 1.5.8 Interfaces - Feed Staging Tank Turnover . . . . . . . A A-10

A1.5.9 Interfaces - Delivered Waste . . . . . . . . . . . A-11

A1.5.10 Interfaces - Proof of Delivered Waste Composition . . A-11

A1.5.11 Interfaces - Method-of-Proof . . . . . . . . A-11

A1.6 DERIVED REQUIREMENTS . . . . . . . . . . . . A A-12

A 1.6.1 Target Feed - Solids Content . . . . . . . . . . . A-12

A 1.6.2 Design Basis - LAW Capacity . . . . . . . . . A-12

A 1.6.3 Design Basis - HLW Capacity . . . . . . . . . A-14

A1.7 ENABLING ASSUMPTIONS . . . . . . . . . . . . A-14

A 1.7.1 Tank Inventory Data - DST Compositions ......... A-14

A 1.7.2 Tank Inventory Data - SST Compositions ........ A-15 


\section{CONTENTS (cont'd)}

A 1.7.3 Tank Inventory Data - DST Projections . . . . . . . A-15

A 1.7.4 Schedule - LAW Extensions . . . . . . . . . . A-16

A1.7.5 Feed Quantities - HLW Order Quantities . . . . . . . A-16

A 1.7.6 Number of HLW Treatment Facilities . . . . . . . . . A-16

A1.7.7 Schedule - HLW Proof-of-Concept Demonstration .... A A-17

A.1.7.8 Schedule - HLW Extension . . . . . . . . . . . A-17

A.1.7.9 DST Volumes - Minimum Achievable Heel . . . . . . . A A-17

A.1.7.10 Safety Issue Resolution ............... A-18

A 1.7.11 Interfaces - "Entrained Solids" and "Strontium/TRU" . A-18

A 1.7.12 Intermediate Staging Tanks . . . . . . . . . . A A-19

A 1.7.13 Common use of Transfer Lines . . . . . . . . A A-19

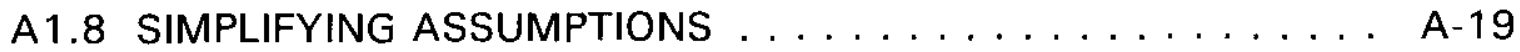

A 1.8.1 Physical Property Limits . . . . . . . . . . . . A-19

A1.8.2 Tank Inventory Data - Decay Dates for Envelope

Assessments . . . . . . . . . . . . . . A A-20

A1.8.3 DST Volumes - Maximum Liquid Level . . . . . . . . . A-20

A 1.8.4 Heel Composition - Staging Tank . . . . . . . . . . A-20

A1.8.5 Heel Composition - Intermediate Staging Tank . . . . A A-20

A1.8.6 Waste Mass-Balance Calculations .......... A-21

A1.8.7 Solids Tracking . . . . . . . . . . . . . . A-22

A 1.8.8 Transfer Conflicts During Analysis . . . . . . . . A-22

A1.8.9 Transfer Conflicts For Planning . . . . . . . . A-22

A 1.8.10 Transfer Line Flushes . . . . . . . . . . A A-22

\section{FIGURES}

A1-1 - Functional Flow Diagram for DST Supernate Staging (Part 1) . . . . . A-2 A1-2 - Functional Flow Diagram for Feed Staging (Part 2) . . . . . . . A A 
WHC-SD-WM-RPT-210, Rev. 0

\section{A1. ASSUMPTIONS}

This appendix provides the various assumptions used throughout the analysis. Other lower-level technical assumptions made during the study are not included here. Frequently, there was inconsistent or incomplete information, since the draft RFP is undergoing revision. In this situation, verbal or written direction from the CST was given more importance then the content of draft RFP and the draft RFP was given more importance than the current snapshot of the TWRS Functions and Requirements Document (FRD). Enabling assumptions were made if information was still inconsistent or lacking.

\section{A1.1 FUNCTIONS AND INTERFACES}

The TWRS Functions and Requirements Document (WHC 1995a) was reviewed for functions supporting staging of DST supernate during Phase I. A "filtered" version of the FRD was obtained that showed only elements related to these functions. The filtered version was reviewed for inputs and outputs that directly support feed staging of DST supernate; inputs and outputs not directly related to staging of DST supernate have been excluded. The TWRS Requirements Management System Browser was used to provide the latest FRD information (Frank 1996). The FRD is currently being revised to incorporate the requirements, functions and interfaces to support Phase I Privatization. Identification and resolution of the internal and external inconsistencies due to this in-progress revision are outside the scope of this study.

Figure A1-1 shows the main material movement functions and interfaces supporting staging of DST supernate during Phase I. The figure shows which functions support the various aspects of feed staging. Figure A1-2 shows the interfaces controlling the allocation of DSTs to various processing functions. 
WHC-SD-WM-RPT-210, Rev. 0

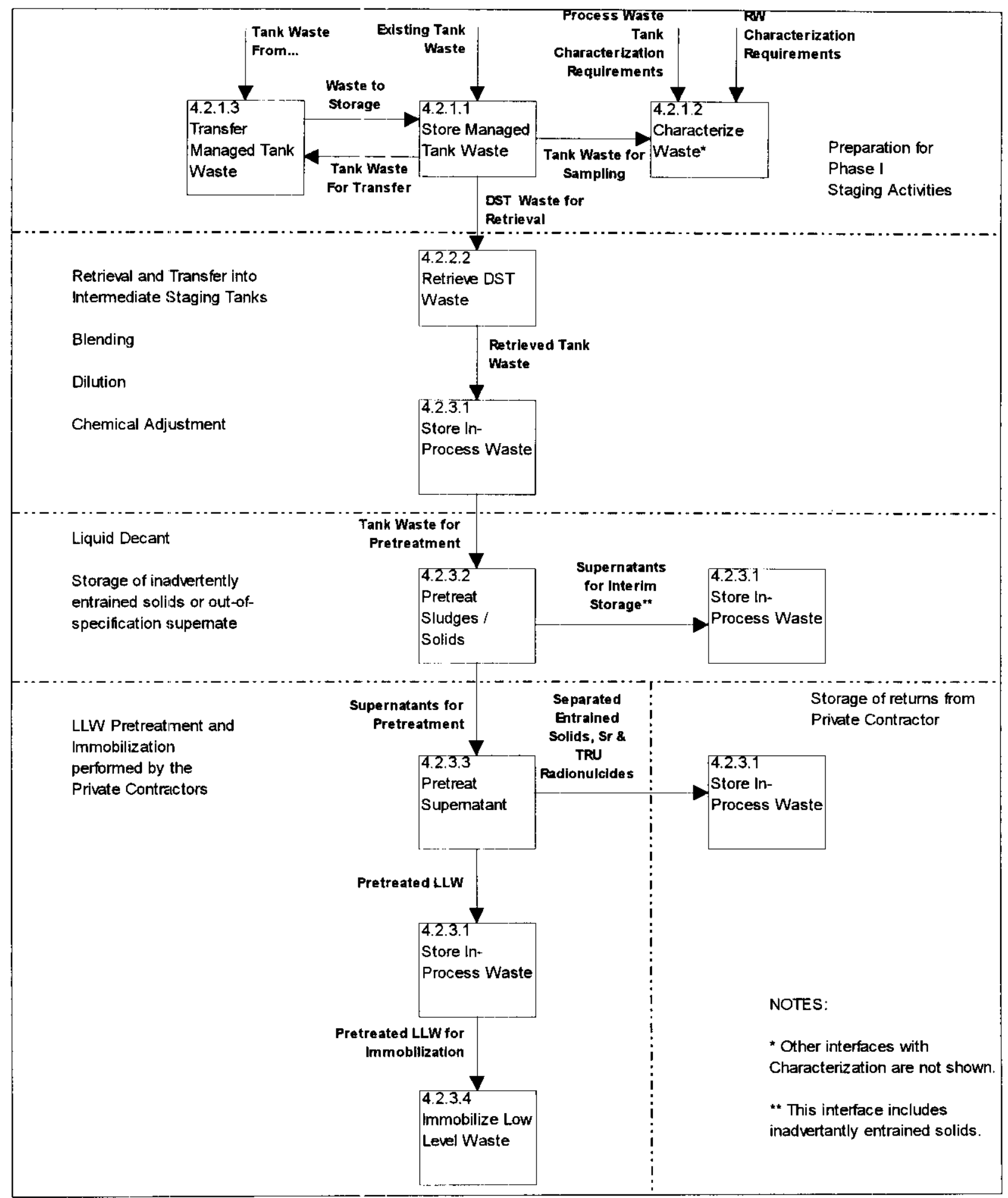

Figure A1-1 - Functional Flow Diagram for DST Supernate Staging (Part 1)

A-2 
WHC-SD-WM-RPT-210, Rev. 0

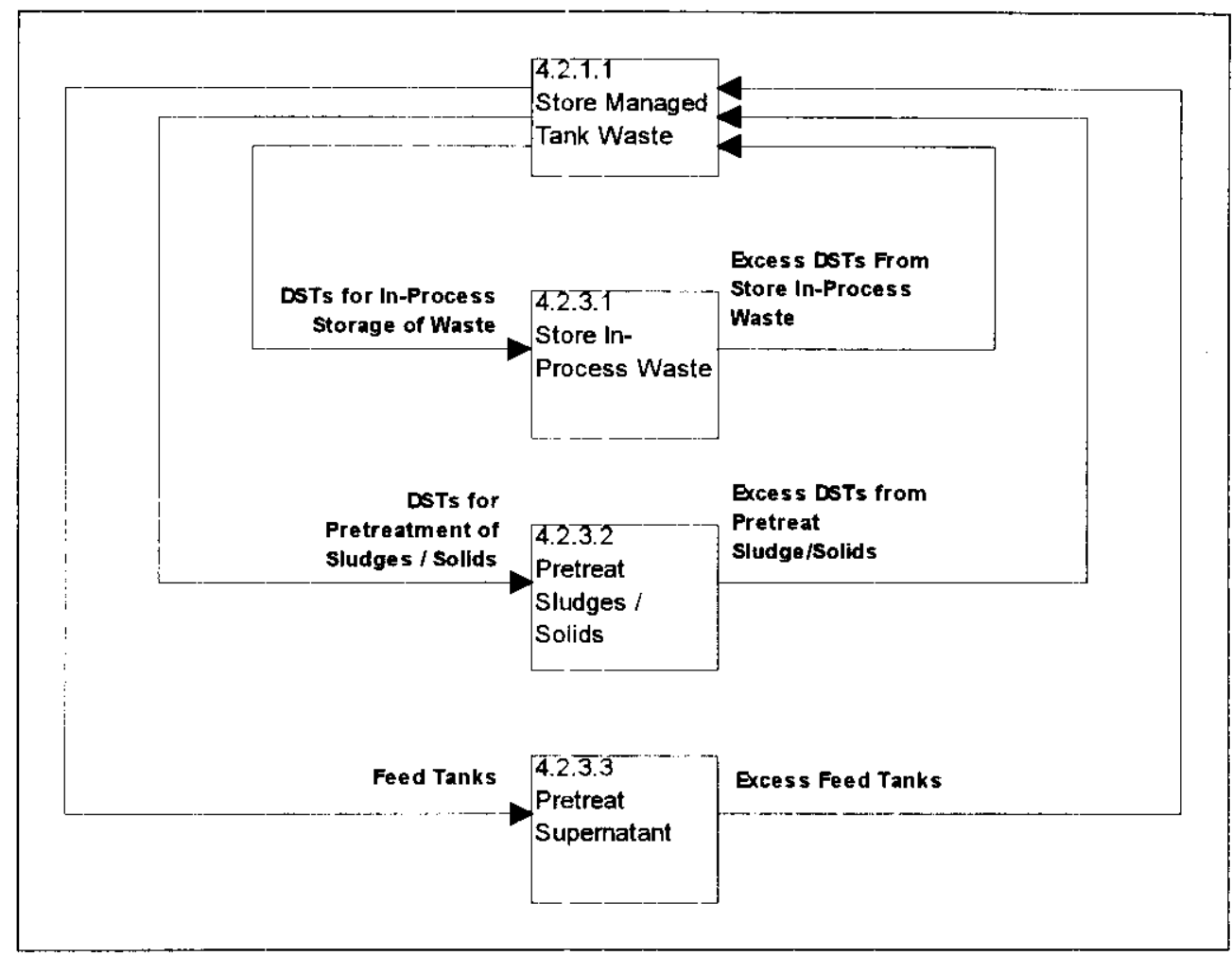

Figure A1-2 - Functional Flow Diagram for Feed Staging (Part 2) 
WHC-SD-WM-RPT-210, Rev. 0

\section{A1.2 CONSTRAINTS FROM FRD}

Applicable constraints will be identified as part of the Interface Control Document for delivery of supernate to the private contractors (to be issued). The FRD is currently being updated to reflect the privatization constraints and requirements.

\section{A1.3 REQUIREMENTS FROM FRD}

Applicable requirements will be identified as part of the Interface Control Document for delivery of supernate to the private contractors (to be issued). The FRD is currently being updated to reflect the privatization constraints and requirements. Several requirements that directly affect feed staging have been included.

\section{A1.3.1 DST Volumes - Maximum Liquid Levels}

Assumption: The maximum level of waste in AP-Farm DSTs is 419 inches.

Source: OSD-T-151-00007, Rev H-5.

Discussion: Calculations will use 416 inches (See Assumption A1.8.3).

\section{A1.3.2 DST Volumes - Minimum Tank Heel}

Assumption: A minimum heel of 6 inches is required when the ventilation system is running.

Source: OSD-T-151-00007, Rev H-5.

\section{A1.3.3 Phase I - Feedstock to LLW Immobilization}

Assumption: "The feedstock to the Phase I LLW Immobilization process shall have undergone a gravity settling of solids with decantation of the supernatant to the LLW immobilization feed tanks." Traces to 4.2.3.2 Pretreat Sludges/Solids.

Source: (Frank 1996). 
WHC-SD-WM-RPT-210, Rev. 0

\section{A1.3.4 Phase I - Storage Capacity}

Assumption: "A storage capacity of $7.5 \mathrm{E}+06$ liters (equivalent to two existing DSTs) shall be provided during Phase I processing for receipt and interim storage of retrieved tank waste." Traces to 4.2.3.1 Store In-Process Waste.

Source: (Frank 1996).

\section{A1.3.5 Transfer of Feed Tanks}

Assumption: "The operation control of the feed staging tanks (full tanks) will be transferred from the $M \& O$ to the privatization contractors." Traces to 4.2.3.3 Pretreat Supernate.

Source: (Frank 1996).

\section{A1.3.6 Waste Compatibility}

Assumption: Waste compatibility requirements, documented in "Data Quality Objectives for Tank Farms Waste Compatibility Program" and "Tank Farm Wast Transfer Compatibility Program", will be used to determine if transfers of waste within the DST system are permissible.

Source: (Fowler 1995a, Fowler 1995b).

Discussion: These two documents consolidate requirements from various sources into a set of decision rules. The rules consider criticality, flammable gas accumulation, energetics, corrosion, watch-list tanks, chemical compatibility, tank waste type, TRU waste segregation, heat generation rate, complexant waste segregation, waste pumpability and high phosphate waste.

This assumption is being used in lieu of citing all the source documents and requirements from the FRD. 


\section{A1.4 REQUIREMENTS FROM RFP}

\section{A1.4.1 Target Feed - Composition}

Assumption: Waste supplied to the private contractors during the LAW proof-of-concept demonstration and extension will meet the limits established by feed envelopes A-C per the draft RFP. See issues below for exceptions.

Source: (DOE-RL 1995a), Section C.6, Specification 7.

Discussion: The Contract Support Team (CST) has prepared four (only three will be incorporated into the draft RFP) draft feed envelope descriptions. One envelope corresponds to the production challenge; the other three envelopes correspond to the technical challenges of producing glass limited in compounds other than sodium, of processing waste with complexed radionuclides and of demonstrating solids/liquid separation on strontium and TRU bearing suspended solids. The envelopes are currently designated as A-D, respectively (McKee et al. 1995). The unused LAW Envelope D is not the same as Envelope D (HLW) in the draft RFP.

Issue: The concentration of $\mathrm{PO}_{4}$ at $7 \mathrm{M} \mathrm{[Na]} \mathrm{that} \mathrm{corresponds} \mathrm{to} \mathrm{the}$ solubility of $\mathrm{P}_{2} \mathrm{O}_{5}$ in a $20 \mathrm{wt} \% \mathrm{Na}_{2} \mathrm{O}$ silicate glass was incorrectly stated as $4.6 \mathrm{~g} / \mathrm{l}$. The correct value is $44 \mathrm{~g} / \mathrm{l}$. See Assumption A1.5.1.

Source: Verbal communication, K.D. Wiemers, January 5, 1996.

Issue: The physical property limits were ignored during the feasibility study (Certa et.al. 1995b). Cursory examination suggest that these limits (with the possible exception of solids) are not consistent with the chemical analyte ranges. See Assumption A.1.8.1.

\section{A1.4.2 Schedule - LAW Proof of Concept Demonstration}

Assumption: Each private contractor will process the minimum quantities of waste (see Section A1.4.3) through their LAW facility as a proof-of-concept demonstration from June 1, 2002 through June 1, 2007.

Source: (WHC 1995a), Section F, CLIN 003A, 003B and 003C. 
WHC-SD-WM-RPT-210, Rev. 0

\section{A1.4.3 Feed Quantities - DST Supernate Order Quantities}

Assumption: The minimum and maximum order quantities of DST supernate provided to each private contractor are (in MT of sodium):

\begin{tabular}{|c|c|c|}
\hline Envelope & $\begin{array}{c}\text { Minimum } \\
\text { (per contractor) }\end{array}$ & $\begin{array}{c}\text { Maximum } \\
\text { (per contractor) }\end{array}$ \\
\hline $\mathrm{A}$ & 2600 & 6500 \\
\hline $\mathrm{B}$ & 100 & 1000 \\
\hline $\mathrm{C}$ & 100 & 3700 \\
\hline
\end{tabular}

Source: (WHC 1995a), Section H.5.a, H.5.b and H.5.C.

\section{A1.4.4 Feed Quantities - Minimum DST Supernate Batch Size}

Assumption: The minimum DST Supernate feed batch size is 90 MT Na.

Source: (WHC 1995a), Section H.5.a, H.5.b and H.5.c.

\section{A 1.4.5 Interfaces - Feed Staging Tank Allocation}

Assumption: Tanks 241-AP-106 and 241-AP-108 will be turned over to the control of the private contractors, one to each private contractor.

Source: (WHC 1995a), Section C.7, Interface Summary 7.

\section{A1.4.6 Interfaces - "Entrained Solids"}

Assumption: The private contractors will return an "Entrained Solids" stream to the M\&l contractors for storage in the DST system.

Source: (WHC 1995a), Section C.6, Specification 3. 
WHC-SD-WM-RPT-210, Rev. 0

\section{A1.4.7 Interfaces - "Strontium and TRU"}

Assumption: The private contractors will return a "Strontium and TRU" stream to the M\&l contractors for storage in the DST system.

Source: (WHC 1995a), Section C.6, Specification 6.

\section{A1.5 CST REQUIREMENTS}

\section{A 1.5.1 Target Feed - Composition $\mathrm{PO}_{4}{ }^{-}$Exception}

Assumption: The concentration of $\mathrm{PO}_{4}^{-}$at $7 \mathrm{M}[\mathrm{Na}$ ] that corresponds to the solubility of $\mathrm{P}_{2} \mathrm{O}_{5}$ in a $20 \mathrm{wt} \% \mathrm{Na}_{2} \mathrm{O}$ silicate glass is $44 \mathrm{~g} / \mathrm{l}$.

Source: Verbal communication, K.D. Wiemers, January 5, 1996.

\section{A1.5.2 Target Feed - Composition}

Assumption: The concentration limits specified in the feed envelopes for the proof-of-concept demonstration are bulk concentrations (average composition of the waste including any solids).

Source: (Wiemers 1995a)

Discussion: The staging strategy will be flexible enough to deal with entrained solid. However, it is unlikely that solids can be dealt with rigorously at this time.

\section{A1.5.3 Target Feed - Intra/Inter Contractor Batch Homogeneity}

Assumption: a) Multiple batches of waste provided to a specific private contractor do not need to have the same composition. They just need to fall within the proper feed envelope. b) The two private contractors do not require waste batches of the same composition as long as each receives waste within the proper feed envelope.

Source: Certa 1995a. 
WHC-SD-WM-RPT-210, Rev. 0

Discussion: Keeping the waste similar when convenient may avoid unintentional biases and potential legal challenges.

\section{A1.5.4 Number of LAW Treatment Facilities}

Assumption: Two private LAW contractors will independently operate their respective LAW facility.

Source: LSW 1995.

\section{A1.5.5 Design Basis - Facility Processing Rates}

Assumption: The actual facility processing rates will be estimated as $(P O E)\left(C_{d}\right)$ while feed is available.

Source: Verbal direction, WG Richmond.

Discussion: The phase "while feed is available" is equivalent to application of the FAE. For DST supernate, feed is available when it has been delivered to the contractor's feed tank and has been shown to meet the envelope limits.

Discussion: See Assumption A1.6.2 for the definition of POE and FAE.

\section{A1.5.6 Feed Schedule - Protocol - Private Contrator Notice}

Assumption: The M\&l contractor will transfer this waste to the private contractor's feed tank no earlier than the stated ready date and no later than 60 days after the ready date.

Source: (Wiemers 1995b).

Discussion: The draft RFP incorrectly linked the delivery dates with the date of notification instead of the stated ready date. 


\section{A1.5.7 Feed Sequence}

Assumption: During the proof-of-concept demonstration and extensions, DST supernate will be provided independently to each private contractor according to the following schedule. The M\&l contractor will provide waste containing the stated mass of $\mathrm{Na}$ from the stated envelope and in the stated sequence.

\begin{tabular}{|c|c|c|l|}
\hline Sequence & Type & Envelope & Required Mass of Na \\
\hline 1 & Single Batch & A & $600 \mathrm{MT}-5 \%,+15 \%$ \\
\hline 2 & Single Batch & $\mathrm{B}$ & $>=100 \mathrm{MT}$ \\
\hline 3 & Single Batch & $\mathrm{C}$ & $>=100 \mathrm{MT}$ \\
\hline 4 & Multiple Batches & $\mathrm{A}$ & $\begin{array}{l}\text { Amounts required to reach } \\
\text { minimum order quantity. }\end{array}$ \\
\hline 5 & Multiple Batches & $\begin{array}{c}\text { A, B, } \\
\text { and/or C }\end{array}$ & $\begin{array}{l}\text { Amounts not to exceed } \\
\text { maximum order quantities }\end{array}$ \\
\hline
\end{tabular}

Discussion: The feed batches supplied for sequences 1-4 are for the proofof-concept demonstration. Feed batches supplied for sequence 5 are for the extension.

Issue: The draft RFP does not provide an understandable, internally consistent, schedule. The assumed schedule is consistent with parts of the draft RFP and verbal direction provided before the availability of the draft RFP.

Source: (WHC 1995a), Section H.5.e.

Source: Verbal direction, RA Gilbert, October 20, 1995.

\section{A1.5.8 Interfaces - Feed Staging Tank Turnover}

Assumption: On or before June 1, 2001, each feed staging tank will contain the first batch of feed for each private contractor.

Source: Verbal direction, WG Richmond, December 14, 1995.

Discussion: The draft RFP incorrectly states that the first batch of hot feed must be delivered on the date of hot startup. 
WHC-SD-WM-RPT-210, Rev. 0

\section{A1.5.9 Interfaces - Delivered Waste}

Assumption: The composition of the actual waste delivered to the private contractors' feed tank is required to meet the limits established by the envelopes.

Source: Verbal direction, WG Richmond.

Discussion: For small feed batches, the mixture resulting from blending the newly delivered waste with the heel in the private contractors' tank may fall outside the intended feed envelope. This may result in the private contractors' facilities not being challenged by the intended waste. A heel mixing study investigate this further.

\section{A1.5.10 Interfaces - Proof of Delivered Waste Composition}

Assumption: The M\&I must clearly demonstrate that delivered waste meets the envelope specifications.

Source: Verbal direction, L Kovach, October 20, 1995.

\section{A1.5.11 Interfaces - Method-of-Proof}

Assumption: Until proven otherwise, the M\&l contractor will demonstrate the delivered waste meets the envelopes by sampling and analysis of the waste immediately before [or immediately after for direct staging] transfer to the private contractors feed tanks.

Source: Part not in [brackets]: Verbal direction, L Kovach, October 20, 1995.

Source: Part in [brackets]: Enabling Assumption, PJ Certa.

Discussion: The bulk composition of retrieved supernate may be of different composition than estimated due to projection uncertainties or large amounts of entrained solids. If dilution water (dilute caustic) is required for the retrieval/transfer of waste or to meet envelope limits, the composition may be further altered by dissolution or precipitation of solids. A similar concern exists for blending wastes to provide the proper batch sizes or using dilute waste as an 
alternative to water for dilution. Staging activities may further mix wastes.

Allowing the $M \& 1$ to demonstrate that waste meets the envelope limits after transfer to the private contractor's feed tanks is to permit investigation of a strategy in which waste is staged directly into the private contractor's tank. In this case, feed will not be considered available until it is demonstrated as meeting the envelope limits.

Issue: This assumption strongly affects system behavior (expected feed outages and amount of time available for contingencies) but does not, in-and-ofitself change the selected alternative. See Chapter ? for more information.

\section{A1.6 DERIVED REQUIREMENTS}

\section{A1.6.1 Target Feed - Solids Content}

Assumption: Waste supplied to the private contractors will contain no more than 0.7 weight percent solids.

Source: (Certa 1995c)

Discussion: The draft RFP imposes a 5 volume percent limit, however the condition under which this is to be measured is not specified (DOE-RL 1995a, Section C.6, Specification 7). A nominal 0.7 weight percent solids concentration was used in an example flowsheet used to support a privatization cost estimate (Garfield 1995a). This is consistent with a 5 volume percent settled solids limit (Certa 1995c).

\section{A1.6.2 Design Basis - LAW Capacity}

Assumption: The facility design capacity will be estimated from the following relationship:

$$
\frac{T P_{\min }}{T_{p o c}}=(F A E)(P O E) C_{d}
$$


WHC-SD-WM-RPT-210, Rev. 0

Where,

\begin{tabular}{|c|c|}
\hline$T P_{\text {min }}=$ & $\begin{array}{l}\text { Throughput (MT of } \mathrm{Na} \text { in the feed). } \\
\text { Corresponds to Minimum Order Quantities. }\end{array}$ \\
\hline$T_{p o c}=$ & $\begin{array}{l}\text { Time allocated for proof-of-concept in days } \\
\text { ( } 365 \text { days/year, } 24 \text { hours/day). }\end{array}$ \\
\hline$F A E=$ & $\begin{array}{l}\text { Feed Availability Efficiency (fraction of the } \\
\text { time that feed is available in the private } \\
\text { contractors feed tanks). A value of } 0.80 \text { is } \\
\text { commonly used. The } F A E \text { used to estimate } \\
\text { the plant capacity will be based on the } \\
\text { lower of the value coresponding to the } \\
\text { recommended feed staging strategy and } \\
0.80 \text {. }\end{array}$ \\
\hline$P O E=$ & $\begin{array}{l}\text { Plant Operating Efficiency. This is the ratio } \\
\text { of the facility's average throughput (after } \\
\text { adjusting for reduced rate operation, startup } \\
\text { and shutdown transients and all plant } \\
\text { outages planned or otherwise, except for } \\
\text { lack of feed) to the design capacity. } \\
\text { A value of } 0.75 \text { is commonly used and will } \\
\text { be held constant in this study. }\end{array}$ \\
\hline & $\begin{array}{l}\text { design capacity (the maximum } \\
\text { ineous processing rate). Units are } \mathrm{MT} \mathrm{Na} \text { in }\end{array}$ \\
\hline
\end{tabular}

Source: Derived from Assumptions A1.4.2 and A1.4.3.

Discussion: For an $F A E$ of 0.8 and a $P O E$ of 0.75 , the $C_{d}=2.5 \mathrm{MT} \mathrm{Na} / \mathrm{day}$. This corresponds to $17 \mathrm{MT} /$ day of 20 weight $\% \mathrm{Na}_{2} \mathrm{O}$ glass product.

The Total Operating Efficiency (TOE) is the product of the FAE and POE. Using the common values for FAE and POE, the TOE is 0.60 . The FAE is an attribute of the system, while the term (POE) $C_{d}$ is an attribute of the plant. 
Issue: The draft RFP does not explicitly state required plant capacities and probably should not. However, TOE should be controlled and allocated by the system engineering process. It is critical that a consistent basis be used for separating the system attribute (FAE) from the private contractors facility attribute (POE) $C_{d}$. The methodology and values must be controlled. One set of values (conservative, based on a top-down approach) may be used for establishing the facility design basis, while a different set of values (based on a bottom-up approach) may be used to predict system behavior.

\section{A1.6.3 Design Basis - HLW Capacity}

Assumption: The design capacity of the HLW demonstration facility will be estimated using an approach similar to Assumption A1.6.2. The actual facility processing rate will be estimated as in Section A1.5.5.

Source: Derived from Assumptions A1.7.5 and A1.7.7.

Discussion: For an FAE of 0.80 and POE of 0.75 , the $C_{d}=0.17$ MT waste oxide per day excluding $\mathrm{Si}$ and $\mathrm{Na}$. The HLW facility is optional at DOE-RL's discretion (See Assumption A1.7.6).

Issue: See the issue in Section A1.6.2.

\section{A1.7 ENABLING ASSUMPTIONS}

\section{A1.7.1 Tank Inventory Data - DST Compositions}

Assumption: The starting DST compositions used in this study as a basis for projections will be based upon laboratory analysis and process knowledge.

Discussion: The specific file is named "INVEN5.xIs". This inventory partitions the waste into a supernate fraction and solids/sludge fraction. The inventory includes both chemicals and radionuclides. Tank contents are estimated as of February 1994; radionuclides are then decayed to December 31, 1999. This inventory is consistent with the inventory used in the 1995 TWRS Process Flowsheet. 
Issue: Tank inventory estimates are subject to periodic revisions. For example, the TWRS Characterization Project is preparing official tank inventory estimates for all tanks during Fiscal Year 1996.

\section{A 1.7.2 Tank Inventory Data - SST Compositions}

Assumption: The SST compositions used in this study will be provided by L. W. Shelton. These compositions are shown in Appendix B.

Discussion: This inventory partitions the waste into a soluble fraction and an insoluble fraction. The inventory includes both chemicals and radionuclides. Tank contents are estimated as of February 1994; radionuclides are then decayed to December 31,1999 . The minimum water necessary to reduce the [Na] to $5 \mathrm{M}$ or less and the solids concentration to 10 weight percent or less has been added. This inventory is consistent with the inventory used in the 1995 TWRS Process Flowsheet.

\section{A1.7.3 Tank Inventory Data - DST Projections}

Assumption: Inventories will be adjusted to reflect projected DST contents at the beginning of feed staging activities for the Phase I proof-of-concept demonstration. Decay dates will be adjusted to planned waste delivery dates. These compositions are shown in Appendix A.

Discussion: This projection will account for aging waste consolidation, evaporator operations, interim stabilization, caustic addition to 102-AN and 107-AN and receipt of new waste from outside the TWRS.

The nominal beginning of feed staging for non-aging waste tanks is December 1998, after which most of the dilute waste has been concentrated. The nominal beginning of feed staging for aging waste tanks is circa FY 2002, after which aging waste consolidation is complete. This dual date is acceptable since the two sets of tanks do not overlap.

Issue: The consolodation of TRU solids from 103-AW, 105-AW and 102-SY into 103-AW was not included in these projections. Not enough information concerning consolodation plans and the solubility of TRU sludge was available. 
Issue: Projections are subject to change. Generally, the more complicated the projection, the more likely it is to change. For example, a static tank's projection should be as accurate as the starting inventory, while a tank filled with evaporator bottoms from new tank waste will be more variable.

\section{A1.7.4 Schedule - LAW Extensions}

Assumption: Each private contractor will process up to the maximum quantities of waste (see Assumption A1.4.3) through their facility during an extension beginning when the minimum quantities have been completed through June 1, 2011.

Source: (WHC 1995a), Section F, CLIN 004A, 004B and 004C.

Issue: Operation of the LAW demonstration facilities during this extension is optional. This study assumes that both facilities operate during this period.

\section{A1.7.5 Feed Quantities - HLW Order Quantities}

Assumption: The minimum order quantity of HLW provided to the HLW vendor is $190 \mathrm{MT}$ waste oxide exclusive of $\mathrm{Si}$ and $\mathrm{Na}$.

Source: (WHC 1995a), Section B.2, CLIN 005A.

\section{A 1.7.6 Number of HLW Treatment Facilities}

Assumption: One private contractor will operate one HLW demonstration facility.

Source: none

Issue: The Phase I HLW proof-of-concept demonstration is optional at DOE's discretion (WHC 1995a). 
WHC-SD-WM-RPT-210, Rev. 0

\section{A1.7.7 Schedule - HLW Proof-of-Concept Demonstration}

Assumption: One private contractor will process the minimum quantities of waste (see 0) through a HLW facility as a proof-of-concept demonstration from June 1, 2002 through June 1, 2007.

Source: (WHC 1995a), Section F, CLIN 005A.

Discussion: The Phase I HLW proof-of-concept demonstration is optional at DOE's discretion.

\section{A1.7.8 Schedule - HLW Extension}

Assumption: The HLW private contractor will process additional HLW through its facility during an extension beginning when the minimum quantities have been completed through June 1, 2011.

Source: (WHC 1995a), Section F, CLIN 005B.

Discussion: Operation of the HLW demonstration facility during this extension is optional. Assume that this facility is built and used to process HLW feed, if available.

\section{A1.7.9 DST Volumes - Minimum Achievable Heel}

Assumption: The minimum achievable tank volumes (heels) are assumed to be 10 inches for standard deep-well turbine pumps, 40 inches for current floating suctions pumps, and 10 inches for the new decant pump.

Discussion: The current floating suction pumps will lose suction with about 10-40 inches of waste remaining in the tank. The pump will lose prime below 6 feet if turned off.

Source: Verbal discussion, M.R. Elmore, D.A. Burbank, J.L. Foster.

Discussion: A new decant pump can probably pump within 10 inches of the bottom of the tank or solids level. This is consistent with performance observed during a vendor test of the pump. 
Source: TW Staehr and H-2-820774, Piping Decant Pump Assembly Elevation and Details, Sheets 1 \& 2, Rev 1.

Discussion: The inlet of most deep-well turbine pumps is about 10 inches from the bottom.

\section{A1.7.10 Safety Issue Resolution}

Assumption: Safety issues concerning DST waste will be resolved in order to permit feed staging activities to occur as planned.

Discussion:

It is desired to dispose of waste from watchlist tanks as soon as possible. We should not try to avoid using waste from watchlist tanks for feed to the privatization vendor. Tank space can made available faster, by processing the most dilute of the concentrated wastes first.

Source: (Barton 1996).

\section{A 1.7.11 Interfaces - "Entrained Solids" and "Strontium/TRU"}

Assumption: For planning purposes, it is assumed that the "Entrained Solids" and "Strontium and TRU" streams from both LAW private contractors are combined and stored in a single DST. The volume of this stream is $8 \%$ of the original feed volume ( $5 \mathrm{M} \mathrm{Na}$, nominal) and of the following composition:

$$
\begin{array}{ll}
\text { Solids } & 10 \text { weight \% } \\
{ }^{90} \mathrm{Sr} & 0.28 \mathrm{Ci} / \mathrm{L} \\
\mathrm{TRU} & 0.0011 \mathrm{Ci} / \mathrm{L} \\
\mathrm{Na}^{+} & 0.16 \underline{\mathrm{M}} \\
\mathrm{OH}^{+} & 0.12 \underline{\mathrm{M}} \\
\mathrm{NO}_{2}{ }^{+} & 0.02 \underline{\mathrm{M}} \\
\mathrm{NO}_{3}{ }^{+} & 0.02 \underline{\mathrm{M}}
\end{array}
$$

Source: (Certa 1995c). 
WHC-SD-WM-RPT-210, Rev. 0

Issue: The calculations used to estimate the volume and composition of these streams are biased high. The volume and heat loading of this stream may affect the number and location of DSTs allocated to receive this waste. The volume of this stream is driven by the assumed quantity of entrained solids in the feed delivered to the private contractor. The heat loading $\left({ }^{90} \mathrm{Sr}\right)$ and TRU content are determined by the composition of each feed batch and the assumed process flowsheet. Different waste envelopes will probably require different flowsheets. These process flowsheet(s) are being developed as part of the "TWRS Privazaiton Process Technical Baseline" due in September 1996 (Activity L1W02729A, Milestone Control Number T32-96-018).

\section{A1.7.12 Intermediate Staging Tanks}

Assumption: Tanks 102-AP and 104-AP will be used as intermediate staging tanks, if internediate staging tanks are required.

Discussion: For the indirect staging stagegies to be sucessful, the final waste transfer should be a short, straigthforward transfer with minimal setup time and minimal potential for conflict with other transfers.

Issue: Transfer hydraulics from AN-Farm towards AP-Farm may require that tanks in AW-Farm be used as the intermediate staging tanks.

\section{A 1.7.13 Common use of Transfer Lines}

Assumption: The prior use of a transfer line for one class of waste (HLW, TRU or DST supernate) does not preclude its use for another class.

\section{A1.8 SIMPLIFYING ASSUMPTIONS}

\section{A1.8.1 Physical Property Limits}

Assumption: The physical property limits ( $\mathrm{Spg}, \mathrm{pH}, \mathrm{wt} \%$ water) provided by the feed envelopes will be ignored in this study. Solids handling is discusses elsewhere. 
WHC-SD-WM-RPT-210, Rev. 0

\section{A1.8.2 Tank Inventory Data - Decay Dates for Envelope Assessments}

Assumption: For envelope assessment purposes only, the nominal decay date for radionuclides will be December 31, 2007.

Discussion: The two short half-life nuclides of interest $\left({ }^{137} \mathrm{Cs}\right.$ and $\left.{ }^{90} \mathrm{Sr}\right)$ have half-lives of about 30 years. The duration combined Phase I proof-of-concept demonstration is 9 years. The delivery dates may vary by up to 4.5 years from the nominal decay date. The radionuclide inventory may vary $\pm 10 \%$ during this period, a negligible error for this analysis.

\section{A1.8.3 DST Volumes - Maximum Liquid Level}

Assumption: The maximum liquid level in AP-Farm DSTs used by this study will be 416 inches.

Discussion: The high liquid level alarm is set at $\mathbf{4 1 9}$ inches of waste. For planning purposes, this study will assume a three-inch margin below the Operating Specification Document limit.

\section{A 1.8.4 Heel Composition - Staging Tank}

Assumption: The heels in the private contractors' staging tanks are assumed to have the same composition as the last full batch of waste staged in the tank.

Issue: This assumption may be modified if sufficient information becomes available on solids entrainment during retrieval and on solids composition.

\section{A 1.8.5 Heel Composition - Intermediate Staging Tank}

Assumption: If intermediate staging tanks are recommended, their heels are assumed to have the same composition as the last full batch of waste staged in the tank.

Discussion: This does not, however, preclude the need for solids/liquid separation (decant) of supernate from the retrieved waste. 
Issue: This assumption may be modified if sufficient information becomes available on solids entrainment during retrieval and on solids composition to perform a more rigorous analysis.

\section{A1.8.6 Waste Mass-Balance Calculations}

Assumption: Simple mass balances will be used when mixing waste with other waste or dilution water. Solid-Liquid equilibria will be ignored. Dilution will be accomplished using raw water.

Discussion: Dilution of aluminate containing waste with water may precipitate Gibbsite.

The crystalline Gibbsite that forms when water is added to a solution of aluminate should not cause much of a problem. In the lab samples, it settles neatly out of solution, leaving the solution nice and clear. The particles are easily re-suspended. They behave more-or-less like real fine sand.

I have seen a number of cases where dilution of a sample with water caused Al to precipitate as Gibbsite, but never as a gel. The precipitation occurs so slowly, apparent/y, that it goes to Gibbsite as fast as it precipitates. The only $\mathrm{Al}(\mathrm{OH})_{3}$ gels I've seen in the laboratory occurred when acid was added to aluminate solution, or base was added to ANN solution, so that the $\mathrm{Al}(\mathrm{OH})_{3}$ formed virtually instantaneously.

Source: (Herting 1996a)

Discussion: For typical samples, the volume fraction of settled gibbsite is on the order of 3 percent. The solubility of gibbsite is primarily a function of the $\left[\mathrm{OH}^{-}\right]$. For the Al-Na-OH-H2O system, the minimun $\left[\mathrm{OH}^{-}\right]$is about $6 \mathrm{M}$. This value is reduced as the ionic strength of the solution increases (by adding additional sodium salts), down to about $2 \mathrm{M}$ for DSS.

Source: Phone conversation with D.L. Herting, January 6, 1996.

Issue: The quantity of gibbsite that precipitates during staging will need to 
be estimated (perhaps using chemical equilibria software such as ESP) to confirm the validity of this assumption and to estimate the solids buildup in the intermediate staging tanks. This may also influence dilution water requirements (perphaps by requiring the ability to add caustic) and the solids handling strategy.

\section{A 1.8.7 Solids Tracking}

Assumption: The amount and composition of solids will not be tracked. However, the capability to separate solids from liquids during feed staging will be assumed.

\section{A1.8.8 Transfer Conflicts During Analysis}

Assumption: The analysis of the alternative feed staging strategies will assume that staging for each private contractor is independent of the other. Transfer conflicts will not be modeled.

Discussion: Transfer conflicts lumped into the time available for contingencies.

\section{A1.8.9 Transfer Conflicts For Planning}

Assumption: Only one staging related transfer will be permited to occur at a time for scheduling purposes.

Discussion: The staging schedule is meant to identify which tanks will be processed and to provide the general timing of retrieval and staging activities. The detailed schedules will be prepared and maintained by Tank Farm Operations. This assumption provides additional scheduling flexiblity.

\section{A1.8.10 Transfer Line Flushes}

Assumption: The duration of transfer line flushes will be neglected in this analysis. 
WHC-SD-WM-RPT-210, Rev. 0

Discussion: The holdup of the longer transfer routes within 200 East Area is about $4000 \mathrm{~L}$ (1000 gal). A flush of two line-volumes would take about

30 minutes at a $230 \mathrm{liter} / \mathrm{min}(60 \mathrm{gpm})$ flush rate. This is negligable compared to the other durations. 
WHC-SD-WM-RPT-210, Rev. 0

\section{APPENDIX B - FEED STAGING STRATEGY}


WHC-SD-WM-RPT-210, Rev, 0

This page intentionally left blank.

B-ii 
WHC-SD-WM-RPT-210, Rev. 0

\section{CONTENTS}

B1. FEED STAGING STRATEGY $\ldots \ldots \ldots \ldots \ldots \ldots \ldots \ldots$ B-1

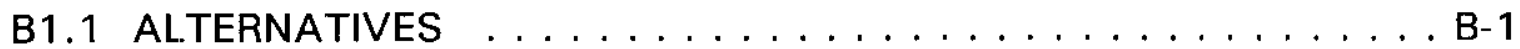

B1.2 TECHNICAL ASSUMPTIONS $\ldots \ldots \ldots \ldots \ldots \ldots \ldots \ldots$ B-5

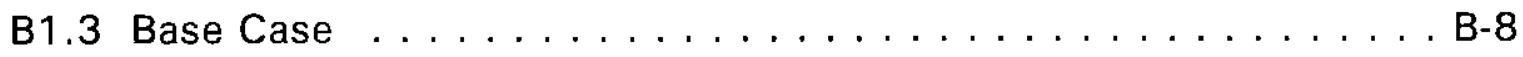

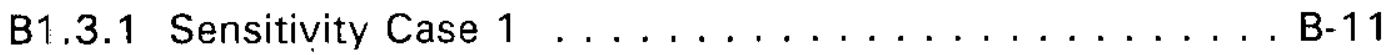

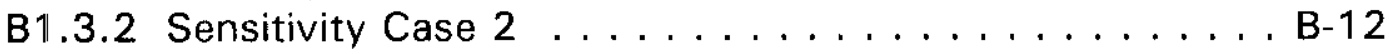

B1.3.3 Sensitivity Case $3 \ldots \ldots \ldots \ldots \ldots \ldots \ldots \ldots$ B-12

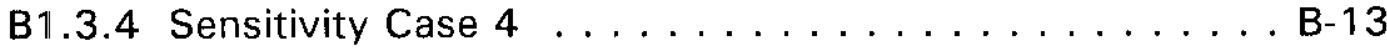

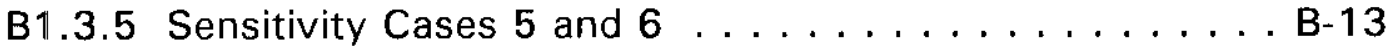

B1.3.6 Sensitivity Case $7 \ldots \ldots \ldots \ldots \ldots \ldots$ B-14

B1.3.7 Recommended Case . . . . . . . . . . . . B-15

B1.4 CALCULATIONS ................... B-16

B1.4.1 Common Calculations . . . . . . . . . . B-16

B1.4.2 Direct Staging . . . . . . . . . . . . B-18

B1.4.3 Indirect Staging - When Notified . . . . . . . B-18

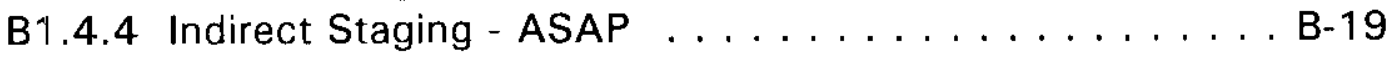

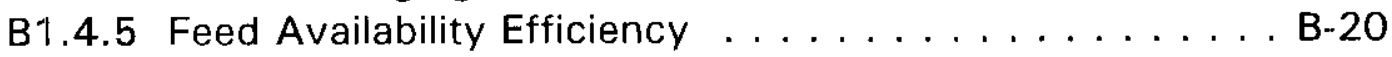

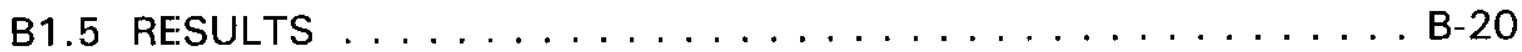

B1.5.1 Simulation Results . . . . . . . . . . . B-20

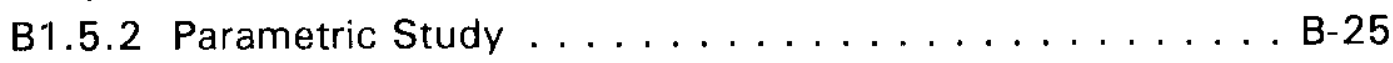

B1.6 OTHER CONSIDERATIONS $\ldots \ldots \ldots \ldots \ldots \ldots \ldots \ldots \ldots$ B-32

B1.6.1 Entrained Solids . . . . . . . . . . . . B-32

B1.6.2 Transfer Conflicts ... . . . . . . . . . . B-32

B1.6.3 Campaign Length and Window Duration . . . . . . B-33

B1.7 CONCLUSIONS .................... B-33 
WHC-SD-WM-RPT-210, Rev. 0

FIGURES

B1-1 - Direct Staging . . . . . . . . . . . . . . . . B-2 B1-2 - Indirect Staging (both When Notified and ASAP) . . . . . . . . B-3 B1-3 - Timing of Alternative Feed Staging Strategies . . . . . . . . . . B-4 B1-4 - Basecase Distribution of Outage and Contingency . . . . . . . . . B-24 B1-5 - Nominal Outage and Contingency versus $\mathrm{Tx} \ldots \ldots \ldots$. . . . . B-27 B1-6 - Nominal Outage and Contingency versus $\operatorname{Tr} \ldots \ldots \ldots \ldots$. . . . . . . . B1-7 - Outage and Contingency versus $\operatorname{Tr}$ (Indirect - ASAP) . . . . . . . B-29 B1-8 - Nominal Outage and Contingency versus Taps . . . . . . . . . B B-30 B1-9 - Outage and Contingency versus Taps (Indirect - ASAP) . . . . . . . B-31

\section{TABLES}

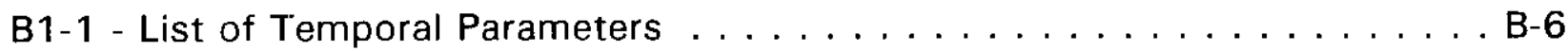

B1-2 - List of Other Parameters . . . . . . . . . . . . . . B-7

B1-3 - Scenario Probabilities . . . . . . . . . . . . . . B-8

B1-4 - Scenario Definitions . . . . . . . . . . . . . . . B-9

B1-5 - Random Variable Distributions . . . . . . . . . . . . B-10

B1-6 - S'cenario Probabilities for Sensitivity Case $1 \ldots \ldots \ldots$. . . . . . B-11

B1-7 - Random Variable Distributions for Sensitivity Case . . . . . . . . . B-11

B1-8 - Random Variable Distributions for Sensitivity Case . . . . . . . . . B-12

B1-9 - Random Variable Distributions for Sensitivity Case $3 \ldots \ldots$. . . . . B-12

B1-10 - Scenario Probabilities for Sensitivity Case $4 \ldots \ldots \ldots$. . . . . . . .

B1-11 - Random Variable Distributions for Sensitivity . . . . . . . . . . B-13

B1-12 - Random Variable Distributions for Sensitivity Case 7 . . . . . . . B-14

B1-13 - Random Variable Distributions for Sensitivity Cases 5 and $6 \ldots$. . . B-14

B1-14 - Random Variable Distributions for Recommended Case . . . . . . . B-16

B1-15 - Summary of Simulation Results . . . . . . . . . . . . B-23 


\section{B1. FEED STAGING STRATEGY}

Three alternative feed staging strategies were analyzed. The strategies were compared in terms of the median length of outage required for feed staging, the median time available for contingencies (such as correcting a bad feed batch or working around scheduling conflicts), the robustness of the strategy against changes in assumptions, the fraction of successful cases, and an estimated feed availability efficiency.

A mathematical model was built that relates these measures to the durations of the underlying activities (e.g., transfer setup time). The durations used by the model are not point estimates. They either span a range of values or are calculated from parameters that span a range of values. For example, the time required to setup a transfer can vary from about 1 to 60 days depending on the complexity of the transfer, weather conditions, competition for resources, or interference with other activities. A Monte Carlo simulation was used to address this aspect (stochastic nature) of feed staging.

Seven sensitivity studies were performed to test the robustness of the decision against the assumed activities and their durations. Three parametric studies also were performed to examine the nominal behavior of the three staging strategies and to identify restrictions on the campaign length (batch size). A recommended case was developed using the results of the sensitivity and parametric studies.

\section{B1.1 ALTERNATIVES}

Three alternative staging strategies were analyzed. They are Direct Staging, Indirect Staging - When Notified, and Indirect Staging - ASAP. In the Direct Staging alternative (Figure B1-1), all transfers are made directly into the private contractors' feed tank. Transfers can not begin until the previous batch of supernate in the private contractor's feed tank has been processed. In both Indirect Staging variants (Figure B1-2), all transfers are made into an intermediate staging tank, then transferred into the private contractors' feed tank. In the Indirect Staging - When Notified strategy, transfers begin when notification from the private contractor is received, however the final transfer into the private contractor's feed tank can not begin until the previous batch of supernate in the private contractor's feed tank has been processed. In the Indirect Staging - ASAP strategy, transfers begin as soon as the intermediate feed staging tank is emptied, 
however the final transfer into the private contractor's feed tank can not begin until the previous batch of supernate in the private contractor's feed tank has been processed.

Figure B1-3 shows the timing of the three strategies in relation to the timing requirements derived from the draft RFP. The private contractor must provide between 30 and 90 days notice in advance of the ready-for-feed date. The M\&l contractor must deliver this feed within the 60-day window after the ready-forfeed date.

The Direct Staging alternative was given a slight advantage by allowing the first transfer to be set up in advance of the anticipated start date for the actual transfer. In some cases, the transfer lines would need to remain unavailable for other use until the transfer is ready to start. The other two alternatives were not given this advantage.

The time available for contingencies was defined so that it primarily represents the time available to correct for out-of-specification feed batches. This time can be used to correct for other problems as well. For Direct Staging, the contingency is the time remaining within the feed delivery window after the approved feed is available. The duration between the setup of the primary transfer (T1s) and the remaining activities (Tx) is excluded since (1) it is not know at this time if the waste is in specification and (2) the transfer set-up time distribution already includes allowance for pump failures.

The contingency for both Indirect Staging alternatives consists of two parts. Part 1 is the time available between the time when waste has been staged in the intermediate staging tanks and the ready-for-feed date. Part 2 is the time remaining within the feed delivery window after approved feed is delivered.

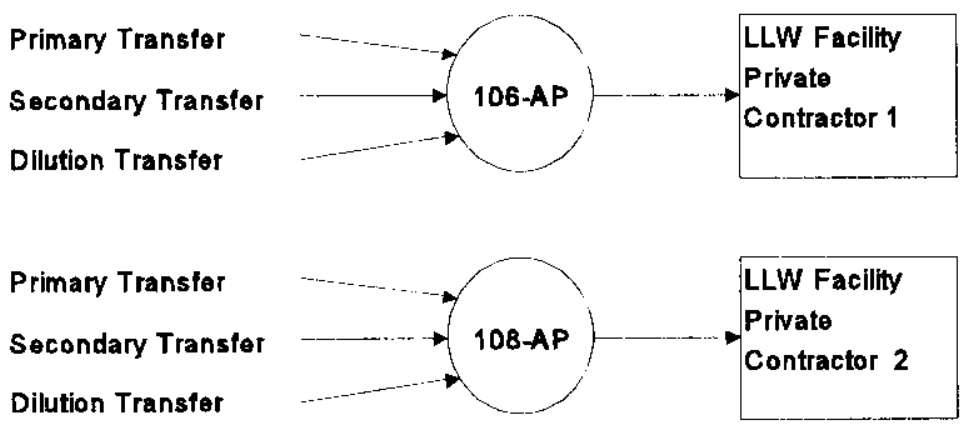

Figure B1-1 - Direct Staging 


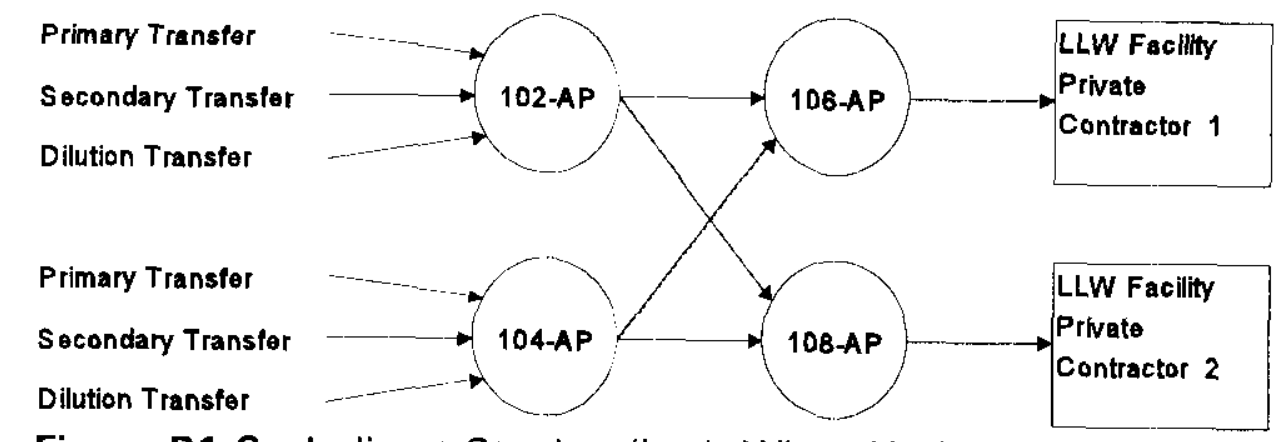

Figure B1-2 - Indirect Staging (both When Notified and ASAP) 
WHC-SD-WM-RPT-210, Rev. 0

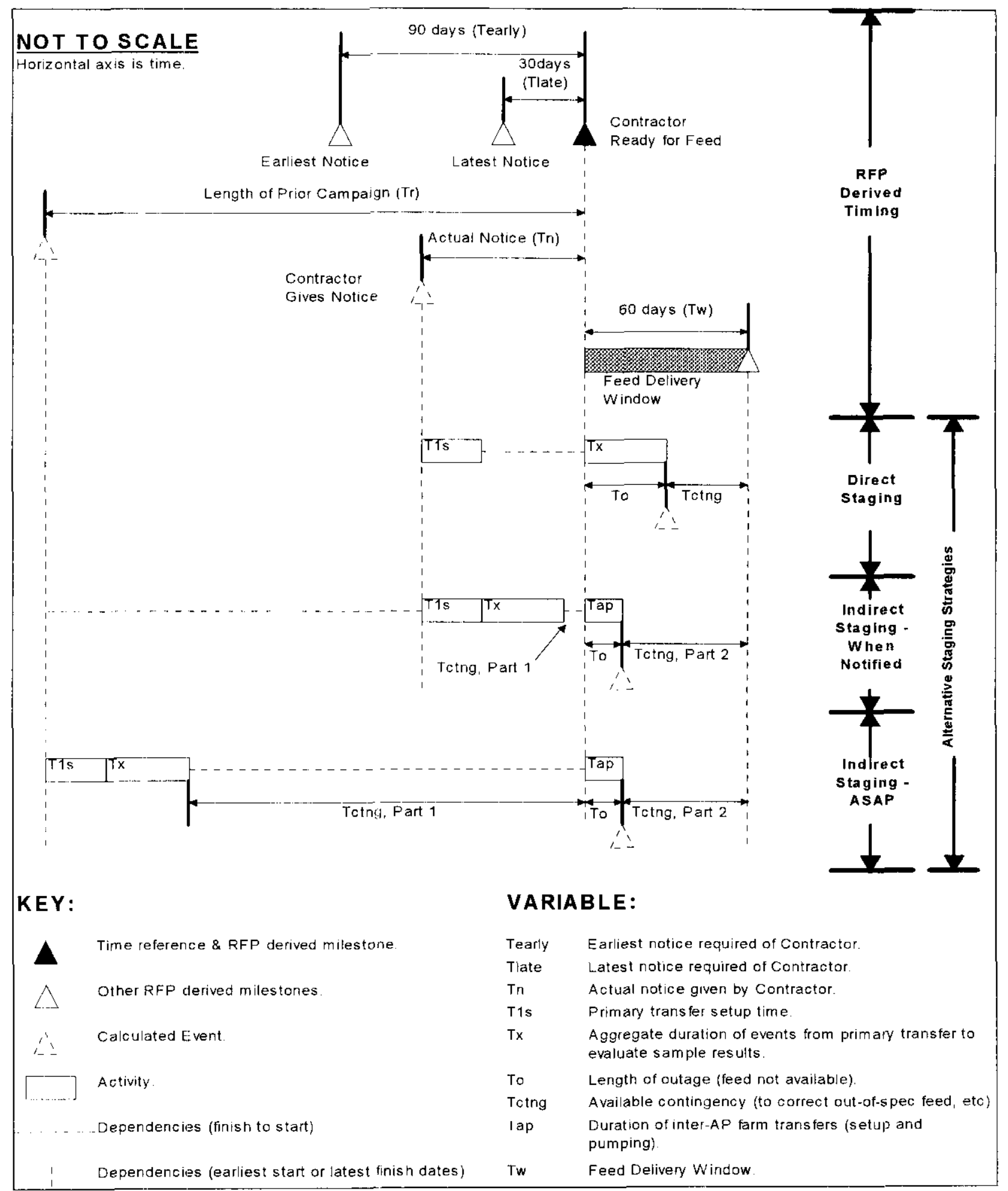

Figure B1-3 - Timing of Alternative Feed Staging Strategies 
WHC-SD-WM-RPT-210, Rev. 0

\section{B1.2 TECHNICAL ASSUMPTIONS}

These technical assumptions are the 'low-level' assumptions used to perform the feed staging strategy analysis. The base case assumptions provide the best estimate of the expected feed staging behavior consistent with the assumptions is Appendix A. These assumptions are intended to provide realistic estimates for the various durations in the model. The seven sensitivity cases analyze the effect of potential changes in these durations on the measures.

The major parameters (variables and constants) used in the model are defined in Tables B1-1 and B1-2. Table B1-1 shows only the temporal (dates and durations) parameters. Table B1-2 shows the remainder. 
WHC-SD-WM-RPT-210, Rev. 0

Table B1-1 - List of Temporal Parameters

\begin{tabular}{|c|c|c|c|}
\hline & Time Element & Variable & Notes \\
\hline \multirow{3}{*}{ 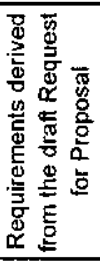 } & Earyy Natice & Teany & $\begin{array}{l}\text { The contractor must provide notice at least Teany days in advance of the date he } \\
\text { will be ready to receive feed. Held constant at } 30 \text { days. }\end{array}$ \\
\hline & Late Notice & Thate & $\begin{array}{l}\text { The contractor must provide nofice no more than Tlate days in advance of the date } \\
\text { he will be ready to receive feed. Held constant at } 90 \text { days. }\end{array}$ \\
\hline & Window & $T w$ & $\begin{array}{l}\text { Duration of the feed delivery window. The feed delivery window begins at the "Ready } \\
\text { for Feed" date. }\end{array}$ \\
\hline \multirow{16}{*}{ 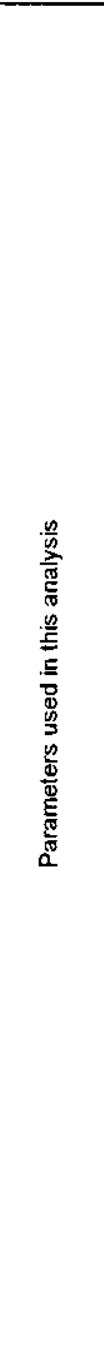 } & Primary Transfer Setup & TTs & $\begin{array}{l}\text { Time to sefup for first waste transter from source tank. Includes allowance for } \\
\text { weather and other factors. }\end{array}$ \\
\hline & Primary Transfer andFlush & $T T x$ & Time to perform the first waste transfer. \\
\hline & Secondeiry Transfer Setup & $12 \mathrm{~s}$ & $\begin{array}{l}\text { Time to sefup for second waste transfer from source tank. Includes allowance for } \\
\text { weather and other factors. }\end{array}$ \\
\hline & Secondeiry Transfer andFlush & $T 2 x$ & Time to perform the secondary waste transter. \\
\hline & Dilution Transter & Tdii & $\begin{array}{l}\text { Time to add dilution water to the waste in either the intermediate staging tanks or } \\
\text { the feed tanks. Assumes only actual transfer time. }\end{array}$ \\
\hline & Mixing & Trmix & $\begin{array}{l}\text { Time to mixing the waste in either the intermediafe staging tanks or the vendor feed } \\
\text { tanks in order to dissolve soluble solids and insure a relatively homogeneous waste } \\
\text { prior to sampling. }\end{array}$ \\
\hline & Sampling & Tsample & $\begin{array}{l}\text { Time required to setup and obtain the grab samples from either the intermediate } \\
\text { staging or vendor feed tanks and transport those samples to the laboratory. }\end{array}$ \\
\hline & Analysis & Thab & Time required to analyze and report on the samples. \\
\hline & Evaluate & Teval & $\begin{array}{l}\text { Time required to evaluate the sample results and determine the acceptability of the } \\
\text { staged waste. }\end{array}$ \\
\hline & Sorids Settling & Tseftle & $\begin{array}{l}\text { Time required to settle solids pror to decant of waste from intermediate staging } \\
\text { tanks. This occurs in parallel with Analysis and Evaluation. }\end{array}$ \\
\hline & Prior Caimpaign (Ruñ) & Tr & Time required to process the previous batch of feed. \\
\hline & Inter-AP Farm Transfer Setup & Taps & $\begin{array}{l}\text { Time to setup to transfer waste from the intermediate staging tanks to the private } \\
\text { contractors feed tanks. Includes allowance for weather and other factors. }\end{array}$ \\
\hline & Inter-AP Fam Transfer and Fush & Tapx & Time to periom the Tnter-AP Farm transter. \\
\hline & $\begin{array}{l}\text { Inter-AP Farm Transfer Overall } \\
\text { Duration }\end{array}$ & Tap & The total time needed to setup and transfer waste within AP-Farm. \\
\hline & Advance Notice & Tn & Amount of advance notice provided by the contractor. \\
\hline & Cumped Duration & $T x$ & $\begin{array}{l}\text { This calculated value is used for convenience. It is the sum of all time elements } \\
\text { from } T 1 \times \text { to Tsample plus the longer of Tsettle and (Tlab+Teval). }\end{array}$ \\
\hline \multirow{3}{*}{ 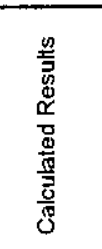 } & Contingency & Tctng & $\begin{array}{l}\text { Time available to recover from out-of-specification waste, correct other problems, or } \\
\text { perform additional work. }\end{array}$ \\
\hline & Outage & To & $\begin{array}{l}\text { Duration of outage (time that feed is not available in the private contractor's feed } \\
\text { tank. }\end{array}$ \\
\hline & Restage & Trestage & $\begin{array}{l}\text { Approximate fime needed to recover from out-of-specification waste (time required } \\
\text { to empty the tank and stage again). }\end{array}$ \\
\hline
\end{tabular}


Table B1-2 - List of Other Parameters

\begin{tabular}{|c|c|c|c|}
\hline Type & Element & Varlable & Notes \\
\hline Constant & Scenario Probabillites & c & $\begin{array}{l}\text { Vector that partiflons all the cases into four scenarlos (requiring diffe } \\
\text { ratlos of primary, secondary, and dllutlon transfers). The vector give. } \\
\text { fractlon of the cases that fall into each scenarlo. }\end{array}$ \\
\hline Constant & Sconario Dofinitions & $\mathrm{v}$ & $\begin{array}{l}\text { Matrlx specifying the volume of primary, secondary, and dilution } \\
\text { transters as a fraction of Batch Volume for each scenarlo. }\end{array}$ \\
\hline Random & Foed Batch Volume & Vbatch & $\begin{array}{l}\text { Estlmated volume of feed in each batch dellvered to the private } \\
\text { contractor. }\end{array}$ \\
\hline Random & Primary Transfer Rate & $R 1 x$ & $\begin{array}{l}\text { The Primary Transfer Rate is used to estimate the duration of the } \\
\text { primary transfer glven the volume of the transfer. }\end{array}$ \\
\hline Random & Socondary Transfor Rato & $22 x$ & $\begin{array}{l}\text { The secondary Transfer Rate is used to estimate the duration of the } \\
\text { secondary transfer glven the volume of the transfer. }\end{array}$ \\
\hline Random & Dilution Transfer Rate & Rdilx & $\begin{array}{l}\text { The Dilutlon Transfer Rate ls used to estlmate the duratlon of the dllu } \\
\text { water transfer given the volume of the transfer. }\end{array}$ \\
\hline Random & Inter-AP Transfer Rate & $\operatorname{Rapx}$ & $\begin{array}{l}\text { The Inter-AP Transfer Rate is used to estimate the duration of the } \\
\text { transfers between the intermediate staging tanks and the private } \\
\text { contractors feed tanks glven the volume of the transfer. }\end{array}$ \\
\hline $\begin{array}{l}\text { summary } \\
\text { statistic }\end{array}$ & Food Avaliabillty Efficlency & FAE & $\begin{array}{l}\text { An ectimate of the fraction of the time that feed is avallable for each } \\
\text { staging strategy. }\end{array}$ \\
\hline $\begin{array}{l}\text { Summary } \\
\text { statistic }\end{array}$ & Percent Successful & Ps & $\begin{array}{l}\text { Percent of successful simulation cases for each strategy. The } \\
\text { cimulation case is considered successful if the length of the outage } 1 \\
\text { less than or equal to the window (To }<=\text { TW). }\end{array}$ \\
\hline
\end{tabular}




\section{B1.3 Base Case}

The durations of the primary, secondary, and dilution transfers are all related to the total feed batch volume and transfer rates. The relationship depends on the blending and dilution requirements of that particular batch of waste. A series of simplifying assumptions were made to facilitate analysis by separating the timing requirements from the waste composition requirements. One assumption is that there are four typical staging scenarios. Scenario A requires only a single (primary) transfer of waste. Scenario B requires both a primary and secondary transfer. Scenario $C$ requires a primary transfer and a dilution water transfer. Scenario $D$ requires all three. The fraction of cases for which each scenario applies is estimated based on the number of tanks assigned to each envelope and estimates of the required dilution (Table B1-3). Similarly, each scenario is defined by stating the fraction of the total batch volume that is provided by each applicable transfer (Table B1-4).

The distributions of the random variables are represented by a two-segment uniform distribution. The minimum, maximum, and median values are specified in Table B1-5.

Table B1-3 - Scenario Probabilities

\begin{tabular}{|l|c|c|c|c|}
\cline { 2 - 5 } \multicolumn{1}{c|}{} & \multicolumn{4}{|c|}{ Scenario } \\
\cline { 2 - 6 } \multicolumn{1}{c|}{ This is vector "C". } & A & B & C & D \\
\hline Fraction of Cases & 0.1 & 0.1 & 0.7 & 0.1 \\
\hline
\end{tabular}


Table B1-4 - Scenario Definitions

\begin{tabular}{|l|c|c|c|c|}
\cline { 2 - 5 } \multicolumn{1}{c|}{} & \multicolumn{4}{|c|}{ Scenario } \\
\cline { 2 - 5 } \multicolumn{1}{c|}{ This is matrix "V". } & A & B & C & D \\
\hline Primary Transfer:Vbatch & 1.0 & 0.5 & 0.5 & 0.4 \\
\hline Secondary Transfer:Vbatch & 0.0 & 0.5 & 0.0 & 0.2 \\
\hline Dilution Transfer:Vbatch & 0.0 & 0.0 & 0.5 & 0.4 \\
\hline
\end{tabular}


WHC-SD-WM-RPT-210, Rev. 0

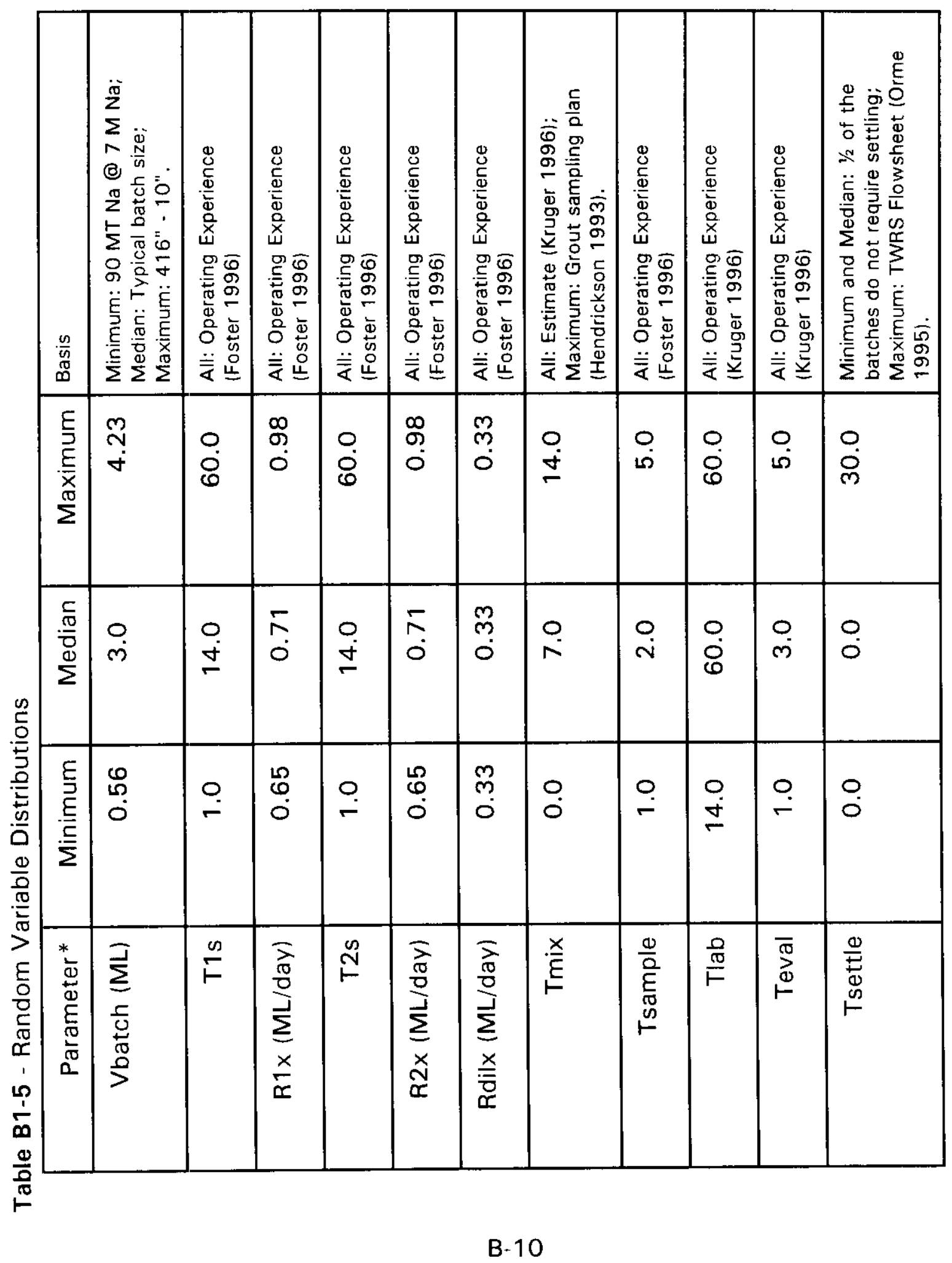




\section{B1.3.1 Sensitivity Case 1}

This sensitivity case bounds the effects of deleting enabling assumption (See Section ?): Until proven otherwise, the M\&/ contractor will demonstrate the delivered waste meets the envelopes by characterization of the waste immediately before [or immediately after] transfer to the private contractors' feed tanks. Additionally, this case assumes that blending is never required and that retrieved supernate always contains solids of an acceptable quantity and composition. This tests the sensitivity to the scenario probabilities and definitions in Table B1-3 and Table B1-4.

To bound these effects, it is assumed that the M\&l contractor can demonstrate that waste meets the envelopes prior to retrieval and staging. Therefore, the mixing, sampling, lab analysis, evaluation, settling, and secondary transfers are not required.

All parameters are the same as base case with the exception of those in Tables B1-6 and B1-7.

Table B1-6 - Scenario Probabilities for Sensitivity Case 1

\begin{tabular}{|l|c|c|c|c|}
\cline { 2 - 5 } \multicolumn{1}{c|}{} & \multicolumn{4}{c|}{ Scenario } \\
\cline { 2 - 5 } \multicolumn{1}{c|}{} & A & B & C & D \\
\hline Fraction of Cases & 0.2 & 0.0 & 0.8 & 0.0 \\
\hline
\end{tabular}


WHC-SD-WM-RPT-210, Rev. 0

Table B1-7 - Random Variable Distributions for Sensitivity Case 1

\begin{tabular}{|r|r|r|r|}
\hline Parameter $^{*}$ & Minimum & Median & Maximum \\
\hline Tmix & 0.0 & 0.0 & 0.0 \\
\hline Tsample & 0.0 & 0.0 & 0.0 \\
\hline Tlab & 0.0 & 0.0 & 0.0 \\
\hline Teval & 0.0 & 0.0 & 0.0 \\
\hline Tsettle & 0.0 & 0.0 & 0.0 \\
\hline
\end{tabular}

* Units are days unless stated otherwise.

\section{B1.3.2 Sensitivity Case 2}

Sensitivity Case 2 is a less severe version of Case 1 . It is assumed that only sampling, lab analysis, and evaluation are not required. All parameters are the same as base case with the exception of those in Table B1-8.

Table B1-8 - Random Variable Distributions for Sensitivity Case 2

\begin{tabular}{|r|r|r|r|}
\hline Parameter $^{*}$ & Minimum & Median & Maximum \\
\hline Tsample & 0.0 & 0.0 & 0.0 \\
\hline Tlab & 0.0 & 0.0 & 0.0 \\
\hline Teval & 0.0 & 0.0 & 0.0 \\
\hline
\end{tabular}

* Units are days unless stated otherwise.

\section{B1.3.3 Sensitivity Case 3}

In Sensitivity Case 3, the maximum time for setup of the final feed staging transfer (inter-AP-farm) is reduced to see how strongly the system behavior is affected. All parameters are the same as base case with the exception of those in Table B1-9. 
WHC-SD-WM-RPT-210, Rev. 0

Table B1-9 - Random Variable Distributions for Sensitivity Case 3

\begin{tabular}{|r|r|r|r|}
\hline Parameter $^{*}$ & Minimum & Median & Maximum \\
\hline Taps & 1.0 & 1.0 & 30.0 \\
\hline
\end{tabular}

* Units are days unless stated otherwise.

\section{B1.3.4 Sensitivity Case 4}

Sensitivity Case 4 explores what happens if an envelope's limits are changed to permit supply of more concentrated feed. This eliminates dilution water transfers, secondary transfers and mixing. All parameters are the same as base case with the exception of those in Tables B1-10 and B1-11.

Table B1-10 - Scenario Probabilities for Sensitivity Case 4

\begin{tabular}{|l|c|c|c|c|}
\cline { 2 - 5 } \multicolumn{1}{c|}{} & \multicolumn{4}{|c|}{ Scenario } \\
\cline { 2 - 5 } \multicolumn{1}{c|}{} & A & B & C & D \\
\hline Fraction of Cases & 1.0 & 0.0 & 0.0 & 0.0 \\
\hline
\end{tabular}

Table B1-11 - Random Variable Distributions for Sensitivity Case 4

\begin{tabular}{|r|r|r|r|}
\hline Parameter* & Minimum & Median & Maximum \\
\hline Tmix & 0.0 & 0.0 & 0.0 \\
\hline
\end{tabular}

* Units are days unless stated otherwise.

\section{B1.3.5 Sensitivity Cases 5 and 6}

The purpose of these two sensitivity cases is to analyze the effect of the shape of the random variable distributions. The method used is to set the median values of each random variable to either the minimum or maximum value. In Sensitivity Case 5, the most favorable of the minimum or maximum are used. 
Sensitivity Case 6 uses the least favorable of the minimum or maximum. All parameters are the same as base case with the exception of those in Table B1-13.

\section{B1.3.6 Sensitivity Case 7}

This sensitivity case was developed after the results from the Base case and other sensitivity cases were interpreted (these results are discussed in Section B1.5, page 20). One of the recommendations was that the campaign length be increase to about 90 days and batch size to $170 \mathrm{MT} \mathrm{Na}$. In addition, the minimum batch volume (Vbatch) was increase to correspond to $170 \mathrm{MT} N$ at $7 \mathrm{M} \mathrm{Na}$. All parameters are the same as base case with the exception of those in Table B1-12.

Table B1-12 - Random Variable Distributions for Sensitivity Case 7

\begin{tabular}{|r|c|c|c|}
\hline Parameter * $^{*}$ & Minimum & Median & Maximum \\
\hline Vbatch (ML) & 1.06 & 3.0 & 4.23 \\
\hline $\mathrm{Tr}$ & 90.0 & 300.0 & 363.0 \\
\hline
\end{tabular}

* Units are days unless stated otherwise. 
WHC-SD-WM-RPT-210, Rev, 0

Table B1-13 - Random Variable Distributions for Sensitivity Cases 5 and 6

\begin{tabular}{|r|c|c|c|c|}
\cline { 3 - 4 } \multicolumn{2}{c}{} & \multicolumn{2}{c}{ Median } & \multicolumn{1}{c}{} \\
\hline Parameter & Minimum & Case 5 & Case 6 & Maximum \\
\hline Vbatch (ML) & 0.56 & 0.56 & 4.23 & 4.23 \\
\hline T1s & 1.0 & 1.0 & 60.0 & 60.0 \\
\hline R1x (ML/day) & 0.65 & 0.98 & 0.65 & 0.98 \\
\hline T2s & 1.0 & 1.0 & 60.0 & 60.0 \\
\hline R2x (ML/day) & 0.65 & 0.98 & 0.65 & 0.98 \\
\hline Rdilx (ML/day) & 0.33 & 0.33 & 0.33 & 0.33 \\
\hline Tmix & 0.0 & 0.0 & 14.0 & 14.0 \\
\hline Tsample & 1.0 & 1.0 & 5.0 & 5.0 \\
\hline Tlab & 14.0 & 14.0 & 60.0 & 60.0 \\
\hline Teval & 1.0 & 1.0 & 5.0 & 5.0 \\
\hline Tsettle & 0.0 & 0.0 & 30.0 & 30.0 \\
\hline Tr & 48.0 & 363.0 & 48.0 & 363.0 \\
\hline Taps & 1.0 & 1.0 & 60.0 & 60.0 \\
\hline Rapx (ML/day) & 0.65 & 0.98 & 0.65 & 0.98 \\
\hline Tn & 30.0 & 90.0 & 30.0 & 90.0 \\
\hline Unis & & & \\
\hline
\end{tabular}

* Units are days unless stated otherwise.

\section{B1.3.7 Recommended Case}

This sensitivity case was developed after the results from the Base case and other sensitivity cases were interpreted (these results are discussed in Section B1.5, page 201. The minimum campaign length was increased to 90 days and the minimum batch volume (Vbatch) was increase to $1.06 \mathrm{ML}$. Additionally, the maximum value for the final transfer setup time (Taps) was decreased from 
WHC-SD-WM-RPT-210, Rev. 0

60 days to 50 days. All parameters are the same as base case with the exception of those in Table B1-14.

Table B1-14 - Random Variable Distributions for Recommended Case

\begin{tabular}{|r|c|c|c|}
\hline Parameter $^{*}$ & Minimum & Median & Maximum \\
\hline Vbatch (ML) & 1.06 & 3.0 & 4.23 \\
\hline $\mathrm{Tr}$ & 90.0 & 300.0 & 363.0 \\
\hline Taps & 1.0 & 1.0 & 50.0 \\
\hline
\end{tabular}

* Units are days unless stated otherwise.

\section{B1.4 CALCULATIONS}

\section{B1.4.1 Common Calculations}

The calculations in this section are common to all three staging strategies.

The two-segment uniform distribution is calculated with the following equation where ' $c p^{\prime}$ ' is the cumulative probability (a computer-generated random number of uniform distribution between 0 and 1 , inclusive):

$$
\begin{gathered}
\text { IF } c p \leq 0.5 \\
T H E N, \phi=\text { minimum }+2 c p(\text { median }- \text { minimum }) \\
\text { ELSE, } \phi=\text { median }+2 *(c p-0.5)(\text { maximum }-m e d i a n)
\end{gathered}
$$

The following parameters are calculated based only on their assigned distribution:

$$
\begin{aligned}
& V_{\text {batch }}=\phi(\text { minimum, median, maximum,cp }) \\
& T_{\text {ovel }}=\phi(\text { minimum, median, maximum,cp) }
\end{aligned}
$$


WHC-SD-WM-RPT-210, Rev. 0

$$
\begin{aligned}
& T_{\text {sottlo }}=\phi(\text { minimum, median, maximum,cp }) \\
& T_{1 s}=\phi(m i n i m u m, \text { median }, \text { maximum }, c p) \\
& T_{\text {lab }}=\phi(m i n i m u m, \text { median, maximum, } c p) \\
& T_{\text {semplo }}=\phi(\text { minimum, median, maximum, } c p) \\
& T_{m / x}=\phi(m i n i m u m, \text { median, maximum, } c p) \\
& T_{r}=\phi(m i n i m u m, \text { median, maximum }, c p) \\
& T_{n}=\phi(\text { minimum, median, maximum,cp })
\end{aligned}
$$

scenerio $=C^{*}(c p)$; where $C^{*}$ is the distribution implied by vector $C$.

The following parameter is zero for scenarios that do not have a secondary transfer, otherwise it takes on its assigned distribution:

$$
\begin{gathered}
\text { IF } V(\text { scenerio, secondary transfer })=0 \\
T H E N, T_{28}=0
\end{gathered}
$$

$E L S E, T_{2 s}=\phi(m i n i m u m, m e d i a n$, maximum, $c p)$ 
The following parameters are calculated from combinations of other variables and constants:

$$
\begin{aligned}
& T_{1 x}=\frac{V_{\text {betch }} \times V(\text { scenerio,primary transfer })}{R_{1}} \\
& T_{2 x}=\frac{V_{b e t c h} \times V(s c e n e r i o, \text { secondary transfer })}{R_{2}} \\
& T_{d i l}=\frac{V_{\text {batch }} \times V(\text { scenerio,dilution transfer })}{R_{d l l x}} \\
& T_{x}=T_{1 x}+T_{2 s}+T_{2 x}+T_{d i l}+T_{m i x}+T_{\text {semplo }}+\max \left(T_{\text {lab }}+T_{\text {evel }}, T_{\text {sottlo }}\right)
\end{aligned}
$$

\section{B1.4.2 Direct Staging}

$$
\begin{aligned}
& T_{0}=T_{x}+\max \left(0, T_{1,}-T_{n}\right) \\
& T_{\text {cing }}=\max \left(0, T_{w}-T_{0}\right)
\end{aligned}
$$

B1.4.3 Indirect Staging - When Notified

$$
T_{\text {sps }}=\phi(\text { minimum, median, maximum,cp })
$$


WHC-SD-WM-RPT-210, Rev. 0

$$
\begin{gathered}
R_{e p x}=\phi(\text { minimum,median,maximum,cp) } \\
T_{e p x}=\frac{V_{b e t c h}}{R_{e p x}} \\
T_{e p}=T_{a p s}+T_{e p x} \\
T_{0}=T_{e p}+\max \left(0, T_{1 s}+T_{x}-\min \left(T_{n}, T_{p}\right)\right) \\
T_{c t n g}=\max \left(0, T_{w}-T_{0}\right)+\max \left(0, \min \left(T_{n}, T_{r}\right)-T_{1 s}-T_{x}\right)
\end{gathered}
$$

B1.4.4 Indirect Staging - ASAP

$$
\begin{aligned}
& T_{\text {aps }}=\phi(\text { minimum, median, maximum, } c p) \\
& R_{x p x}=\phi(m i n i m u m, \text { median, maximum, } c p) \\
& T_{s p x}=\frac{V_{b s t c h}}{R_{s p x}} \\
& T_{\text {sp }}=T_{\text {sps }}+T_{\text {spx }}
\end{aligned}
$$


WHC-SD-WM-RPT-210, Rev. 0

$$
\begin{gathered}
T_{0}=T_{\text {op }}+\max \left(0, T_{1 s}+T_{x}-T_{r}\right) \\
T_{\text {ctng }}=\max \left(0, T_{w}-T_{0}\right)+\max \left(0, T_{r}-T_{1 s}-T_{x}\right)
\end{gathered}
$$

\section{B1.4.5 Feed Availability Efficiency}

The feed availability efficiency (FAE) was estimated using the following equation. This method of calculating the FAE only considers outages required for the feed staging strategy. The strategy subscript indicates that the term applies to a specific strategy.

$$
F A E_{\text {strategy }} \approx \frac{\sum T_{r}}{\sum T_{r}+\left.\sum T_{0}\right|_{\text {strategy }}}
$$

\section{B1.5 RESULTS}

\section{B1.5.1 Simulation Results}

Table B1-15 compares the Monte Carlo simulation results for the three alternative feed staging strategies. Strategies are compared in terms of their median length of outage, median time available for contingencies, percent of successful simulation cases and estimated feed availability efficiency.

The base case results show that Direct Staging is successful for only $27 \%$ of the simulation cases with a median outage of 75 days, no time for contingencies, and a $0.77 \mathrm{FAE}$. For most cases, this does not satisfy the timing requirements imposed by the draft RFP or the allocated $0.80 \mathrm{FAE}$.

Indirect Staging - When Notified is successful for $53 \%$ of the simulation cases with a median outage of 57 days, 4 days for contingencies and a 0.81 FAE. For most cases, this does not satisfy the timing requirements imposed by the draft RFP, however the allocated 0.80 FAE is satisfied. 
WHC-SD-WM-RPT-210, Rev. 0

Indirect Staging - ASAP is successful for $94 \%$ of the simulation cases with a median outage of 13 days, 213 days for contingencies and a 0.91 FAE. Most cases satisfy the timing requirements, provides a generous amount of time for contingencies, and exceed the allocated 0.80 FAE.

The cumulative distribution of the length of outage and available contingency for the base case results are shown in Figure B1-4. Figure B1-4a can be used to estimate the effect of reducing the feed delivery window (Tw). If $\mathrm{TW}=\mathrm{To}=30$ days, then approximately $65 \%$ of the Indirect Staging - ASAP cases are successful.

Sensitivity Case 1 is a bounding case in which there is no mixing, sampling, analysis, evaluation, settling, or secondary transfers. The purpose is to see if the strategy decision is sensitive to these assumptions. The performance of all three strategies improved with Direct Staging showing the greatest improvement. All three strategies were similar in median outage, percent of successful cases and FAE. However, Indirect Staging - ASAP performed significantly better with 282 days of contingency available versus 54 days for Direct Staging and 72 days for Indirect Staging - When Notified.

Sensitivity Case 2 is a less aggressive version of Sensitivity Case 1 where there is no sampling, analysis, or evaluation. Results are similar to those from Sensitivity Case 1.

Sensitivity Case 3 reduces the maximum transfer setup time for the final staging transfer (inter AP-farm) from 60 days to 30 days to see if there are drivers to implement such a change. Jumpers would need to be configured to avoid pit work and reduce the chance of transfer conflicts. Spare pumps and critical equipment would need to be available on short notice with the capability to change them out. These changes, would at the least, favorably change the shape of the setup time distribution. The performance of Direct Staging remained the same as expected since Direct Staging does not use this transfer. The performance of Indirect Staging - When Notified improves slightly. The performance of Indirect Staging - ASAP improves from $94 \%$ successful simulation cases to $99 \%$.

Sensitivity Case 4 eliminates the dilution and secondary transfers and mixing time. This tests sensitivity to a potential envelope modification that permits higher $\mathrm{Na}$ concentrations. The performance of all staging strategies improve slightly. 
Sensitivity Cases 5 and 6 set the medians of all random variables to either their most favorable (Case 5) or least favorable (Case 6) values. The purpose is to verify that the assumed shape of the distributions are not artificially forcing the recommended feed staging strategy. These test distributions are not meant to represent a realistic case. In Case 5, the Indirect Staging-ASAP performs significantly better than both Direct Staging and Indirect Staging - When Notified. This is the same behavior seen in the Base Case. In Case 6, all strategies perform similarly (very poorly).

Sensitivity Case 7 increases the minimum campaign length and batch size according to the guidelines provided in Section 0 (page 33). Performance of all strategies improved slightly.

The Recommended Case was similar to Sensitivity Case 7, however the final transfer setup time (Taps) was reduced from 60 to 50 days according to the observations in Section 0. This resulted in nearly $100 \%$ of the simulation cases for the Indirect Staging - ASAP strategy being successful. The median outage was 9 days, 222 days was available for contingencies and the estimated FAE was 0.93 . 
WHC-SD-WM-RPT-210, Rev. 0

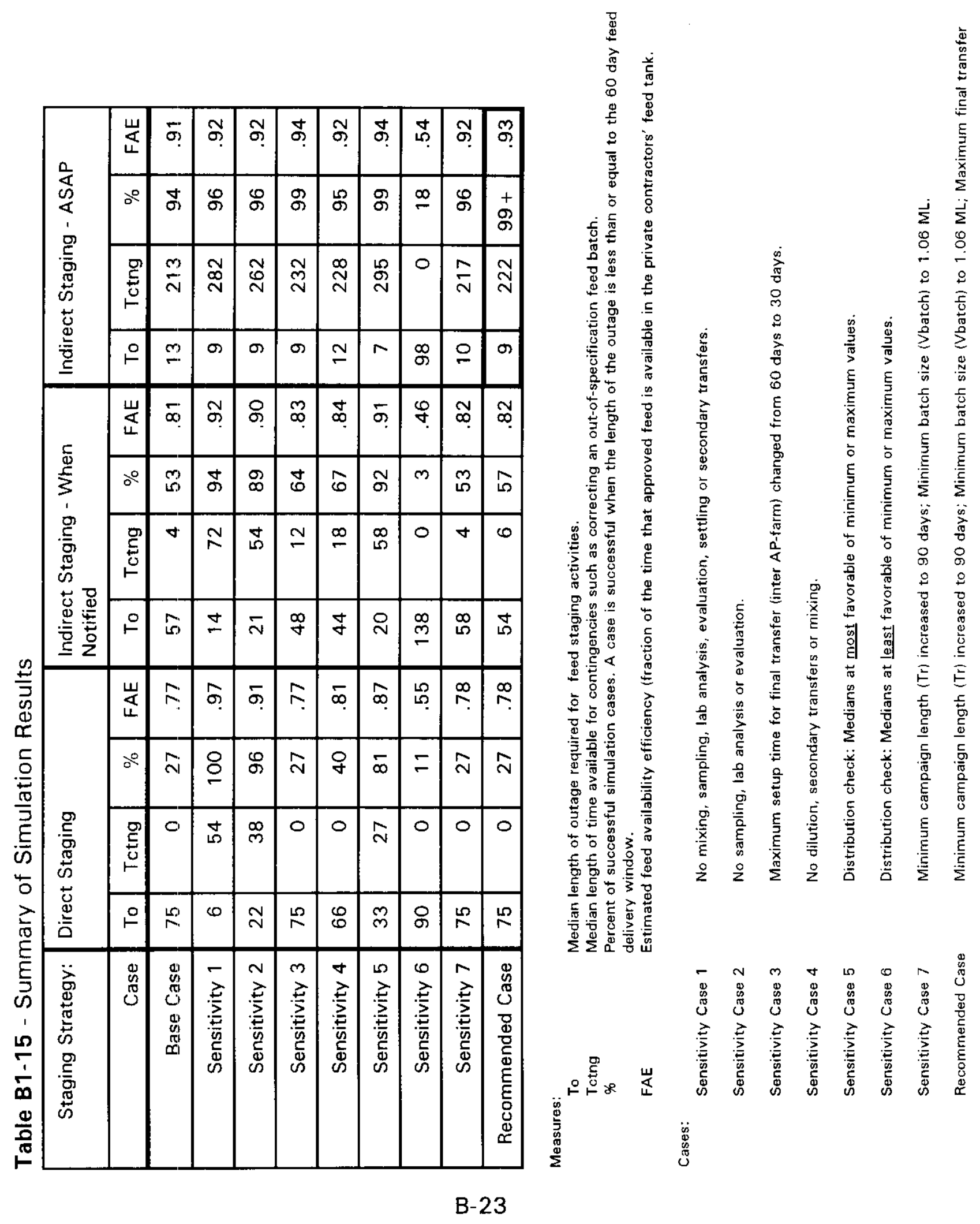


WHC-SD-WM-RPT-210, Rev. 0
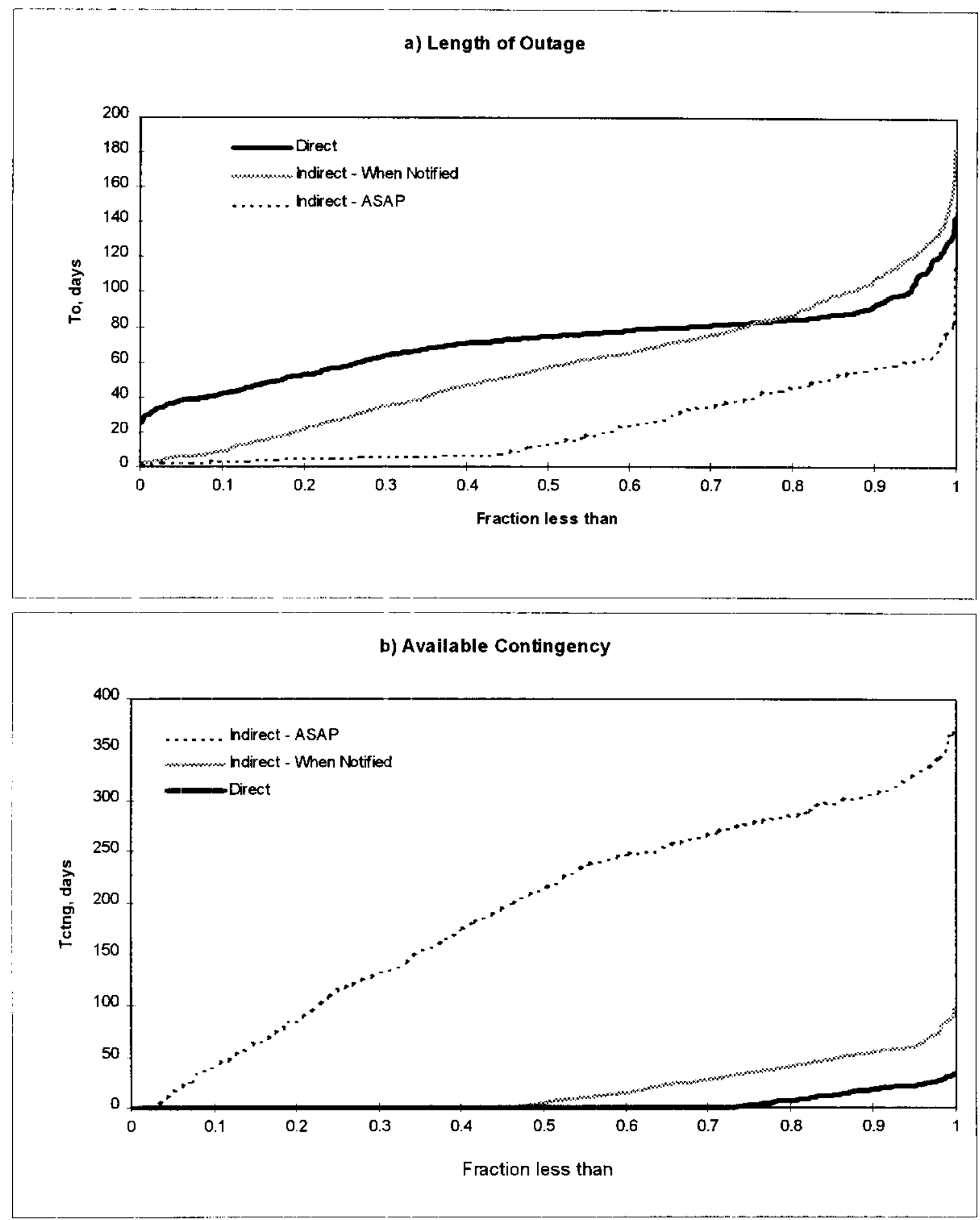

Figure B1-4 - Basecase Distribution of Outage and Contingency

\section{B-24}




\section{B1.5.2 Parametric Study}

The purpose of performing parametric studies is to identify which parameters affect the desired outcome and to provide a basis for limiting the range of those parameters so that the behavior of the system is acceptable. Parametric studies were performed on the lumped duration (Tx), the prior campaign length (Tr), and final transfer setup time (Taps). All other independent variables were held at their nominal (median values from the base case Monte-Carlo simulation) and then Tx, Tr or Taps varied. The length of the outage and available contingency were calculated using the equations in Sections 0,0 , and 0 and then plotted.

Indirect Staging - ASAP behaves well for reasonable values of Tx. The length of outage is not sensitive to Tx (Figure B1-5a) and the available contingency remains high (Figure B1-5b). For values of Tx less than the minimum observed in this study, Direct Staging performs better than either of the Indirect Staging variants in terms of length of outage but the time available for contingency remains low. This (the improved outage at low values of $T x$ ) is an artifact of the bias discussed in Section B1.1.

The approximate contingency needed to restage the feed (empty the intermediate staging tank and prepare a new batch of feed) is overlaid on Figure B1-5b. This was estimated as:

$$
T_{\text {restege }}=2 T_{1 s}+T_{1 x}+T_{x}
$$

The available contingency for Indirect Staging - ASAP is always enough to allow the restaging of an unacceptable feed batch. Both Indirect Staging - When Notified and Direct Staging show unfavorable relationships between Tx and available contingency. They do not provide enough contingency to allow the restaging of an unacceptable feed batch unless Tx can be maintained consistently near or below the minimum value observed during the simulation study. About 170 days of contingency are needed to restage waste at the maximum observed Tx of 140 days.

Figure B1-6 shows that both Indirect Staging - ASAP and Indirect Staging When Notified are sensitive to the length of the previous campaign. This is expected since these strategies references the length of the previous campaign. The length of the outage increases when $\mathrm{Tr}$ is less than about 90 days for Indirect 
Staging - ASAP and 60 days for Indirect Staging - When Notified. In these regions, the available contingency increases linearly with Tr for Indirect Staging ASAP and remains level for Indirect Staging - When Notified. The value of $\mathrm{Tr}$ needed to provide 170 days contingency (the required value when $T x$ is at is observed maximum) is about 200 days for the Indirect Staging - ASAP strategy.

Figure B1-7a plots the base case simulation outage length for Indirect Staging - ASAP against campaign length. The nominal behavior from Figure B1-6a is overlaid. The nominal behavior is swamped by the variability introduced by the setup time for the final staging transfer (Taps). When Taps is removed from the calculations, the cases closely follow the nominal behavior (not shown). The value of $\operatorname{Tr}$ needed to avoid increasing the length of the outage is about 120 days. This is larger than the value ( 90 days) estimated by the nominal behavior alone (Figure B1-6a) because variability is considered.

Figure B1-7b plots the base case simulation available contingency for Indirect Staging - ASAP against campaign length. The nominal behavior from Figure B1-6b is overlaid. The value of $\operatorname{Tr}$ needed to consistently provide 170 days contingency (the required value when $T x$ is at the observed maximum) is about 275 days. This is larger than the value ( 200 days) estimated by the nominal behavior alone (Figure B1-6b) because variability is considered.

Figure B1-8 shows that both Indirect Staging - When Notified and Indirect Staging - ASAP are sensitive to the final staging transfer setup time (Taps). The length of the outage increases linearly with Taps. The available contingency decreases linearly with Taps, leveling off when the Part 2 contingency reaches zero. The value of Taps needed to maintain the outage below 60 days is about 55 days.

Figure B1-9a plots the base case simulation outage length for Indirect Staging - ASAP against final staging transfer setup time (Taps). The nominal behavior from Figure B1-8a is overlaid. The nominal behavior closely follows simulation cases. The "flyers" represent cases in which the previous campaign length was too short. Ignoring the flyers, the value of Taps needed to maintain the outage below 60 days is about 50 - 55 days.

Figure B1-9b plots the base case simulation available contingency for Indirect Staging - ASAP against final staging transfer setup time (Taps). The nominal behavior from Figure B1-8b is overlaid. No correlation is seen since Taps affects only part 2 of the contingency and the values of part 1 are much larger than part 2. 
WHC-SD-WM-RPT-210, Rev. 0
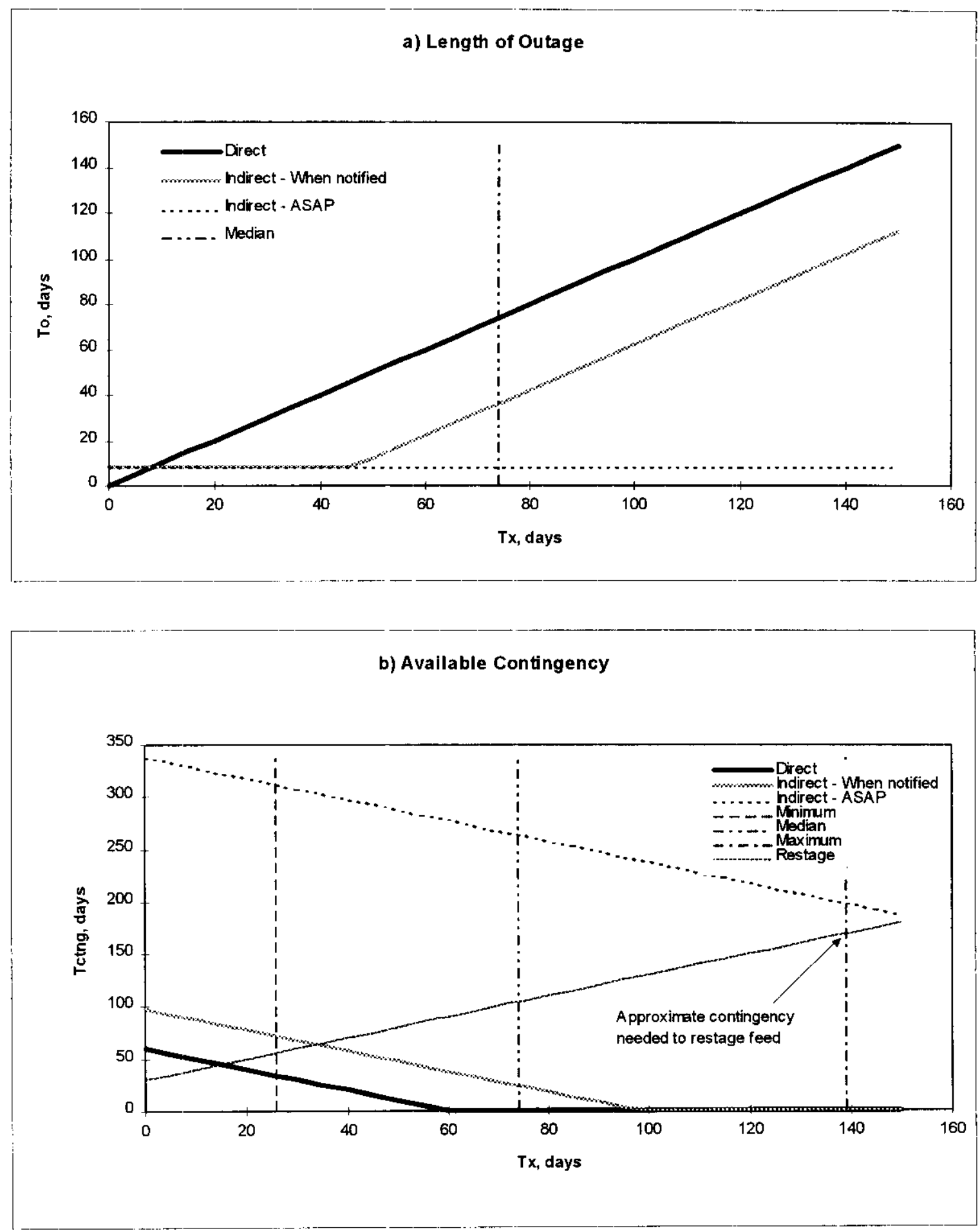

Figure B1-5 - Nominal Outage and Contingency versus Tx 
WHC-SD-WM-RPT-210, Rev. 0

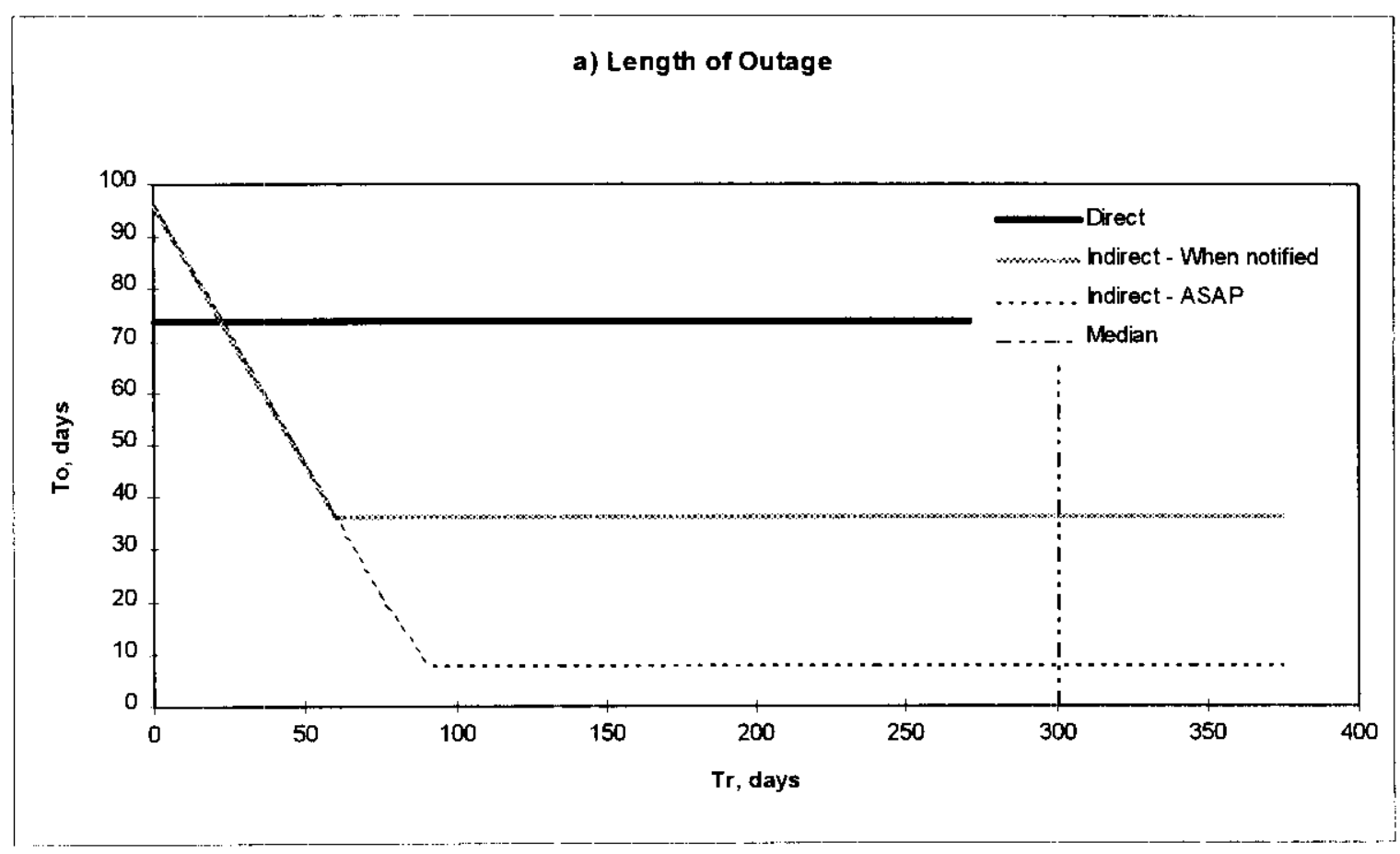

b) Available Contingency

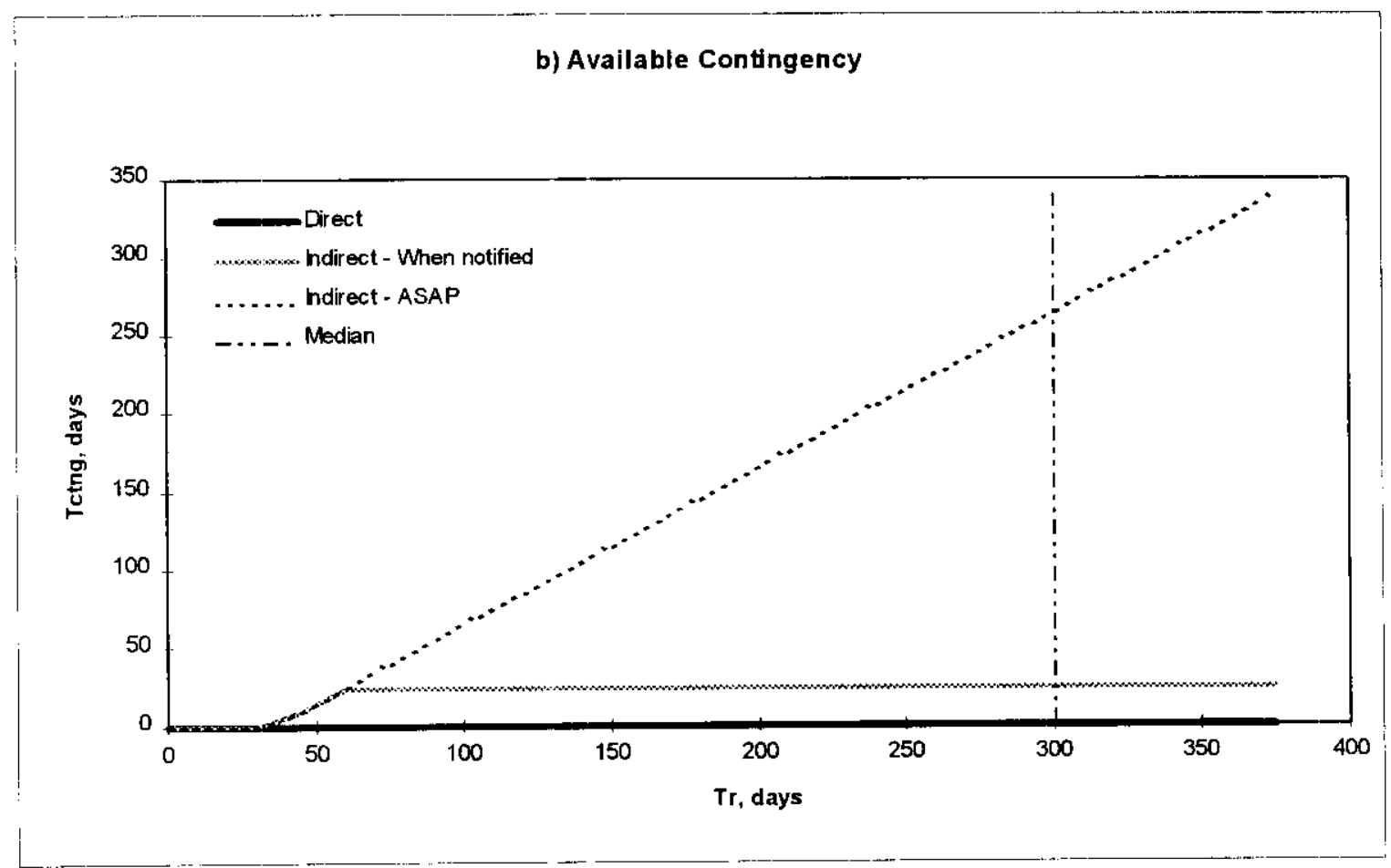

Figure B1-6 - Nominal Outage and Contingency versus Tr 
WHC-SD-WM-RPT-210, Rev. 0
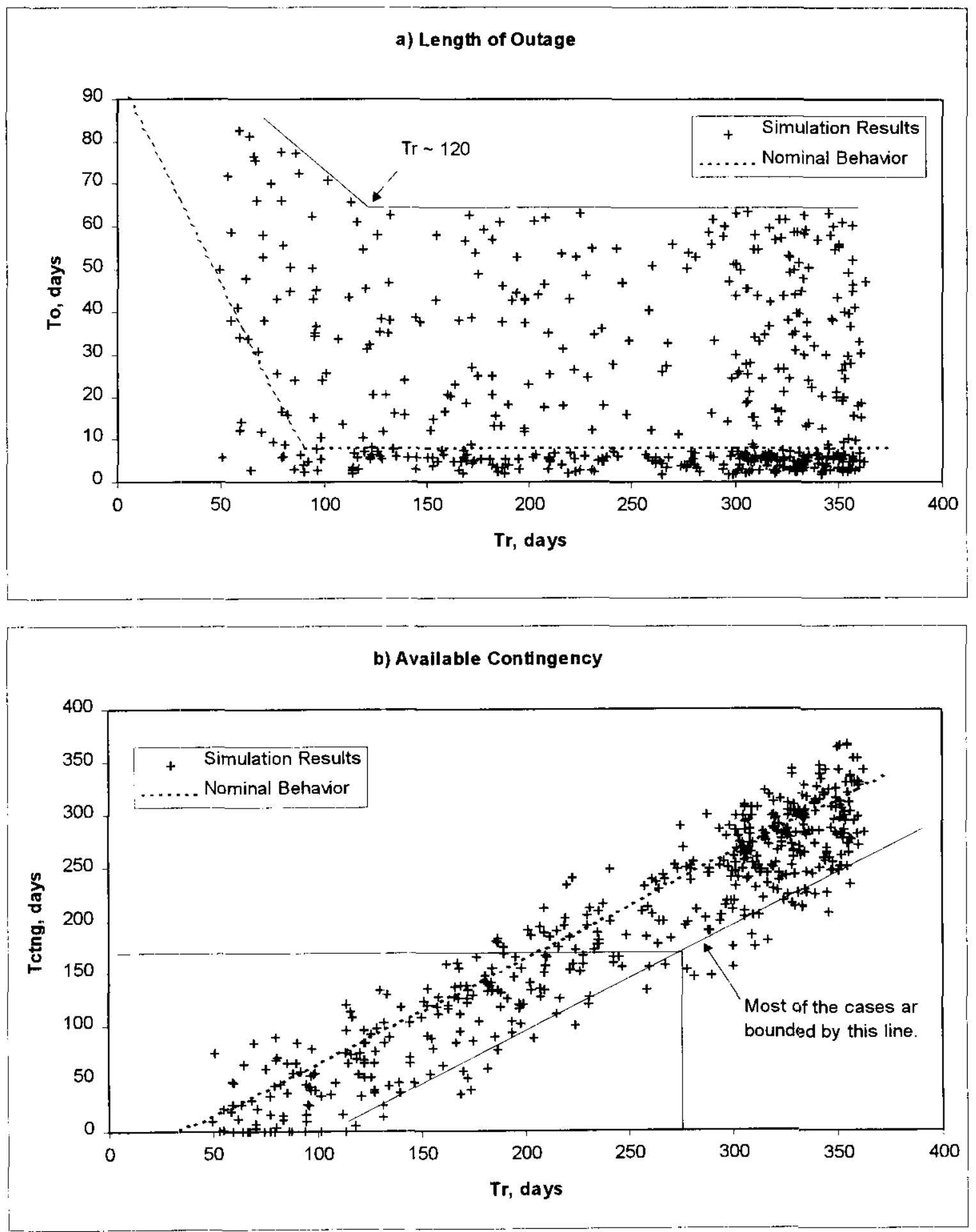

Figure B1-7 - Outage and Contingency versus Tr (Indirect - ASAP) 
WHC-SD-WM-RPT-210, Rev. 0

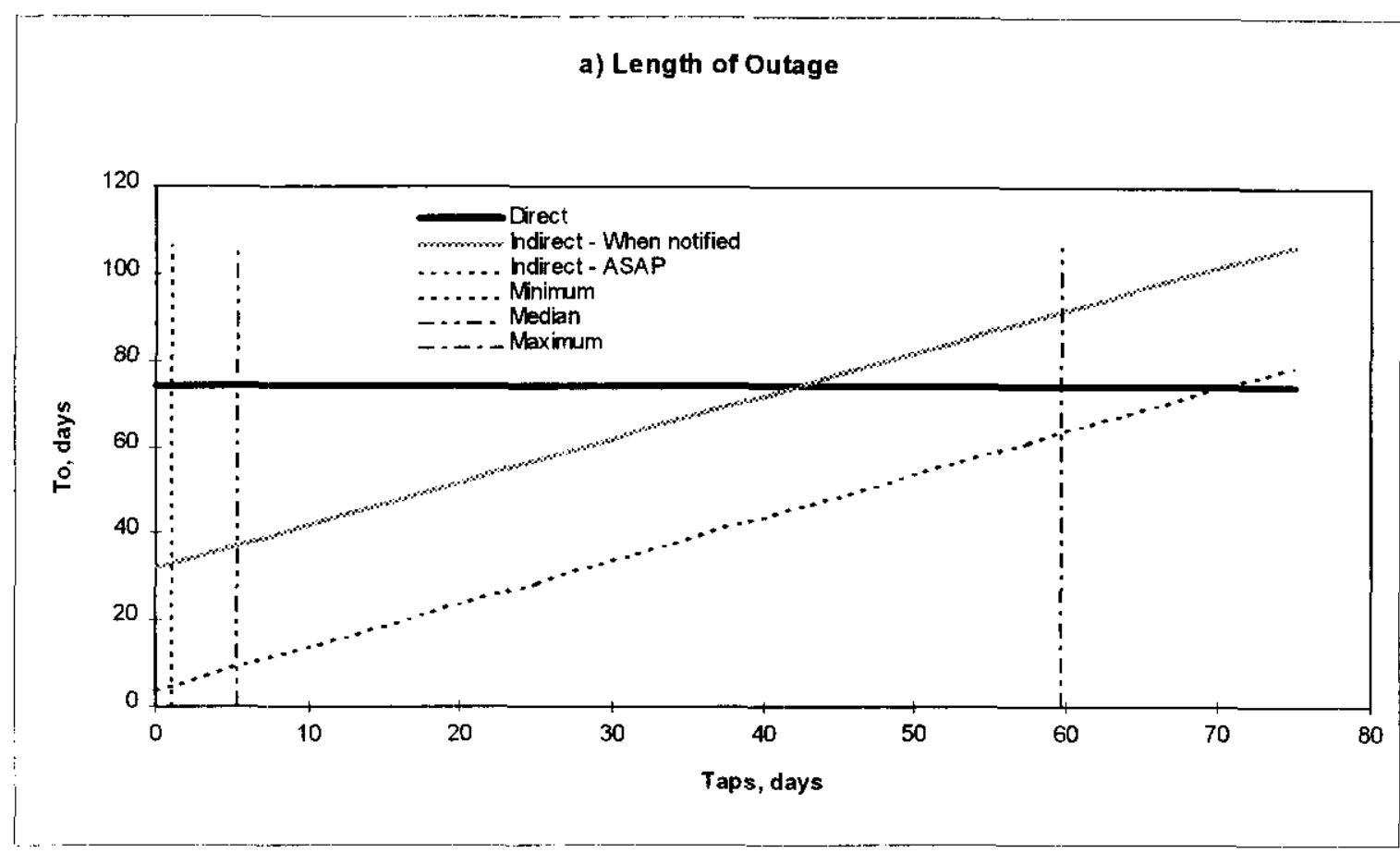

b) Available Contingency

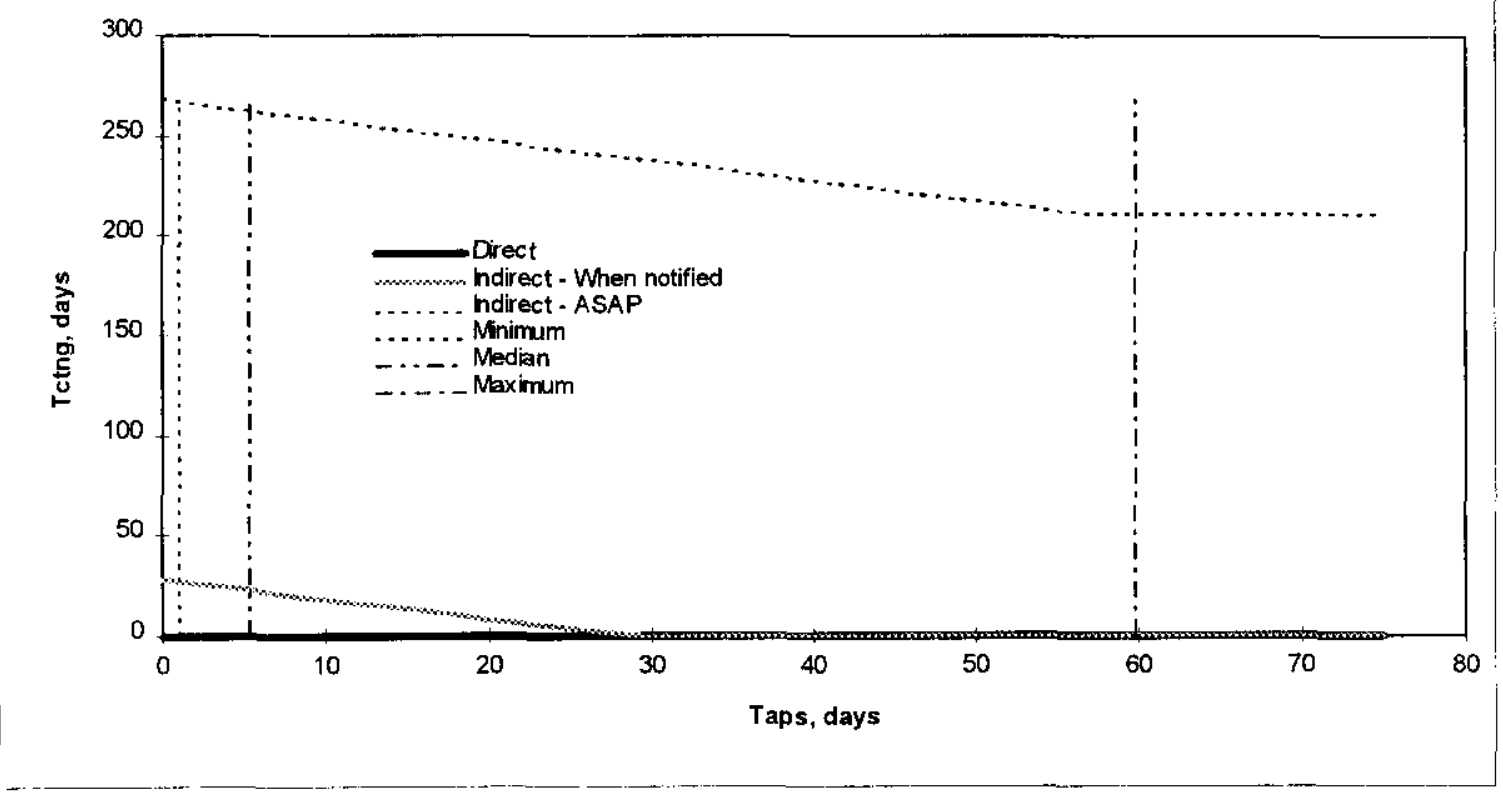

Figure B1-8 - Nominal Outage and Contingency versus Taps 
WHC-SD-WM-RPT-210, Rev. 0
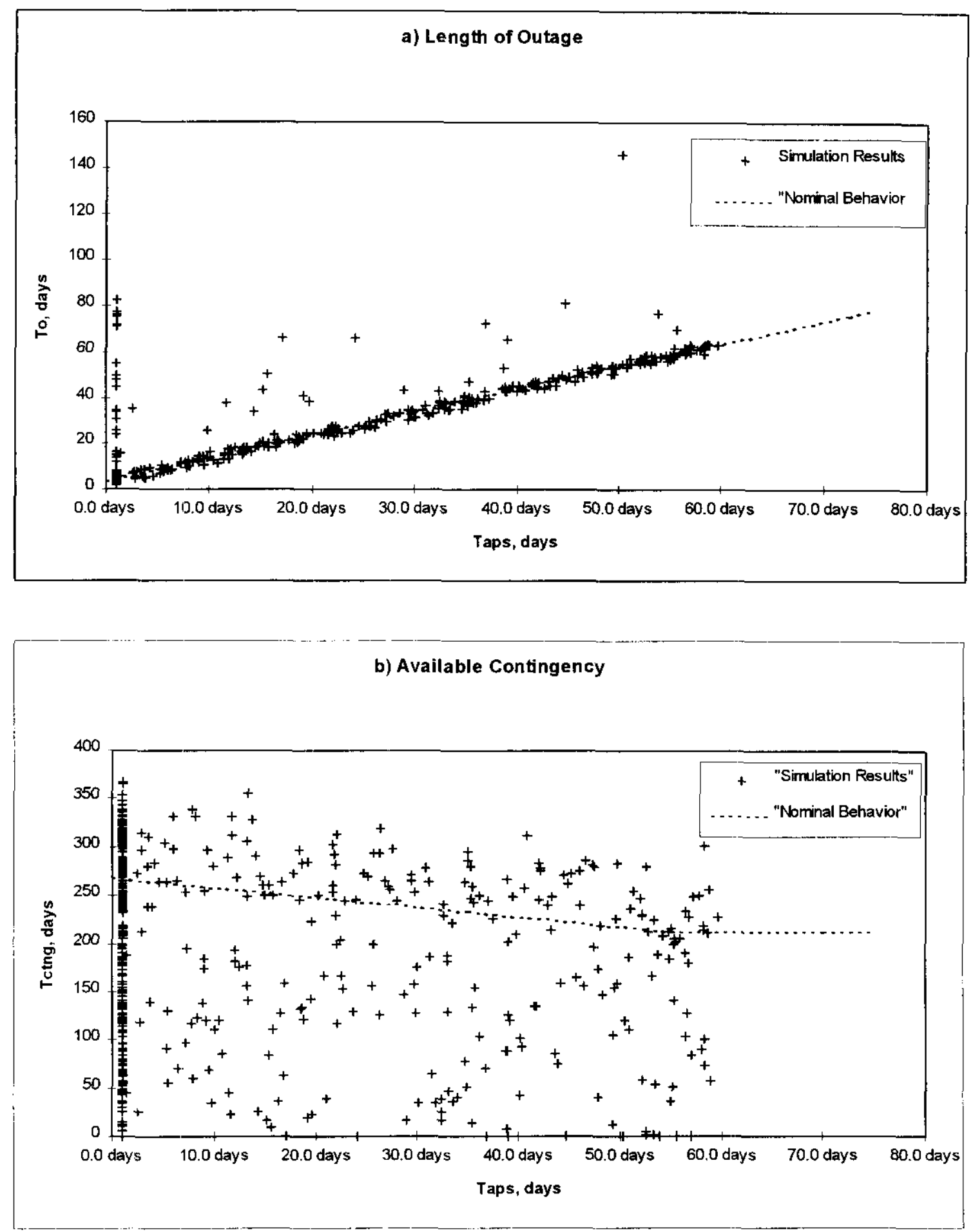

Figure B1-9 - Outage and Contingency versus Taps (Indirect - ASAP) 
WHC-SD-WM-RPT-210, Rev. 0

\section{B1.6 OTHER CONSIDERATIONS}

\section{B1.6.1 Entrained Solids}

It is difficult to predict the amount and composition of solids entrained in the retrieved DST supernate. Both variants on Indirect Staging provides a location where entrained solids can be measured and controlled. If the solids in the intermediate staging tank are not acceptable as feed, the supernate will be decanted during the final transfer to the private contractors' feed tank. If the solids in the intermediate staging tanks build up to a level that causes operational or other problems, they will need to be transferred to another DST for future processing. Indirect Staging - ASAP provides contingency time during which this transfer can take place.

Direct staging will require that each DST being retrieved be equipped with a means to measure and control the amount of entrained solids being transferred. Alternatively, the waste could be transferred without any special controls and the risk of violating the solids limit for the delivered waste be accepted.

\section{B1.6.2 Transfer Conflicts}

The idea behind indirect staging is to separate all of the long duration activities from the final transfer into the private contractors' feed tank. The large contingency available with Indirect Staging - ASAP can absorb reasonable transfer delays that are a result of other activities. The actual transfer of feed to the private contractor's feed tank is generally a shorter-duration, minimal setup transfer within AP-Farm. With existing jumpers, simultaneous transfers from the intermediate staging tanks to the private contractor's feed tanks would cause a conflict. Most of the time the 60-day window should be able to absorb the delays, however it is prudent to investigate ways to consistently shorten the setup times for these critical transfers.

Direct Staging places the transfers that retrieve waste from the source DSTs on the critical path. Transfer conflicts will necessarily cause delays by increasing the duration of the outage. Operational planning become more difficult since the critical path transfers are inter-Farm (many are from AN-Farm which is the farm furthest from AP-Farm) and thus more likely to conflict with other activities. 


\section{B1.6.3 Campaign Length and Window Duration}

Determination of minimum campaign lengths and window duration involve complicated trades beyond the scope of this analysis. For example, reduction of the window may result in lower per unit prices bid by the private contractors. This is offset by the increased chance that RL will incur costs if the M\&l can not deliver the feed within this window. On top of that, part of this risk can be reduced by configuring the final transfer system to improve the distribution of setup time. Likewise, the trades between minimum campaign length primarily involves balance of the risk of not being able to restage waste with the risk of not being able to provide the larger feed batch (perhaps a result of feed near the lower end of the [Na] limit).

\section{B1.7 CONCLUSIONS}

- Indirect Staging - ASAP is the recommended staging strategy. It can consistently meet the RFP timing requirements and provides sufficient contingency (nominal 213 days) for conflicting transfers and restaging or adjustment of waste to correct an out-of-specification feed batch including clean out of problematic quantities solids.

- Direct Staging performs poorly with base case assumptions. It fails most of the time and nominally provides little or no contingency. A bounding sensitivity study showed that elimination of all activities other than the primary transfer and dilution transfer allows it to successfully stage waste in the allocated time. However, only a nominal 54 days of contingency are available, which is not sufficient to restage out-of-specification waste.

The performance of the Indirect Staging - ASAP strategy is degraded by short duration campaigns (processing time). The following guidelines will maintain reasonable values of contingency and outage.

- The minimum scheduled campaign length should be kept larger than about 200-275 days to ensure that sufficient contingency for restaging waste is maintained. This corresponds to a feed batch containing about $400-500 \mathrm{MT} \mathrm{Na}$ at a 0.75 POE.

- $\quad$ The minimum scheduled campaign length should be kept larger than 90 to 120 days to avoid increases in the nominal outage. This corresponds to a feed batch containing about 170 to $225 \mathrm{MT} \mathrm{Na}$ at a 0.75 POE. 
- The performance of the Indirect Staging - ASAP strategy is also sensitive to the maximum setup time for the final staging transfer (Taps). A slight decrease of Taps (from 60 days to 50 days) combined with increased campaign length, results in nearly $100 \%$ of the simulation cases being successful. Therefore, the location and connectivity of DSTs allocated as intermediate feed staging tanks need to be considered to provide minimal setup transfers and reduce the potential for conflicting transfers. Methods for reducing the setup time for the final staging transfer should be investigated.

- Each intermediate feed staging tank will require the capability to:

- Add dilution water

- $\quad$ Mix and sample the waste

- $\quad$ Transfer the supernate and solids (if the solids content and composition is acceptable) to the private contractors' feed tanks

- Decant and transfer the supernate to the private contractors' feed tanks leaving all or some of the solids behind

- Transfer the entire tank's contents (excluding the heel) if the waste is out-of-spec and must be moved out of the way for later disposition.

- Remove problematic solids due to either their quantity or composition. 
WHC-SD-WM-RPT-210, Rev. 0

APPENDIX C - Projected DST Supernate Inventory 
WHC-SD-WM-RPT-210, Rev. 0

This page intentionally left blank.

C-ii 
WHC-SD-WM-RPT-210, Rev. 0

\begin{tabular}{|c|c|c|c|c|c|c|c|c|c|c|}
\hline Supernatant Source & Ol-AN & $102-\mathrm{AN}$ & $1113-\mathrm{AN}$ & $104 \cdot A N$ & $105-\mathrm{AN}$ & $106-\mathrm{AN}$ & $107-A N$ & $101-A P$ & $102-A P$ & $103-\mathrm{AP}$ \\
\hline Inits & MT & MT & MI & MT & MT & MT & MT & MT & MT & MT \\
\hline Projection Date & $2 / 31 / 98$ & $12 / 31 / 98$ & $12 / 31 / 98$ & $12 / 31 / 98$ & $12 / 31 / 98$ & $12 / 31 / 98$ & $12 / 31 / 98$ & $2 / 31 / 98$ & $12 / 31 / 98$ & $12 / 31 / 98$ \\
\hline Decay Dite & $2 / 31 / 07$ & $12 / 31 / 07$ & $12 / 31 / 07$ & $12 / 31 / 07$ & $12 / 31 / 07$ & $12 / 31 / 07$ & $12 / 31 / 07$ & $2 / 31 / 07$ & $12 / 31 / 07$ & $12 / 31 / 07$ \\
\hline \multicolumn{11}{|l|}{ Conponent } \\
\hline & $66 \mathrm{E}+02$ & $97 E+02$ & $7.33 \mathrm{E}+102$ & $3.99 E+02$ & $7.09 \varepsilon+02$ & $1.83 E+02$ & $1.48 E+(0)]$ & $1.26 E+02$ & $1.70 E+102$ & $8.85 E-1) 2$ \\
\hline 2 & $14 \mathrm{E}-04$ & $0.00 E+00$ & $0.00 \mathrm{E}+00$ & $0.0010+000$ & $0.00 E+00$ & $1.09 \mathrm{E}-02$ & $0.00 E+00$ & $1.96 \mathrm{E}-103$ & $1.18 \mathrm{E}-03$ & $0.00 \mathrm{E}+10$ \\
\hline$-?$ & $13 \mathrm{E}-03$ & $1.66 \mathrm{E}+00$ & $3.13 \mathrm{E} \cdot 01$ & $0.00 \mathrm{E}+00$ & $0.00 \mathrm{E}+00$ & $4.31 \mathrm{E}-01$ & $1.92 E+010$ & $2.05 \mathrm{E}-01$ & $0.00 E+100$ & (3.00E+ +100) \\
\hline & $00 E+00$ & $0.00 \mathrm{E}+00$ & $5.79 \mathrm{E} \cdot 02$ & $0.00 \mathrm{E}+00$ & $0.00 \mathrm{E}+00$ & $9.65 E-03$ & $0.00 E+010$ & $5.45 E-03$ & $6.11 \mathrm{E}-03$ & $1.1 \overline{3 E}-05$ \\
\hline $\mathrm{OH}) 4-$ & $85 \mathrm{E}-01$ & $2.48 \mathrm{E}+000$ & $7.118 \mathrm{E}+00$ & $4.71 \mathrm{E}+00$ & $6.70 E+100$ & $1.19 E+00$ & $1.37 \mathrm{E}+00$ & $1.32 \mathrm{E}+00$ & $5.93 \mathrm{E}+100$ & $1.04 \overline{4}-03$ \\
\hline & $09 E-03$ & $0,00 \mathrm{E}+00$ & $2.65 \mathrm{E}-0 \mathrm{l}$ & $3.37 \mathrm{E}-02$ & $4.79 \mathrm{E}-02$ & $5.95 E-02$ & $5.24 E+00$ & $2.03 E-02$ & $1.58 \mathrm{E}-02$ & $1.26 \mathrm{E}-1) 4$ \\
\hline+2 & $00 E+00$ & $0.00 E+00$ & $5.79 \mathrm{E}-02$ & $0.00 \mathrm{E}+00$ & $0.00 E+190$ & $1.08 E-06$ & $0.00 \mathrm{E}+100$ & $0.00 \mathrm{E}+100$ & $.00 E+000$ & $5.11 \mathrm{E}-107$ \\
\hline$\overline{\mathrm{K}+}$ & $38 \mathrm{E}+00$ & $1.47 \mathrm{E}+01$ & $5.50 \mathrm{E}+01$ & $2.16 E+01$ & $2.63 \mathrm{E}+01$ & $1.43 E+02$ & $7.41 \mathrm{E}+000$ & $9.47 E+01$ & $.37 \mathrm{E}+00$ & $1.55 E-101$ \\
\hline+3 & BOE +00 & $0.00 \mathrm{E}+00$ & $0.100 \mathrm{E}+00$ & $0.00 \mathrm{E}+00$ & $0.00 \mathrm{E}+10$ & $1.02 \mathrm{E}-01$ & $0.00 E+010$ & $0.00 \mathrm{E}+100$ & $60 \mathrm{E}+100$ & $0.00 \mathrm{E}+100$ \\
\hline & $34 E+02$ & $1.00 \mathrm{E}+03$ & $1.22 \mathrm{E}+03$ & $8.34 \mathrm{E}+02$ & $1,18 E+2) 3$ & $1.08 \mathrm{E}+1) 3$ & $7.78 \mathrm{E}+02$ & $5.11 E+02$ & $.24 E+02$ & $5.43 \mathrm{E}-\mathrm{n11}$ \\
\hline & $18 \mathrm{E}-03$ & $1.32 E+00$ & $8,68 \mathrm{E} \cdots 02$ & $0.00 \mathrm{E}+100$ & $0.00 \mathrm{E}+10$ & $1.22 \mathrm{E}-01$ & $1.57 \mathrm{E}+010$ & $3.33 \mathrm{E}-02$ & $11 \mathrm{E}-01$ & $0.00 \mathrm{E}+00$ \\
\hline & $3 E-02$ & $0.00 \mathrm{E}-$ & $E-01$ & $0.00 \mathrm{E}+00$ & $E+100$ & $2.14 \mathrm{E}-02$ & $1.15 \mathrm{E}+00$ & $1.65 \mathrm{E}-02$ & $.37 \mathrm{E}-02$ & 0. DODE +00 \\
\hline & $9 E-05$ & 1). $.00 \mathrm{E}+100$ & $4.45 E \cdot 01$ & $0.00 E+00$ & $0.00 \mathrm{E}+100$ & $1.41 E+00$ & $0 . \overline{00 E}+100$ & $1.33 \mathrm{E}-01$ & $.46 \mathrm{E}-02$ & $3.77 \mathrm{E}-104$ \\
\hline $3-2$ & $08 E+01$ & $2.53 E+02$ & $3.24 E+101$ & $8.56 \mathrm{E}+01$ & $E+101$ & $2.58 \mathrm{E}+02$ & $.62 \mathrm{E}+02$ & $6.89 E+01$ & $.11 E+02$ & $2.63 \mathrm{E} \cdot 01$ \\
\hline Ci & $2.47 \mathrm{E}+01$ & $1.47 \mathrm{E}+01$ & $3.47 \mathrm{E}+01$ & $2.27 \mathrm{E}+\mathrm{il}$ & $65 E+01$ & $5.70 \mathrm{E}+100$ & $1.08 \mathrm{E}+01$ & $7.23 E+00$ & $21 E+01$ & $5.06[-03$ \\
\hline & 1. $56 \mathrm{E}+01$ & $7.86 \mathrm{E}+00$ & $2.66 \mathrm{E}+00$ & $0.00 \mathrm{E}+00$ & $00 \mathrm{E}+1) 0$ & $3.15 E+101$ & $0.00 \mathrm{E}+00$ & $4.66 \mathrm{E}+00$ & $.00 E+00$ & $1.32 \mathrm{E}-02$ \\
\hline $5(4-2$ & $3 E+01$ & 5.4 & $5.79 \mathrm{E}+00$ & $1.98 \mathrm{E}+01$ & $2.81 \mathrm{E}+01$ & $3 . \overline{08 E}+01$ & $4.79 E+01$ & $7.46 E+00$ & $88 \mathrm{E}+01$ & $3.58 \mathrm{E}-10 ?$ \\
\hline & +02 & +02 & $5.79 E+102$ & $5.81 \mathrm{E}+02$ & $8.30 \mathrm{E}+02$ & $8.92 \mathrm{E}+02$ & $8.28 \mathrm{E}+02$ & $5.05 E+02$ & $25 \mathrm{E}+02$ & $4.13[111$ \\
\hline & $2.07 E+02$ & & 4. $9 \overline{9 E+02}$ & $2.67 \mathrm{E}+102$ & $15 E+102$ & $3.39 \mathrm{E}+112$ & $.72 E+12$ & $1.48 \mathrm{E}+02$ & $.58 \mathrm{E}+(1) 2$ & $1.33 \mathrm{E}-01$ \\
\hline & $1.03 E+01$ & $1.86 \mathrm{E}+01$ & $3.36 \mathrm{E}+00$ & $8.43 \mathrm{E}+00$ & $8.15 \mathrm{E}+00$ & $2.00 \mathrm{E}+41$ & $85 \mathrm{E}+00$ & $1.37 \mathrm{E}+00$ & $.83 \mathrm{E}+10 \mathrm{l}$ & $1.4 \overline{2 E}-102$ \\
\hline & $1.27 \mathrm{E}+02$ & $4.04 \mathrm{E}+01$ & $3.53 E+02$ & $2.10 \mathrm{E}+02$ & $2.66 \mathrm{E}+02$ & $1.34 \mathrm{E}+02$ & $\overline{6} . \overline{25 E+111}$ & $1.65 \mathrm{E}$ & $81 \mathrm{E}+01$ & $1.73 \mathrm{E}-6$ \\
\hline$\overline{T O C}$ & $1.08 E+01$ & 9.89 & $2.66 \mathrm{E}+01$ & $1.39 \mathrm{E}+01$ & $1.67 \mathrm{E}+01$ & $9.93 \mathrm{E}+101$ & $1.50 \mathrm{E}+02$ & $8.48 E+00$ & $1.36 E+01$ & 1. $14 \mathrm{E}-112$ \\
\hline $14 \mathrm{C}$, (Ci) & $19 E-01$ & +01 & $7.10 E+00$ & $0.00 \bar{E}+00$ & $0.00 \mathrm{E}+00$ & $2.02 \mathrm{E}-\mathrm{B1}$ & $.00 E+000$ & $6.65 \mathrm{E}-01$ & $1.74 \mathrm{E}+00$ & $4.56 \mathrm{E}-104$ \\
\hline $90 \mathrm{St}, \quad(\mathrm{Ci})$ & $98 E+01$ & $2.16 E+105$ & $2.58 \mathrm{EE}+04$ & $1.47 \mathrm{E}+104$ & $6.83 \mathrm{E}+103$ & $2.83 E+104$ & $1.78 \mathrm{E}+05$ & $3.87 \mathrm{E}+02$ & $3.62 E+03$ & $1.56 \mathrm{E}-111$ \\
\hline 90YY. (Ci) & $E+01$ & 2.160 & $2.58[+04$ & $1.47 \mathrm{E}+04$ & $6.83 \mathrm{E}+03$ & $2.83 E+04$ & $1.78 \mathrm{E}+05$ & $3.87 \mathrm{E}+02$ & $3.62 E+03$ & $1.56 \mathrm{E}-(1)$ \\
\hline $99 \mathrm{Te}$, & $3.6 \mathrm{IE}+101$ & $1.17 \mathrm{E}+03$ & $6 .(14 \mathrm{E}+02$ & $5.44 \mathrm{E}+02$ & $7.5 \mathrm{lE}+02$ & $2.86 \mathrm{E}+12$ & $1.75 \mathrm{E}+03$ & $2.14 E+02$ & $3.57 \mathrm{E}+02$ & $3.11 \mathrm{E} \cdot 01$ \\
\hline $13 / \mathrm{Cs}$. & $9.70 \mathrm{E}+00$ & & $1.53 E+06$ & $E+06$ & $1.10 \mathrm{E}+06$ & $1.58 \mathrm{E}+135$ & $5.08 \mathrm{E}+05$ & $4.32 \mathrm{E}+05$ & $5.89 E+03$ & $4.00 \mathrm{E}+102$ \\
\hline $13 / \mathrm{Bd}$. & $E+00$ & & 1. $46 \mathrm{E}+06$ & $1.11 E+06$ & $1.05 \mathrm{E}+106$ & $1.50 \mathrm{E}+135$ & $4.82 E+105$ & $4.11 E+05$ & $5.59 E+03$ & $3.80 E+102$ \\
\hline $154 \mathrm{Eu}$. & $6.46 E+00$ & $3.00 \mathrm{E}$ & $0.00 E+00$ & $0.00 \mathrm{E}+$ & $0.00 \mathrm{E}+100$ & $8.03 \mathrm{E}+00$ & $5.33 \mathrm{E}+1.3$ & $1.67 \mathrm{E}-02$ & $0.00 \mathrm{E}+00)$ & $1.73 \mathrm{E}+100$ \\
\hline 2354. & $0.00 E+00$ & $0.00 E+00$ & $0.6 \overline{O E}+60$ & $0.00 E+00$ & $0.00 E+00$ & $0.00 E+00$ & $0.00 \mathrm{E}+00$ & $0.00 E+00$ & $0.00 E+00$ & $0.00 \mathrm{E}+00$ \\
\hline 23864 & $0.00 \mathrm{E}+00$ & $0.00 \mathrm{E}+00$ & $0.00 \mathrm{E}+00$ & $0.00 \mathrm{E}+00$ & $0.00 \mathrm{E}+100$ & & $0.00 \mathrm{E}+00$ & $0.00 \mathrm{E}+00$ & $0.00 E+00$ & $0.00 \bar{E}+116$ \\
\hline $237 \mathrm{~Np}$. (Ci) & $0.00 \mathrm{E}+00$ & $0.00 E+10$ & $E+00$ & & $\overrightarrow{0 E+00}$ & $2.10 \mathrm{E}-103$ & $0.00 \bar{E}+000$ & $0.00 \mathrm{E}+000$ & $0.00 E+00$ & $0.00 \mathrm{E}+0100$ \\
\hline $238 \mathrm{Pu}$ (Ci) & & & $E+00$ & $0.00 E+00$ & $0,00 \mathrm{E}+00$ & $1.92 \mathrm{E}+00$ & $0.00 \mathrm{E}+000$ & $0.00 E+00$ & $0.000 \mathrm{E}+(00)$ & $0.000++000$ \\
\hline $2398 \mathrm{fu},(\mathrm{Ci})$ & $.15 E-02$ & $2.52 E+1) 2$ & $6.75 E+00$ & $3.14 E+01$ & $4.46 \mathrm{E}+01$ & $1.34 \mathrm{E}+101$ & $1.31 \mathrm{E}+02$ & $4.89 \mathrm{E} \cdot 01$ & $3.12 \mathrm{E}-01$ & $7.13 \mathrm{E}-104$ \\
\hline $240 \mathrm{Pu}$ & $3.16 E-05$ & $6.39 \mathrm{E}+01$ & $1.144 \mathrm{E}+190$ & $4.82 \mathrm{E}+00$ & $6.84 \mathrm{E}+00$ & $3.30 \mathrm{E}+100$ & $3.32 \mathrm{E}+11$ & $7.52 \mathrm{E}-02$ & $4.79 \mathrm{E}-02$ & $1.09 \mathrm{t}-114$ \\
\hline $2410^{2}$ & $0.00 E+00$ & $6.16 \mathrm{E}+01$ & $3.3 \mathrm{IE}+00$ & $4.79 \mathrm{E}+00$ & $6.79 \mathrm{E}+00$ & $1.03 E+00$ & $3.14 \mathrm{E}+01$ & $1.12 \mathrm{E}-01$ & $7.06 \mathrm{E}-102$ & $1.5 \mathrm{IE} 0$ \\
\hline $241 \mathrm{Am}, \quad(\mathrm{Ci})$ & $6.07 \mathrm{E}-0 \mathrm{l}$ & $2.33 \mathrm{E}+02$ & $8.119 E+00$ & $4.58 \mathrm{E}+00$ & & & & & $1.73 \mathrm{E}+00$ & $1.15 E \cdot 03$ \\
\hline Volune, (L) & $3.68 \mathrm{E}+06$ & $3.95 \mathrm{E}+106$ & $3.62 \mathrm{E}+06$ & $3.02 E+06$ & $4.29 \mathrm{E}+06$ & $4.47 E+06$ & $3.68 \mathrm{E}+06$ & $3.39 \mathrm{E}+06$ & $4.16 \mathrm{E}+06$ & $1.02 \mathrm{E}+105$ \\
\hline & & & & & & & & & & \\
\hline & $6.32 \mathrm{E}+00$ & & $1.46 \mathrm{E}+01$ & $1.20 \mathrm{E}+01$ & $1.20 \mathrm{E}+101$ & $1.05 E+01$ & $9.19 \mathrm{E}+00$ & $6.56 \mathrm{E}+00$ & $4.43 \mathrm{E}+00$ & $2.31 \mathrm{E}-01$ \\
\hline & $2.41 E+06$ & $2.18 \mathrm{E}+06$ & $1.65 E+106$ & $1.54 \mathrm{E}+06$ & $2.05 \bar{E}+06$ & $2.43 \mathrm{E}+06$ & $2.12 \mathrm{E}+06$ & $2.18 \mathrm{E}+06$ & $3.09 E+06$ & $1,00 t+10 t$ \\
\hline
\end{tabular}

C-1 
WHC-SD-WM-RPT-210, Rev. 0

\begin{tabular}{|c|c|c|c|c|c|c|c|c|c|c|}
\hline Supernatant: Source & $104-A P$ & $105-\mathrm{AP}$ & $106-A P$ & $107-A P$ & $10 B-A P$ & $101-\mathrm{AW}$ & $102-\mathrm{AW}$ & 103-AW & $104-\mathrm{AW}^{\prime}$ & $105-\mathrm{AW}$ \\
\hline Units & MT & MT & MT & MT & MT & MT & MT & MT & MT & MT \\
\hline Projection Date & $12 / 31 / 98$ & $12 / 31 / 98$ & $12 / 31 / 98$ & $12 / 31 / 98$ & $12 / 31 / 98$ & $12 / 31 / 98$ & not est. & $12 / 31 / 98$ & $12 / 31 / 98$ & $12 / 31 / 98$ \\
\hline Dexay Date & $12 / 31 / 107$ & $12 / 31 / 07$ & $12 / 31 / 07$ & $12 / 31 / 07$ & $12 / 31 / 07$ & $12 / 31 / 07$ & not est. & $12 / 31 / 07$ & $12 / 31 / 07$ & $12 / 31 / 07$ \\
\hline \multicolumn{11}{|l|}{ Component } \\
\hline $\mathrm{Al}(\mathrm{OH}) 4$ & $83 \mathrm{E}+02$ & $2.85 E+00$ & $2.75 E+02$ & $7.67 \mathrm{E}-03$ & $1.71 E+00$ & $3.87 \mathrm{E}+02$ & not est. & $2.59 \mathrm{E}-01$ & $7.06 \mathrm{E}+100$ & $4.83 E_{-}+01$ \\
\hline $\mathrm{Bu+2}$ & $4.30 \mathrm{E}-08$ & $1.36 \mathrm{E}-04$ & $1.27 \mathrm{E}-04$ & $3.10 \mathrm{E}-05$ & $1.62 \mathrm{E}-05$ & $0.00 \mathrm{E}+00$ & not est. & $3.03 \mathrm{E}-104$ & $9.25 \mathrm{E}-06$ & $2.59 E-05$ \\
\hline $\mathrm{C} a+2^{2}$ & $4.40 E-05$ & $5.06 \mathrm{E}-03$ & $4.6, \overline{6 E}-02$ & $2.14 \mathrm{E}-03$ & $6.73 E-05$ & $1.30 \mathrm{E}-01$ & not est. & $3.34 \mathrm{E}-03$ & $5.81 \mathrm{E}-1104$ & $9.40 E-03$ \\
\hline $\mathrm{Cu}+2$ & $1.72 \mathrm{E}-08$ & $5.37 \mathrm{E}-06$ & $0.00 \mathrm{E}+00$ & $0.00 \mathrm{E}+00$ & $5.89 \mathrm{E}-04$ & $0.00 E+00$ & not est. & $0.00 \mathrm{E}+100$ & $0.00 \mathrm{E}+100$ & $0.00 E+00$ \\
\hline $\mathrm{Cr}(\mathrm{OH}) 4-$ & $3.38 \mathrm{E}-04$ & $2.99 \mathrm{E}-03$ & $1.31 \mathrm{E}-01$ & $2.62 \mathrm{E}-03$ & $6.70 \mathrm{E}+00$ & $1.46 \mathrm{E}+00$ & not est. & $9.09 E-02$ & $3.96 \mathrm{E}-02$ & $2.6 \mathrm{IE}-(02$ \\
\hline $\mathrm{Fe}+3$ & $1.80 \mathrm{E}-103$ & $2.53 E-04$ & $1.82 \mathrm{E}-02$ & $2.25 \mathrm{E}-04$ & $7.11 \bar{E}-04$ & $0.00 \mathrm{E}+00$ & not est. & $6.86 \mathrm{E}-03$ & $2.52 E-04$ & $8.46 E-102$ \\
\hline $\mathrm{He}+2$ & $0.00 \mathrm{E}+100$ & $0.00 E+00$ & $0.00 \mathrm{E}+00$ & $0.00 \mathrm{E}+00$ & $0.00 E+00$ & $0.00 \mathrm{E}+00$ & not est. & $0.00 E+100$ & $0.00 \mathrm{E}+00$ & $0.00 \mathrm{E}+100$ \\
\hline $\mathrm{K}+$ & $3.68 \mathrm{E}-02$ & $1.02 \mathrm{E}-01$ & $1.57 \mathrm{E}+01$ & $3.17 \mathrm{E}-01$ & $1.02 \mathrm{E}-01$ & $1.65 \mathrm{E}+02$ & not est. & $1.10 \mathrm{E}+101$ & $2.75 \mathrm{E}-101$ & $3.14 \mathrm{E}+1) 0$ \\
\hline $\mathrm{La}+3$ & $0.00 E+00$ & $1.43 E-03$ & $0.0 \overline{0}+00$ & $0.00 \mathrm{E}+00$ & $0.00 E+00$ & $0.00 \mathrm{E}+00$ & not est. & $0.00 E+100$ & $0.00 \mathrm{E}+00$ & $0.00 E+00$ \\
\hline $\mathrm{Nat}$ & $5.67 \mathrm{E}+02$ & $1.54 E+01$ & $5.95 \mathrm{E}+02$ & $9.83 \mathrm{E}-01$ & $1.60 \mathrm{E}+02$ & $9.06 \mathrm{E}+02$ & not est. & $1.87 \mathrm{E}+01$ & $3.64 \mathrm{E}+101$ & $1.08 \mathrm{E}+112$ \\
\hline $\mathrm{Ni+3}$ & $1.72 \mathrm{E}-08$ & $1.49 \mathrm{E}-03$ & $0.00 \mathrm{E}+00$ & $4.60 \mathrm{E}-05$ & $4.06 \mathrm{E}-05$ & $0.00 \mathrm{E}+100$ & not est. & $1.60 \mathrm{E}-03$ & $2.59 \mathrm{E}-1) 4$ & $0.00 \mathrm{E}+1) 0$ \\
\hline $\mathrm{Pb}+4$ & $3.44 \mathrm{E}-07$ & $1.64 E-05$ & $0.0 \overline{0}+00$ & $4.38 \mathrm{E}-05$ & $.00 E+00$ & $1.19 E+00$ & not est. & 1).00E +00 & $1.33 \mathrm{E}-03$ & $0.00 E+100$ \\
\hline$\overline{\mathrm{Jg} / \mathrm{I}}$ & $1.44 \mathrm{E}-03$ & $5.87 \mathrm{E} \cdot 04$ & $2.40 \mathrm{E}-02$ & $1.74 E-04$ & $4.62 \mathrm{E}+00$ & $8.83 \mathrm{E}-01$ & not est. & $5.34 \mathrm{E}-03$ & $3.52 \mathrm{E}-06$ & $3.70 \overline{[\cdot 02}$ \\
\hline $0,03-2$ & $7.62 \mathrm{E}+01$ & $2.61 \mathrm{E}+00$ & $7.84 \mathrm{E}+01$ & $9.83 \mathrm{E}-02$ & $2.61 \mathrm{E}-01$ & $0.00 E+00$ & not est. & 0. $.00 \mathrm{E}+00$ & $2.19 \mathrm{E}+100$ & $1.38 \mathrm{E}+111$ \\
\hline$C L-$ & $2.97 E+01$ & $1.77 \overline{\mathrm{E}}-02$ & $2.89 \overline{\mathrm{E}}+0 \mathrm{1}$ & $6.90 \mathrm{E}-03$ & $5.89 \mathrm{E}-03$ & $2.04 \mathrm{E}+01$ & not est. & $2.4 \mathrm{lE}-01$ & $4.87 \mathrm{E}-01$ & $5.14 E+100$ \\
\hline$F-$ & $2.11 \mathrm{E}+01$ & $1.20 \mathrm{E}-01$ & $3.34 E+01$ & $4.23 \mathrm{E}-01$ & $3.05 E+00$ & $0.00 E+00$ & not est. & $1.45 E+101$ & $1.77 \mathrm{E} \cdot 01$ & $6.21 \mathrm{E}+110$ \\
\hline $504-2$ & $1.53 \mathrm{E}+01$ & $5.66 \mathrm{E}-01$ & $1.62 \mathrm{E}+01$ & $9.15 E-03$ & $5.19 E+01$ & $4.06 \mathrm{E}+00$ & not est. & $0.00 E+00$ & 4.231 & $3.24 \mathrm{E}+100$ \\
\hline NO3- & $4.43 \mathrm{E}+02$ & $1.21 \mathrm{E}+0 \mathrm{l}$ & $4.64 \mathrm{E}+02$ & $2.89 \mathrm{E}-01$ & $7.18 E+01$ & $8.43 E+02$ & not est. & $4.54 \mathrm{E}+900$ & $1.26 \mathrm{E}+111$ & $1.14 \mathrm{E}+1) 2$ \\
\hline $\mathrm{NO} 2$ & $2.19 E+02$ & $4.73 E+00$ & $2.16 \mathrm{E}+02$ & $1.34 \mathrm{E}-01$ & $8.29 E+01$ & $4.02 E+02$ & not est. & $7.22 \mathrm{E}-01$ & $5.86 \mathrm{E}+1010$ & $3.89 \mathrm{E}+1) 1$ \\
\hline$P(4)-3$ & $1.12 \mathrm{E}+01$ & $2.96 \bar{E}-01$ & $1.15 \bar{E}+01$ & $7.33 \mathrm{E}-04$ & $2.13 \bar{E}-02$ & $8.31 E+00$ & not est. & $2.55 \mathrm{E}-02$ & $3.41 \mathrm{E}-01$ & $2.40 \mathrm{E}+100$ \\
\hline $0 \mathrm{OH}$ & $1.36 \mathrm{E}+02$ & $6.97 \mathrm{E}-01$ & $1.45 \mathrm{E}+02$ & $2.97 \mathrm{E}-01$ & $5.79 E+01$ & $3.40 \mathrm{E}+02$ & not est. & $4.08 \mathrm{E}+100$ & 3.77 & $2.67 \mathrm{t}+117$ \\
\hline ToC & $1.18 \mathrm{E}+01$ & $2.11 \mathrm{E}+00$ & $1.38 \mathrm{E}+01$ & $2.33 \mathrm{E}-02$ & $5.07 \mathrm{E}-02$ & $9.69 \mathrm{E}+00$ & not est & $7.26 \mathrm{E}-191$ & $3.66 \mathrm{E}-101$ & $2.83 \mathrm{E}+1) 0$ \\
\hline (Ci) & $1.07 \mathrm{E}-07$ & $6.60 \mathrm{E}-04$ & $1.24 E-07$ & $1.05 \mathrm{E}-05$ & $9.28 \mathrm{E}-06$ & $1.45 \mathrm{E}+00$ & not est. & $0.00 E+00$ & $2.54 \mathrm{E}-02$ & $2.17 \mathrm{E} \cdot 08$ \\
\hline $9115 r, \quad(\mathrm{Ci})$ & $9.14 \mathrm{E} \cdots 0.3$ & $4.32 \mathrm{E}+02$ & $9.65 \mathrm{E}-04$ & $2.37 \mathrm{E}-04$ & $5.58 \mathrm{E}+02$ & $2.22 \mathrm{E}+03$ & not est. & $0.00 E+00$ & $3.97 \mathrm{E}+101$ & $1.62 E \quad 04$ \\
\hline 901). (Ci) & $9.14 \mathrm{E}-103$ & $4.32 \mathrm{E}+02$ & $9.65 \mathrm{E}-04$ & $2.37 \mathrm{E}-04$ & $5.58 \mathrm{E}+02$ & $2.22 \mathrm{E}+03$ & not est. & $0.00 \mathrm{E}+00$ & $3.97 \mathrm{E}+01$ & $1.62 \mathrm{E}-104$ \\
\hline $99[\mathrm{c}, \quad(\mathrm{Ci})$ & $8.40 \bar{E}-01$ & $3.37 \mathrm{E}+00$ & $8.86 \mathrm{E}-05$ & $6.78 E-05$ & $4.77 E+02$ & $5.94 \mathrm{E}+02$ & not est. & $0.00 E+(100$ & $7.74 E+100$ & $1.55 E-105$ \\
\hline 137Cs, (Ci) & $7 E+01$ & $1.33 \mathrm{E}+03$ & $1.44 \mathrm{E}-01$ & $1.03 E-103$ & $2 E+05$ & $6 E+106$ & not $e$ & $2.57 \mathrm{E}+04$ & & $1.26 \varepsilon+103$ \\
\hline $137 \mathrm{Ba}$ & $20 E+101$ & $1.26 \mathrm{E}+03$ & $1.37 \mathrm{E}-01$ & $9.77 \mathrm{E}-04$ & $3.25 \mathrm{E}+05$ & $1.00 \mathrm{E}+06$ & not est & $2.44 \mathrm{E}+04$ & $7.54 \mathrm{E}+103$ & $1.20 E+103$ \\
\hline 15AEU. & $00 \mathrm{E}+(010$ & $(1.00 \mathrm{E}+00)$ & $6.73 \mathrm{E}-06$ & $3.84 \mathrm{E}-04$ & $5.05 \mathrm{E}-03$ & $0.00 \mathrm{E}+00$ & not est & $0.00 E+00$ & $1.38 E+00$ & $1.18 \mathrm{E}-06$ \\
\hline $23519,(\mathrm{Ci})$ & $0.00 E+100$ & $0.00 \mathrm{E}+00$ & $0.00 \mathrm{E}+00$ & $0.00 E+00$ & $0.00 \mathrm{E}+00$ & $0.00 \mathrm{E}+00$ & not est. & $0.00 \mathrm{E}+00$ & $0.00 \mathrm{E}+00$ & $0.00 E+100$ \\
\hline $23801 . \quad$ (ci) & $0.00 \mathrm{E}+00$ & $0.00 E+00$ & $0.0 \bar{E}+0 \overline{0}$ & $0.00 E+00$ & $0.00 \mathrm{E}+00$ & $0.00 \mathrm{E}+100$ & not est. & $0.00 E+00$ & $0.00 E+00$ & $0.00 E+100$ \\
\hline $23 / \mathrm{Np}, \quad$ (Ci) & $2.27 \mathrm{E}-0.3$ & $0.00 E+00$ & $1.3 \overline{7 E}-\overline{07}$ & $0.00 E+00$ & $3.57 \mathrm{E}-05$ & $0.00 \mathrm{E}+100$ & not est. & $0.00 \mathrm{E}+00$ & 0.0 & $6.60 \mathrm{E}-04$ \\
\hline $238 \mathrm{Pu}, \quad(\mathrm{Ci})$ & $0.00 E+00$ & $0.00 \mathrm{E}+00$ & $0.00 \mathrm{E}+00$ & $1.80 \mathrm{E}-06$ & $3.27 \mathrm{E}-02$ & $0.00 \mathrm{E}+00$ & not est. & $6.26 E+01$ & $0.00 E+00$ & $6.05 \mathrm{E}-101$ \\
\hline $239 \mathrm{Pu}$ & $89 \mathrm{E}-03$ & $1.82 \mathrm{E}-01$ & $1.62 \mathrm{E}-05$ & $1.76 \mathrm{E}-03$ & $2.15 \mathrm{E}-0.5$ & $6.05 E+20$ & not est. & $0.00 \mathrm{E}+00$ & $3.90 \mathrm{E}-02$ & $2.85 \bar{E}-106$ \\
\hline $240 f^{\prime} 11$. & $6.80 \mathrm{E}-04$ & $4.55 E-02$ & $8.52 \mathrm{E}-08$ & $2.71 \mathrm{E}-04$ & $3.30 \mathrm{E}-06$ & $9.29 \mathrm{E}-01$ & inot. est & $0.00 \mathrm{E}+00$ & $5.60 \mathrm{E}-03$ & $1.49 \mathrm{E}-08$ \\
\hline $241 \mathrm{Pu} .(\mathrm{CH})$ & $6 . \overline{60 E}-03$ & $1.62 \mathrm{E}-02$ & $5.66 \mathrm{E}-07$ & $4.04 \mathrm{E}-04$ & $5.44 \mathrm{E}-07$ & $1.20 \mathrm{E}+00$ & not est. & $0.00 \mathrm{E}+(10)$ & $8.82 \mathrm{E}-03$ & $9.17 \mathrm{E} \cdot 108$ \\
\hline 24/Am. (Ci) & $6.35 \mathrm{E}-06$ & $1.01 \mathrm{E}+00$ & $4.86 \mathrm{E}-05$ & $2.09 \mathrm{E}-03$ & $4.81 \mathrm{E}-06$ & $6.36 \mathrm{E}+00$ & not est. & $0.00 \mathrm{E}+00$ & $8.90 \mathrm{E}-02$ & $8.52 \mathrm{E}-06$ \\
\hline Volume. (L) & $4.23 \mathrm{E}+06$ & $7.56 \mathrm{E}+04$ & $3.133 \mathrm{E}+06$ & $1.17 \mathrm{E}+105$ & $3.10 E+06$ & $3.94 E+06$ & not est. & $5.41 E+05$ & $5.68 \mathrm{E}+05$ & $4.31 \mathrm{E}+116$ \\
\hline & & & & & & & & & & \\
\hline Na Molarity & $5.83 \mathrm{E}+00$ & $8.87 E+00$ & $8.65 \mathrm{E}+00$ & $3.65 \mathrm{E}-01$ & $2.25 \mathrm{E}+00$ & $1.00 E+01$ & not est & $1.50 \mathrm{E}+100$ & $1.26 \mathrm{E}+00$ & $1.09 \mathrm{E}+100$ \\
\hline H2O Estimate & $2.86 E+16$ & $4.76 E+04$ & $1.74 \mathrm{E}+06$ & $1.15 E_{-}+05$ & $2.75 E+06$ & $1.95 \mathrm{E}+06$ & not est & $4.90 \mathrm{E}+1) 5$ & $5.21 \mathrm{E}+125$ & $3.95 E+106$ \\
\hline
\end{tabular}


WHC-SD-WM-RPT-210, Rev. 0

\begin{tabular}{|c|c|c|c|c|c|c|c|c|c|c|}
\hline Supernatant Source & $106-\mathrm{AW}$ & $10 \mathrm{I}-\mathrm{AY}$ & $102-A Y$ & $101-A Z$ & $102-A Z$ & $101-S Y$ & 10ISY-TOT & $102 S Y$ & $103 S Y$ & $103 \mathrm{SY}-\mathrm{T} 0 \mathrm{~T}$ \\
\hline Units & MT & MT & MT & MT & MT & MT & $M T$ & MT & MT & MT \\
\hline Projection Date & not est. & FY 2002 & FY 2002 & FY 2002 & FY 2002 & $12 / 31 / 98$ & $12 / 31 / 98$ & $12 / 31 / 98$ & $12 / 31 / 98$ & $12 / 31 / 98$ \\
\hline Decay Date & not est. & $12 / 31 / 07$ & $12 / 31 / 07$ & $12 / 31 / 07$ & $12 / 31 / 07$ & $12 / 31 / 07$ & $12 / 31 / 07$ & $12 / 31 / 07$ & $12 / 31 / 07$ & $12 / 31 / 07$ \\
\hline \multicolumn{11}{|l|}{ Component } \\
\hline $\mathrm{Al}(\mathrm{OH}) 4-$ & not est. & $1.7 \mathrm{lE}+01$ & $5.71 E+101$ & $1.06 \mathrm{E}+02$ & $5.39 \mathrm{E}+01$ & $1.02 E+01$ & $6.52 \mathrm{E}+02$ & $9.38 \mathrm{E}+00$ & $6.11 \mathrm{E}+01$ & $4.98 \mathrm{E}+132$ \\
\hline $\mathrm{Ba}+2$ & not est. & $3.33 \bar{E}-05$ & $8.89 \mathrm{E}-03$ & $2.19 \mathrm{E}-04$ & $1.40 \bar{E}-03$ & $0.100 \mathrm{E}+00$ & $0.00 \mathrm{E}+00$ & $0.00 \mathrm{E}+00$ & $2.27 \mathrm{E}-03$ & $2.93[-102$ \\
\hline $\mathrm{Ca}+?$ & not est. & $3.65 \mathrm{E} \cdot 04$ & $3.25 E-01$ & $7.53 \mathrm{E}-03$ & $4.89 \mathrm{E}-02$ & $5.11 \mathrm{E}-02$ & $3.68 \mathrm{E}+00$ & $9.36 \mathrm{E}-07$ & $4.38 \mathrm{E}-02$ & $5.65 \mathrm{E}-10 \mathrm{l}$ \\
\hline$C d+2$ & not est. & $0.00 \mathrm{E}+100$ & $5.18 E-02$ & $4.61 \mathrm{E}-04$ & $7.66 \mathrm{E}-03$ & $0.00 E+00$ & $0.00 \mathrm{E}+001)$ & $0.00 \mathrm{E}+00$ & $0.00 E+010$ & $0.00 \mathrm{E}+100$ \\
\hline $\mathrm{Cr}(\mathrm{OH}) 4-$ & not est. & $2.91 \overline{1 E}-101$ & $1.76 \mathrm{E}+100$ & $9.92 \mathrm{E}+00$ & $1.05 \mathrm{E}+00$ & $1.28 \mathrm{E}-02$ & $2.72 \mathrm{E}+00$ & $7.19 \mathrm{E}-06$ & $2.19 \mathrm{E}+100$ & $3.56 \mathrm{E}+1) 1$ \\
\hline $\mathrm{Fe}+3$ & not est. & $3.23 \mathrm{E}-04$ & $3.54 \overline{4 E}-01$ & $9.15 \bar{E}-04$ & $5.31 \mathrm{E}-02$ & $1.34 E-03$ & $1.43 \mathrm{E}-0 \mathrm{i}$ & $6.03 \mathrm{E} \cdot 05$ & $2.96 \mathrm{E}-0 \mathrm{l}$ & $4.03 \mathrm{E}+100$ \\
\hline $\mathrm{Hg}+?$ & not est. & $0.00 \mathrm{E}+00$ & $2.14 E-03$ & $0.00 \mathrm{E}+00$ & $3.17 \mathrm{E}-04$ & $0.00 \mathrm{E}+00$ & $0.00 \mathrm{E}+00$ & $0.00 \mathrm{E}+01 \mathrm{i}$ & $0.00 \mathrm{E}+100$ & $0.00 \mathrm{E}+1) 0$ \\
\hline $\mathrm{K}+$ & not est. & $3.28 \mathrm{E}-01$ & $0.00 E+00$ & $1.29 \mathrm{E}+01$ & $8.38 \mathrm{E}-0 \mathrm{l}$ & $3.37 E-01$ & $1.90 \mathrm{E}+01$ & $7.83 \mathrm{E}-04$ & $7.56 \mathrm{E}-01$ & $1.07 \mathrm{~F}+1) 1$ \\
\hline $\mathrm{Ia}+3$ & not est. & $6.41 E-155$ & $5.4 \overline{2 E}-02$ & $2.20 \mathrm{E}-03$ & $8.17 \mathrm{E}-03$ & $0.00 \mathrm{DE}+00$ & $0.00 \mathrm{E}+0 i)$ & $0.00 \mathrm{E}+00$ & $6.89[-13.3$ & $0.00 \mathrm{E}+100$ \\
\hline $\mathrm{Na}+$ & not est. & $4.99 \mathrm{E}+01$ & $2.86 \mathrm{E}+02$ & $4.31 \mathrm{I}+02$ & $1.79 \mathrm{E}+02$ & $1.83 \mathrm{E}+01$ & $1.19 \mathrm{E}+03$ & $1.88 \mathrm{E}+01$ & $1.91 \mathrm{E}+02$ & $8.70 \mathrm{E}+1) 2$ \\
\hline $\mathrm{Ni}+3$ & not est. & $4.89 \vec{E}-05$ & $0.00 \mathrm{E}+00$ & $2.28 \mathrm{E}-03$ & $1.25 \mathrm{E}-104$ & $3.54 \mathrm{E}-03$ & $1.70 \mathrm{E}-01$ & $0.00 \mathrm{E}+00$ & $2.82 \mathrm{E}-102$ & $3.84 \mathrm{E}-101$ \\
\hline$p b+4$ & not est. & $2.20 \mathrm{E} \cdot 04$ & $7.01 E-02$ & $0.00 \mathrm{E}+00$ & $1.09 E-02$ & $0.00 \mathrm{E}+00$ & (1).00E+0ii) & $0.00 \mathrm{E}+00$ & $0.00 \mathrm{E}+00$ & $0.00 E+100$ \\
\hline $\mathrm{Ug} / \mathrm{l}$ & not est. & $8.42 \mathrm{E}-02$ & $1.29 \mathrm{E}-02$ & $3.62 \mathrm{E}+00$ & $2.17 \mathrm{E}-0 \mathrm{l}$ & $0.00 \mathrm{E}+00$ & $0.00 \mathrm{E}+0 \mathrm{i}$ & $4.82 E \cdot 05$ & $0.00 \mathrm{E}+00$ & $0.00 E+100$ \\
\hline$c 03-2$ & not est. & $1.09 \mathrm{E}+00$ & $4.27 \mathrm{E}+00$ & $9.28 \mathrm{E}+01$ & $3.42 \mathrm{E}+00$ & $0.00 \mathrm{E}+00$ & $0.00 \mathrm{E}+00$ & $2.53 \mathrm{E}+100$ & $2.55 \mathrm{E}+0 \mathrm{l}$ & $6.97 E+1) 1$ \\
\hline $\mathrm{CL}$ - & not est. & $7.34 \mathrm{E}-102$ & $1.02 \mathrm{E}-01$ & $5.74 \mathrm{E}-01$ & $2.03 E-01$ & $9.40 \mathrm{E}-01$ & $4.82 \mathrm{E}+01$ & $9.86 \mathrm{E}-01$ & $1.61 \mathrm{E}+00$ & $2.28 E+1) 1$ \\
\hline F & not est. & $3.45 E-01$ & $3.71 \mathrm{E}-01$ & $7.44 \mathrm{E}+100$ & $9.36 \mathrm{E}-101$ & $0.00 \mathrm{E}+00$ & $6.95 \mathrm{E}-0 \mathrm{l}$ & $7.00 \mathrm{E}-01$ & $1.32 \mathrm{E}+00$ & $4.83 \mathrm{E}+100$ \\
\hline $504-2$ & not est. & $2.73 E+00$ & $3.16 \mathrm{E}+00$ & $8.98 \mathrm{E}+11$ & $7.44 \mathrm{E}+00$ & $9.33 \mathrm{E}-02$ & $2.54 E+01$ & $5.08 \mathrm{E}-01$ & $4.78 \mathrm{E}+00$ & $1.15 E+01$ \\
\hline$\overline{\mathrm{NO} 3}$ & not est. & $\overline{6} . \overline{88 \bar{E}}+00$ & $8.37 \mathrm{E}+00$ & $2.69 \mathrm{E}+02$ & $1.81 \mathrm{E}+01$ & $1.55 \mathrm{E}+(1) \mathrm{l}$ & $2.65 \mathrm{E}+02$ & $1.47 \mathrm{E}+101$ & $1.45 \mathrm{E}+122$ & $6.54 \mathrm{E}+102$ \\
\hline N02 & not est. & $5.6 \mathrm{JE}+00$ & $1.39 \mathrm{E}+00$ & $2.46 \mathrm{E}+02$ & $1.45 E+1) 1$ & $1.34 \mathrm{E}+01$ & $2.28 \mathrm{E}+02$ & $7.27 \mathrm{E}+100$ & $4.10 \mathrm{E}+101$ & 1). $00 \mathrm{E}+1) 0$ \\
\hline$P(0)-\overline{3}$ & not est. & $1.03 \bar{E}+100$ & $3.97 \mathrm{E}+101$ & $4.24 \mathrm{E}+00$ & $8.72 E+00$ & $5.40 \mathrm{E}-0 \mathrm{l}$ & $4.0 \mathrm{lE}+01$ & $3.71 \mathrm{E}-01$ & $3.69 \mathrm{E}+100$ & $1.57 \mathrm{E}+101$ \\
\hline $\mathrm{OH}$ & not est. & $2.85 \mathrm{E}+0 \mathrm{i}$ & $1.66 \mathrm{E}+02$ & $4.11 E+01$ & $1.04 \mathrm{E}+02$ & $2.81 \mathrm{E}+010$ & $7.26 \mathrm{E}+02$ & $4.51 \mathrm{E}+100$ & $8.85 E+100$ & $3.72 E+1) 2$ \\
\hline TOC & not est. & $7.44 \mathrm{E}-02$ & $4.88 \mathrm{E}+100$ & $3.67 E+00$ & $9.11 \vec{E}-01$ & $9.33 \mathrm{E}-01 \mathrm{l}$ & $9.44 \mathrm{E}+0]$ & $3.91 \mathrm{E}-01$ & $2.11 \mathrm{E}+01$ & $3.31 E+101$ \\
\hline $14 \mathrm{C} . \quad(\mathrm{C} \dagger)$ & not est. & $2.86 \mathrm{E}+100$ & $0.00 \mathrm{E}+00$ & $0.00 E+00$ & $7.3 \overline{1 E}+00$ & $0.00 \overline{\mathrm{E}}+00$ & $0.00 \mathrm{E}+0,0$ & $0.00 E+00$ & $0.00 E+00$ & $0.00[+00$ \\
\hline 9usr. (Ci) & not est. & $4.83 \mathrm{E}+04$ & $4.10 \mathrm{E}+03$ & $6.52 \mathrm{E}+03$ & $1.45 \mathrm{E}+05$ & $1.28 \mathrm{E}+02$ & $3.08 \mathrm{E}+04$ & $2.52 \mathrm{E} \cdot 04$ & $3.46 \mathrm{E}+03$ & $5.10 \mathrm{E}+04$ \\
\hline $90 Y . \quad(\mathrm{Ci})$ & not est. & $4.83 \mathrm{E}+104$ & $4.10 \mathrm{E}+03$ & $6.52 \mathrm{E}+03$ & $1.45 \mathrm{E}+05$ & $1.28 \mathrm{E}+122$ & $3.0 \mathrm{BE}+04$ & $2.52 E-04$ & $3.46 \mathrm{E}+03$ & $5.10 \mathrm{E}+104$ \\
\hline $99 \mathrm{TC}, \quad$ (Ci) & not est. & $1.38 \mathrm{E}+02$ & $6.69 \mathrm{E}+01$ & $1.02 \mathrm{E}+03$ & $8.80 \mathrm{E}+01$ & $1.52 \mathrm{E}+02$ & $2.57 E+03$ & $2.02 \mathrm{E}-02$ & $1.31 E+02$ & $1.88 \mathrm{E}+(03)$ \\
\hline $13 / \mathrm{Cs}, \quad(\mathrm{Ci})$ & not est. & $1.90 \mathrm{E}+05$ & $1.45 E+105$ & $5.58 \mathrm{E}+06$ & $3.93 \mathrm{E}+05$ & $1.94 E+04$ & $9.75 E+05$ & $1.50 E+00$ & $4.46 \mathrm{E}+04$ & $6.68 \mathrm{E}+05$ \\
\hline $137 \mathrm{Bd}, \quad(\mathrm{Ci})$ & not est. & $1.81 \overline{1 E}+05$ & $1.38 \bar{E}+05$ & $5.30 \mathrm{E}+106$ & $3.74 \mathrm{E}+05$ & $1.84 \mathrm{E}+104$ & $9.26 \vec{E}+05$ & $1.43 \mathrm{E}+00$ & $4.24 \mathrm{E}+04$ & $6.35 \mathrm{E}+105$ \\
\hline 154Eu. (Ci) & not est. & $0.00 \mathrm{E}+00$ & $0.00 \mathrm{OF}+00$ & $0.00 \mathrm{E}+00$ & $0.00 \mathrm{E}+100$ & $0.00 \mathrm{E}+00$ & $0.00 \mathrm{E}+00$ & $0.00 \mathrm{E}+00$ & $0.00 \mathrm{E}+00$ & $0.00 \mathrm{E}+00$ \\
\hline $235 \mathrm{II}, \quad(\mathrm{Ci})$ & not est. & $0.00 \mathrm{E}+130$ & $0.00 \mathrm{E}+00$ & $0.00 \mathrm{E}+00$ & $0.00 \mathrm{E}+100$ & $0.00 \mathrm{E}+00$ & $0.00 \mathrm{E}+00$ & $0.00 \mathrm{E}+00$ & $0.00 \mathrm{E}+00$ & $0.00 \mathrm{E}+100$ \\
\hline $2380, \quad$ (Ci) & not est. & $0.00 \mathrm{E}+00$ & $0.00 \mathrm{E}+00$ & $0.00 \mathrm{E}+100$ & $0.00 \mathrm{E}+100$ & $0.00 \mathrm{E}+00$ & $0.00 \mathrm{E}+00$ & $0.00 \mathrm{E}+100$ & $0.00 \mathrm{E}+00$ & $0.00 \mathrm{E}+00$ \\
\hline $23 / \mathrm{Np} . \quad(\mathrm{Ci})$ & not est. & $2.56 \mathrm{E} \cdot 0 \mathrm{l}$ & $0.00 \mathrm{E}+00$ & $0.00 \mathrm{E}+100$ & $6.54 \mathrm{E}-1) 1$ & $0.00 \mathrm{E}+00$ & $0.00 \mathrm{E}+00$ & $5.45 E-05$ & $0.00 \mathrm{E}+00$ & $0.00 \mathrm{E}+00$ \\
\hline $238 \mathrm{Pu} . \quad(\mathrm{Ci})$ & not est. & $0.00 E+00$ & $0.00 \mathrm{E}+00$ & $0.00 \mathrm{E}+00$ & $0.00 \mathrm{E}+00$ & $0.00 \mathrm{E}+00$ & $0.00 \mathrm{E}+100$ & $0.00 \mathrm{E}+100$ & $0.00 \mathrm{E}+00$ & $0.00 E+00$ \\
\hline $239 p^{2} u$ & not est. & $1.42 \mathrm{E}-01$ & $6.16 \mathrm{E}+01$ & $1.22 \mathrm{E}+100$ & $9.13 E+00$ & $9.43 \mathrm{E}-03$ & $8.81 E+00$ & $4.53 \mathrm{E}-05$ & $2.06 \mathrm{E}-0 \mathrm{1}$ & $1.14 \mathrm{E}+101$ \\
\hline 241$) P \mathrm{I}, \quad(\mathrm{Ci})$ & not est. & $3.90 \mathrm{E} \cdot 02$ & $0.00 \mathrm{E}+00$ & $3.38 E-01$ & $8.94 \mathrm{E}-03$ & $2.39 E-03$ & $2.39 E+00$ & $1.63 \mathrm{E}-05$ & $5.23 E-02$ & $3.11 \mathrm{f}+(00)$ \\
\hline $24 ! P_{1}$ & not est. & $8.93 \mathrm{E}-02$ & $0.00 E+00$ & $4.84 \mathrm{E}+00$ & $1.44 \mathrm{E}-01$ & $1.94 \mathrm{E}-103$ & $5.85 E+100$ & $2.08 E-04$ & $3.21 \mathrm{E}-02$ & $5.99 \mathrm{E}+00$ \\
\hline 24 lAn. (Ci) & not est. & $2.31 \mathrm{E}+102$ & $4.29 E-01$ & $5.39 E+01$ & $5.88 \mathrm{E}+02$ & $3.83 E-02$ & $8.03 \mathrm{E}+101$ & $2.11 E-07$ & $1.04 \mathrm{E}+00$ & $8.21 \mathrm{~F}+101$ \\
\hline Volunik'. (l) & not, est. & $1.52 \mathrm{E}+1) 6$ & $2.98 E+166$ & $2.95 \mathrm{E}+06$ & $2.67 \mathrm{E}+06$ & $6.81 \mathrm{E}+04$ & $7.37 E+06$ & $1.40 \mathrm{E}+05$ & $6.43 \mathrm{E}+055$ & $5.4(1)+(0) 6$ \\
\hline Na Molarity & not est. & $1.43 \mathrm{E}+00$ & $4.1 \overline{7}+00$ & $6.35 \bar{E}+00$ & $2.91 E+00$ & $1.17 \mathrm{E}+01$ & $7.00 \mathrm{E}+110$ & $5.83 \mathrm{E}+00$ & $1.29 \mathrm{E}+101$ & $7.00[+1) 0$ \\
\hline 1+20 Est.timate & not est. & $1.41 \mathrm{E}+1) 6$ & $2.52 \mathrm{E}+06$ & $1.98 \mathrm{E}+06$ & $2.33 \mathrm{E}+06$ & $2.97 \mathrm{E}+04$ & $5.00 \mathrm{E}+106$ & $9.48 \mathrm{E}+04$ & $3.46 \mathrm{E}+05$ & $3.52 \mathrm{E}+06$ \\
\hline
\end{tabular}


WHC-SD-WM-RPT-210, Rev. 0

This page intentionally left blank.

C-4 
WHC-SD-WM-RPT-210, Rev. 0

\section{APPENDIX D - ESTIMATED SST INVENTORY}

(Soluble Fraction Only, Retrieval Water Added per TWRS Process Flowsheet)

D-i 
WHC-SD-WM-RPT-210, Rev. 0

This page intentionally left blank.

D-ii 
WHC-SD-WM-RPT-210, Rev. 0

\begin{tabular}{|c|c|c|c|c|c|c|c|c|c|c|}
\hline Source & $101-\mathrm{A}$ & $102-A$ & $103-\mathrm{A}$ & 104-A & $105-A$ & $106-A$ & $101-A X$ & $102-A X$ & 103-AX & 104-AX \\
\hline Units & $\mathrm{kg}$ & $\mathrm{kg}$ & $\mathrm{kg}$ & $\mathrm{kg}$ & $\mathrm{kg}$ & $\mathrm{kg}$ & $\mathrm{kg}$ & $\mathrm{kg}$ & $\mathrm{kg}$ & $\mathrm{kg}$ \\
\hline \multicolumn{11}{|l|}{ Component } \\
\hline $\mathrm{AL}(\mathrm{OH}) 4$ & $8.97 E+04$ & $3.01 E+03$ & $2.81 E+04$ & $0.00 \mathrm{E}+00$ & $0.00 E+00$ & $2.97 \mathrm{E}+03$ & $6.47 \mathrm{E}+04$ & $2.67 \mathrm{E}+03$ & $6.06 \mathrm{E}+03$ & $0.00 \mathrm{E}+00$ \\
\hline $\mathrm{BA}+2$ & $0.00 \mathrm{E}+00$ & $0.00 \mathrm{E}+00$ & $0.00 \mathrm{E}+00$ & $0.00 \mathrm{E}+00$ & $0.00 \mathrm{E}+00$ & $0.00 \mathrm{E}+00$ & $0.00 \mathrm{E}+00$ & $0.00 \mathrm{E}+00$ & $0.00 \mathrm{E}+00$ & $0.00 \mathrm{E}+00$ \\
\hline $\mathrm{CA}+2$ & $1.27 \mathrm{E}+02$ & $4.52 \mathrm{E}+00$ & $6.09 \mathrm{E}+01$ & $2.69 \mathrm{E}-01$ & $1.84 \mathrm{E}-01$ & $1.05 E+01$ & $1.06 \mathrm{E}+02$ & $5.13 \mathrm{E}+00$ & $1.65 E+01$ & $6.78 \mathrm{E}-02$ \\
\hline $\mathrm{CD}+2$ & $0.00 \mathrm{E}+00$ & $0.00 \mathrm{E}+00$ & $0.00 \mathrm{E}+00$ & $0.00 \mathrm{E}+00$ & $0.00 \mathrm{E}+00$ & $0.00 \mathrm{E}+00$ & $0.00 \mathrm{E}+00$ & $0.00 \mathrm{E}+00$ & $0.00 \mathrm{E}+00$ & $0.00 \mathrm{E}+00$ \\
\hline $\mathrm{CR}(\mathrm{OH}) 4-$ & $4.87 \mathrm{E}+03$ & $1.75 E+02$ & $1.48 \mathrm{E}+03$ & $5.78 \mathrm{E}+00$ & $3.58 \mathrm{E}-01$ & $3.87 E+02$ & $3.55 E+03$ & $1.30 \mathrm{E}+02$ & $4.00 \mathrm{E}+02$ & $1.32 \mathrm{E}-01$ \\
\hline $\mathrm{FE}+3$ & $3.54 \mathrm{E}+02$ & $1.35 \mathrm{E}+01$ & $1.67 \mathrm{E}+02$ & $1.55 \mathrm{E}+01$ & $3.88 E+01$ & $4.95 \mathrm{E}+01$ & $3.09 \mathrm{E}+02$ & $2.94 \mathrm{E}+01$ & $7.34 \mathrm{E}+01$ & $1.43 E+01$ \\
\hline $\mathrm{HG}+2$ & $0.00 \mathrm{E}+00$ & $0.00 \mathrm{E}+00$ & $0.00 \mathrm{E}+00$ & $0.00 \mathrm{E}+00$ & $0.00 E+00$ & $0.00 \mathrm{E}+00$ & $0.00 \mathrm{E}+00$ & $0.00 \mathrm{E}+00$ & $0.00 \mathrm{E}+00$ & $0.00 \mathrm{E}+00$ \\
\hline $\mathrm{K}+$ & $2.87 \mathrm{E}+03$ & $1.03 \mathrm{E}+02$ & $9.37 \mathrm{E}+02$ & $0.00 \mathrm{E}+00$ & $0.00 \mathrm{E}+00$ & $2.26 \mathrm{E}+02$ & $2.13 \mathrm{E}+03$ & $8.04 \mathrm{E}+01$ & $2.53 \mathrm{E}+02$ & $0.00 E+00$ \\
\hline$L A+3$ & $0.00 \mathrm{E}+00$ & $0.00 \mathrm{E}+00$ & $0.00 \mathrm{E}+00$ & $0.00 \mathrm{E}+00$ & $0.00 E+00$ & $0.00 \mathrm{E}+00$ & $0.00 \mathrm{E}+00$ & $0.00 \mathrm{E}+00$ & $0.00 \mathrm{E}+00$ & $0.00 \mathrm{E}+00$ \\
\hline $\mathrm{NA}+$ & $1.68 \mathrm{E}+06$ & $6.17 \mathrm{E}+04$ & $6.38 \mathrm{E}+05$ & $1.77 \mathrm{E}+04$ & $3.13 E+04$ & 1.57E+05 & $1.31 E+06$ & $5.34 \mathrm{E}+04$ & $1.89 \mathrm{E}+05$ & 1.15E+04 \\
\hline $\mathrm{Nl}+3$ & $7.85 \mathrm{E}+01$ & $2.77 \mathrm{E}+00$ & $3.76 \mathrm{E}+01$ & $4.21 \mathrm{E}-01$ & $2.85 \mathrm{E}-01$ & $6.54 \mathrm{E}+00$ & $6.52 \mathrm{E}+01$ & $3.03 \mathrm{E}+00$ & $1.03 E+01$ & $1.05 \mathrm{E}-01$ \\
\hline $\mathrm{PB}+4$ & $2.73 \mathrm{E}+02$ & $9.81 E+00$ & $8.63 E+01$ & $0.00 \mathrm{E}+00$ & $0.00 \mathrm{E}+00$ & $2.14 \mathrm{E}+01$ & $2.01 \mathrm{E}+02$ & $7.48 E+00$ & $2.33 \mathrm{E}+01$ & $0.00 \mathrm{E}+00$ \\
\hline $\mathrm{CO}-2$ & $5.19 \mathrm{E}+04$ & $1.97 \bar{E}+03$ & $1.79 \mathrm{E}+04$ & $4.16 \mathrm{E}+02$ & $2.83 \mathrm{E}+02$ & $5.51 \mathrm{E}+03$ & $3.92 E+04$ & $2.05 E+03$ & $5.02 \mathrm{E}+03$ & $1.05 \mathrm{E}+02$ \\
\hline $\mathrm{CL}-$ & $1.76 \mathrm{E}+04$ & $6.56 \mathrm{E}+02$ & $6.42 \mathrm{E}+03$ & $7.03 \mathrm{E}+01$ & $5.99 E+00$ & $1.69 \mathrm{E}+03$ & 1.35E+04 & $5.51 \mathrm{E}+02$ & $1.73 E+03$ & $2.21 \mathrm{E}+00$ \\
\hline $\mathrm{F}-$ & $1.51 E+04$ & $5.41 \mathrm{E}+02$ & $4.85 \mathrm{E}+03$ & $0.00 \mathrm{E}+00$ & $0.00 E+00$ & $1.18 \mathrm{E}+03$ & $1.11 \mathrm{E}+04$ & $4.18 \mathrm{E}+02$ & $1.31 \mathrm{E}+03$ & $0.00 \mathrm{E}+00$ \\
\hline $\mathrm{SO} 4-2$ & $5.06 \mathrm{E}+04$ & $1.82 E+03$ & $2.44 \mathrm{E}+04$ & 1.17E+02 & $8.18 \mathrm{E}+03$ & $4.44 \mathrm{E}+03$ & $4.63 E+04$ & $1.95 E+03$ & $1.26 E+04$ & $3.02 E+03$ \\
\hline NO3- & $2.35 E+06$ & $8.40 E+04$ & $1.01 \mathrm{E}+06$ & $8.71 \mathrm{E}+03$ & $5.87 E+02$ & $1.93 \mathrm{E}+05$ & $1.88 E+06$ & $8.30 \mathrm{E}+04$ & $2.69 \mathrm{E}+05$ & $2.17 \mathrm{E}+02$ \\
\hline NO2- & $3.19 E+05$ & $1.15 E+04$ & $1.01 \mathrm{E}+05$ & $1.50 \mathrm{E}+00$ & $3.09 \mathrm{E}+00$ & $2.51 E+04$ & $2.34 E+05$ & $8.76 \mathrm{E}+03$ & $2.73 \mathrm{E}+04$ & 1.14E+00 \\
\hline PO4-3 & $4.77 \mathrm{E}+04$ & $1.71 \mathrm{E}+03$ & $1.50 E+04$ & $8.31 \mathrm{E}+01$ & $0.00 \mathrm{E}+00$ & $3.81 E+03$ & $3.50 \mathrm{E}+04$ & $1.32 \mathrm{E}+03$ & $4.05 \mathrm{E}+03$ & $0.00 \mathrm{E}+00$ \\
\hline $\mathrm{OH}$ & $4.47 \mathrm{E}+05$ & $1.91 E+04$ & $1.47 \mathrm{E}+05$ & 1.04E+04 & $2.24 \mathrm{E}+04$ & $6.77 \mathrm{E}+04$ & $3.44 E+05$ & $1.23 \mathrm{E}+04$ & $5.33 \mathrm{E}+04$ & $8.26 E+03$ \\
\hline TOC & $3.68 \mathrm{E}+04$ & $2.39 E+03$ & 1.16E+04 & $0.00 \mathrm{E}+00$ & $0.00 \mathrm{E}+00$ & $1.25 \mathrm{E}+04$ & $2.82 \mathrm{E}+04$ & $1.01 \mathrm{E}+03$ & $3.24 \mathrm{E}+03$ & $0.00 E+00$ \\
\hline Sr90 & $1.64 \mathrm{E}+06$ & $4.14 E+06$ & $1.12 \bar{E}+04$ & $2.16 \mathrm{E}+06$ & $1.64 E-02$ & $2.77 \mathrm{E}-03$ & $1.84 \mathrm{E}-06$ & $8.30 \mathrm{E}-11$ & 1.15E+04 & $5.35 \mathrm{E}+06$ \\
\hline Tc99 & $0.00 \mathrm{E}+00$ & $1.38 E+02$ & $4.13 \mathrm{E}+01$ & $3.78 \mathrm{E}-17$ & $6.22 \mathrm{E}+00$ & 1.27E-07 & $1.08 \mathrm{E}-08$ & $9.51 \mathrm{E}-16$ & $7.92 \mathrm{E}+00$ & $1.81 \mathrm{E}+01$ \\
\hline $\operatorname{Cs} 137$ & $0.00 \mathrm{E}+00$ & $8.16 E+04$ & $5.33 E+03$ & $3.89 \mathrm{E}-14$ & $9.75 \mathrm{E}+03$ & $7.54 E-05$ & $8.00 \mathrm{E}-07$ & $1.12 \mathrm{E}-12$ & $4.68 \mathrm{E}+03$ & $3.17 E+04$ \\
\hline TRU & $3.14 \mathrm{E}+03$ & $2.37 E+03$ & $7.10 \mathrm{E}+02$ & $1.11 \mathrm{E}+03$ & 4.52E-02 & $1.37 \mathrm{E}+03$ & $3.20 \mathrm{E}+02$ & $1.52 E+02$ & 1.27E+01 & $3.91 \mathrm{E}+02$ \\
\hline $\mathrm{H} 2 \mathrm{O}$ & 1.31E+07 & $4.82 E+05$ & $4.93 E+06$ & $1.55 \mathrm{E}+05$ & $2.76 \mathrm{E}+05$ & $1.23 E+06$ & $1.02 E+07$ & $4.13 \mathrm{E}+05$ & $1.48 \mathrm{E}+06$ & $1.02 E+05$ \\
\hline Volume (L) & $1.46 E+07$ & $5.36 E+05$ & $5.55 \mathrm{E}+06$ & $1.54 \mathrm{E}+05$ & $2.72 E+05$ & $1.37 \mathrm{E}+06$ & $1.14 \mathrm{E}+07$ & $4.65 \mathrm{E}+05$ & $1.64 \mathrm{E}+06$ & $1.00 \mathrm{E}+05$ \\
\hline
\end{tabular}

D-1 
WHC-SD-WM-RPT-210, Rev. 0

\begin{tabular}{|c|c|c|c|c|c|c|c|c|c|c|}
\hline Source & 101-B & 102-B & 103-B & 104-B & 105-B & 106-B & 107-B & 108-B & 109-B & 110-B \\
\hline Units & $\mathrm{kg}$ & $\mathrm{kg}$ & $\mathrm{kg}$ & $\mathrm{kg}$ & $\mathrm{kg}$ & $\mathrm{kg}$ & & $\mathrm{kg}$ & $\mathrm{kg}$ & $\mathrm{kg}$ \\
\hline \multicolumn{11}{|l|}{ Component } \\
\hline $\mathrm{AL}(\mathrm{OH}) 4$ & $16 \mathrm{E}+02$ & $5 E+02$ & $0 E+00$ & $4.17 \mathrm{E}+03$ & $2.29 \mathrm{E}+02$ & $0.00 \mathrm{E}+00$ & $91 \mathrm{E}+03$ & $40 \mathrm{E}+03$ & $2.56 \mathrm{E}+03$ & $0.00 \mathrm{E}+00$ \\
\hline 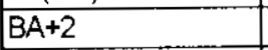 & & $E+00$ & $0 \mathrm{E}+00$ & $0.00 \mathrm{E}+00$ & $0.00 \mathrm{E}+00$ & $0.00 \mathrm{E}+00$ & $0.00 \mathrm{E}+00$ & & & $00 \mathrm{E}+00$ \\
\hline$A+2$ & +01 & $E+\infty$ & $30 E+01$ & $2.61 \mathrm{E}+01$ & $1.14 \mathrm{E}+02$ & $4.76 \mathrm{E}+01$ & $5.81 \mathrm{E}-01$ & $2.47 E+01$ & $3.46 \mathrm{E}+01$ & $49 \mathrm{E}+00$ \\
\hline+2 & +00 & +00 & $O E+00$ & $0.00 \mathrm{E}+00$ & $0.00 \mathrm{E}+\infty 0$ & $0.00 \mathrm{E}+00$ & $0.00 \mathrm{E}+00$ & $0.00 \mathrm{E}+00$ & $0.00 \mathrm{E}+00$ & $0.00 \mathrm{E}+00$ \\
\hline र(OH)4- & +02 & +01 & $12 \mathrm{E}+02$ & $65 E+02$ & $5.64 \mathrm{E}+02$ & $2.32 E+02$ & $3.21 \mathrm{E}+01$ & $1.27 \mathrm{E}+02$ & $1.71 \mathrm{E}+02$ & $4.73 E+01$ \\
\hline $\mathrm{FE}+3$ & +02 & $E+01$ & $31 \mathrm{E}+01$ & $6 \mathrm{E}+02$ & $3.22 \mathrm{E}+02$ & $1.30 \mathrm{E}+02$ & $0 E+01$ & $7.58 \mathrm{E}+01$ & $1.03 E+02$ & $18 \mathrm{E}+02$ \\
\hline $\mathrm{HG}+2$ & +00 & $+\infty$ & DOE+00 & $O E+00$ & $0.00 E+00$ & $0.00 \mathrm{E}+00$ & $E+00$ & $0.00 E+00$ & $0.00 \mathrm{E}+00$ & $00 E+00$ \\
\hline $\mathrm{K}+$ & $\mathrm{DE}+00$ & $E+\infty$ & $\overline{D O E}+00$ & $E+00$ & $0.00 \mathrm{E}+00$ & $0.00 \mathrm{E}+00$ & $E+00$ & $0.00 \mathrm{E}+00$ & $0.00 \mathrm{E}+00$ & $0.00 E+00$ \\
\hline $\mathrm{LA}+3$ & & $+\infty$ & $0.00 \mathrm{E}+00$ & $0.00 \mathrm{E}+00$ & $0.00 \mathrm{E}+00$ & $0.00 \mathrm{E}+00$ & $0.00 \mathrm{E}+00$ & $0.00 \mathrm{E}+00$ & $0.00 E+00$ & $0.00 \mathrm{E}+00$ \\
\hline $\mathrm{NA}+$ & +05 & +04 & $9.61 \mathrm{E}+04$ & $2.80 E+05$ & $4.87 \mathrm{E}+05$ & $1.94 \mathrm{E}+05$ & $1.37 \mathrm{E}+05$ & $1.28 \mathrm{E}+05$ & $1.43 \mathrm{E}+05$ & $08 \mathrm{E}+05$ \\
\hline $\mathrm{NI+3}$ & +01 & & $42 \mathrm{E}+01$ & $1.69 \mathrm{E}+01$ & $7.07 E+01$ & $2.93 \mathrm{E}+01$ & $7.57 \mathrm{E}-01$ & $1.53 \mathrm{E}+01$ & $2.15 \mathrm{E}+01$ & $2.17 \mathrm{E}+00$ \\
\hline \multirow[t]{2}{*}{$\mathrm{PB}+4$} & $2 E-04$ & $0.00 \mathrm{E}+00$ & $0.00 \mathrm{E}+00$ & $0.00 \mathrm{E}+00$ & $0.00 \mathrm{E}+00$ & $0.00 E+00$ & $0.00 E+00$ & $0.00 E+00$ & $0.00 \mathrm{E}+00$ & $0.00 E+00$ \\
\hline & & & & & & & & & & \\
\hline $\mathrm{CO}-2$ & +03 & & $2.09 \mathrm{E}+03$ & $5 E+03$ & 17E+03 & $3.73 E+03$ & $8.97 \mathrm{E}+02$ & $2.12 E+03$ & $2.95 \mathrm{E}+03$ & $30 \mathrm{E}+03$ \\
\hline $\mathrm{CL}-$ & +02 & +02 & $5.48 \mathrm{E}+02$ & $6 \mathrm{E}+03$ & $2.80 \mathrm{E}+03$ & $1.13 E+03$ & $1.88 \mathrm{E}+03$ & $6.47 \mathrm{E}+02$ & $8.41 E+02$ & $8.61 \mathrm{E}+02$ \\
\hline $\mathrm{F}$ & $9 E+03$ & +03 & $4.92 \mathrm{E}+03$ & $4 \mathrm{E}+04$ & $2.58 \mathrm{E}+04$ & $1.02 E+04$ & $6.84 \mathrm{E}+03$ & $6.68 \mathrm{E}+03$ & $7.38 \mathrm{E}+03$ & $1.23 E+04$ \\
\hline$\overline{\mathrm{SO} 4-2}$ & $6 \mathrm{E}+03$ & $2.45 E+03$ & $5.22 \mathrm{E}+03$ & $2 E+03$ & $2.43 E+04$ & $1.00 \mathrm{E}+04$ & $9.55 \mathrm{E}+02$ & $5.39 \mathrm{E}+03$ & $7.28 \mathrm{E}+03$ & $2.13 \mathrm{E}+03$ \\
\hline NO3- & +05 & & $8.96 \mathrm{E}+04$ & $1.72 \mathrm{E}+05$ & $4.53 \mathrm{E}+05$ & $1.85 E+05$ & $3.56 E+04$ & $1.03 E+05$ & $1.38 \mathrm{E}+05$ & $1.27 \mathrm{E}+05$ \\
\hline NO2- & $E+03$ & \begin{tabular}{|c|}
$9.72 E+02$ \\
\end{tabular} & $2.16 \mathrm{E}+03$ & $5.21 \mathrm{E}+03$ & $1.12 \mathrm{E}+04$ & $4.48 \mathrm{E}+03$ & $3.85 \mathrm{E}+03$ & $3.12 E+03$ & $3.82 E+03$ & $3.25 E-01$ \\
\hline $\mathrm{PO} 4-3$ & $4.70 E+04$ & $1.52 \mathrm{E}+04$ & \begin{tabular}{|l|}
$3.51 \mathrm{E}+04$ \\
\end{tabular} & $8.74 \mathrm{E}+04$ & $1.80 \mathrm{E}+05$ & $7.22 \mathrm{E}+04$ & $4.01 \mathrm{E}+04$ & $4.57 \mathrm{E}+04$ & $5.24 E+04$ & $4.85 \mathrm{E}+04$ \\
\hline $\mathrm{OH}-$ & $8 \mathrm{E}+04$ & $9.77 \mathrm{E}+03$ & $2.11 \mathrm{E}+04$ & $9.45 \mathrm{E}+04$ & $E+05$ & $4.07 \mathrm{E}+04$ & $5.98 \mathrm{E}+04$ & $3.33 \mathrm{E}+04$ & $2.93 \mathrm{E}+04$ & $7.99 E+04$ \\
\hline TOC & $6.54 E+02$ & $0.00 \mathrm{E}+00$ & $0.00 \mathrm{E}+00$ & $.00 E+\infty 0$ & $E+\infty$ & $0.00 \mathrm{E}+00$ & $0.00 \mathrm{E}+00$ & $0.00 E+00$ & $0.00 \mathrm{E}+00$ & $0.00 E+0 C$ \\
\hline Sr90 & E-26 & 1.89 & $5.66 \mathrm{E}+03$ & $4.66 \mathrm{E}+03$ & $7.00 \mathrm{E}+02$ & $9.19 \mathrm{E}+01$ & $1.38 \mathrm{E}+04$ & $2.47 \mathrm{E}+04$ & $3.21 \mathrm{E}+03$ & $3.60 \mathrm{E}+04$ \\
\hline Tc99 & E-28 & & $3.17 \mathrm{E}+00$ & $1.11 E+00$ & $8.76 \mathrm{E}+00$ & 4.13E-01 & $7.98 \mathrm{E}+00$ & $1.67 \mathrm{E}+01$ & $5.77 \mathrm{E}+00$ & $1.85 \mathrm{E}+02$ \\
\hline Cs137 & E-26 & +02 & $2.70 \mathrm{E}+03$ & $1.26 \mathrm{E}+03$ & $1.05 E+04$ & \begin{tabular}{|l|}
$4.76 \mathrm{E}+02$ \\
\end{tabular} & $1.23 \mathrm{E}+04$ & $8.62 E+03$ & & $1.73 \mathrm{E}+04$ \\
\hline \multirow[t]{2}{*}{ TRU } & $84 E+02$ & $6.51 \mathrm{E}+01$ & $2.32 \mathrm{E}+02$ & $9.63 \mathrm{E}+01$ & $9.69 E+00$ & $1.19 \mathrm{E}+00$ & $3.71 \mathrm{E}+01$ & $7.00 \mathrm{E}+00$ & $1.65 \mathrm{E}+00$ & $1.07 \mathrm{E}+0$ \\
\hline & & & & & & & & & & \\
\hline $\mathrm{H} 2 \mathrm{O}$ & $E+06$ & & $7.87 \mathrm{E}+05$ & $2.38 \mathrm{E}+06$ & $E+06$ & $59 \mathrm{E}+06$ & $1.19 \mathrm{E}+06$ & $1.06 \mathrm{E}+06$ & $16 E+06$ & $1.77 \mathrm{E}+0$ \\
\hline Volume (L) & $1.26 \mathrm{E}+06$ & & & & & & $1.19 E+06$ & $1.12 E+06$ & $1.24 \mathrm{E}+06$ & $1.80 \mathrm{E}+\mathrm{C}$ \\
\hline
\end{tabular}

\section{D-2}


WHC-SD-WM-RPT-210, Rev. 0

\begin{tabular}{|c|c|c|c|c|c|c|c|c|c|c|}
\hline Source & $111-\mathrm{B}$ & $112-B$ & $201-\mathrm{B}$ & $202-B$ & 203-B & 204-B & 101-BX & 102-BX & $103-B X$ & 104-BX \\
\hline Units & $\mathrm{kg}$ & $\mathrm{kg}$ & $\mathrm{kg}$ & $\mathrm{kg}$ & $\mathrm{kg}$ & $\mathrm{kg}$ & $\mathrm{kg}$ & $\mathrm{kg}$ & $\mathrm{kg}$ & $\mathrm{kg}$ \\
\hline \multicolumn{11}{|l|}{ Component } \\
\hline $\mathrm{AL}(\mathrm{OH}) 4-$ & $.00 E+00$ & $35 E+02$ & DOE+00 & $0.00 E+00$ & $0.00 \mathrm{E}+00$ & $0.00 E+00$ & $3.37 \mathrm{E}+02$ & $9.92 \mathrm{E}+02$ & $1.59 E+03$ & $0.00 E+00$ \\
\hline$B A+2$ & $E+\infty$ & $0 E+00$ & $0 \mathrm{E}+00$ & $00 \mathrm{E}+\infty$ & $0.00 \mathrm{E}+00$ & $00 \mathrm{E}+00$ & & $0.00 \mathrm{E}+00$ & $0.00 E+00$ & $0.00 \mathrm{E}+00$ \\
\hline$\overline{C A}+2$ & $E+00$ & $\overline{E E}+00$ & $7 \vec{E}-01$ & $2.64 E-01$ & \begin{tabular}{|l|}
$4.88 \mathrm{E}-01$ \\
\end{tabular} & $78 \mathrm{E}-01$ & $3.08 \mathrm{E}-01$ & 1.97E-01 & $3.07 \mathrm{E}-01$ & $1.57 \mathrm{E}-01$ \\
\hline $\mathrm{CD}+2$ & & $\mathrm{E}+\infty$ & $O O E+00$ & $0.00 \mathrm{E}+00$ & $0.00 \mathrm{E}+00$ & $0.00 \mathrm{E}+00$ & $0.00 \mathrm{E}+00$ & $0.00 \mathrm{E}+00$ & $0.00 \mathrm{E}+00$ & $0.00 \mathrm{E}+00$ \\
\hline $\mathrm{CR}(\mathrm{OF}$ & & $3 E+02$ & $6.18 \mathrm{E}+00$ & $5.97 \mathrm{E}+00$ & \begin{tabular}{|l|}
$1.10 \mathrm{E}+01$ \\
\end{tabular} & $1.08 \mathrm{E}+01$ & $3.52 \mathrm{E}+00$ & $5.16 \mathrm{E}+00$ & $8.03 E+00$ & $4.99 E+00$ \\
\hline $\mathrm{FE}+3$ & $=02$ & $39 \mathrm{E}+01$ & $1.40 \mathrm{E}+01$ & $1.36 \mathrm{E}+01$ & $2.51 \mathrm{E}+01$ & $2.46 \mathrm{E}+01$ & $1.76 \mathrm{E}+01$ & $9.10 \mathrm{E}+00$ & $43 E+01$ & $72 \mathrm{E}+00$ \\
\hline $\mathrm{HG}+2$ & & $0 E+00$ & $0.00 \mathrm{E}+00$ & $0.00 \mathrm{E}+00$ & $0.00 \mathrm{E}+00$ & $0.00 E+00$ & $0.00 \mathrm{E}+00$ & $0.00 \mathrm{E}+00$ & $0.00 E+00$ & $0.00 \mathrm{E}+00$ \\
\hline $\mathrm{K}+$ & & +01 & $39 \mathrm{E}+02$ & $2.31 E+02$ & $4.27 \mathrm{E}+02$ & $4.19 E+02$ & $0.00 E+00$ & $0.00 \mathrm{E}+00$ & $.00 E+00$ & $0.00 \mathrm{E}+00$ \\
\hline $\mathrm{LA}+\overline{3}$ & & +00 & $63 E+00$ & $1.58 \mathrm{E}+00$ & $2.92 \mathrm{E}+00$ & $2.86 \mathrm{E}+00$ & $0.00 \mathrm{E}+00$ & $0.00 \mathrm{E}+00$ & $0.00 E+00$ & $.00 \mathrm{E}+00$ \\
\hline $\mathrm{NA}+$ & & $46 E+04$ & $2.15 E+04$ & $2.08 E+04$ & $3.84 \mathrm{E}+04$ & $3.77 \mathrm{E}+04$ & $3.06 \mathrm{E}+04$ & $2.86 \mathrm{E}+04$ & $4.42 E+04$ & $23 E+04$ \\
\hline $\mathrm{NI}+3$ & $+\infty$ & $4.05 E+00$ & $4.21 \mathrm{E}-01$ & 4.07E-01 & $7.51 \mathrm{E}-01$ & 7.37E-01 & $1.26 \mathrm{E}+00$ & 2.82E-01 & 4.42E-01 & $2.13 \mathrm{E}-01$ \\
\hline \multirow[t]{2}{*}{$\mathrm{PB}+4$} & E-05 & $4.32 \mathrm{E}+00$ & $0.0 \bar{E}+00$ & $0.00 \mathrm{E}+00$ & $0.00 \mathrm{E}+00$ & $0.00 \mathrm{E}+00$ & $0.00 \mathrm{E}+00$ & $0.00 \mathrm{E}+00$ & $0.00 \mathrm{E}+00$ & $0.00 \mathrm{E}+00$ \\
\hline & & & & & & & & & & \\
\hline $\mathrm{CO} 3-2$ & $9 \mathrm{E}+03$ & $7.75 \mathrm{E}+02$ & $4.21 \mathrm{E}+02$ & $07 \mathrm{E}+02$ & $7.52 \mathrm{E}+02$ & $7.38 \mathrm{E}+02$ & $3.46 \mathrm{E}+03$ & $3.51 \mathrm{E}+03$ & $5.43 \mathrm{E}+03$ & $01 E+03$ \\
\hline $\mathrm{CL}-$ & +02 & $2.73 E+02$ & $1.12 \mathrm{E}+02$ & $09 E+02$ & \begin{tabular}{|l|}
$2.01 \mathrm{E}+02$ \\
\end{tabular} & $1.97 E+02$ & $1.13 E+02$ & $2.12 \mathrm{E}+01$ & $3.33 \mathrm{E}+01$ & $1.61 \mathrm{E}+01$ \\
\hline F- & $E+04$ & $9.29 \mathrm{E}+02$ & $8.71 \mathrm{E}+03$ & $42 E+03$ & $1.56 E+04$ & $1.53 E+04$ & $0.00 E+00$ & $0.00 \mathrm{E}+00$ & $0.00 \mathrm{E}+00$ & $0.00 \mathrm{E}+00$ \\
\hline $\mathrm{SO}_{-2}$ & & +03 & $1.29 \mathrm{E}+01$ & $25 E+01$ & $2.30 \mathrm{E}+01$ & $2.26 \mathrm{E}+01$ & $3.73 E+03$ & $4.31 \mathrm{E}+03$ & $6.66 E+03$ & $5.05 E+03$ \\
\hline NO3- & & +04 & $2.12 \mathrm{E}+04$ & $2.05 \mathrm{E}+04$ & $3.79 E+04$ & $3.72 E+04$ & $9.65 \mathrm{E}+03$ & $4.11 \mathrm{E}+03$ & $6.45 \mathrm{E}+03$ & $2.96 \mathrm{E}+03$ \\
\hline NO2- & & $E+03$ & \begin{tabular}{|l|}
$0.00 E+00$ \\
\end{tabular} & $0.00 \mathrm{E}+00$ & $0.00 \mathrm{E}+00$ & $0.00 \mathrm{E}+00$ & $2.12 \mathrm{E}+01$ & $2.19 \mathrm{E}+02$ & $E+02$ & $0.00 E+0 C$ \\
\hline PO4-3 & $6 \mathrm{E}+04$ & $3.62 \mathrm{E}+03$ & \begin{tabular}{|l}
$7.72 \mathrm{E}+02$ \\
\end{tabular} & $7.46 E+02$ & $1.38 \mathrm{E}+03$ & $1.35 \mathrm{E}+03$ & $2.41 \mathrm{E}+03$ & $2.88 \mathrm{E}+03$ & $4.45 E+03$ & $3.38 \mathrm{E}+0$ \\
\hline $\mathrm{OH}$ & $E+04$ & 7.38 & $3.03 E+03$ & $2.93 E+03$ & $5.41 \mathrm{E}+03$ & $5.31 \mathrm{E}+03$ & $1.82 \mathrm{E}+04$ & $169 \mathrm{E}+04$ & $2.61 \mathrm{E}+04$ & $1.98 \mathrm{E}+04$ \\
\hline TOC & & +02 & $7.64 \mathrm{E}+02$ & $7.39 \mathrm{E}+02$ & $1.36 \mathrm{E}+03$ & $1.34 E+03$ & $2.76 \mathrm{E}+02$ & $0.00 E+00$ & $0.00 \mathrm{E}+00$ & $0.00 \mathrm{E}+00$ \\
\hline Sr90 & $E-05$ & $7.77 \mathrm{E}+04$ & $0.00 \mathrm{E}+00$ & $0.00 \mathrm{E}+00$ & $0.00 E+00$ & $0.00 \mathrm{E}+00$ & $6.58 \mathrm{E}-16$ & $7.35 \mathrm{E}+04$ & $1.43 E+05$ & $1.08 E+04$ \\
\hline Tc99 & $E+03$ & $1.27 \mathrm{E}+02$ & $0.00 \mathrm{E}+00$ & $0.00 E+00$ & $0.00 \mathrm{E}+00$ & $0.00 \mathrm{E}+00$ & $3.76 \mathrm{E}-17$ & $3.97 E+02$ & & $2.05 \mathrm{E}+03$ \\
\hline Cs 137 & $54 E+05$ & $6.33 E+04$ & $0.0 \bar{E}+00$ & $0.00 \mathrm{E}+00$ & $0.00 \mathrm{E}+00$ & $0.00 \mathrm{E}+00$ & $232 \mathrm{E}-15$ & $7.13 E+04$ & $2.46 E-13$ & $1.70 E+05$ \\
\hline \multirow[t]{2}{*}{ TRU } & $4.90 E+01$ & $2.84 E+01$ & $0.00 E+00$ & $2.32 \mathrm{E}+02$ & $7.32 \mathrm{E}-01$ & $7.32 E+00$ & $6.09 \mathrm{E}+02$ & $4.73 E+02$ & $1.44 \mathrm{E}-03$ & $9.12 E+01$ \\
\hline & & & & & & & & & & \\
\hline $\mathrm{H} 2 \mathrm{O}$ & $E+06$ & $3.44 E+05$ & $1.77 \mathrm{E}+05$ & $1.71 \mathrm{E}+05$ & $3.16 \mathrm{E}+05$ & $3.10 \mathrm{E}+05$ & $2.61 \mathrm{E}+05$ & $2.47 \mathrm{E}+05$ & $3.82 E+05$ & $2.81 \mathrm{E}+0$ \\
\hline & $1.82 E+06$ & \begin{tabular}{|c|}
$3.88 E+05$ \\
\end{tabular} & $1.87 \mathrm{E}+05$ & $1.81 E+05$ & $3.34 \mathrm{E}+05$ & $3.28 E+05$ & $6.76 \mathrm{E}+05$ & $4.80 E+05$ & $7.33 E+05$ & $4.32 \mathrm{E}+\mathrm{C}$ \\
\hline
\end{tabular}

D-3 


\section{WHC-SD-WM-RPT-210, Rev. 0}

\begin{tabular}{|c|c|c|c|c|c|c|c|c|c|c|}
\hline Source & $105-\mathrm{BX}$ & 106-BX & $107-B X$ & 108-BX & $109-\mathrm{BX}$ & $110-\mathrm{BX}$ & $111-\overline{B X}$ & $112-\mathrm{BX}$ & 101-BY & 102-BY \\
\hline Units & $\mathrm{kg}$ & $\mathrm{kg}$ & $\mathrm{kg}$ & $\mathrm{kg}$ & $\mathrm{kg}$ & $\mathrm{kg}$ & $\mathrm{kg}$ & $\mathrm{kg}$ & $\mathrm{kg}$ & $\mathrm{kg}$ \\
\hline \multicolumn{11}{|l|}{ Component } \\
\hline$\overline{A L}(\mathrm{OH}) 4$ & $0 \mathrm{E}+00$ & $0.00 \mathrm{E}+00$ & $45 \mathrm{E}+04$ & $10 E+03$ & 74E +03 & $8.82 \mathrm{E}+03$ & $1.11 \mathrm{E}+04$ & $5.55 E+03$ & $1.89 \mathrm{E}+04$ & $1.69 E+04$ \\
\hline $1+2$ & & $0.00 \mathrm{E}+00$ & $00 \mathrm{E}+00$ & $00 \mathrm{E}+00$ & OEE+00 & $0.00 \mathrm{E}+00$ & $0.00 \mathrm{E}+00$ & $0.00 E+00$ & $0.00 E+00$ & \\
\hline$A+2$ & $6 \mathrm{E}-01$ & $1.19 \mathrm{E}-01$ & $22 \mathrm{E}+00$ & $.23 \mathrm{E}-02$ & 1. $09 E+01$ & $70 \mathrm{E}+01$ & $7.07 \mathrm{E}+01$ & $36 \mathrm{E}+01$ & $1,37 \mathrm{E}+02$ & $.23 \mathrm{E}+02$ \\
\hline $\mathrm{D}+2$ & $0 E+00$ & $0.00 \mathrm{E}+00$ & $00 \mathrm{E}+00$ & $0.00 \mathrm{E}+00$ & $0.00 E+00$ & $00 E+00$ & $0.00 \mathrm{E}+00$ & $0.00 E+00$ & $0.00 \mathrm{E}+00$ & $.00 \mathrm{E}+00$ \\
\hline $\mathrm{R}(\mathrm{OH}) 4$ & $59 \mathrm{E}+00$ & $3.77 \mathrm{E}+00$ & $6.74 \mathrm{E}+01$ & $10 E+00$ & $57 E+02$ & $54 E+02$ & $2.25 E+03$ & $9.00 E+01$ & $4.37 \mathrm{E}+03$ & $3.90 E+03$ \\
\hline$=+3$ & $3 \bar{B}+\overline{0}$ & $5.08 \mathrm{E}+00$ & $82 E+01$ & $67 \mathrm{E}+00$ & $5 \mathrm{E}+02$ & $E+01$ & $3 E+02$ & $6 E+01$ & $35 E+02$ & $.41 E+02$ \\
\hline $\mathrm{HG}+2$ & $0 \mathrm{E}+00$ & $00 E+00$ & $00 \mathrm{E}+00$ & $00 \mathrm{E}+00$ & $00 \mathrm{E}+00$ & $0.00 E+00$ & $0.00 E+00$ & $0.00 \mathrm{E}+00$ & $0.00 E+\infty$ & $2.00 \mathrm{E}+0$ \\
\hline $\mathrm{K}+$ & $0 \mathrm{E}+00$ & $00 E+00$ & $00 E+00$ & $00 E+00$ & $\overline{O O E+00}$ & $8.95 E+01$ & $84 E+02$ & $0.00 E+00$ & $7.47 \mathrm{E}+02$ & $0.67 \mathrm{E}+\mathrm{U}_{2}$ \\
\hline$\overline{L A+3}$ & $00 \mathrm{E}+00$ & $00 \mathrm{E}+00$ & $00 E+00$ & $.00 E+00$ & $00 E+00$ & $0.00 \mathrm{E}+00$ & $0.00 \mathrm{E}+00$ & $0.00 E+00$ & $0.00 \mathrm{E}+00$ & $0.00 \mathrm{E}+00$ \\
\hline$\sqrt{A+}$ & $62 \mathrm{E}+04$ & $2.44 E+04$ & $87 \mathrm{E}+05$ & $2.17 \mathrm{E}+04$ & $97 E+05$ & $18 \mathrm{E}+05$ & $4.03 E+05$ & $1.63 E+05$ & $7.62 \mathrm{E}+05$ & $6.69 \mathrm{E}+05$ \\
\hline+3 & $39 \mathrm{E}-01$ & 1.61E-01 & $59 \mathrm{E}+00$ & $E-01$ & $E+01$ & $10 \mathrm{E}+01$ & $E+01$ & $\mathrm{EE}+00$ & $9 \mathrm{E}+01$ & $7.66 E+01$ \\
\hline $\mathrm{PB}+4$ & $\overline{0 E}+00$ & $0.00 \mathrm{E}+00$ & $E+\infty$ & $\mathrm{EE}+00$ & $\mathrm{E}+00$ & $1.13 E+01$ & $55 E+01$ & $\mathrm{OE}+00$ & $9 . \overline{43} E+01$ & $8.42 \mathrm{E}+01$ \\
\hline & & & & & & & & & & \\
\hline $\mathrm{CO} 3-2$ & $9 \mathrm{E}+03$ & $03 E+03$ & $88 \mathrm{E}+03$ & $E+02$ & $90 \mathrm{E}+04$ & $3 E+03$ & $7.40 \mathrm{E}+03$ & $1.75 \mathrm{E}+03$ & 1.77E+04 & $1.43 E+04$ \\
\hline $\mathrm{CL}-$ & $0 \mathrm{E}+01$ & $22 \mathrm{E}+01$ & $13 \mathrm{E}+02$ & $4.64 \mathrm{E}+01$ & $8.73 E+03$ & $8.61 \mathrm{E}+02$ & $2.56 \mathrm{E}+03$ & $5.48 \mathrm{E}+02$ & $4.88 E+03$ & $4.36 \mathrm{E}+03$ \\
\hline F- & $0 \mathrm{E}+00$ & $00 \mathrm{E}+00$ & $43 \mathrm{E}+04$ & $09 \mathrm{E}+03$ & $66 \mathrm{E}+03$ & $7.05 E+03$ & $3.77 \mathrm{E}+03$ & $31 \mathrm{E}+03$ & $4.74 E+03$ & $4.23 \mathrm{E}+0$ \\
\hline$\overline{\mathrm{SO} 4-2}$ & $5.66 \mathrm{E}+03$ & $3.82 \mathrm{E}+03$ & $2.00 \mathrm{E}+03$ & $52 E+02$ & $1.01 E+05$ & $4.16 \mathrm{E}+03$ & $1.42 E+04$ & $3.54 \mathrm{E}+03$ & $3.17 E+04$ & $2.65 \mathrm{E}+04$ \\
\hline NO3- & $3.32 \mathrm{E}+03$ & $2.24 E+03$ & $7.47 \mathrm{E}+04$ & $5.66 \mathrm{E}+03$ & $8.76 E+05$ & $2.17 \mathrm{E}+05$ & $7.91 E+05$ & $7.96 \mathrm{E}+04$ & $1.53 E+06$ & $1.36 E+06$ \\
\hline NO2- & $00 \mathrm{E}+00$ & $0.00 E+00$ & $08 \mathrm{E}+03$ & $11 \mathrm{E}+02$ & $75 E+03$ & $1.37 \mathrm{E}+04$ & $4.38 \mathrm{E}+04$ & $4.34 E+03$ & $8.38 \mathrm{E}+04$ & $7.48 E+04$ \\
\hline $\mathrm{PO} 4-3$ & $8 E+03$ & $2.56 \mathrm{E}+03$ & $42 \mathrm{E}+04$ & $37 \mathrm{E}+03$ & $13 E+04$ & $4.02 \mathrm{E}+04$ & $1.70 \mathrm{E}+04$ & $5.22 \mathrm{E}+04$ & $2.08 \mathrm{E}+04$ & $1.74 \mathrm{E}+04$ \\
\hline $\mathrm{OH}$ & $21 \mathrm{E}+04$ & $1.50 \mathrm{E}+04$ & $27 \mathrm{E}+05$ & $62 E+03$ & $10 \mathrm{E}+05$ & $6.60 \mathrm{E}+04$ & $4.90 \mathrm{E}+04$ & $5.98 \mathrm{E}+04$ & $9.03 E+04$ & $7.34 E+04$ \\
\hline TOC & $0 \mathrm{E}+00$ & $0.00 E+00$ & $.00 \mathrm{E}+00$ & $0.00 \mathrm{E}+00$ & $0.00 E+00$ & $4.10 \mathrm{E}+02$ & $1.98 \mathrm{E}+03$ & $0.00 \mathrm{E}+00$ & $3.93 \mathrm{E}+03$ & $3.52 \mathrm{E}+03$ \\
\hline Sr90 & $32 E+06$ & $49 \mathrm{E}+05$ & $2.56 \mathrm{E}+04$ & $2.80 E+03$ & $2.26 \mathrm{E}+05$ & $1.26 \mathrm{E}+05$ & $1.26 \mathrm{E}+05$ & $2.57 \mathrm{E}+03$ & $1.97 \mathrm{E}+05$ & $8.06 \mathrm{E}+04$ \\
\hline Tc99 & $9.59 \mathrm{E}+02$ & $1.49 \mathrm{E}+03$ & $3.29 \mathrm{E}+00$ & $7.63 \mathrm{E}-02$ & $2.81 \mathrm{E}+00$ & $2.02 \mathrm{E}+02$ & $2.08 \mathrm{E}+02$ & $1.25 \mathrm{E}+00$ & $2.67 E+02$ & $7.72 E+01$ \\
\hline Cs 137 & $.07 \mathrm{E}+04$ & $1.52 E+06$ & $3.73 \mathrm{E}+03$ & $1.23 \mathrm{E}+02$ & $4.22 E+03$ & $1.00 \mathrm{E}+05$ & $1.03 \mathrm{E}+05$ & $1.87 \mathrm{E}+03$ & $1.32 E+05$ & $3.83 E+04$ \\
\hline TRU & $2.27 \mathrm{E}+03$ & $1.60 \mathrm{E}+03$ & $4.28 \mathrm{E}+01$ & $4.28 \mathrm{E}+00$ & $6.89 \mathrm{E}+01$ & $5.67 \mathrm{E}+01$ & $4.21 E+01$ & $1.32 E+01$ & $5.18 \mathrm{E}+01$ & $1.50 \mathrm{E}+0$ \\
\hline $\mathrm{H} 2 \mathrm{O}$ & & & & $90 \mathrm{E}+05$ & $8 E+06$ & $E+06$ & $3.046+06$ & $1.40 E+06$ & $3.11 E+06$ & $4.99 E+0 t$ \\
\hline Volume (L) & $4.91 E+05$ & $5.44 E+05$ & $2.50 \mathrm{E}+06$ & $89 \mathrm{E}+05$ & $3.06 \mathrm{E}+06$ & $1.89 E+06$ & $3.51 \mathrm{E}+06$ & $1.42 E+06$ & $6.63 E+06$ & $5.82 \mathrm{E}+0$ \\
\hline
\end{tabular}


WHC-SD-WM-RPT-210, Rev. 0

\begin{tabular}{|c|c|c|c|c|c|c|c|c|c|c|}
\hline Source & 103-BY & 104-BY & 105-BY & 106-BY & $107-\mathrm{BY}$ & 108-BY & 109-BY & $110-\mathrm{BY}$ & 111-BY & 112-BY \\
\hline Units & $\mathrm{kg}$ & $\mathrm{kg}$ & $\mathrm{kg}$ & $\mathrm{kg}$ & $\mathrm{kg}$ & $\mathrm{kg}$ & $\mathrm{kg}$ & $\mathrm{kg}$ & $\mathrm{kg}$ & $\mathrm{kg}$ \\
\hline \multicolumn{11}{|l|}{ Component } \\
\hline $\mathrm{AL}(\mathrm{OH}) 4-$ & $2.31 E+04$ & $9.38 \mathrm{E}+03$ & $1.40 \mathrm{E}+04$ & $2.67 E+04$ & $5.99 \mathrm{E}+03$ & $0.00 \mathrm{E}+00$ & $2.09 \mathrm{E}+04$ & $9.06 \mathrm{E}+03$ & $2.34 \mathrm{E}+04$ & $1.46 \mathrm{E}+04$ \\
\hline $\mathrm{BA}+2$ & $0.00 E+00$ & $0.00 \mathrm{E}+00$ & $0.00 E+00$ & $0.00 \mathrm{E}+00$ & $0.00 \mathrm{E}+00$ & $0.00 \mathrm{E}+00$ & $0.00 \mathrm{E}+00$ & $0.00 \mathrm{E}+00$ & $0.00 E+00$ & $0.00 \mathrm{E}+00$ \\
\hline $\mathrm{CA}+2$ & $1.54 \mathrm{E}+02$ & $1.02 \mathrm{E}+02$ & $1.34 E+02$ & $2.15 \mathrm{E}+02$ & $5.99 \mathrm{E}+01$ & $2.67 \mathrm{E}+01$ & $1.52 \mathrm{E}+02$ & $8.37 E+01$ & $1.70 E+02$ & $1.08 \mathrm{E}+02$ \\
\hline $\mathrm{CD}+2$ & $0.00 \mathrm{E}+00$ & $0.00 \mathrm{E}+00$ & $0.00 E+00$ & $0.00 \mathrm{E}+00$ & $0.00 E+00$ & $0.00 \mathrm{E}+00$ & $0.00 E+00$ & $0.00 \mathrm{E}+00$ & $0.00 \mathrm{E}+00$ & $0.00 \mathrm{E}+00$ \\
\hline $\mathrm{CR}(\mathrm{OH}) 4$ & $4.89 \mathrm{E}+03$ & $3.21 \mathrm{E}+03$ & $4.23 E+03$ & $6.80 \mathrm{E}+03$ & $1.88 \mathrm{E}+03$ & $8.08 \mathrm{E}+02$ & $4.84 \mathrm{E}+03$ & $2.63 E+03$ & $5.42 E+03$ & $3.43 E+03$ \\
\hline $\mathrm{FE}+3$ & $4.30 \mathrm{E}+02$ & $4.09 \mathrm{E}+02$ & $4.93 E+02$ & $6.71 E+02$ & $2.69 \mathrm{E}+02$ & $2.04 E+02$ & $4.26 E+02$ & $3.61 \mathrm{E}+02$ & $4.75 E+02$ & $3.10 \mathrm{E}+02$ \\
\hline $\mathrm{HG}+2$ & $0.00 \mathrm{E}+00$ & $0.00 \mathrm{E}+00$ & $0.00 \mathrm{E}+00$ & $0.00 \mathrm{E}+00$ & $0.00 \mathrm{E}+00$ & $0.00 \mathrm{E}+00$ & $0.00 \mathrm{E}+00$ & $0.00 \mathrm{E}+00$ & $0.00 \mathrm{E}+00$ & $0.00 \mathrm{E}+00$ \\
\hline $\mathrm{K}+$ & $8.36 \mathrm{E}+02$ & $5.47 \mathrm{E}+02$ & $7.21 \mathrm{E}+02$ & $1.16 \mathrm{E}+03$ & $3.18 \mathrm{E}+02$ & $1.35 \mathrm{E}+02$ & $8.28 \mathrm{E}+02$ & $4.45 E+02$ & $9.27 \mathrm{E}+02$ & $5.86 \mathrm{E}+02$ \\
\hline $\mathrm{LA}+3$ & $0.00 E+00$ & $0.00 \mathrm{E}+00$ & $0.00 E+00$ & $0.00 \mathrm{E}+00$ & $0.00 \mathrm{E}+00$ & $0.00 \mathrm{E}+00$ & $0.00 E+00$ & $0.00 E+00$ & $0.00 E+00$ & $0.00 \mathrm{E}+00$ \\
\hline $\mathrm{NA}+$ & $8.22 E+05$ & $7.00 \mathrm{E}+05$ & $8.75 E+05$ & $1.24 E+06$ & $4.25 \mathrm{E}+05$ & $3.11 \mathrm{E}+05$ & $8.41 E+05$ & $6.30 \mathrm{E}+05$ & $9.30 E+05$ & $5.90 \mathrm{E}+05$ \\
\hline $\mathrm{NI}+3$ & $9.61 \mathrm{E}+01$ & $6.67 \mathrm{E}+01$ & $8.66 \mathrm{E}+01$ & $1.36 \mathrm{E}+02$ & $4.01 E+01$ & $2.08 \mathrm{E}+01$ & $9.52 \mathrm{E}+01$ & $5.62 \mathrm{E}+01$ & $1.06 \mathrm{E}+02$ & $6.75 E+01$ \\
\hline $\mathrm{PB}+4$ & $1.06 \mathrm{E}+02$ & $6.91 \mathrm{E}+01$ & $9.11 \mathrm{E}+01$ & $1.47 \mathrm{E}+02$ & $4.02 \mathrm{E}+01$ & $1.70 \mathrm{E}+01$ & $1.05 E+02$ & $5.62 \mathrm{E}+01$ & $1.17 \mathrm{E}+02$ & $7.40 \mathrm{E}+01$ \\
\hline $\mathrm{CO}-2$ & $1.59 E+04$ & $1.31 E+04$ & $1.78 E+04$ & $2.36 E+04$ & $8.65 E+03$ & $5.42 \mathrm{E}+03$ & $1.91 E+04$ & $1.12 \mathrm{E}+04$ & $2.00 E+04$ & $1.19 \mathrm{E}+04$ \\
\hline CL- & $5.47 \mathrm{E}+03$ & $4.42 E+03$ & $5.52 \mathrm{E}+03$ & $8.18 \mathrm{E}+03$ & $3.01 E+03$ & $1.93 E+03$ & $5.41 \mathrm{E}+03$ & $3.96 \mathrm{E}+03$ & $6.05 E+03$ & $3.91 E+03$ \\
\hline F- & $5.30 \mathrm{E}+03$ & $1.14 E+04$ & $1.21 \mathrm{E}+04$ & $1.23 \mathrm{E}+04$ & $6.03 \mathrm{E}+03$ & $9.09 \mathrm{E}+03$ & $5.25 E+03$ & $1.20 \mathrm{E}+04$ & $5.87 \mathrm{E}+03$ & $4.03 \mathrm{E}+03$ \\
\hline SO4-2 & $3.05 \mathrm{E}+04$ & $6.27 \mathrm{E}+04$ & $6.87 \mathrm{E}+04$ & $6.82 \mathrm{E}+04$ & $3.65 E+04$ & $4.79 E+04$ & $3.46 \mathrm{E}+04$ & $5.60 \mathrm{E}+04$ & $3.70 \mathrm{E}+04$ & $2.45 E+04$ \\
\hline NO3- & $1.71 E+06$ & $1.21 \mathrm{E}+06$ & $1.56 \mathrm{E}+06$ & $2.44 E+06$ & $7.51 \mathrm{E}+05$ & $3.95 \mathrm{E}+05$ & $1.69 \mathrm{E}+06$ & $1.03 E+06$ & $1.89 \mathrm{E}+06$ & $1.21 \mathrm{E}+06$ \\
\hline NO2- & $9.42 E+04$ & $6.14 E+04$ & $8.09 E+04$ & $1.30 \mathrm{E}+05$ & $3.57 E+04$ & $1.51 \mathrm{E}+04$ & $9.28 \mathrm{E}+04$ & $5.08 \mathrm{E}+04$ & $1.04 E+05$ & $6.57 \mathrm{E}+04$ \\
\hline PO4-3 & $1.99 \mathrm{E}+04$ & $2.40 E+04$ & $2.89 \mathrm{E}+04$ & $3.44 \mathrm{E}+04$ & $1.38 E+04$ & $1.45 \mathrm{E}+04$ & $2.27 \mathrm{E}+04$ & $3.01 \mathrm{E}+04$ & $2.42 E+04$ & $1.50 \mathrm{E}+04$ \\
\hline $\mathrm{OH}$ & $8.13 E+04$ & $1.38 \mathrm{E}+05$ & $1.58 \mathrm{E}+05$ & $1.67 \mathrm{E}+05$ & $8.33 \mathrm{E}+04$ & $1.07 \mathrm{E}+05$ & $9.77 \mathrm{E}+04$ & $1.42 E+05$ & $1.02 E+05$ & $6.42 E+04$ \\
\hline TOC & $4.42 E+03$ & $7.48 \mathrm{E}+03$ & $8.15 E+03$ & $1.04 E+04$ & $5.98 \mathrm{E}+03$ & $8.28 E+03$ & $4.35 E+03$ & $9.46 \mathrm{E}+03$ & $4.89 \mathrm{E}+03$ & $3.28 \mathrm{E}+03$ \\
\hline Sr90 & $4.04 \mathrm{E}+05$ & $1.65 E+05$ & $1.38 \mathrm{E}+05$ & $2.10 E+05$ & $9.01 \mathrm{E}+04$ & $2.92 E+04$ & $5.79 E+04$ & $1.92 E+05$ & $1.93 E+05$ & $4.38 \mathrm{E}+04$ \\
\hline Tc99 & $1.25 E+01$ & $2.72 \mathrm{E}+02$ & $2.12 \mathrm{E}+02$ & $2.70 \mathrm{E}+02$ & $9.83 \mathrm{E}+01$ & 1.19E+02 & $8.63 E+01$ & $2.41 \mathrm{E}+02$ & $2.73 E+02$ & $5.01 \mathrm{E}+01$ \\
\hline Cs137 & $6.36 \mathrm{E}+03$ & 1.35E+05 & $1.05 E+05$ & $1.34 E+05$ & $4.89 \mathrm{E}+04$ & $6.33 E+04$ & $4.27 E+04$ & $1.20 E+05$ & $1,35 \mathrm{E}+05$ & $2.48 E+04$ \\
\hline TRU & $1.08 \mathrm{E}+03$ & $2.82 \mathrm{E}+02$ & $1.81 \mathrm{E}+02$ & $1.08 \mathrm{E}+02$ & $7.10 \mathrm{E}+01$ & $9.02 \mathrm{E}+01$ & $1.68 \mathrm{E}+01$ & $1.30 \mathrm{E}+02$ & $5.33 \mathrm{E}+01$ & $9.71 \mathrm{E}+00$ \\
\hline $\mathrm{H} 2 \mathrm{O}$ & $6.12 \mathrm{E}+06$ & $5.36 E+06$ & $6.67 E+06$ & $9.34 \mathrm{E}+06$ & $3.24 E+06$ & $2.47 E+06$ & $6.29 \mathrm{E}+06$ & $4.86 \mathrm{E}+06$ & $6.95 \mathrm{E}+06$ & $4.41 E+06$ \\
\hline Volume (L) & $7.15 \mathrm{E}+06$ & $6.09 \mathrm{E}+06$ & $7.61 \mathrm{E}+06$ & $1.08 \mathrm{E}+07$ & $3.69 \mathrm{E}+06$ & $2.71 E+06$ & $7.31 \mathrm{E}+06$ & $5.48 \mathrm{E}+06$ & $8.09 E+06$ & $5.13 E+06$ \\
\hline
\end{tabular}

D-5 
WHC-SD-WM-RPT-210, Rev. 0

\begin{tabular}{|c|c|c|c|c|c|c|c|c|c|c|}
\hline Source & $101-C$ & $102-C$ & $103-C$ & $104-C$ & $105-C$ & $106-C$ & $107-C$ & $108-C$ & $109-\mathrm{C}$ & $110-C$ \\
\hline Units & $\mathrm{kg}$ & $\mathrm{kg}$ & $\mathrm{kg}$ & $\mathrm{kg}$ & $\mathrm{kg}$ & $\mathrm{kg}$ & $\mathrm{kg}$ & $\mathrm{kg}$ & $\mathrm{kg}$ & $\mathrm{kg}$ \\
\hline \multicolumn{11}{|l|}{ Component } \\
\hline $\mathrm{AL}(\mathrm{OH}) 4-$ & $77 \mathrm{E}+03$ & $97 \mathrm{E}+04$ & $6.33 E+03$ & $3.43 \bar{E}+04$ & $2.49 \mathrm{E}+04$ & $2,48 \mathrm{E}+03$ & $9.14 \mathrm{E}+03$ & $7.59 \mathrm{E}+02$ & $4.22 \mathrm{E}+02$ & $7.88 \mathrm{E}+03$ \\
\hline $\mathrm{BA}+2$ & $00 \mathrm{E}+00$ & $0.00 \mathrm{E}+00$ & $0.00 \mathrm{E}+00$ & $0.00 \mathrm{E}+00$ & $0.00 \mathrm{E}+00$ & $0.00 \mathrm{E}+00$ & $0.00 \mathrm{E}+00$ & $0.00 \mathrm{E}+00$ & $0.00 \mathrm{E}+00$ & $0.00 \mathrm{E}+00$ \\
\hline $\mathrm{CA}+2$ & $1.16 E+00$ & $4.84 E+00$ & $7.00 E-01$ & $3.12 \mathrm{E}+00$ & $1.30 \mathrm{E}+00$ & $2.09 \mathrm{E}+00$ & $1.10 \mathrm{E}+00$ & $7.96 E-01$ & $1.65 \mathrm{E}+00$ & $6.63 \mathrm{E}-01$ \\
\hline $\mathrm{CD}+2$ & $0.00 \mathrm{E}+00$ & $0.00 \mathrm{E}+00$ & $0.00 \bar{E}+00$ & $0.00 \mathrm{E}+00$ & $0.00 \mathrm{E}+00$ & $0.00 \mathrm{E}+00$ & $0.00 \mathrm{E}+00$ & $0.00 \mathrm{E}+00$ & $0.00 E+00$ & $0.00 E+00$ \\
\hline $\mathrm{CR}(\mathrm{OH}) 4-$ & $1.52 \mathrm{E}+01$ & $7.75 \mathrm{E}+01$ & $1.19 E+01$ & $4.24 \mathrm{E}+01$ & $2.85 E+01$ & $2.99 E+01$ & $4.81 \mathrm{E}+01$ & $1.11 \mathrm{E}+01$ & $3.34 \mathrm{E}+00$ & $3.66 \mathrm{E}+01$ \\
\hline $\mathrm{FE}+3$ & $8.94 \mathrm{E}+01$ & $2.79 \mathrm{E}+02$ & $3.74 \mathrm{E}+01$ & $1.74 \mathrm{E}+02$ & $7.48 \mathrm{E}+01$ & $1.31 \mathrm{E}+02$ & $7.45 \mathrm{E}+01$ & $6.15 \mathrm{E}+01$ & $2.31 \mathrm{E}+01$ & $4.79 \mathrm{E}+01$ \\
\hline $\mathrm{HG}+2$ & $0.00 \mathrm{E}+00$ & $0.00 \mathrm{E}+00$ & $0.00 \mathrm{E}+00$ & $0.00 \mathrm{E}+00$ & $0.00 \mathrm{E}+00$ & $0.00 \mathrm{E}+00$ & $0.00 \mathrm{E}+00$ & $0.00 \mathrm{E}+00$ & $0.00 E+00$ & $0.00 \mathrm{E}+00$ \\
\hline $\mathrm{K}+$ & $0.00 \mathrm{E}+00$ & $8.04 E+01$ & $0.00 \mathrm{E}+00$ & $1.51 \mathrm{E}+02$ & $0.00 \mathrm{E}+00$ & $0.00 \mathrm{E}+00$ & $0.00 \mathrm{E}+00$ & $0.00 \mathrm{E}+00$ & $1.75 \mathrm{E}+01$ & $0.00 \mathrm{E}+00$ \\
\hline$L A+3$ & $0.00 \mathrm{E}+00$ & $0.00 \mathrm{E}+00$ & $0.00 \mathrm{E}+00$ & $0.00 \mathrm{E}+00$ & $0.00 \mathrm{E}+00$ & $0.00 \mathrm{E}+00$ & $0.00 \mathrm{E}+00$ & $0.00 E+00$ & $0.00 \mathrm{E}+00$ & $0.00 \mathrm{E}+00$ \\
\hline $\mathrm{NA}+$ & $4.79 \mathrm{E}+04$ & $1.49 \mathrm{E}+05$ & $1.59 \mathrm{E}+04$ & $1.61 \mathrm{E}+05$ & $4.96 \mathrm{E}+04$ & $8.83 E+04$ & $2.23 \mathrm{E}+05$ & $5.07 \mathrm{E}+04$ & $3.66 E+04$ & $1.56 \mathrm{E}+05$ \\
\hline $\mathrm{Nl}+3$ & $1.79 \mathrm{E}+00$ & $7.67 E+00$ & $1.11 \mathrm{E}+00$ & $4.32 \mathrm{E}+00$ & $2.00 E+00$ & $6.03 \mathrm{E}+00$ & $1.13 \mathrm{E}+00$ & $1.47 E+00$ & $7.08 E+00$ & 8.6.2E-01 \\
\hline $\mathrm{PB}+4$ & $0.00 \mathrm{E}+00$ & $0.00 \mathrm{E}+00$ & $0.00 \mathrm{E}+00$ & $2.70 \mathrm{E}-02$ & $0.00 \mathrm{E}+00$ & $0.00 \mathrm{E}+00$ & $0.00 \mathrm{E}+00$ & $0.00 \mathrm{E}+00$ & $1.12 \mathrm{E}+03$ & $0.00 \mathrm{E}+00$ \\
\hline $\mathrm{CO} 3-2$ & $2.75 \mathrm{E}+03$ & $8.38 \mathrm{E}+03$ & $1.08 \mathrm{E}+03$ & $6.94 \mathrm{E}+03$ & $2.25 \mathrm{E}+03$ & $4.81 \mathrm{E}+03$ & $2.46 \mathrm{E}+03$ & $1.96 \mathrm{E}+03$ & $2.55 \mathrm{E}+03$ & $1.02 \mathrm{E}+03$ \\
\hline $\mathrm{CL}-$ & $6.51 \mathrm{E}+02$ & $1.08 \mathrm{E}+03$ & $1.18 \mathrm{E}+02$ & $1.45 \mathrm{E}+03$ & $3.36 \mathrm{E}+02$ & $9.29 \mathrm{E}+02$ & $6.86 \mathrm{E}+02$ & $5.64 \mathrm{E}+02$ & $4.08 E+02$ & $3.33 E+02$ \\
\hline $\mathrm{F}-$ & $0.00 \mathrm{E}+00$ & $1.97 \mathrm{E}+04$ & $0.00 \mathrm{E}+00$ & $4.04 \mathrm{E}+04$ & $0.00 E+00$ & $0.00 E+00$ & $1.02 E+04$ & $7.51 \mathrm{E}+02$ & $4.17 \mathrm{E}+02$ & $7.79 \mathrm{E}+03$ \\
\hline $\mathrm{SO4}-2$ & $7.20 \mathrm{E}+03$ & $4.69 \mathrm{E}+03$ & $8.57 E+01$ & $9.48 \mathrm{E}+02$ & $2.06 \mathrm{E}+03$ & $4.42 \mathrm{E}+03$ & $1.79 \mathrm{E}+03$ & $6.11 \mathrm{E}+03$ & $2.29 \mathrm{E}+02$ & $1.09 E+03$ \\
\hline NO3- & $7.06 \mathrm{E}+04$ & $1.84 E+05$ & $1.46 \mathrm{E}+04$ & $1.16 \mathrm{E}+05$ & $6.22 \mathrm{E}+04$ & $7.78 \mathrm{E}+04$ & $5.74 \mathrm{E}+04$ & $5.82 E+04$ & $5.99 \mathrm{E}+04$ & $4.06 E+04$ \\
\hline NO2- & $1.49 \mathrm{E}+03$ & $1.86 \mathrm{E}+04$ & $1.67 \mathrm{E}+03$ & $1.22 \mathrm{E}+04$ & $1.32 \mathrm{E}+04$ & $4.60 \mathrm{E}+03$ & $5.81 \mathrm{E}+03$ & $5.21 \mathrm{E}+02$ & $1.71 \mathrm{E}+03$ & $4.39 E+03$ \\
\hline $\mathrm{PO4-3}$ & $9.43 E+02$ & $1.25 \mathrm{E}+03$ & $7.41 \mathrm{E}+01$ & $6.22 \mathrm{E}+02$ & $2.44 \mathrm{E}+02$ & $7.78 \mathrm{E}+02$ & $6.00 \mathrm{E}+04$ & $5.20 \mathrm{E}+03$ & $3.41 \mathrm{E}+03$ & $4.57 \mathrm{E}+04$ \\
\hline $\mathrm{OH}$ & $1.18 \mathrm{E}+04$ & $1.94 E+04$ & $5.57 \mathrm{E}+03$ & $6.66 \mathrm{E}+04$ & $9.30 \mathrm{E}+03$ & 4.15E+04 & $1.18 \mathrm{E}+05$ & $1.67 \mathrm{E}+04$ & $1.87 \bar{E}+04$ & $6.90 \mathrm{E}+04$ \\
\hline TOC & $0.00 \mathrm{E}+00$ & $4.54 \mathrm{E}+00$ & $0.00 \bar{E}+00$ & $1.77 \mathrm{E}+04$ & $0.00 \mathrm{E}+00$ & $8.56 \mathrm{E}+02$ & $9.39 E+03$ & $4.09 \mathrm{E}+02$ & $6.99 \mathrm{E}+03$ & $0.00 \mathrm{E}+00$ \\
\hline Sr90 & $4.05 E+04$ & $6.05 \mathrm{E}+05$ & $2.35 \mathrm{E}+05$ & $2.17 \mathrm{E}+05$ & $1.65 \mathrm{E}+06$ & $3.18 \mathrm{E}+05$ & $4.93 \mathrm{E}+04$ & 1.32E+04 & $4.04 \mathrm{E}+01$ & $7.17 \mathrm{E}+03$ \\
\hline Tc99 & $2.97 \mathrm{E}+01$ & $1.99 \mathrm{E}-08$ & $1.60 \mathrm{E}-08$ & 5.13E-09 & $6.90 \mathrm{E}+02$ & $0.00 \mathrm{E}+00$ & $1.34 \mathrm{E}+00$ & $9.14 \mathrm{E}-04$ & $9.21 \mathrm{E}-01$ & $1.74 \mathrm{E}-10$ \\
\hline Cs137 & $4.63 E+04$ & $3.68 \mathrm{E}-05$ & $3.55 \mathrm{E}-05$ & 1.14E-05 & $7.10 \mathrm{E}+04$ & $0.00 \mathrm{E}+00$ & $2.17 \mathrm{E}+03$ & $1.16 \mathrm{E}+00$ & $1.39 E+03$ & $3.24 \mathrm{E}-07$ \\
\hline TRU & $1.58 \mathrm{E}+02$ & $2.86 \mathrm{E}+03$ & $4.06 \mathrm{E}+02$ & $1.29 \mathrm{E}+03$ & $7.83 \mathrm{E}+03$ & $5.59 \mathrm{E}+02$ & $3.35 \mathrm{E}+02$ & $1.14 \mathrm{E}+02$ & $9.58 \mathrm{E}-01$ & $1.33 \mathrm{E}+02$ \\
\hline $\mathrm{H} 2 \mathrm{O}$ & $3.70 \mathrm{E}+05$ & 1.14E+06 & $1.27 E+05$ & $1.29 \mathrm{E}+06$ & $3.74 \mathrm{E}+05$ & $7.29 \mathrm{E}+05$ & $1.93 E+06$ & $4.09 \mathrm{E}+05$ & $2.65 \mathrm{E}+05$ & $1.36 \mathrm{E}+06$ \\
\hline Volume (L) & $8.78 \mathrm{E}+05$ & $8.11 \mathrm{E}+06$ & $9.87 E+05$ & $5.79 E+06$ & $2.47 E+06$ & $2.72 \mathrm{E}+06$ & $1.94 E+06$ & $4.41 E+05$ & $5.58 \mathrm{E}+05$ & $1.36 \mathrm{E}+06$ \\
\hline
\end{tabular}




\section{WHC-SD-WM-RPT-210, Rev. 0}

\begin{tabular}{|c|c|c|c|c|c|c|c|c|c|c|}
\hline Source & $111-C$ & $112-C$ & $201-C$ & $202-C$ & $203-C$ & $204-C$ & 101-S & $102-S$ & $103-S$ & $104-s$ \\
\hline Units & $\mathrm{kg}$ & $\mathrm{kg}$ & $\mathrm{kg}$ & $\mathrm{kg}$ & $\mathrm{kg}$ & $\mathrm{kg}$ & $\mathrm{kg}$ & $\mathrm{kg}$ & $\mathrm{kg}$ & $\mathrm{kg}$ \\
\hline \multicolumn{11}{|l|}{ Component } \\
\hline $\mathrm{AL}(\mathrm{OH}) 4-$ & $4.30 \mathrm{E}+03$ & $81 \mathrm{E}+03$ & $0.00 E+00$ & $00 E+00$ & $0.00 \mathrm{E}+00$ & $0.00 \mathrm{E}+00$ & $5.88 \mathrm{E}+04$ & $6.65 E+04$ & $2.77 \mathrm{E}+04$ & $4.68 E+04$ \\
\hline $\mathrm{BA}+2$ & $0 \mathrm{E}+00$ & $\mathrm{DOE}+00$ & $00 E+00$ & $00 \mathrm{E}+00$ & $00 \mathrm{E}+00$ & $00 \mathrm{E}+00$ & $00 \mathrm{E}+00$ & $00 \mathrm{E}+00$ & $00 \mathrm{E}+00$ & $00 \mathrm{E}+00$ \\
\hline $\mathrm{CA}+2$ & $9 \mathrm{E}-01$ & $75 E+00$ & $.67 \mathrm{E}-03$ & $84 \mathrm{E}-03$ & 92E-02 & $15 \mathrm{E}-02$ & $44 E+01$ & $2 \mathrm{E}+01$ & $7 E+01$ & $9 \mathrm{E}+00$ \\
\hline $\mathrm{CD}+2$ & +00 & $0 \mathrm{E}+00$ & $00 E+00$ & $0 \mathrm{E}+00$ & $O E+00$ & $E+00$ & $00 E+00$ & $\mathrm{E}+00$ & $\mathrm{EE}+00$ & $0 E+00$ \\
\hline $\mathrm{CR}(\mathrm{OH}) 4$ & $2 E+01$ & $43 E+00$ & 2.43E-01 & $1.22 \mathrm{E}-01$ & $6.08 \mathrm{E}-01$ & $3.65 E-01$ & $23 E+03$ & $3.25 \mathrm{E}+03$ & $2 \mathrm{E}+03$ & $79 E+03$ \\
\hline $\mathrm{FE}+3$ & $0 \mathrm{E}+01$ & $27 \mathrm{E}+01$ & $3.28 \mathrm{E}-01$ & $1.64 \mathrm{E}-01$ & $8.19 \mathrm{E}-01$ & $4.91 \mathrm{E}-01$ & $1.46 \mathrm{E}+02$ & $9.26 \mathrm{E}+01$ & $74 E+01$ & $12 E+02$ \\
\hline $\mathrm{HG}+2$ & $0 \mathrm{E}+00$ & $00 E+00$ & $0.00 E+00$ & $0.00 E+00$ & $0.00 E+00$ & $0.00 \mathrm{E}+00$ & $0.00 E+00$ & $00 E+00$ & $00 E+00$ & $00 \mathrm{E}+00$ \\
\hline$\overline{K+}$ & $E+00$ & $E+00$ & $00 \mathrm{E}+00$ & $00 \mathrm{E}+00$ & $00 \mathrm{E}+00$ & $0.00 \mathrm{E}+00$ & $7.59 \mathrm{E}+02$ & $E+03$ & $66 \mathrm{E}+02$ & $.00 \mathrm{E}+00$ \\
\hline$A+3$ & $E+00$ & $E+\infty$ & $00 E+00$ & $00 \mathrm{E}+00$ & $00 \mathrm{E}+00$ & $0.00 \mathrm{E}+00$ & $0.00 E+00$ & $\mathrm{E}+00$ & $\mathrm{E}+00$ & $10 \mathrm{E}+00$ \\
\hline $\mathrm{NA}+$ & $E+04$ & $74 \mathrm{E}+04$ & $57 \mathrm{E}+03$ & $87 E+02$ & $3.94 E+03$ & $2.36 \mathrm{E}+03$ & $4.71 \mathrm{E}+05$ & $.98 \mathrm{E}+05$ & $E+05$ & $15 E+05$ \\
\hline$\overline{N A+3}$ & $4 E+\infty$ & $1.11 \mathrm{E}+01$ & $1.04 \mathrm{E}-02$ & $5.20 \mathrm{E}-03$ & $2.60 \mathrm{E}-02$ & $1.56 \mathrm{E}-02$ & $220 \mathrm{E}+01$ & $4.10 E+01$ & $E+01$ & $\mathrm{BE}+\mathrm{t}+\mathrm{c}$ \\
\hline $\mathrm{PB}+4$ & $0 \mathrm{EE}+00$ & $4.78 \mathrm{E}+02$ & $0.00 \mathrm{E}+00$ & $.00 \mathrm{E}+00$ & $0.00 \mathrm{E}+00$ & $0.00 E+00$ & 1.14E-01 & $3.17 E-01$ & $1.30 \mathrm{E}-01$ & $0.00 E+00$ \\
\hline $\mathrm{CO}_{-}-$ & & & & & & & & & & \\
\hline CL- & $\mathrm{EE}+02$ & $E+02$ & $7.85 \mathrm{E}-01$ & $3.92 \mathrm{E}-01$ & $96 \mathrm{E}+00$ & $18 \mathrm{E}+00$ & $4.67 \mathrm{E}+03$ & $1.02 E+04$ & $2 \mathrm{E}+03$ & $\frac{1}{E+03}$ \\
\hline F- & $0 \mathrm{E}+03$ & $6.24 E+02$ & $0.00 E+00$ & $0.00 \mathrm{E}+00$ & $00 \mathrm{E}+00$ & $0.00 \mathrm{E}+00$ & $1.82 \mathrm{E}+03$ & $5.40 \mathrm{E}+03$ & $2.12 \mathrm{E}+03$ & $0.00 \mathrm{E}+00$ \\
\hline SO4-2 & $27 \mathrm{E}+02$ & $72 E+02$ & $2.46 E+02$ & $23 E+02$ & $6.16 \mathrm{E}+02$ & $3.69 \mathrm{E}+02$ & $6.88 \mathrm{E}+03$ & $1.68 \mathrm{E}+04$ & $7.25 \mathrm{E}+03$ & $5.62 \mathrm{E}+02$ \\
\hline NO3- & $4 E+04$ & $41 \mathrm{E}+04$ & $44 E+02$ & $22 \mathrm{E}+01$ & $61 \mathrm{E}+02$ & $17 \mathrm{E}+02$ & $7.94 E+05$ & $1.38 \mathrm{E}+06$ & $6.32 \mathrm{E}+05$ & $2.70 E+05$ \\
\hline NO2- & $4 E+03$ & $33 E+03$ & $00 E+00$ & $00 \mathrm{E}+00$ & $E+\infty$ & $0.00 \mathrm{E}+00$ & $8.06 E+04$ & $E+05$ & $8.62 E+04$ & $\mathrm{E}+0$ \\
\hline$\overline{\mathrm{PO} 4-3}$ & $8.91 \mathrm{E}+03$ & $5.16 \mathrm{E}+03$ & $1.65 \mathrm{E}+02$ & $23 \mathrm{E}+01$ & $4.12 \mathrm{E}+02$ & $2.47 \mathrm{E}+02$ & $7.06 \mathrm{E}+03$ & $2.06 \mathrm{E}+04$ & $8.16 \mathrm{E}+03$ & $0.00 \mathrm{E}+0 \mathrm{C}$ \\
\hline$\overline{\mathrm{OH}}$ & $7 E+04$ & $65 \mathrm{E}+04$ & $64 \mathrm{E}+02$ & $82 \mathrm{E}+02$ & $41 \mathrm{E}+03$ & $1.35 \mathrm{E}+03$ & $8.29 \mathrm{E}+04$ & $2.56 \mathrm{E}+05$ & $.04 E+05$ & $0.00 \mathrm{E}+0 \mathrm{C}$ \\
\hline $\mathrm{TOC}$ & $69 \mathrm{E}+02$ & $1.00 \mathrm{E}+04$ & $0.00 \mathrm{E}+00$ & $0.00 \mathrm{E}+00$ & $0.00 E+00$ & $0.00 E+00$ & $4.43 E+03$ & $1.39 \mathrm{E}+04$ & $5.43 E+03$ & $0.00 \mathrm{E}+00$ \\
\hline Sr90 & $5.26 \mathrm{E}+04$ & $2.21 E+04$ & $3.60 \mathrm{E}+00$ & \begin{tabular}{|l|}
$3.14 \mathrm{E}-14$ \\
\end{tabular} & $3.77 \mathrm{E}+02$ & $1.55 \mathrm{E}-01$ & $3.44 \mathrm{E}+05$ & $3.14 E+04$ & $1.74 \mathrm{E}-04$ & $2.85 \mathrm{E}+05$ \\
\hline Tc99 & 7.05E-01 & $5.82 \mathrm{E}-01$ & $4.09 \mathrm{E}-04$ & \begin{tabular}{|c|}
$1.19 \mathrm{E}-16$ \\
\end{tabular} & $1.17 \mathrm{E}-09$ & $1.77 \mathrm{E}-05$ & $1.24 \mathrm{E}+02$ & $1.70 \mathrm{E}-07$ & $2.55 \mathrm{E}-07$ & $6.39 \mathrm{E}+0 \mathrm{C}$ \\
\hline Cs137 & $1.08 \mathrm{E}+03$ & $9.34 E+02$ & & & & $2.02 \mathrm{E}-02$ & $2.41 \mathrm{E}+04$ & $9.86 \mathrm{E}-05$ & $7.59 \mathrm{E}-05$ & $8.60 \mathrm{E}+03$ \\
\hline TRU & $7.88 \mathrm{E}+01$ & $7.80 \mathrm{E}+01$ & $2.45 \mathrm{E}-02$ & $6.74 \mathrm{E}-02$ & $6.74 \mathrm{E}-03$ & $2.38 \mathrm{E}-05$ & $4.40 \mathrm{E}+02$ & $2.60 \mathrm{E}+01$ & $2.90 \mathrm{E}+00$ & $2.44 \mathrm{E}+02$ \\
\hline & & & & & & & & & & \\
\hline & & $\frac{4.76 \mathrm{E}+05}{9.30 \mathrm{E}+05}$ & $\mid \frac{1.37 E+04}{2.11 E+04}$ & & \begin{tabular}{|l|}
$3.43 E+04$ \\
$5.26 E+04$
\end{tabular} & $2.05 E+04$ & $4.10 E+06$ & & & \\
\hline
\end{tabular}


WHC-SD-WM-RPT-210, Rev. 0

\begin{tabular}{|c|c|c|c|c|c|c|c|c|c|c|}
\hline Source & $105-S$ & $106-S$ & $107-5$ & 108-S & $109-\mathrm{s}$ & $110-\mathrm{S}$ & $1111-\mathrm{S}$ & $112-s$ & $101-S X$ & $102-S X$ \\
\hline Units & $\mathrm{kg}$ & $\mathrm{kg}$ & $\mathrm{kg}$ & $\mathrm{kg}$ & $\mathrm{kg}$ & $\mathrm{kg}$ & $\mathrm{kg}$ & $\mathrm{kg}$ & $\mathrm{kg}$ & $\mathrm{kg}$ \\
\hline \multicolumn{11}{|l|}{ Component } \\
\hline$\overline{\mathrm{AL}}(\mathrm{OH}) 4$ & $1 \mathrm{E}+04$ & $6 E+04$ & $4.37 \mathrm{E}+04$ & $7.17 \mathrm{E}+04$ & $6.82 \mathrm{E}+04$ & $5.04 \mathrm{E}+04$ & $6.58 E+04$ & $.57 \mathrm{E}+04$ & $6.66 \mathrm{E}+04$ & $6.41 \mathrm{E}+04$ \\
\hline$B A+2$ & $E+00$ & $0 \mathrm{E}+00$ & $00 E+00$ & $0.00 \mathrm{E}+00$ & $00 \mathrm{E}+00$ & $0 \mathrm{E}+00$ & $.00 E+00$ & $00 \mathrm{E}+00$ & & $.00 \mathrm{E}+00$ \\
\hline $\mathrm{CA}+2$ & $E+02$ & $1 \mathrm{E}+02$ & $10 E+01$ & $32 E+02$ & $27 \mathrm{E}+02$ & $22 \mathrm{E}+01$ & $9.64 E+01$ & $1.39 E+02$ & $2.15 E+01$ & $.13 E+02$ \\
\hline $\mathrm{CD}+2$ & +00 & $E+00$ & $0.00 \mathrm{E}+00$ & $0.00 \mathrm{E}+00$ & $0.00 \mathrm{E}+00$ & $00 \mathrm{E}+00$ & $0.00 E+00$ & $0.00 \mathrm{E}+00$ & $0.00 E+00$ & $.00 \mathrm{E}+00$ \\
\hline $\mathrm{CR}(\mathrm{OH}$ & $E+03$ & $88 \mathrm{E}+03$ & $4.56 E+03$ & $4.51 \mathrm{E}+03$ & $5.41 \mathrm{E}+03$ & $4.21 \mathrm{E}+03$ & $4.73 E+03$ & $5.21 \mathrm{E}+03$ & $5.50 E+03$ & $1.56 \mathrm{E}+04$ \\
\hline $\mathrm{FE}+3$ & $E+02$ & $22 \mathrm{E}+02$ & $1.96 E+02$ & $1.97 E+02$ & $6.32 E+02$ & $1.98 E+02$ & $2.23 E+02$ & $2.79 E+02$ & $1.42 E+02$ & $.51 \mathrm{E}+02$ \\
\hline $\mathrm{HG}+2$ & $\mathrm{E}+00$ & $0 \mathrm{E}+00$ & $0.00 \mathrm{E}+00$ & $00 E+00$ & $0.00 \mathrm{E}+00$ & $00 \mathrm{E}+00$ & $00 E+00$ & $.00 E+00$ & $00 \mathrm{E}+00$ & $0.00 \mathrm{E}+00$ \\
\hline $\mathrm{K}+$ & +03 & $E+03$ & $5.13 E+02$ & $2.06 \mathrm{E}+03$ & $1.91 E+03$ & $9.53 E+02$ & $1.54 E+03$ & $2.17 E+03$ & $4.59 E+02$ & $1.70 \mathrm{E}+03$ \\
\hline $\mathrm{LA}+3$ & $E+00$ & $00 E+00$ & $0.00 \mathrm{E}+00$ & $0.00 E+00$ & $0.00 \mathrm{E}+00$ & $0.00 \mathrm{E}+00$ & $0.00 E+00$ & $0.00 \mathrm{E}+00$ & $0.00 E+00$ & $0.00 \mathrm{E}+00$ \\
\hline $\mathrm{NA}+$ & $7 \mathrm{E}+05$ & $1.05 E+06$ & $4.40 \mathrm{E}+05$ & $1.22 \mathrm{E}+06$ & $1.13 E+06$ & $6.06 \mathrm{E}+05$ & $9.41 E+05$ & $1.29 E+06$ & $3.57 E+05$ & $9.99 E+05$ \\
\hline $\mathrm{Ni}+3$ & $E+01$ & $75 \mathrm{E}+01$ & $2.96 E+01$ & $7.81 \mathrm{E}+01$ & $39 \mathrm{E}+01$ & $3.88 \mathrm{E}+01$ & $5.56 \mathrm{E}+01$ & $8.42 \mathrm{E}+01$ & $1.45 \mathrm{E}+01$ & $8.55 E+01$ \\
\hline $\mathrm{PB}+4$ & & $3.80 \bar{E}-02$ & $3.10 \mathrm{E}-01$ & $7 \mathrm{E}-01$ & $43 \mathrm{E}-01$ & $2.31 \mathrm{E}-01$ & $3.26 \mathrm{E}-01$ & $6.90 \mathrm{E}-02$ & $2.55 \mathrm{E}-01$ \\
\hline & & & & $F+04$ & $F+04$ & $6 E+04$ & $485 \mathrm{E}+04$ & $78 \mathrm{E}+04$ & $29 E+04$ & \\
\hline $\mathrm{CL}-$ & & & $18 F+03$ & $\frac{2 E+03}{22+3}$ & $8.73 E+03$ & $498 \mathrm{E}+03$ & $7.39 E+03$ & $9.92 E+03$ & $4.04 E+03$ & $\frac{5.06 \mathrm{E}+04}{8.25 \mathrm{E}+03}$ \\
\hline \begin{tabular}{|l}
$\mid \mathrm{CL}-$ \\
F-
\end{tabular} & $\begin{array}{ll}E^{+}+03 \\
+033\end{array}$ & $364 \mathrm{E}+03$ & $480 \mathrm{E}+04$ & $\frac{27 E+03}{27 E}$ & $3.95 \mathrm{E}+03$ & $1.97 \mathrm{E}+03$ & $3.18 E+03$ & $4.49 E+03$ & $1.11 \mathrm{E}+03$ & $\frac{8.25 E+03}{3.65 E+03}$ \\
\hline $\mathrm{SO}-2$ & $2 E+04$ & $1.71 \mathrm{E}+04$ & $5.07 \mathrm{E}+03$ & $2.00 E+04$ & $1.86 \mathrm{E}+04$ & $9.49 \mathrm{E}+03$ & $1.51 \mathrm{E}+04$ & $2.11 \mathrm{E}+04$ & $4.61 E+03$ & $1.61 E+04$ \\
\hline NO3- & $=+06$ & $E+06$ & $00 E+05$ & $2.03 E+06$ & $1.88 E+06$ & $1.06 \mathrm{E}+06$ & $1.59 \mathrm{E}+06$ & $2.13 E+06$ & $7.17 E+05$ & $1.63 E+06$ \\
\hline NO2- & $E+05$ & $1.55 E+05$ & $4.18 \mathrm{E}+04$ & $1.80 \mathrm{E}+05$ & $1.67 \mathrm{E}+05$ & $8.32 \mathrm{E}+04$ & $1.37 E+05$ & $1.90 \mathrm{E}+05$ & $4.52 E+04$ & $1.53 \mathrm{E}+0$ \\
\hline PO4-3 & $1.31 \mathrm{E}+04$ & $1.47 \mathrm{E}+04$ & $3.33 E+03$ & $73 \mathrm{E}+04$ & $1.60 E+04$ & $7.97 \mathrm{E}+03$ & $1.29 \mathrm{E}+04$ & $E+0$ & $4.28 E+03$ & $1.46 \mathrm{E}+0$ \\
\hline $\mathrm{OH}-$ & $84 \mathrm{E}+05$ & $2.07 \mathrm{E}+05$ & $3.52 \mathrm{E}+04$ & $2.42 E+05$ & $E+05$ & $1.04 E+05$ & $1.78 E+05$ & $2.55 \mathrm{E}+05$ & $3.25 E+04$ & $2.03 \mathrm{E}+0$ \\
\hline TOC & $29 E+03$ & +03 & $E+03$ & $E+04$ & $9.87 \mathrm{E}+03$ & $4.74 \mathrm{E}+03$ & $7.81 \mathrm{E}+03$ & $1.12 \mathrm{E}+04$ & $2.60 \mathrm{E}+03$ & $9.31 \mathrm{E}+0$ \\
\hline Sr.90 & +04 & $7.47 \mathrm{E}+03$ & $3.88 \mathrm{E}+05$ & $E+04$ & $4.99 E+04$ & $3.40 \mathrm{E}+05$ & $4.28 \mathrm{E}+05$ & $8.42 \mathrm{E}+05$ & $4.28 \mathrm{E}+05$ & $1.21 \mathrm{E}+06$ \\
\hline Tcs & $E+01$ & $57 E+01$ & $2.55 \mathrm{E}-07$ & $E+02$ & $3.60 \mathrm{E}+02$ & $2.38 \mathrm{E}+02$ & $2.22 \mathrm{E}+02$ & $1.55 \mathrm{E}+03$ & $6.87 \mathrm{E}-09$ & $7.14 \mathrm{E}-01$ \\
\hline $\operatorname{cs} 137$ & +04 & $4.66 \mathrm{E}+04$ & $3.76 \mathrm{E}-05$ & $6.31 E+04$ & $3.55 \mathrm{E}+05$ & $3.96 \mathrm{E}+05$ & $3.65 \mathrm{E}+05$ & $1.23 \mathrm{E}+06$ & $3.99 E-06$ & $1.09 \mathrm{E}+02$ \\
\hline \multirow{2}{*}{\multicolumn{6}{|c|}{\begin{tabular}{l|l|l|l|l}
$2 \mathrm{E}+01$ & $2.68 \mathrm{E}+00$ & $1.38 \mathrm{E}+03$ & $1.26 \mathrm{E}+02$ \\
\end{tabular}}} & $1.31 \mathrm{E}+02$ & & $6.66 \mathrm{E}+02$ & & $2.93 \mathrm{E}+0$ \\
\hline & & & $3.34 E+\infty 6$ & $1 E+06$ & & & & & & \\
\hline Volume $(\mathrm{L})$ & $8.06 E+06$ & $9.12 \mathrm{E}+06$ & $4.25 E+06$ & $1.06 \mathrm{E}+07$ & $9.86 E+06$ & $5.27 t+06$ & $.18 E+0 E$ & & & \\
\hline
\end{tabular}


WHC-SD-WM-RPT-210, Rev. 0

\begin{tabular}{|c|c|c|c|c|c|c|c|c|c|c|}
\hline Source & $103-S X$ & 104-SX & $105-S X$ & $106-S X$ & $107-S X$ & $108-S X$ & $109-S X$ & $110-S X$ & $111-S X$ & 112-SX \\
\hline Units & $\mathrm{kg}$ & $\mathrm{kg}$ & $\mathrm{kg}$ & $\mathrm{kg}$ & $\mathrm{kg}$ & $\mathrm{kg}$ & $\mathrm{kg}$ & $\mathrm{kg}$ & $\mathrm{kg}$ & \\
\hline \multicolumn{11}{|l|}{ Component } \\
\hline$\overline{\mathrm{AL}(\mathrm{OH}) 4-}$ & $8.14 \mathrm{E}+04$ & $7.90 \mathrm{E}+04$ & $8.11 \mathrm{E}+04$ & $5.80 \mathrm{E}+04$ & $1.49 E+04$ & $1.66 \mathrm{E}+04$ & $1.83 E+04$ & $3.84 \mathrm{E}+03$ & 1.19E+04 & $1.06 \mathrm{E}+04$ \\
\hline $\mathrm{BA}+2$ & $0.00 E+00$ & $0.00 E+00$ & $0.00 \mathrm{E}+00$ & $0.00 \mathrm{E}+00$ & $0.00 \mathrm{E}+00$ & $0.00 \mathrm{E}+00$ & $0.00 \mathrm{E}+00$ & $0.00 \mathrm{E}+00$ & $0.00 \mathrm{E}+00$ & $0.00 \mathrm{E}+00$ \\
\hline $\mathrm{CA}+2$ & $1.21 \mathrm{E}+02$ & $9.98 \mathrm{E}+01$ & $1.42 E+02$ & $4.87 \mathrm{E}+01$ & $8.37 \mathrm{E}-01$ & $8.91 \mathrm{E}-01$ & $8.54 E+01$ & $1.34 E+01$ & $1.79 \mathrm{E}+01$ & $7.99 \mathrm{E}+00$ \\
\hline $\mathrm{CD}+2$ & $0.00 \mathrm{E}+00$ & $0.00 \mathrm{E}+00$ & $0.00 \mathrm{E}+00$ & $0.00 \mathrm{E}+00$ & $0.00 E+00$ & $0.00 \mathrm{E}+00$ & $0.00 \mathrm{E}+00$ & $0.00 E+00$ & $0.00 \mathrm{E}+00$ & $0.00 \mathrm{E}+00$ \\
\hline $\mathrm{CR}(\mathrm{OH}) 4$ & 16.76E +03 & $6.60 E+03$ & $8.16 \mathrm{E}+03$ & $3.11 \mathrm{E}+03$ & $3.92 \mathrm{E}+03$ & $4.06 \mathrm{E}+03$ & $8.66 \mathrm{E}+03$ & $4.40 \mathrm{E}+03$ & $6.30 \mathrm{E}+03$ & $3.93 \mathrm{E}+03$ \\
\hline $\mathrm{FE}+3$ & $3.57 E+02$ & $3.14 E+02$ & $4.11 \mathrm{E}+02$ & $8.75 E+01$ & $5.11 E+01$ & $5.40 \mathrm{E}+01$ & $1.69 \mathrm{E}+02$ & $6.19 \mathrm{E}+01$ & $9.29 E+01$ & $5.73 E+01$ \\
\hline $\mathrm{HG}+2$ & $0.00 \mathrm{E}+00$ & $0.00 \mathrm{E}+00$ & $0.00 E+00$ & $0.00 E+00$ & $0,00 \mathrm{E}+00$ & $0.00 E+00$ & $0.00 \mathrm{E}+00$ & $0.00 \mathrm{E}+00$ & $0.00 \mathrm{E}+00$ & $0.00 E+00$ \\
\hline K+ & $1.86 \mathrm{E}+03$ & $1.53 \mathrm{E}+03$ & $2.10 \mathrm{E}+03$ & $1.90 \mathrm{E}+03$ & $0.00 \mathrm{E}+00$ & $0.00 \mathrm{E}+00$ & $0.00 \mathrm{E}+00$ & $0.00 \mathrm{E}+00$ & $0.00 \mathrm{E}+00$ & $0.00 \mathrm{E}+00$ \\
\hline $\mathrm{LA}+3$ & $0.00 E+00$ & $0.00 E+00$ & $0.00 \mathrm{E}+00$ & $0.00 \mathrm{E}+00$ & $0.00 \mathrm{E}+00$ & $0.00 \mathrm{E}+00$ & $0.00 \mathrm{E}+00$ & $0.00 \mathrm{E}+00$ & $0.00 E+00$ & $0.00 \mathrm{E}+00$ \\
\hline $\mathrm{NA}+$ & $1.14 E+06$ & $9.69 \mathrm{E}+05$ & $1.31 \mathrm{E}+06$ & $8.38 \mathrm{E}+05$ & $4.33 E+04$ & $4.74 E+04$ & $5.87 \mathrm{E}+05$ & $1.29 \mathrm{E}+05$ & $1.91 \mathrm{E}+05$ & $1.02 \mathrm{E}+05$ \\
\hline $\mathrm{NI}+3$ & $7.48 \mathrm{E}+01$ & $6.22 \mathrm{E}+01$ & $8.78 E+01$ & $2.94 E+01$ & $1.21 E+00$ & $1.28 \mathrm{E}+00$ & $4.15 \mathrm{E}+01$ & $7.35 \mathrm{E}+00$ & $1.01 \mathrm{E}+01$ & $4.89 \mathrm{E}+00$ \\
\hline $\mathrm{PB}+4$ & $2.79 \mathrm{E}-01$ & \begin{tabular}{|l|}
$2.30 \mathrm{E}-01$ \\
\end{tabular} & $3.16 \mathrm{E}-01$ & \begin{tabular}{|c|}
$2.86 \mathrm{E}-01$ \\
\end{tabular} & $0.00 \mathrm{E}+00$ & $0.00 \mathrm{E}+00$ & $0.00 \mathrm{E}+00$ & $0.00 \mathrm{E}+00$ & $0.00 \mathrm{E}+00$ & $0.00 \mathrm{E}+00$ \\
\hline $\mathrm{CO} 3-2$ & $5.87 \mathrm{E}+04$ & $4.90 \mathrm{E}+04$ & $6.66 \mathrm{E}+04$ & $3.00 E+04$ & $1.29 \mathrm{E}+03$ & $1.38 E+03$ & $5.95 \mathrm{E}+03$ & $1.81 \mathrm{E}+03$ & $2.74 E+03$ & $1.64 E+03$ \\
\hline $\mathrm{CL}-$ & $9.09 E+03$ & $7.92 E+03$ & $1.02 \mathrm{E}+04$ & $9.29 \mathrm{E}+03$ & $6.69 \mathrm{E}+02$ & $7.31 \mathrm{E}+02$ & $1.09 \mathrm{E}+03$ & $3.73 \mathrm{E}+02$ & $7.31 \mathrm{E}+02$ & $5.50 \mathrm{E}+02$ \\
\hline F- & $3.84 E+03$ & $3.17 \mathrm{E}+03$ & $4.44 E+03$ & $5.11 \mathrm{E}+03$ & $0.00 \mathrm{E}+00$ & $0.00 \mathrm{E}+00$ & $0.00 \mathrm{E}+00$ & $0.00 \mathrm{E}+00$ & $0.00 E+00$ & $0.00 \mathrm{E}+00$ \\
\hline SO4-2 & $1.83 E+04$ & $1.52 E+04$ & $2.12 E+04$ & $1.42 \mathrm{E}+04$ & $239 \mathrm{E}+02$ & $2.62 E+02$ & $3.82 \mathrm{E}+02$ & $1.15 \mathrm{E}+02$ & $2.44 E+02$ & $1.90 \mathrm{E}+02$ \\
\hline NO3- & $1.95 \mathrm{E}+06$ & $1.69 \mathrm{E}+06$ & $2.22 E+06$ & $1.08 E+06$ & $1.02 \mathrm{E}+05$ & $1.12 E+05$ & $1.56 \mathrm{E}+06$ & $3.40 \mathrm{E}+05$ & $4.99 E+05$ & $2.63 \mathrm{E}+05$ \\
\hline NO2- & $1.62 E+05$ & $1.34 E+05$ & $1.87 \mathrm{E}+05$ & $2.04 E+05$ & $0.00 \mathrm{E}+00$ & $0.00 \mathrm{E}+00$ & $0.00 E+00$ & $0.00 \mathrm{E}+00$ & $0.00 \mathrm{E}+00$ & $0.00 \mathrm{E}+0 \mathrm{C}$ \\
\hline $\mathrm{PO} 4-3$ & $1.55 \mathrm{E}+04$ & $1.28 \mathrm{E}+04$ & $1.78 \mathrm{E}+04$ & $1.92 \mathrm{E}+04$ & $0.00 \mathrm{E}+00$ & $0.00 \mathrm{E}+00$ & $0.00 \mathrm{E}+00$ & $0.00 \mathrm{E}+00$ & $0.00 \mathrm{E}+00$ & $0.00 \mathrm{E}+00$ \\
\hline $\mathrm{OH}$ & $2.10 \mathrm{E}+05$ & $1.68 \mathrm{E}+05$ & $2.46 \mathrm{E}+05$ & $2.33 E+05$ & $0.00 E+00$ & $0.00 \mathrm{E}+00$ & $0.00 \mathrm{E}+00$ & $0.00 \mathrm{E}+00$ & $0.00 \mathrm{E}+00$ & $0.00 \mathrm{E}+00$ \\
\hline TOC & $9.38 E+03$ & \begin{tabular}{|l|}
$7.62 \mathrm{E}+03$ \\
\end{tabular} & $1.09 E+04$ & $1.32 E+04$ & $0.00 \mathrm{E}+00$ & $0.00 \mathrm{E}+00$ & $0.00 \mathrm{E}+00$ & $0.00 \mathrm{E}+00$ & $0.00 \mathrm{E}+00$ & $0.00 \mathrm{E}+00$ \\
\hline Sr90 & $4.17 E+05$ & $4.29 \mathrm{E}+04$ & $2.19 \mathrm{E}+05$ & $9.61 \mathrm{E}+04$ & $1.07 E+06$ & $6.64 \mathrm{E}+05$ & $2.00 E+05$ & $4.36 \mathrm{E}+05$ & $6.11 \mathrm{E}+05$ & $7.06 \mathrm{E}+05$ \\
\hline Tc99 & $1.35 \mathrm{E}+03$ & $1.89 E+02$ & $4.24 \mathrm{E}+02$ & $1.60 \mathrm{E}+02$ & $2.05 \mathrm{E}-06$ & $4.08 \mathrm{E}-06$ & 2.05E-06 & 1.27E-07 & $6.08 \mathrm{E}-14$ & 4.62E-01 \\
\hline Cs 137 & $4.61 \mathrm{E}+05$ & $3.14 E+04$ & $6.49 \mathrm{E}+04$ & $6.33 E+04$ & 1.83E-03 & 3.53E-03 & $3.76 \mathrm{E}-03$ & $6.79 \mathrm{E}-05$ & 1.25E-10 & $7.64 \mathrm{E}+02$ \\
\hline TRU & $1.78 \mathrm{E}+03$ & $5.47 \mathrm{E}+02$ & $6.46 \mathrm{E}+02$ & \begin{tabular}{|l|}
$2.71 E+02$ \\
\end{tabular} & $5.71 E+02$ & $6.15 \mathrm{E}+02$ & $3.09 E+02$ & $7.47 E+02$ & $9.61 E+02$ & $3.89 \mathrm{E}+02$ \\
\hline $\mathrm{H} 2 \mathrm{O}$ & $8.73 E+06$ & $7.38 \mathrm{E}+06$ & $1.00 \mathrm{E}+07$ & $6.61 E+06$ & $3.04 \mathrm{E}+05$ & $3.33 E+05$ & $4.20 \mathrm{E}+06$ & $9.19 E+05$ & $1.36 \mathrm{E}+06$ & $7.25 E+05$ \\
\hline Volume $(\mathrm{L})$ & $9.92 \mathrm{E}+06$ & $8.42 \mathrm{E}+06$ & $1.14 E+07$ & $7.29 \mathrm{E}+06$ & $1.76 E+06$ & $1.92 \mathrm{E}+06$ & $5.10 \mathrm{E}+06$ & $1.12 E+06$ & $1.66 \mathrm{E}+06$ & $1.18 E+06$ \\
\hline
\end{tabular}


WHC-SD-WM-RPT-210, Rev. 0

\begin{tabular}{|c|c|c|c|c|c|c|c|c|c|c|}
\hline Source & 113-SX & $114-S X$ & $115-5 x$ & 101-T & $102-\mathrm{T}$ & 103-T| & 104-T & 105-T & $106-T$ & 107 \\
\hline Units & $\mathrm{kg}$ & $\mathrm{kg}$ & $\mathrm{kg}$ & $\mathrm{kg}$ & $\mathrm{kg}$ & $\mathrm{kg}$ & $\mathrm{kg}$ & $\mathrm{kg}$ & $\mathrm{kg}$ & $\mathrm{kg}$ \\
\hline \multicolumn{11}{|l|}{ Čomponent } \\
\hline$(\mathrm{OH}) 4$ & $2 \mathrm{E}+02$ & $5 E+03$ & $16 \mathrm{E}+02$ & $88 \mathrm{E}+03$ & $37 \mathrm{E}+03$ & $3.71 \mathrm{E}+03$ & $1.5 \overline{2 E}+04$ & $1.89 \mathrm{E}+01$ & $2.11 \mathrm{E}+03$ & $5.52 \mathrm{E}+03$ \\
\hline $3 A+2$ & $O O E+00$ & $0 \mathrm{EE}+00$ & $.00 E+00$ & $00 E+00$ & $00 E+00$ & $0.00 E+00$ & $0.00 E+00$ & $0 . \overline{00 E}+00$ & $0.00 E+00$ & $00 \mathrm{E}+00$ \\
\hline$\overline{C A}+2$ & $97 \mathrm{E}-03$ & $7.11 \mathrm{E}+01$ & $4.77 \mathrm{E}+00$ & $4.47 \mathrm{E}-01$ & $2.19 \mathrm{E}-01$ & $1.74 E+00$ & $1.34 \mathrm{E}+00$ & $5.01 \mathrm{E}-01$ & $8.60 \mathrm{E}-02$ & $4.64 \mathrm{E}-01$ \\
\hline $\mathrm{CD}+2$ & $0.00 E+00$ & $0.00 \mathrm{E}+00$ & $0.00 E+00$ & $0.00 E+00$ & $0.00 \mathrm{E}+00$ & $0.00 E+00$ & $0.00 E+00$ & $0.00 \mathrm{E}+00$ & $0.00 \mathrm{E}+00$ & $0.00 E+00$ \\
\hline $\mathrm{CR}(\mathrm{OH}) 4-$ & $2.69 E+01$ & $8.96 E+03$ & $1.42 E+03$ & $6.62 \mathrm{E}+00$ & $3.32 \mathrm{E}+00$ & $1.00 E+02$ & $9.62 \mathrm{E}+01$ & $2.03 E+01$ & $4.14 \mathrm{E}+00$ & $2.57 \mathrm{E}+01$ \\
\hline $\mathrm{FE}+3$ & $29 E-01$ & $30 E+02$ & $2.80 \bar{E}+01$ & $2.40 \mathrm{E}+01$ & $1.17 \mathrm{E}+01$ & $8 \mathrm{E}+01$ & $8.90 \mathrm{E}+01$ & $3.75 E+01$ & $4.46 \mathrm{E}+00$ & $3.36 E+01$ \\
\hline $\bar{G}+2$ & $0.00 E+00$ & $0.00 E+00$ & $0.00 E+00$ & $0.00 \mathrm{E}+00$ & $0.00 \mathrm{E}+00$ & $0.00 E+00$ & $0.00 \mathrm{E}+00$ & $0.00 \mathrm{E}+00$ & $0.00 E+00$ & $0.00 E+00$ \\
\hline $\mathrm{K}+$ & $0.00 E+00$ & $0.00 \mathrm{E}+00$ & $0.00 E+00$ & $0.00 \mathrm{E}+00$ & $0.00 \mathrm{E}+00$ & $0.00 \mathrm{E}+00$ & $0.00 E+00$ & $0.00 \mathrm{E}+00$ & $0.00 \mathrm{E}+00$ & $0.00 E+00$ \\
\hline$A+3$ & $0.00 E+00$ & $0.00 \mathrm{E}+00$ & $0.00 E+00$ & $0.00 E+00$ & $0.00 E+00$ & $0.00 E+00$ & $0.00 \mathrm{E}+00$ & $0.00 E+00$ & $0.00 \mathrm{E}+00$ & $0.00 \mathrm{E}+00$ \\
\hline$\sqrt{A}+$ & $7.49 E+02$ & $20 \mathrm{E}+05$ & $57 E+04$ & $9.89 \mathrm{E}+03$ & $5.14 E+03$ & $1.58 \mathrm{E}+04$ & $3.23 \mathrm{E}+05$ & $7.27 \mathrm{E}+04$ & $1.05 E+04$ & $1.09 \mathrm{E}+05$ \\
\hline $11+3$ & $7 \bar{E}-02$ & $58 \mathrm{E}+01$ & $3.65 \mathrm{E}+00$ & E-01 & $3.50 \mathrm{E}-01$ & $1.29 \mathrm{E}+00$ & $1.65 \mathrm{E}+00$ & $7.06 \mathrm{E}-01$ & $1.20 \mathrm{E}-01$ & $6.04 \mathrm{E}-01$ \\
\hline $\mathrm{PB}+4$ & $30 E+00$ & $00 E+00$ & $0.00 \mathrm{E}+00$ & $0.00 \mathrm{E}+00$ & $0.00 \mathrm{E}+00$ & $0.00 E+00$ & $0.00 \mathrm{E}+00$ & $0.00 E+00$ & $0.00 \mathrm{E}+00$ & $0.00 E+00$ \\
\hline $\mathrm{CO}^{3}-2$ & $54 E+01$ & $5.44 \mathrm{E}+03$ & $3.62 \mathrm{E}+02$ & $8.74 \mathrm{E}+02$ & $5.20 E+02$ & & $206 \mathrm{E}+03$ & $\mathrm{E}+02$ & $133 E+02$ & $716 \mathrm{E}+02$ \\
\hline$\overline{\mathrm{CL}}-$ & $13 E+01$ & $7.86 \mathrm{E}+02$ & $7.15 E+01$ & $7.24 \mathrm{E}+01$ & $2.62 E+01$ & $9.45 E+01$ & $8.63 \mathrm{E}+02$ & $3.11 \mathrm{E}+02$ & $3.59 \mathrm{E}+01$ & $2.33 \mathrm{E}+02$ \\
\hline F- & $00 E+00$ & $00 E+00$ & $0.00 E+00$ & $0.00 E+00$ & $0.00 E+00$ & $2.58 \mathrm{E}+01$ & $1.64 E+04$ & $4.50 E+03$ & $3.22 E+02$ & $5.46 E+03$ \\
\hline SO4-2 & $4.35 E+00$ & $2.54 \mathrm{E}+02$ & $2.20 E+01$ & $2.62 E+02$ & $2.52 E+02$ & $3.09 \mathrm{E}+02$ & $2.86 \mathrm{E}+03$ & $5.63 \mathrm{E}+02$ & $7.57 \mathrm{E}+01$ & $7.62 \mathrm{E}+02$ \\
\hline NO3- & $1.75 E+03$ & $39 \mathrm{E}+06$ & $6.78 \mathrm{E}+04$ & $1.43 E+04$ & $5.55 E+03$ & $3.37 E+04$ & $1.09 \mathrm{E}+05$ & $4.24 E+04$ & $6.49 \mathrm{E}+03$ & $2.84 E+04$ \\
\hline NO2- & $0.00 E+00$ & $0 \mathrm{E}+00$ & $00 E+00$ & $1.54 \mathrm{E}+03$ & $7.42 E+02$ & $1.83 \mathrm{E}+03$ & $1.15 \mathrm{E}+04$ & $7.52 E+02$ & $2.02 E+03$ & $3.08 E+03$ \\
\hline $\mathrm{PO4-3}$ & $00 E+00$ & $0 E+00$ & $00 \mathrm{E}+00$ & $1.65 E+02$ & $1.64 E+02$ & $\mathrm{BE}+02$ & $9.01 \mathrm{E}+04$ & $1.85 E+04$ & $1.59 \mathrm{E}+03$ & $3.21 \mathrm{E}+04$ \\
\hline $\mathrm{OH}$ & $0 O E+00$ & $00 \mathrm{E}+00$ & $0.00 E+00$ & $1.30 E+03$ & $1.17 E+03$ & $7.83 \mathrm{E}+02$ & 1.37E+05 & $2.73 E+04$ & $3.68 \mathrm{E}+03$ & $4.84 E+04$ \\
\hline TOC & $0.00 E+00$ & $00 \mathrm{E}+00$ & $0.00 \mathrm{E}+00$ & $0.00 \mathrm{E}+00$ & $0.00 \mathrm{E}+00$ & $1.98 E+01$ & $0.00 \mathrm{E}+00$ & $0.00 E+00$ & $0.00 E+00$ & $0.00 \mathrm{E}+00$ \\
\hline sr9o & $1.86 E+05$ & $6.40 E+05$ & $4.59 E+05$ & $1.49 E+03$ & $2.53 E+01$ & $1.25 E+04$ & $2.36 E+04$ & $2.88 E+03$ & $1.47 \mathrm{E}+02$ & $2.08 \mathrm{E}+04$ \\
\hline $\mathrm{T} \subset 99$ & $7.64 E+01$ & $6.08 \mathrm{E}-14$ & $1.49 \mathrm{E}+02$ & $4.78 \mathrm{E}+01$ & $8.10 \mathrm{E}-01$ & $4.48 \mathrm{E}+00$ & $2.16 \mathrm{E}+00$ & $2.04 \mathrm{E}-16$ & $1.12 \mathrm{E}-01$ & $1.05 \mathrm{E}-16$ \\
\hline $\operatorname{cs} 137$ & $14 E+05$ & $1.20 \mathrm{E}-10$ & $2.31 \mathrm{E}+05$ & $6.87 \mathrm{E}+03$ & $1.16 \mathrm{E}+02$ & $5.58 \mathrm{E}+02$ & $2.91 \mathrm{E}+03$ & $2.08 \mathrm{E}-13$ & $1.64 \mathrm{E}+02$ & $2.10 \mathrm{E}-13$ \\
\hline TRU & $83 E+01$ & $9.48 \mathrm{E}+02$ & $2.18 \mathrm{E}+02$ & \begin{tabular}{|l|}
$5.89 E+01$ \\
\end{tabular} & $1.00 E+00$ & $5.73 \mathrm{E}+00$ & $1.41 \mathrm{E}+02$ & $1.78 \mathrm{E}+02$ & $1.98 \mathrm{E}+01$ & $4.12 \mathrm{E}+01$ \\
\hline $\mathrm{H} 2 \mathrm{O}$ & $26 E+03$ & $3.72 \mathrm{E}+06$ & $1.83 E+05$ & $7.15 E+04$ & $3.86 E+04$ & $1.14 E+05$ & $2.80 E+06$ & $6.22 E+05$ & $8.70 E+04$ & $9.55 E+05$ \\
\hline Volume (L) & $2.83 E+04$ & $4.53 E+06$ & $2.23 \mathrm{E}+05$ & $7.65 \mathrm{E}+05$ & $3.68 \mathrm{E}+05$ & $3.38 E+05$ & $2.81 E+06$ & $6.32 E+05$ & $2.25 E+05$ & $9.51 \mathrm{E}+0$ \\
\hline
\end{tabular}

D-10 


\section{WHC-SD-WM-RPT-210, Rev. 0}

\begin{tabular}{|c|c|c|c|c|c|c|c|c|c|c|}
\hline Source & 108-T & 109-T & $110-T$ & 111-T & $112-T$ & 201-T & 202-T & $203-T$ & 204-T & $101-\mathrm{TX}$ \\
\hline Units & $\mathrm{kg}$ & $\mathrm{kg}$ & $\mathrm{kg}$ & $\mathrm{kg}$ & $\mathrm{kg}$ & $\mathrm{kg}$ & $\mathrm{kg}$ & $\mathrm{kg}$ & $\mathrm{kg}$ & $\mathrm{kg}$ \\
\hline \multicolumn{11}{|l|}{ Component } \\
\hline $\mathrm{L}(\mathrm{OH}) 4$ & $\mathrm{E}+02$ & $0 \mathrm{E}+00$ & $0 E++0$ & $0 \mathrm{E}+00$ & $00 \mathrm{E}+00$ & $.00 \mathrm{E}+00$ & $0.00 E+00$ & $.00 E+00$ & $0.00 E+00$ & $1.18 E+04$ \\
\hline $3 \mathrm{~A}+2$ & $E+00$ & $0 E+00$ & $O E+00$ & $0 \mathrm{E}+00$ & & $0.00 \mathrm{E}+00$ & $00 E+00$ & $0.00 \mathrm{E}+00$ & $0.00 \mathrm{E}+00$ & $.00 E+00$ \\
\hline$C A+2$ & $5 E+00$ & $5 \mathrm{E}+01$ & $2.42 E+00$ & $4.27 \mathrm{E}+00$ & $6.56 \mathrm{E}-01$ & $2.73 \mathrm{E}-01$ & $2.05 E-01$ & $3.41 \mathrm{E}-01$ & 3.70E-01 & \\
\hline $\mathrm{CD}+2$ & $O E+00$ & $00 \mathrm{E}+00$ & $0.00 E+00$ & $0.00 \mathrm{E}+00$ & $0.00 E+00$ & $0.00 \mathrm{E}+00$ & $0.00 E+00$ & $0.00 \mathrm{E}+00$ & $0.00 \mathrm{E}+00$ & $.00 E+00$ \\
\hline $\mathrm{CR}(\mathrm{OH}) 4-$ & $91 \mathrm{E}+01$ & $14 E+02$ & $7.75 E+01$ & $43 E+02$ & $2.31 E+01$ & $6.18 \mathrm{E}+00$ & $4.64 E+00$ & $7.71 E+00$ & $8.37 \mathrm{E}+00$ & $1.09 \mathrm{E}+03$ \\
\hline$F E+3$ & $3.18 \mathrm{E}+01$ & $68 \mathrm{E}+01$ & $1.84 E+02$ & $7 \mathrm{E}+02$ & $E+01$ & $1.40 E+01$ & $1.06 \mathrm{E}+01$ & $1.75 E+01$ & $1.90 \mathrm{E}+01$ & $264 E+01$ \\
\hline $4 G+2$ & $0 \mathrm{E}+00$ & $00 \mathrm{E}+00$ & $00 \mathrm{E}+00$ & $0 E+00$ & $0.00 E+00$ & $0.00 E+00$ & $0.00 E+00$ & $0.00 E+00$ & $.00 E+00$ & $0.00 \mathrm{E}+00$ \\
\hline & $0 \mathrm{E}+00$ & $0 E+\infty$ & $8.56 \mathrm{E}+01$ & $07 E+02$ & $0.00 E+00$ & $2.39 E+02$ & $1.80 E+02$ & $2.99 \mathrm{E}+02$ & $3.24 E+02$ & $1.00 \mathrm{E}+0 \mathrm{C}$ \\
\hline$A+3$ & $\mathrm{OE}+00$ & $0.00 \mathrm{E}+00$ & $5.84 \mathrm{E}-01$ & $2.10 E+00$ & $0.00 \mathrm{E}+00$ & $1.63 E+00$ & $1.23 \mathrm{E}+00$ & $2.04 \mathrm{E}+00$ & $2.21 \mathrm{E}+00$ & $00 E+00$ \\
\hline$\sqrt{A+}$ & $65 E+04$ & $9.93 E+04$ & $3.07 \mathrm{E}+05$ & $40 \mathrm{E}+05$ & $2.02 E+04$ & $2.15 E+04$ & $1.62 \mathrm{E}+04$ & $2.69 E+04$ & $2.92 E+04$ & $82 E+04$ \\
\hline $1+3$ & $6 \mathrm{E}+00$ & $51 \mathrm{E}+01$ & $5 \bar{E}+00$ & $5 \overline{9 E}+00$ & $+\infty$ & 4.21E-01 & $3 . \overline{16 E-01}$ & $5.25 \mathrm{E}-01$ & $5.70 \mathrm{E}-01$ & $2.02 \mathrm{E}+00$ \\
\hline $\mathrm{PB}+4$ & $0 \mathrm{E}+00$ & $0 \mathrm{E}+00$ & $0 E+00$ & $0 \mathrm{E}+00$ & $0.00 \mathrm{E}+00$ & $0.00 \mathrm{E}+00$ & $0.00 \mathrm{E}+00$ & $0.00 \mathrm{E}+00$ & $0.00 \mathrm{E}+00$ & $0.00 E+00$ \\
\hline OO3-2 & $E+02$ & $9 \mathrm{E}+03$ & $3.74 \mathrm{E}+03$ & $6.58 \mathrm{E}+03$ & $1.01 E+03$ & $4.21 \mathrm{E}+02$ & $3.17 E+02$ & $\mathrm{E}+02$ & $5.71 \mathrm{E}+02$ & $E+03$ \\
\hline CL- & $E+02$ & $56 \mathrm{E}+02$ & $1.34 \mathrm{E}+03$ & $1.62 E+03$ & $2.10 E+02$ & $1.12 \mathrm{E}+02$ & $8.45 \mathrm{E}+01$ & $1.40 E+02$ & $1.52 \mathrm{E}+02$ & $5.50 \mathrm{E}+02$ \\
\hline $\mathrm{F}-$ & $94 \mathrm{E}+03$ & $23 E+03$ & $2.10 E+04$ & $2.24 E+04$ & $8.74 E+02$ & $8.71 E+03$ & $6.55 \mathrm{E}+03$ & $1.09 \mathrm{E}+04$ & $1.18 E+04$ & $4.29 \mathrm{E}+01$ \\
\hline$\overline{O 4-2}$ & $16 \mathrm{E}+03$ & $5.16 \mathrm{E}+03$ & $1.91 \mathrm{E}+03$ & $2.07 E+03$ & $2.82 E+02$ & $1.29 \mathrm{E}+01$ & $9.69 \mathrm{E}+00$ & $1.61 \mathrm{E}+01$ & $1.75 E+01$ & $8.10 E+02$ \\
\hline $103-$ & $16 \mathrm{E}+04$ & $42 E+04$ & $99 \mathrm{E}+05$ & $2.36 \mathrm{E}+05$ & $2.89 \mathrm{E}+04$ & $2.12 E+04$ & $1.60 \mathrm{E}+04$ & $2.65 \mathrm{E}+04$ & $2.88 \mathrm{E}+04$ & $1.18 \mathrm{E}+05$ \\
\hline $\mathrm{OO} 2-$ & $36 \mathrm{E}+03$ & $2.20 E+03$ & $0.00 E+00$ & $0.00 \mathrm{E}+00$ & $0.00 E+00$ & $0.00 \mathrm{E}+00$ & $0.00 \mathrm{E}+00$ & $0.00 E+00$ & $0.00 \mathrm{E}+00$ & $0.00 \mathrm{E}+00$ \\
\hline $\mathrm{PO4-3}$ & $8 E+04$ & $3.71 \mathrm{E}+04$ & $7.07 \mathrm{E}+04$ & $4.44 \mathrm{E}+04$ & $3.32 \mathrm{E}+03$ & $7.72 \mathrm{E}+02$ & $5.80 \mathrm{E}+02$ & $9.63 \mathrm{E}+02$ & $1.05 E+03$ & $3.68 E+02$ \\
\hline $\mathrm{OH}$ & EE+04 & $10 \mathrm{E}+04$ & +05 & $6.63 \mathrm{E}+04$ & +03 & $3.03 \mathrm{E}+03$ & $\mathrm{E}+03$ & $E+03$ & +03 & $0.00 \mathrm{E}+00$ \\
\hline TOC & $0 \mathrm{E}+00$ & $0 \mathrm{E}+00$ & $2.55 \mathrm{E}+02$ & $8.87 \mathrm{E}+02$ & $0.00 \mathrm{E}+00$ & $7.64 \mathrm{E}+02$ & $5.75 \mathrm{E}+02$ & $9.54 \mathrm{E}+02$ & 03 & $3.21 \mathrm{E}+01$ \\
\hline Sr90 & $2.09 \mathrm{E}+03$ & $4.21 \mathrm{E}+01$ & $2.14 E+03$ & $1.81 \mathrm{E}+03$ & $2.70 \mathrm{E}+03$ & $0.00 E+00$ & $0.00 \mathrm{E}+00$ & $0.00 \mathrm{E}+00$ & $0.00 \mathrm{E}+00$ & $5.05 E+03$ \\
\hline Tc99 & $1.99 \mathrm{E}-01$ & $1.24 E+00$ & $6.23 \mathrm{E}-11$ & $0.00 \mathrm{E}+00$ & $3.22 \mathrm{E}-36$ & $0.00 \mathrm{E}+00$ & $0.00 \mathrm{E}+00$ & $0.00 \mathrm{E}+00$ & $0.00 E+00$ & $6.38 \mathrm{E}-08$ \\
\hline Cs137 & $3.40 \mathrm{E}+02$ & $1.43 E+03$ & $6.38 \mathrm{E}-08$ & $0.00 \mathrm{E}+00$ & $2.57 \mathrm{E}-32$ & $0.00 \mathrm{E}+00$ & $0.00 \mathrm{E}+00$ & $0.00 \mathrm{E}+00$ & $0.00 \mathrm{E}+00$ & 1.85E-05 \\
\hline TRU & $12 \mathrm{E}+00$ & 4.65E-01 & $1.61 \mathrm{E}+02$ & $1.24 \mathrm{E}+02$ & $2.14 E+02$ & $0.00 E+00$ & $3.11 \mathrm{E}-01$ & $3.11 \mathrm{E}+00$ & $0.00 \mathrm{E}+00$ & $1.09 \mathrm{E}-03$ \\
\hline & & & & & & & & & & \\
\hline $\mathrm{H} 2 \mathrm{O}$ & $4.72 E+05$ & & E+06 & 1.98E+06 & $1 E+05$ & 1.77E+05 & BE+05 & $21 \mathrm{E}+05$ & +05 & 3.42 \\
\hline Volume (L) & 4.92E+05 & $8.63 E+05$ & $2.67 E+06$ & $2.08 E+06$ & $1.76 \mathrm{E}+05$ & $1.87 \mathrm{E}+05$ & $1.41 \mathrm{E}+05$ & $2.34 E+05$ & & $1.01 \mathrm{E}+06$ \\
\hline
\end{tabular}


WHC-SD-WM-RPT-210, Rev. 0

\begin{tabular}{|c|c|c|c|c|c|c|c|c|c|c|}
\hline Source & $102-\mathrm{TX}$ & 103-TX & 104-TX & 105-TX & 106-TX & $107-\mathrm{TX}$ & 108-TX & $109-\mathrm{TX}$ & $110-\mathrm{TX}$ & 111-TX \\
\hline Units & $\mathrm{kg}$ & $\mathrm{kg}$ & $\mathrm{kg}$ & $\mathrm{kg}$ & $\mathrm{kg}$ & $\mathrm{kg}$ & $\mathrm{kg}$ & $\mathrm{kg}$ & $\mathrm{kg}$ & $\mathrm{kg}$ \\
\hline \multicolumn{11}{|l|}{ Component } \\
\hline$\overline{A L}(\mathrm{OH}) 4$ & $4 \mathrm{E}+03$ & $9.95 \mathrm{E}+03$ & $96 \mathrm{E}+03$ & $37 \mathrm{E}+04$ & $2.95 E+04$ & $1.74 \mathrm{E}+03$ & $8.24 E+03$ & $1.62 \mathrm{E}+04$ & $84 \mathrm{E}+04$ & $21 E+04$ \\
\hline $\mathrm{BA}+2$ & $\overline{\mathrm{OE}}+00$ & $0.00 E+00$ & $00 \mathrm{E}+00$ & $0 E+00$ & $0.00 E+00$ & $0.00 \mathrm{E}+00$ & $0.00 E+00$ & $0.00 E+00$ & $00 E+00$ & $.00 \mathrm{E}+00$ \\
\hline $4+2$ & $9 \mathrm{E}+01$ & $4.72 E+01$ & $1.44 \mathrm{E}+01$ & $1.84 E+02$ & $1.37 E+02$ & $8.28 \mathrm{E}+00$ & $3.34 E+01$ & $1.36 E+00$ & $30 \mathrm{E}+02$ & $.99 E+01$ \\
\hline $\mathrm{D}+2$ & $0 E+00$ & $0.00 \mathrm{E}+00$ & $00 E+00$ & $0.00 E+00$ & $0.00 E+00$ & $0.00 E+00$ & $0.00 \mathrm{E}+00$ & $.00 \mathrm{E}+00$ & $\overline{0 O E}+00$ & $00 \mathrm{E}+00$ \\
\hline & $5 E+03$ & $0 \mathrm{E}+03$ & $8.93 E+02$ & $7 \mathrm{E}+04$ & $8 E+03$ & $5.24 \mathrm{E}+02$ & $2.47 \mathrm{E}+03$ & $7.54 E+01$ & $8.25 E+03$ & $34 E+03$ \\
\hline $\mathrm{FE}+$ & $8 \mathrm{E}+01$ & $1.29 E+02$ & $13 \mathrm{E}+01$ & $3 E+02$ & $3.99 \mathrm{E}+02$ & $2.38 \mathrm{E}+01$ & $3.30 \mathrm{E}+01$ & $9.86 E+01$ & $3.61 \mathrm{E}+02$ & $78 \mathrm{E}+02$ \\
\hline $\mathrm{HG}+2$ & $0 \mathrm{E}+00$ & $0.00 E+00$ & $0.00 \mathrm{E}+00$ & $00 E+00$ & $0.00 E+00$ & $0.00 \mathrm{E}+00$ & $0.00 E+00$ & $0.00 E+00$ & $.00 \mathrm{E}+00$ & $0.00 \mathrm{E}+00$ \\
\hline $\mathrm{K}+$ & $0 E+00$ & $0 \mathrm{E}+00$ & $0.00 \mathrm{E}+00$ & $0.00 E+00$ & $0.00 E+00$ & $0.00 \mathrm{E}+00$ & $0.00 \mathrm{E}+00$ & $0.00 E+00$ & $0.00 E+00$ & $00 \mathrm{E}+00$ \\
\hline$L A+3$ & $0 \mathrm{E}+00$ & $00 E+00$ & $0.00 \mathrm{E}+00$ & $0 \mathrm{E}+00$ & $0.00 \mathrm{E}+00$ & $0.00 E+00$ & $0.00 \mathrm{E}+00$ & $0.00 \mathrm{E}+00$ & $0.00 \mathrm{E}+00$ & $0.00 E+00$ \\
\hline & $4 E+05$ & $54 E+05$ & $19 \mathrm{E}+05$ & $7 \bar{E}+06$ & $1.02 \mathrm{E}+06$ & $83 E+04$ & $2.95 E+05$ & $3.21 \mathrm{E}+05$ & $9.92 E+05$ & $7.69 \mathrm{E}+05$ \\
\hline $\mathrm{N} \mid+3$ & $09 \mathrm{E}+01$ & $1 \mathrm{E}+01$ & $8.76 \bar{E}+00$ & $13 \mathrm{E}+02$ & $8.47 E+01$ & $5.13 \mathrm{E}+00$ & $1.56 \mathrm{E}+01$ & $1.77 \mathrm{E}+00$ & $.03 E+01$ & $6.17 \mathrm{E}+01$ \\
\hline \multirow[t]{2}{*}{$\mathrm{PB}+4$} & $0 \mathrm{E}+\infty$ & $00 E+00$ & $0.00 \mathrm{E}+00$ & $0.00 E+00$ & $0.00 \mathrm{E}+00$ & $0.00 E+00$ & $0.00 \mathrm{E}+00$ & $0.00 E+00$ & $0.00 \mathrm{E}+00$ & $0.00 E+00$ \\
\hline & & & +03 & & & & & & & $04 E+03$ \\
\hline$\overline{C L}-$ & $1.52 \mathrm{E}+03$ & $2.12 E+03$ & $6.37 \mathrm{E}+02$ & $25 E+03$ & $6.15 \mathrm{E}+03$ & $2 E+02$ & $E+03$ & $6.86 E+02$ & $5.90 \mathrm{E}+03$ & $4.57 \mathrm{E}+03$ \\
\hline $\mathrm{F}-$ & $5.96 \mathrm{E}+02$ & $8.30 \mathrm{E}+02$ & $2.47 E+02$ & $3.23 E+03$ & $2.40 E+03$ & $1.45 \mathrm{E}+02$ & $6.88 \mathrm{E}+02$ & $1.60 E+04$ & $3.56 \mathrm{E}+03$ & $3.14 E+03$ \\
\hline$\overline{\mathrm{SO}} 4-2$ & $4.22 \mathrm{E}+03$ & $5.90 \mathrm{E}+03$ & $3.86 \mathrm{E}+03$ & $2.25 E+04$ & $1.61 E+04$ & $1.95 E+03$ & $5.34 E+03$ & $2.24 \mathrm{E}+03$ & $1.55 \mathrm{E}+04$ & $1.20 \mathrm{E}+04$ \\
\hline NO3- & & & & $39 \mathrm{E}+06$ & $2.53 E+06$ & $53 \mathrm{E}+05$ & $7.27 \mathrm{E}+05$ & $8.36 E+04$ & $2.41 \mathrm{E}+06$ & $1.86 E+06$ \\
\hline & $E+04$ & $55 E+04$ & $8 E+03$ & $1.31 \mathrm{E}+05$ & $9.70 E+04$ & $5.86 \mathrm{E}+03$ & $2.78 E+04$ & $9.03 E+03$ & $9.33 \mathrm{E}+04$ & $7.21 \mathrm{E}+04$ \\
\hline $\mathrm{PO4}$ & $35 E+03$ & $2.60 \mathrm{E}+03$ & $2.18 E+03$ & $9.80 \mathrm{E}+03$ & $6.91 \mathrm{E}+03$ & $1.07 \mathrm{E}+03$ & $1.66 \mathrm{E}+03$ & $9.42 E+04$ & $1.31 E+04$ & $1.18 \mathrm{E}+04$ \\
\hline $\mathrm{OH}$ & $7.62 E+03$ & $4.37 \mathrm{E}+03$ & $9.53 \mathrm{E}+03$ & $1.57 E+04$ & $8.64 E+03$ & $4.89 \mathrm{E}+03$ & $3.96 \mathrm{E}+03$ & $1.42 \mathrm{E}+05$ & $1.82 E+04$ & $1.66 \mathrm{E}+0$ \\
\hline TOC & $5.28 \mathrm{E}+02$ & $7.36 \mathrm{E}+02$ & $2.13 \mathrm{E}+02$ & $2.87 \mathrm{E}+03$ & $2.13 E+03$ & $1.26 \mathrm{E}+02$ & $E+02$ & $E+\infty$ & $1.99 E+03$ & $1.51 E+03$ \\
\hline Sr90 & $E+02$ & $4.30 E+02$ & $3.79 \mathrm{E}-05$ & $1.89 \mathrm{E}+03$ & 1E-06 & $5.86 E-04$ & $3.04 E+03$ & $8.72 E+04$ & $6.11 E+04$ & $2.88 \mathrm{E}+04$ \\
\hline $\operatorname{Tc9}$ & $4 \mathrm{E}+00$ & $9.54 \mathrm{E}-01$ & $1.02 E-06$ & $11 \mathrm{E}+01$ & $6.02 E+00$ & $2.91 \mathrm{E}-07$ & $2.28 E+01$ & $5.81 \mathrm{E}+02$ & $2.08 \mathrm{E}+02$ & $3.08 \mathrm{E}+0$ \\
\hline $\mathrm{Cs} 13$ & $1 E+02$ & $7.93 \mathrm{E}+02$ & $1.33 \mathrm{E}-04$ & $5.53 \mathrm{E}+03$ & $8.96 E+03$ & $2.65 \mathrm{E}-04$ & $3.32 E+04$ & $2.38 \mathrm{E}+05$ & $1.00 \mathrm{E}+05$ & $2.27 \mathrm{E}+04$ \\
\hline TRU & BOE-02 & $7.33 \mathrm{E}-02$ & $3.63 \mathrm{E}-04$ & $2.63 \mathrm{E}-01$ & $4.46 \mathrm{E}-02$ & $1.35 E-06$ & $1.33 E+00$ & $2.34 \mathrm{E}+02$ & $4.11 \mathrm{E}+01$ & $4.31 E+00$ \\
\hline $\mathrm{H} 2 \mathrm{O}$ & & & & & & & $E+06$ & $2.80 E+06$ & $718 \mathrm{E}+06$ & \\
\hline Volume & $E+06$ & & & 1.20E+Ur & & & & $2.79 E+06$ & $8.62 E+06$ & \\
\hline & & & & & & & & & & \\
\hline
\end{tabular}

D. 12 
WHC-SD-WM-RPT-210, Rev. 0

\begin{tabular}{|c|c|c|c|c|c|c|c|c|c|c|}
\hline Source & 112-TX & 113-TX & 114-TX & 115-TX & 116-TX| & $117-\mathrm{TX}$ & $118-\mathrm{T} X$ & $101-T Y$ & $102-T Y$ & 103-TY \\
\hline Units & $\mathrm{kg}$ & $\mathrm{kg}$ & $\mathrm{kg}$ & $\mathrm{kg}$ & $\mathrm{kg}$ & $\mathrm{kg}$ & $\mathrm{kg}$ & $\mathrm{kg}$ & $\mathrm{kg}$ & $\mathrm{kg}$ \\
\hline \multicolumn{11}{|l|}{ Component } \\
\hline$(\mathrm{OH}) 4$ & $2 E+04$ & $3.46 \mathrm{E}+04$ & $3.05 E+04$ & $4.06 \mathrm{E}+04$ & $1.77 \mathrm{E}+04$ & $2.66 \mathrm{E}+04$ & $2.36 \mathrm{E}+04$ & $0.00 E+00$ & $2.18 E+03$ & $2.63 E+03$ \\
\hline $\mathrm{BA}+2$ & $0 \mathrm{E}+00$ & $00 \mathrm{E}+00$ & $0 \mathrm{OE}+00$ & $00 \mathrm{E}+00$ & $0.00 \mathrm{E}+00$ & $0.00 \mathrm{E}+00$ & $0.00 \mathrm{E}+00$ & $0.00 \mathrm{E}+00$ & & $0.00 \mathrm{E}+00$ \\
\hline$\overline{C A}+2$ & $1 E+02$ & $30 E+02$ & $69 \mathrm{E}+02$ & $93 E+02$ & $2.24 E+02$ & $2.12 \mathrm{E}+02$ & $9.69 \mathrm{E}+01$ & $2.00 \mathrm{E}+01$ & $2.29 \mathrm{E}+01$ & $1.78 \mathrm{E}+01$ \\
\hline$C D+2$ & $0 \mathrm{E}+0 \mathrm{O}$ & $0.00 E+00$ & $0.00 E+00$ & $0.00 E+00$ & $0.00 E+00$ & $0.00 \mathrm{E}+00$ & $0.00 E+00$ & $0.00 \mathrm{E}+00$ & $0.00 E+00$ & $0.00 \mathrm{E}+00$ \\
\hline $\mathrm{CR}(\mathrm{OH})$ & $2 \mathrm{E}+04$ & $8.24 \mathrm{E}+03$ & $9.29 \mathrm{E}+03$ & $1.22 \mathrm{E}+04$ & $6.21 \mathrm{E}+03$ & $8.56 \mathrm{E}+03$ & $5.99 \mathrm{E}+03$ & $9.14 \mathrm{E}+01$ & $7.36 \mathrm{E}+02$ & $1.06 E+03$ \\
\hline $\mathrm{FE}+3$ & $19 \mathrm{E}+02$ & $4.00 \mathrm{E}+02$ & $4.63 E+02$ & $5.36 \mathrm{E}+02$ & $6.11 \mathrm{E}+02$ & $5.78 E+02$ & $2.72 \mathrm{E}+02$ & $7.18 \mathrm{E}+01$ & $6.26 \mathrm{E}+01$ & $1.34 E+02$ \\
\hline $\mathrm{HG}+2$ & $0.00 \mathrm{E}+00$ & $0.00 \mathrm{E}+00$ & $0.00 \mathrm{E}+00$ & $0.00 E+00$ & $0.00 \mathrm{E}+00$ & $0.00 \mathrm{E}+00$ & $0.00 E+00$ & $0.00 \mathrm{E}+00$ & $0.00 \mathrm{E}+00$ & $0.00 \mathrm{E}+00$ \\
\hline $\mathrm{K}+$ & $00 E+00$ & $0.00 \mathrm{E}+00$ & $00 \mathrm{E}+00$ & $0.00 E+00$ & $0.00 E+00$ & $0.00 E+00$ & $0.00 \mathrm{E}+00$ & $0.00 E+00$ & $0.00 \mathrm{E}+00$ & $0.00 \mathrm{E}+00$ \\
\hline $\mathrm{LA}+3$ & $00 \mathrm{E}+00$ & $0.00 \mathrm{E}+00$ & $0.00 \mathrm{E}+00$ & $0.00 \mathrm{E}+00$ & $0.00 \mathrm{E}+00$ & $0.00 \mathrm{E}+00$ & $0.00 \mathrm{E}+00$ & $0.00 \mathrm{E}+00$ & $0.00 \mathrm{E}+00$ & $0.00 E+\infty$ \\
\hline NAt & $46 E+06$ & $1.11 E+06$ & $1.18 \mathrm{E}+06$ & $1.44 \mathrm{E}+06$ & $1.20 \mathrm{E}+06$ & $1.29 E+06$ & $7.29 \mathrm{E}+05$ & $2.00 \mathrm{E}+05$ & $1.29 \mathrm{E}+05$ & $2.45 \mathrm{E}+05$ \\
\hline $\mathrm{NI}+3$ & $1.24 \mathrm{E}+02$ & $8.06 \mathrm{E}+01$ & $1.04 E+02$ & $19 E+02$ & $1.38 \mathrm{E}+02$ & $1.31 \mathrm{E}+02$ & $5.99 \mathrm{E}+01$ & $1.43 \mathrm{E}+01$ & $1.41 E+01$ & $1.30 E+01$ \\
\hline $\mathrm{PB}+4$ & $00 \mathrm{E}+00$ & $0.00 \mathrm{E}+00$ & $00 \mathrm{E}+00$ & $00 \mathrm{E}+00$ & $0.00 \mathrm{E}+00$ & $0.00 \mathrm{E}+00$ & $0.00 \mathrm{E}+00$ & $0.00 \mathrm{E}+00$ & $0.00 E+00$ & $0.00 \mathrm{E}+00$ \\
\hline & & & & & & & & & & \\
\hline $\begin{array}{l}\mathrm{CO} 3 \\
\mathrm{CL}-\end{array}$ & $9 E+04$ & $2 E+04$ & $33 E+04$ & $55 E+04$ & $1.74 E+04$ & $1.66 \mathrm{E}+04$ & $8.58 \mathrm{E}+03$ & $45 \mathrm{E}+03$ & & $4.22 E+03$ \\
\hline $\begin{array}{l}\mathrm{CL}- \\
\mathrm{F}-\end{array}$ & $0 \mathrm{E}+03$ & $6.13 E+03$ & $7.04 E+03$ & $8.75 E+03$ & $7.03 E+03$ & $7.67 \mathrm{E}+03$ & $4.79 \mathrm{E}+03$ & $4.99 \mathrm{E}+02$ & $7.58 \mathrm{E}+02$ & $1.47 \mathrm{E}+03$ \\
\hline F- & $53 \mathrm{E}+03$ & \begin{tabular}{|c|}
$9.89 E+03$ \\
\end{tabular} & $7.93 \mathrm{E}+03$ & $3.39 \mathrm{E}+03$ & $3.06 \mathrm{E}+04$ & $2.00 \mathrm{E}+04$ & $2.20 \mathrm{E}+03$ & $8.83 E+03$ & $2.80 \mathrm{E}+03$ & $3.35 \mathrm{E}+03$ \\
\hline $\mathrm{SO} 4-2$ & $2.45 E+04$ & $1.62 \mathrm{E}+04$ & $2.21 \mathrm{E}+04$ & $2.37 \mathrm{E}+04$ & $3.90 E+04$ & $3.26 \mathrm{E}+04$ & $1.16 \mathrm{E}+04$ & $4.30 \mathrm{E}+03$ & $3.83 \mathrm{E}+03$ & $1.02 E+04$ \\
\hline NO3- & $57 E+06$ & $2.43 \mathrm{E}+06$ & $2.76 \mathrm{E}+06$ & $3.57 \mathrm{E}+06$ & $2.15 \mathrm{E}+06$ & $2.70 \mathrm{E}+06$ & $1.79 \mathrm{E}+06$ & $8.06 \mathrm{E}+04$ & $2.45 \mathrm{E}+05$ & $3.75 \mathrm{E}+05$ \\
\hline NO2- & $7 \bar{E}+05$ & $62 \mathrm{E}+04$ & $1.05 E+05$ & $1.37 \mathrm{E}+05$ & $7.47 \mathrm{E}+04$ & $9.90 E+04$ & $6.72 \mathrm{E}+04$ & $2.43 \mathrm{E}+03$ & $8.70 E+03$ & $1.22 \mathrm{E}+04$ \\
\hline PO4-3 & $9 \bar{E}+04$ & $5.11 E+04$ & $4.53 E+04$ & $9.72 \mathrm{E}+03$ & $2.11 \mathrm{E}+05$ & $1.32 \mathrm{E}+05$ & $8.52 \mathrm{E}+03$ & $6.84 \mathrm{E}+04$ & $1.91 \mathrm{E}+04$ & $2.72 \mathrm{E}+04$ \\
\hline $\mathrm{OH}$ & $2.04 \mathrm{E}+04$ & $7.52 E+04$ & $3.10 E+04$ & $1.36 \mathrm{E}+04$ & $1.20 \mathrm{E}+05$ & $7.78 \mathrm{E}+04$ & $7.59 \mathrm{E}+03$ & $8.25 \mathrm{E}+04$ & $1.10 \mathrm{E}+04$ & $5.50 \mathrm{E}+04$ \\
\hline$\overline{T O C}$ & $2.98 \mathrm{E}+03$ & \begin{tabular}{|c|}
$1.90 \mathrm{E}+03$ \\
\end{tabular} & $2.23 \mathrm{E}+03$ & $3.01 \mathrm{E}+03$ & $1.31 \mathrm{E}+03$ & $1.96 \mathrm{E}+03$ & $1.44 \mathrm{E}+03$ & $2.13 E+03$ & $61 \mathrm{E}+02$ & $1.61 \mathrm{E}+03$ \\
\hline Srao & $4.57 E+03$ & $4.89 E+03$ & $4.58 E+02$ & $1.78 E+04$ & $2.32 \mathrm{E}+04$ & $4.41 \mathrm{E}+04$ & $4.55 \mathrm{E}+05$ & $1.01 \mathrm{E}+04$ & $7.17 \mathrm{E}+03$ & $6.46 E+04$ \\
\hline Tc99 & $1.57 \mathrm{E}+01$ & $5.25 \mathrm{E}+00$ & $1.47 E+01$ & $7.01 E+00$ & $3.53 \mathrm{E}+00$ & $1.44 E+00$ & $5.46 \mathrm{E}+02$ & $1.32 \mathrm{E}+00$ & $1.55 E+02$ & $4.32 \mathrm{E}+02$ \\
\hline Cs137 & $1.76 E+04$ & $6.02 \mathrm{E}+03$ & $1.75 E+04$ & $9.81 \mathrm{E}+03$ & $4.17 \mathrm{E}+03$ & $1.69 \mathrm{E}+03$ & $2.78 \mathrm{E}+05$ & $1.62 \mathrm{E}+03$ & $1.87 \mathrm{E}+04$ & $3.73 \mathrm{E}+04$ \\
\hline TRU & $3.33 \mathrm{E}-01$ & $4.81 \mathrm{E}+01$ & $4.90 \mathrm{E}+00$ & $5.66 \mathrm{E}-01$ & $2.83 \mathrm{E}-02$ & 1.91E-02 & $2.03 \mathrm{E}+03$ & $2.12 \mathrm{E}+02$ & $4.08 \mathrm{E}+00$ & $2.65 E+02$ \\
\hline $\mathrm{H} 2 \mathrm{O}$ & $06 \mathrm{E}+07$ & $8.26 E+06$ & $8.58 \mathrm{E}+06$ & $1.04 E+07$ & $9.20 \mathrm{E}+06$ & $9.65 \mathrm{E}+06$ & $5.26 \mathrm{E}+06$ & $1.72 E+06$ & $9.77 \mathrm{E}+05$ & $1.92 \mathrm{E}+06$ \\
\hline Volume (L) & $1.27 \mathrm{E}+07$ & $9.70 E+06$ & $1.0 \bar{E} \bar{E}+07$ & $1.25 E+07$ & $1.05 \bar{E}+07$ & $1.13 \mathrm{E}+07$ & & & $1.12 \mathrm{E}+06$ & $2.13 E+06$ \\
\hline
\end{tabular}

D-13 
WHC-SD-WM-RPT-210, Rev. 0

\begin{tabular}{|c|c|c|c|c|c|c|c|c|c|c|}
\hline Source & 104-TY & $105-\mathrm{TY}$ & $106-T Y$ & 101-U & $102-U$ & $103-U$ & 104-U & $105-U$ & $106-U$ & $107-U$ \\
\hline Units & $\mathrm{kg}$ & $\mathrm{kg}$ & $-\overline{\mathrm{kg}}$ & $\mathrm{kg}$ & $\mathrm{kg}$ & $\mathrm{kg}$ & $\mathrm{kg}$ & $\mathrm{kg}$ & $\mathrm{kg}$ & \\
\hline \multicolumn{11}{|l|}{ Component } \\
\hline$\overline{\mathrm{AL}}(\mathrm{OH}) 4-$ & $0 \mathrm{E}+00$ & $0 \mathrm{E}+00$ & $0.00 \mathrm{E}+00$ & $0.00 \mathrm{E}+00$ & $2.48 \mathrm{E}+04$ & $5.04 E+04$ & $00 \mathrm{E}+00$ & $80 \mathrm{E}+04$ & $19 E+04$ & $38 \mathrm{E}+04$ \\
\hline $\mathrm{BA}+2$ & $0 \mathrm{E}+00$ & $0 \mathrm{E}+00$ & $0.00 \mathrm{E}+00$ & $0.00 \mathrm{E}+00$ & $00 E+00$ & $00 \mathrm{E}+00$ & $.00 E+00$ & $00 E+\infty$ & $00 \bar{E}+00$ & $00 \mathrm{E}+00$ \\
\hline $\mathrm{CA}+2$ & $6 \mathrm{E}-01$ & $19 \mathrm{E}+00$ & $2.22 \mathrm{E}-01$ & $8.41 \mathrm{E}-02$ & $43 E+01$ & $35 \mathrm{E}+01$ & $1.53 \mathrm{E}-01$ & $45 E+01$ & $13 \mathrm{E}+01$ & $5 \mathrm{E}+01$ \\
\hline$\overline{C D}+2$ & $\overline{O E+00}$ & $00 \mathrm{E}+00$ & $0.00 E+00$ & $0.00 E+00$ & $0.00 E+00$ & $00 \mathrm{E}+00$ & $0.00 \mathrm{E}+00$ & $00 E+00$ & $\mathrm{E}+00$ & $0 E+00$ \\
\hline $\mathrm{CR}(\mathrm{OH}) 4$ & $24 E+00$ & $2.66 \mathrm{E}+01$ & $2.70 \mathrm{E}+00$ & $2.66 \mathrm{E}+00$ & $4.73 E+03$ & $3.75 \mathrm{E}+03$ & $4.86 \mathrm{E}+00$ & $27 \mathrm{E}+03$ & $81 \mathrm{E}+03$ & $20 E+03$ \\
\hline $\mathrm{FE}+3$ & $7 E+01$ & $1.97 \mathrm{E}+02$ & $2.00 \mathrm{E}+01$ & $3.59 \mathrm{E}+00$ & $2.54 E+02$ & $2.14 \mathrm{E}+02$ & $6.55 E+00$ & $43 E+02$ & $\mathrm{E}+02$ & $2 E+01$ \\
\hline$\overline{\mathrm{HG}+2}$ & $0 \mathrm{E}+00$ & $00 \mathrm{E}+00$ & $0.00 \mathrm{E}+00$ & $0.00 \mathrm{E}+00$ & $0.00 E+00$ & $.00 E+00$ & $0.00 \mathrm{E}+00$ & $00 E+00$ & $E+00$ & $\mathrm{E}+00$ \\
\hline $\mathrm{K}+$ & $30 E+00$ & $00 \mathrm{E}+00$ & $0.00 \mathrm{E}+00$ & $0.00 \mathrm{E}+00$ & $4.08 E+02$ & $1.54 \mathrm{E}+03$ & $0.00 \mathrm{E}+00$ & $.13 E+03$ & $6.37 \mathrm{E}+02$ & $18 \mathrm{E}+03$ \\
\hline $\mathrm{LA}+3$ & $0 E+00$ & $0 \mathrm{E}+00$ & $0.00 \mathrm{E}+00$ & $0.00 \mathrm{E}+00$ & $0.00 E+00$ & $0.00 E+00$ & $0.00 \mathrm{E}+00$ & $0.00 \mathrm{E}+00$ & $0.00 E+00$ & $.00 E+00$ \\
\hline $\mathrm{NA}+$ & $24 E+04$ & $19 \mathrm{E}+05$ & $1.21 \mathrm{E}+04$ & $1.73 E+04$ & $6.89 \mathrm{E}+05$ & $8.45 \mathrm{E}+05$ & $3.15 \mathrm{E}+04$ & $62 \mathrm{E}+05$ & $3.98 \mathrm{E}+05$ & $68 \mathrm{E}+05$ \\
\hline$\sqrt{1+3}$ & $22 \mathrm{E}-01$ & $3.28 \mathrm{E}+00$ & 3.32E-01 & $1.14 \mathrm{E}-01$ & $4.75 \mathrm{E}+01$ & $4.73 E+01$ & $2.08 \mathrm{E}-01$ & $2.82 E+01$ & $2.55 \mathrm{E}+01$ & $07 \mathrm{E}+01$ \\
\hline$\overline{P B+4}$ & $0 \mathrm{E}+00$ & $00 \mathrm{E}+00$ & $0.00 E+00$ & $0.00 \mathrm{E}+00$ & $6.12 \mathrm{E}-02$ & 2.31E-01 & $0.00 \mathrm{E}+00$ & 1.70E-01 & $9.57 \mathrm{E}-02$ & $1.77 \mathrm{E}-01$ \\
\hline & & & & & & & & & & \\
\hline $\mathrm{CO} 3-2$ & $2 E+03$ & $94 E+03$ & $2 \mathrm{E}+02$ & $2.14 \mathrm{E}+03$ & $.47 \mathrm{E}+04$ & & $91 \mathrm{E}+03$ & $96 \mathrm{E}+04$ & $2.24 E+04$ & $1.95 \mathrm{E}+04$ \\
\hline $\mathrm{CL}-$ & $6 \mathrm{E}+02$ & $1.78 \mathrm{E}+03$ & $1.81 \mathrm{E}+02$ & $8.60 \mathrm{E}+00$ & $4.80 \mathrm{E}+03$ & $7.01 \mathrm{E}+03$ & $1.57 \mathrm{E}+01$ & $6.44 \mathrm{E}+03$ & $2.83 \mathrm{E}+03$ & $5.91 \mathrm{E}+0$ \\
\hline $\bar{F}-$ & $0 E+00$ & $0.00 \mathrm{E}+00$ & $0.00 \mathrm{E}+00$ & $0.00 \mathrm{E}+00$ & $2.28 E+03$ & $3.54 E+03$ & $0.00 E+00$ & $3.57 \mathrm{E}+03$ & $1.32 \mathrm{E}+03$ & $3.37 \mathrm{E}+03$ \\
\hline $\mathrm{SO} 4-2$ & +03 & $2.11 E+04$ & $E+03$ & $2.70 \mathrm{E}+03$ & $1.58 E+04$ & $1.75 \mathrm{E}+04$ & $4.92 \mathrm{E}+03$ & $1.46 \mathrm{E}+04$ & $9.39 E+03$ & $E+04$ \\
\hline NO3- & $34 E+04$ & $1.78 \mathrm{E}+05$ & $1.80 \mathrm{E}+04$ & $1.58 \mathrm{E}+03$ & $1.41 E+06$ & $1.26 \mathrm{E}+06$ & $2.89 \mathrm{E}+03$ & $9.73 E+05$ & $6.27 \mathrm{E}+05$ & $1 E+0$ \\
\hline NO2- & $0 \mathrm{E}+00$ & $0.00 E+00$ & $0.00 \mathrm{E}+00$ & $0.00 E+00$ & $9.14 E+04$ & $1.46 \mathrm{E}+05$ & $0.00 \mathrm{E}+00$ & $1.42 E+05$ & $5.56 \mathrm{E}+04$ & $1.43 \mathrm{E}+05$ \\
\hline PO4-3 & $8 E+02$ & $57 \mathrm{E}+03$ & $2.60 \mathrm{E}+02$ & $1.81 E+03$ & $1.57 \mathrm{E}+04$ & $1.65 \mathrm{E}+04$ & $3.29 \mathrm{E}+03$ & $1.83 E+04$ & $7.47 \mathrm{E}+03$ & $1.56 \mathrm{E}+04$ \\
\hline $\mathrm{OH}$ & $3 \mathrm{E}+03$ & $3.25 E+04$ & $3.29 \mathrm{E}+03$ & $1.06 \mathrm{E}+04$ & $7.47 E+04$ & $1.99 \mathrm{E}+05$ & $1.93 E+04$ & $1.56 \mathrm{E}+05$ & $8.74 E+04$ & $1.70 \mathrm{E}+05$ \\
\hline TOC & $0 \mathrm{E}+00$ & $00 E+00$ & $0.00 \mathrm{E}+00$ & $0.00 \mathrm{E}+00$ & $E+03$ & & $0.00 \mathrm{E}+00$ & $8.69 \mathrm{E}+03$ & $3.27 \mathrm{E}+03$ & $\overline{\mathrm{E}+03}$ \\
\hline Sr90 & & & & $7.95 \mathrm{E}+03$ & $3.04 E+04$ & & 2.15E-04 & $1.94 \mathrm{E}+00$ & $1.25 \mathrm{E}-03$ & $\mathrm{E}+0$ \\
\hline Tc99 & $34 \mathrm{E}-01$ & $6 \mathrm{E}+00$ & $3.19 \mathrm{E}-08$ & $.16 E+01$ & $2.92 \mathrm{E}+01$ & $4.55 \mathrm{E}-03$ & $7.22 \mathrm{E}-08$ & $8.41 \mathrm{E}-03$ & 3.19E-08 & $75 E+0$ \\
\hline Cs 137 & $25 \mathrm{E}+02$ & \begin{tabular}{|l|}
$7.41 \mathrm{E}+03$ \\
\end{tabular} & $4.68 \mathrm{E}-05$ & $1.61 \mathrm{E}+04$ & $4.04 E+04$ & $6.61 \mathrm{E}+00$ & $9.70 \mathrm{E}-05$ & $1.24 E+01$ & $6.79 \mathrm{E}-05$ & $2.28 \mathrm{E}+04$ \\
\hline TRU & $6 \mathrm{EE}+00$ & $7.69 \mathrm{E}+01$ & $8.54 \mathrm{E}+00$ & $7.17 \mathrm{E}+00$ & $3.64 E+00$ & $2.54 \mathrm{E}-04$ & $1.86 \mathrm{E}-07$ & $1.59 \mathrm{E}-01$ & $3.83 \mathrm{E}-05$ & $9.77 \mathrm{E}+01$ \\
\hline $\mathrm{H} 2 \mathrm{O}$ & $3 E+05$ & $31 E+05$ & $9.43 \bar{E}+04$ & $1.50 \mathrm{E}+05$ & $5.14 E+06$ & $6.58 \mathrm{E}+06$ & $2.74 E+05$ & $5.14 E+06$ & $3.08 E+06$ & $4.51 \mathrm{E}+06$ \\
\hline Volume (L) & & & & & & & & & $3.46 \mathrm{E}+06$ & \\
\hline
\end{tabular}


WHC-SD-WM-RPT-210, Rev. 0

\begin{tabular}{|c|c|c|c|c|c|c|c|c|c|}
\hline Source & $108-0$ & $109-U$ & $110-U$ & $111-U$ & $112-U$ & $201-U$ & $202-U$ & $203-4$ & $204-U$ \\
\hline Units & $\mathrm{kg}$ & $\mathrm{kg}$ & $\mathrm{kg}$ & $\mathrm{kg}$ & $\mathrm{kg}$ & $\mathrm{kg}$ & $\mathrm{kg}$ & $\mathrm{kg}$ & $\mathrm{kg}$ \\
\hline \multicolumn{10}{|l|}{ Component } \\
\hline$\overline{A L}(\mathrm{OH}) 4-$ & $51 E+04$ & $27 \mathrm{E}+04$ & $62 \mathrm{E}+03$ & $3.88 \mathrm{E}+04$ & $3.68 E+03$ & $.29 \mathrm{E}+02$ & $8.29 E+02$ & $4.15 E+02$ & $4.15 \mathrm{E}+02$ \\
\hline$A+2$ & $0 \mathrm{E}+00$ & $0 \mathrm{E}+00$ & $0 \mathrm{EE}+00$ & $0 \mathrm{E}+00$ & & $00 \mathrm{E}+00$ & $00 \mathrm{E}+00$ & $00 \mathrm{E}+00$ & $00 \mathrm{E}+00$ \\
\hline $4+2$ & $9 \bar{E}+01$ & $72 E+01$ & $70 \mathrm{E}-01$ & $90 \mathrm{E}+01$ & $79 \mathrm{E}-01$ & 07E-02 & $2.07 \mathrm{E}-02$ & $.03 \mathrm{E}-02$ & $.03 \mathrm{E}-02$ \\
\hline $\mathrm{D}+2$ & $0 E+00$ & $00 E+00$ & $00 \mathrm{E}+00$ & $30 \mathrm{E}+00$ & $00 \mathrm{E}+00$ & $00 \mathrm{E}+00$ & $00 \mathrm{E}+00$ & $.00 \mathrm{E}+00$ & $00 E+00$ \\
\hline$(\mathrm{OH}$ & $49 \mathrm{E}+03$ & $31 E+03$ & $4.38 E+01$ & $54 E+03$ & $1.01 \mathrm{E}+02$ & $7.75 E-01$ & $7.75 \mathrm{E}-01$ & $3.87 \mathrm{E}-01$ & $3.87 \mathrm{E}-01$ \\
\hline$E+3$ & $97 \mathrm{E}+02$ & $88 \mathrm{E}+01$ & $65 \mathrm{E}+01$ & $22 \mathrm{E}+01$ & $15 \mathrm{E}+01$ & $9.67 \mathrm{E}-01$ & 9.67E-01 & $4.83 \mathrm{E}-01$ & $4.83 \mathrm{E}-01$ \\
\hline $\mathrm{HG}+2$ & $E+00$ & $E+00$ & $\mathrm{E}+00$ & $30 \mathrm{E}+00$ & $E+00$ & $0 \mathrm{E}+00$ & $E+00$ & $00 \mathrm{E}+00$ & $0.00 E+00$ \\
\hline $\mathrm{K}+$ & $56 E+03$ & $48 \mathrm{E}+03$ & $00 \mathrm{E}+00$ & $1.17 E+03$ & $0.00 E+00$ & $.00 E+00$ & $.00 E+00$ & $.00 E+00$ & $0.00 \mathrm{E}+00$ \\
\hline $\mathrm{LA}+3$ & $0 \mathrm{E}+00$ & $00 \mathrm{E}+00$ & $00 \mathrm{E}+00$ & $0.00 \mathrm{E}+00$ & $0.00 \mathrm{E}+00$ & $00 E+00$ & $00 E+00$ & $00 \mathrm{E}+00$ & $00 E+00$ \\
\hline $\mathrm{NA}+$ & $3 E+05$ & $77 \mathrm{E}+05$ & $1.16 \mathrm{E}+05$ & $5.65 \mathrm{E}+05$ & $3.26 \mathrm{E}+04$ & $2.20 \bar{E}+03$ & $2.20 \mathrm{E}+03$ & $1.10 E+03$ & $1.10 E+03$ \\
\hline $\mathrm{NI}+3$ & $0 \mathrm{E}+01$ & $.01 \mathrm{E}+01$ & $5.33 \mathrm{E}-01$ & $2.34 \mathrm{E}+01$ & $2.40 \mathrm{E}-01$ & $2.99 \mathrm{E}-02$ & $2.99 \mathrm{E}-02$ & $1.49 \mathrm{E}-02$ & $1.49 \mathrm{E}-02$ \\
\hline $\mathrm{PB}+4$ & 2.34E-01 & $2.23 \mathrm{E}-01$ & $0.00 \mathrm{E}+00$ & 1.76E-01 & $0.00 E+00$ & $0.00 \mathrm{E}+00$ & $0.00 \mathrm{E}+00$ & $0.00 \mathrm{E}+00$ & $0.00 \mathrm{E}+00$ \\
\hline $\mathrm{CO} 3-2$ & & & & $E+04$ & & $E+01$ & $E+01$ & $60 \mathrm{~F}+01$ & $60 E+01$ \\
\hline CL- & $23 E+03$ & $90 \mathrm{E}+03$ & $82 E+02$ & $5.60 \mathrm{E}+03$ & $1.05 E+02$ & $5.94 \mathrm{E}+00$ & $5.94 \mathrm{E}+00$ & $2.97 E+00$ & $2.97 \mathrm{E}+00$ \\
\hline F. & $7 \mathrm{E}+03$ & $62 E+03$ & $70 \mathrm{E}+03$ & $3.42 \mathrm{E}+03$ & $1.33 E+03$ & $.00 \mathrm{E}+00$ & $.00 \mathrm{E}+00$ & $0.00 \mathrm{E}+00$ & $0.00 \mathrm{E}+00$ \\
\hline 4 & $5 \mathrm{E}+04$ & $54 \mathrm{E}+04$ & $38 \mathrm{E}+03$ & $9.42 \mathrm{E}+03$ & $2.04 E+02$ & $1.80 \mathrm{E}+00$ & $80 \mathrm{E}+00$ & $8.99 \mathrm{E}-01$ & $8.99 \mathrm{E}-01$ \\
\hline & $E+06$ & $10 E+06$ & $04 \mathrm{E}+04$ & $7.77 \mathrm{E}+05$ & $1.72 E+04$ & $1.64 \mathrm{E}+03$ & $.64 \mathrm{E}+03$ & $8.19 \mathrm{E}+02$ & $8.19 E+02$ \\
\hline$\overline{\mathrm{O} 2}$ & $1.55 \mathrm{E}+05$ & $1.53 \mathrm{E}+05$ & $5.12 \mathrm{E}+03$ & $1.22 E+05$ & $2.15 \mathrm{E}+03$ & $9.34 E+02$ & $9.34 \mathrm{E}+02$ & $4.67 \mathrm{E}+02$ & $4.67 \bar{E}+02$ \\
\hline $\mathrm{PO4}-3$ & $1.48 \mathrm{E}+04$ & $.59 \mathrm{E}+04$ & $2.89 \mathrm{E}+04$ & $1.26 \mathrm{E}+04$ & $7.82 \mathrm{E}+03$ & $0.00 \mathrm{E}+00$ & $0.00 \mathrm{E}+00$ & $0.00 \mathrm{E}+00$ & $0.00 \mathrm{E}+00$ \\
\hline $\mathrm{OH}_{-}^{-1}$ & $1.89 E+05$ & $1.95 \mathrm{E}+05$ & $4.78 \mathrm{E}+04$ & $1.45 \mathrm{E}+05$ & $1.24 \mathrm{E}+04$ & $6.91 E+02$ & $6.91 \mathrm{E}+02$ & $3.46 \mathrm{E}+02$ & $3.34 \mathrm{E}+02$ \\
\hline TOC & $9.66 \mathrm{E}+03$ & $9.26 \mathrm{E}+03$ & $0.00 \mathrm{E}+00$ & $7.66 \mathrm{E}+03$ & $0.00 \mathrm{E}+00$ & $0.00 \mathrm{E}+00$ & $0.00 \mathrm{E}+00$ & $0.00 \mathrm{E}+00$ & $0.00 \mathrm{E}+00$ \\
\hline Sr90 & $2.97 E+04$ & $5.28 \mathrm{E}+02$ & $1.84 \mathrm{E}+05$ & \begin{tabular}{|l|}
$2.37 E+04$ \\
\end{tabular} & $1.63 \mathrm{E}+03$ & $1.03 \mathrm{E}+01$ & $9.49 \mathrm{E}+00$ & $8.78 \mathrm{E}+00$ & $2.74 \mathrm{E}+00$ \\
\hline & $1.23 \mathrm{E}-02$ & $58 \mathrm{E}+00$ & $1.99 \mathrm{E}-01$ & $1.51 \mathrm{E}+01$ & $1.97 \mathrm{E}+01$ & $3.08 \mathrm{E}+00$ & $3.22 \mathrm{E}+00$ & $2.84 \mathrm{E}+00$ & $7.48 \mathrm{E}-01$ \\
\hline Cs 13 & $1.79 E+01$ & $5.56 \mathrm{E}+03$ & $88 \mathrm{E}+02$ & $6.05 \bar{E}+03$ & $2.63 E+04$ & $4.14 E+03$ & $4.35 \mathrm{E}+03$ & $3.83 \mathrm{E}+03$ & $1.02 E+03$ \\
\hline TRU & $1.85 \mathrm{E}+01$ & $2.44 \mathrm{E}-01$ & $2.72 \mathrm{E}+02$ & $3.06 \mathrm{E}+01$ & $6.96 \mathrm{E}-01$ & $2.28 \mathrm{E}-02$ & $2.39 \mathrm{E}-02$ & 2.10E-02 & $5.58 \mathrm{E}-03$ \\
\hline & & & & $4.42 \mathrm{E}+06$ & $2.77 E+05$ & $1.76 \mathrm{E}+04$ & $1.76 E+04$ & $8.78 \mathrm{E}+03$ & $8.82 \mathrm{E}+03$ \\
\hline (L) & $6.89 \mathrm{E}+06$ & $6.76 E+06$ & $1.01 \mathrm{E}+06$ & $4.91 E+06$ & $4.65 \mathrm{E}+05$ & $8.44 E+04$ & $8.44 E+04$ & $4.30 \mathrm{E}+04$ & $3.54 \bar{E}+0$ \\
\hline
\end{tabular}


WHC-SD-WM-RPT-210, Rev. 0

\section{APPENDIX E - ESTIMATED COMPOSTION OF STAGED FEED}

(In the private contractors feed tanks, decayed to process start date) 
WHC-SD-WM-RPT-210, Rev. 0

This page intentionally left blank. 
WHC-SD-WM-RPT-210, Rev. 0

\begin{tabular}{|c|c|c|c|c|c|c|c|c|c|c|c|}
\hline Contractor & C1 & C1 & C1 & C1 & C1 & C1 & C1 & C1 & C1 & C1 & C1 \\
\hline Batch & 1 & 2 & 3 & 4 & 5 & 6 & 7 & 8 & 9 & 10 & 11 \\
\hline Process Start Date & 1-Jun-02 & 16-Apr-03 & 19-Aug-03 & $4 \sqrt{\operatorname{an}-04}$ & 18-Dec-04 & $26-0 c t-06$ & 12-Jun-06 & 18-Feb-07 & 11-Jan-08 & 3 -sep-08 & 23-Jan-09 \\
\hline Chemical & MT & MT & MT & MT & MT & MT & MT & MT & MT & MT & MT \\
\hline Al(OH)4- & $2.58 E+02$ & $5.78 E+01$ & $9.10 E+\infty$ & $3.57 \mathrm{E}+02$ & $2.61 E+02$ & $1.92 E+02$ & $1.91 E+02$ & $3.50 E+02$ & $8.20 E+01$ & $4.10 E+01$ & $9.49 \mathrm{E}+01$ \\
\hline $\mathrm{Ba}+2$ & $1.36 \mathrm{E}-04$ & $1.04 E-04$ & $4.70 E-06$ & $1.70 E-05$ & $1.43 E-04$ & 6.57E-06 & $3.24 E-07$ & $1.16 \mathrm{E}-08$ & 3.92E-03 & $2.41 E-03$ & $1.88 E-04$ \\
\hline $\mathbf{C a + 2}$ & $8.06 \mathrm{E}-03$ & $3.68 E-03$ & 4.38E-01 & $2.49 E-02$ & $4.42 E-02$ & $2.02 E-03$ & 6.03E-02 & $1.48 \mathrm{E}-01$ & $1.62 \mathrm{E}-01$ & $9.56 \mathrm{E}-02$ & $7.81 \mathrm{E}-01$ \\
\hline $\mathrm{Cd}+2$ & $1.39 \mathrm{E}-04$ & $2.13 E-04$ & $9.63 E-06$ & $1.04 E-06$ & 4.49E-07 & $1.52 E-08$ & $6.56 E-10$ & 2.69E-02 & $4.72 E-03$ & $2.18 E-03$ & $1.69 E-04$ \\
\hline CrOH) & 5.86E-01 & $4.48 E+\infty$ & 5.15E-01 & $3.38 \mathrm{E}+\infty$ & $2.68 E-01$ & $2.14 E+\infty$ & $8.17 E-01$ & $3.33 E+\infty$ & 5.81E-01 & $2.68 E-01$ & $1.18 E+\infty$ \\
\hline $\mathrm{Fe}+3$ & $3.79 E-03$ & $5.55 E-04$ & $1.19 E+\infty$ & 1.17E-01 & $2.05 E-02$ & $1.61 \mathrm{E}-02$ & $1.05 E-03$ & $1.18 E-01$ & $2.60 \mathrm{E}-02$ & $1.34 E-02$ & 1.04E-03 \\
\hline $\mathrm{Hg}+2$ & $0.00 E+\infty 0$ & $0.00 E+\infty$ & $0.00 E+\infty$ & $0.00 E+\infty$ & $0.00 E+\infty$ & $0.00 E+\infty$ & $0.00 E+\infty$ & $2.60 E-02$ & $1.25 E-03$ & 4.35E-05 & $2.29 E-06$ \\
\hline $\mathrm{K}+$ & $3.74 E+\infty 0$ & $5.95 E+\infty 0$ & $1.96 E+\infty)$ & $1.42 \mathrm{E}+01$ & $1.49 E+01$ & $1.05 E+01$ & $7.67 \mathrm{E}+01$ & $2,96 E+01$ & $5.29 E+01$ & $3.17 E+01$ & $9.33 E+\infty 0$ \\
\hline$[a+3$ & $0.00 E+\infty$ & $9.91 E-04$ & 4.48E-05 & 4.91E-05 & 2.13E-06 & $7.17 \mathrm{E}-08$ & $3.11 \mathrm{E}-09$ & $1.03 E-10$ & $3.69 E-02$ & $2.27 \mathrm{E}-02$ & $1.77 \mathrm{E}-03$ \\
\hline Nat & $5.21 E+02$ & $2.14 E+02$ & $1.93 E+02$ & $6.24 E+02$ & $5.59 E+02$ & $4.03 E+02$ & $4.45 E+02$ & $5.87 \mathrm{E}+02$ & 4.17E+02 & $2.40 \mathrm{E}+02$ & $4.86 E+02$ \\
\hline $\mathrm{Ni+3}$ & $5.44 E-03$ & $1.24 E-03$ & $3.59 E-01$ & $1.67 \mathrm{E}-02$ & $4.33 E-04$ & $1.10 E-05$ & $3.95 \mathrm{E}-07$ & $4.03 E-02$ & $4.58 E-02$ & $2.70 E-02$ & $6.20 \mathrm{E}-01$ \\
\hline $\mathrm{Pb}+4$ & $1.54 E-02$ & 6.14E-04 & 2.E3E-01 & $1.22 \mathrm{E}-02$ & $3.25 E-04$ & 8.46E-06 & $5.51 \mathrm{E}-01$ & $1.50 E-01$ & $1.43 \mathrm{E}-02$ & 4.96E-03 & $3.81 E-04$ \\
\hline UgI & $1.12 E-03$ & $1.63 E+\infty$ & $7.35 E-02$ & $9.78 E-02$ & $2.58 E-02$ & $1.14 E-03$ & 4.08E-01 & $2.28 E-01$ & 5.19E-01 & $3.13 E-01$ & $2.44 E-02$ \\
\hline $\cos -2$ & $7.03 E+01$ & $4.45 E+01$ & $6.26 \mathrm{E}+0 \mathrm{t}$ & $5.51 \mathrm{E}+01$ & 7.24E+01 & $4.20 E+01$ & $2.72 E+\infty 0$ & $1.51 E+01$ & $9.35 E+01$ & $5.70 E+01$ & $1.22 \mathrm{E}+02$ \\
\hline CL- & $2.40 E+01$ & $1.20 E+\infty 0$ & $2.85 E+\infty$ & $1.97 E+01$ & $2.67 E+01$ & $1.15 E+01$ & $1.02 E+01$ & $1.66 E+01$ & $2.82 E+\infty$ & $1.29 E+\infty$ & $6.94 E++0$ \\
\hline $\mathrm{F}=$ & $1.54 E+01$ & $3.95 E+\infty$ & 4.11E-01 & $3.08 E+\infty$ & $3.03 E+01$ & $1.40 E+\infty 0$ & $6.88 \mathrm{E}-02$ & $1.24 E+\infty$ & 1.14E+01 & $6.98 E+\infty$ & $4.21 \mathrm{E}+\infty$ \\
\hline SO4-2 & $1.41 \mathrm{E}+01$ & 4.00E+01 & $1.29 E+01$ & $1.72 E+01$ & $1.52 E+01$ & $9.64 E+\infty 0$ & $2.50 E+00$ & $2.81 E+\infty$ & $1.12 \mathrm{E}+01$ & $6.81 \mathrm{E}+\infty$ & $2.58 \mathrm{E}+01$ \\
\hline NOS- & $4.06 E+02$ & $1.37 E+02$ & $2.00 E+02$ & $4.57 \mathrm{E}+02$ & $4.35 E+02$ & $2.82 \bar{E}+02$ & $4.08 E+02$ & $2.90 E+02$ & $3.35 \mathrm{E}+\infty$ & $1.98 E+02$ & $4.04 E+02$ \\
\hline NO2- & $2.01 \mathrm{E}+02$ & $1.19 E+02$ & $4.71 E+01$ & $2.67 \mathrm{E}+02$ & $2.04 E+02$ & $1.30 E+02$ & $1.94 E+02$ & $2.42 E+02$ & $1.33 E+\infty 2$ & $7.54 E+01$ & $1.53 E+02$ \\
\hline PO4-3 & $1.10 E+01$ & $2.34 E+\infty)$ & $6.51 E-01$ & $5.06 E+\infty$ & $1.05 E+01$ & $4.30 E+\infty 0$ & 4.11E++0 & $1.77 \mathrm{E}+\infty$ & $7.29 E+00$ & $4.43 E+\infty 0$ & $9.01 E+\infty$ \\
\hline OH & $1.22 \mathrm{E}+02$ & $2.33 E+01$ & $1.68 E+01$ & $1.39 E+02$ & $1.35 E+02$ & $1.01 \mathrm{E}+02$ & $1.64 E+02$ & $1.73 E+02$ & $5.61 \mathrm{E}+01$ & $2.98 E+01$ & $2.11 \mathrm{E}+01$ \\
\hline TOC & $1.07 \bar{E}+01$ & $2.07 E+00$ & $3.44 E+01$ & $1.08 E+01$ & $1.27 E+01$ & $6.88 E+00$ & $4.92 \mathrm{E}+\infty$ & $1.26 \mathrm{E}+01$ & $3.64 E+01$ & $2.20 E+01$ & $4.79 E+01$ \\
\hline $14 C,(C)$ & $1.49 E-01$ & $5.96 E-03$ & $2.70 E-04$ & $1.07 \mathrm{E}-04$ & $1.43 E-05$ & $6,00 \mathrm{E}-07$ & 6.70E-01 & $3.33 \mathrm{E}+\infty$ & 2.27E-01 & $5.01 \mathrm{E}-02$ & $3.22 E+01$ \\
\hline $90 \mathrm{Sr},(\mathrm{Ci})$ & $1.68 \mathrm{E}+02$ & $3.28 E+02$ & $4.50 E+04$ & $5.30 \mathrm{E}+03$ & $2.40 E+02$ & $7.00 E+03$ & $1.58 E+03$ & $1.23 E+04$ & $1.07 E+04$ & $6.17 \mathrm{E}+03$ & $9.85 E+04$ \\
\hline $90 \mathrm{Y},(\mathrm{Ci})$ & $1.68 E+02$ & $3.28 E+02$ & $4.50 E+04$ & $5.30 E+\infty$ & $2.40 E+02$ & $7.00 E+03$ & $1.58 E+03$ & $1.23 E+04$ & $1.07 E+04$ & $6.17 \mathrm{E}+03$ & $9.85 \mathrm{E}+04$ \\
\hline 99Tc, (Ci) & $4.14 E+01$ & $6.70 E+02$ & $4.29 E+02$ & $4.03 E+02$ & $1.74 E+01$ & $2.47 E+02$ & $2.91 E+02$ & $2.96 \mathrm{E}+02$ & $1.17 \mathrm{E}+02$ & $6.39 E+01$ & $5.49 \mathrm{E}+02$ \\
\hline $137 \mathrm{Cs},(\mathrm{C})$ & $1,62 E+02$ & $3.14 E+05$ & $2.51 \mathrm{E}+05$ & $6.79 E+05$ & $3.55 E+04$ & $5.56 E+\infty 5$ & $5.47 E+05$ & $7.54 E+06$ & $9.02 E+04$ & $3.55 E+04$ & $3.29 E+05$ \\
\hline $137 \mathrm{Ba}$, (C) & $1.54 E+02$ & $2.98 E+05$ & $2.38 E+05$ & $6.45 E+05$ & $3.37 \mathrm{E}+04$ & $5.28 E+\infty 5$ & $5.20 E+05$ & $7.16 \mathrm{E}+05$ & $8.57 E+04$ & $3.38 E+04$ & $3.12 E+05$ \\
\hline 164Eu (C) & $5.95 E+00$ & $2.40 E-01$ & $1.21 \mathrm{E}+03$ & $5.65 E+01$ & $1.31 \mathrm{E}+00$ & $3.04 E-02$ & $1.00 E-03$ & $2.68 E-05$ & $2.89 E+\infty$ & $1.78 E+\infty$ & $1.40 \mathrm{E}+03$ \\
\hline $236 \mathrm{U},(\mathrm{C})$ & $0.00 E+\infty$ & $0.00 E+\infty$ & $0.00 E+\infty$ & $0.00 E+\infty$ & $0.00 E+\infty$ & $0.00 E+\infty$ & $0.00 E+\infty$ & $0.00 E+\infty$ & $0.00 E+\infty$ & $0.00 \mathrm{E}+\infty$ & $0.00 E+\infty$ \\
\hline $2384,(C)$ & $0.00 E+\infty$ & $0.00 E+\infty$ & $0.00 E+00$ & $0.006+\infty$ & $0.00 E+00$ & $0.00 E+\infty$ & $0.00 E+\infty$ & $0.00 E+\infty$ & $0.00 E+\infty 0$ & $0.00 E+\infty$ & $0.00 E+\infty 0$ \\
\hline $237 \mathrm{~Np}$, (Ci) & $5.17 \mathrm{E}-09$ & $1.26 E-05$ & $2.56 E-05$ & $3.09 E-04$ & 1.38E-05 & 4.70E-07 & $2.05 E-08$ & $6.82 \mathrm{E}-10$ & $7,55 E-04$ & 4.64E-04 & $3.61 \mathrm{E}-05$ \\
\hline 238Pu, (Ci) & 6.90E-07 & $1.15 E-02$ & $5.20 \mathrm{E}-04$ & 2.82E-01 & $1.25 \mathrm{E}-02$ & $4.25 E-04$ & $1.85 E-05$ & $6.15 E-07$ & $6.92 E-01$ & $4.25 E-01$ & $3.31 \mathrm{E}-02$ \\
\hline $239 \mathrm{Pu}(\mathrm{C})$ & $3.61 E-02$ & 6.00E-01 & $2.99 E+01$ & $2.23 E+01$ & $9.57 E-01$ & $1.42 E+01$ & $3.73 E+\infty$ & $3.32 \mathrm{E}+\infty$ & $4.97 \mathrm{E}+00$ & $2.96 E+\infty 0$ & $1.18 \mathrm{E}+02$ \\
\hline 240Pu, (Ci) & $1.12 E-03$ & 1. $6 \overline{E E}-01$ & $7.59 E+\infty$ & $3.56 \mathrm{E}+00$ & $1.50 E-01$ & $2.19 E+00$ & 5.73E-01 & $5.10 E-01$ & $1.21 \mathrm{E}+00$ & $7.31 E-0 t$ & $2.99 E+01$ \\
\hline $241 \mathrm{Pu},(\mathrm{C})$ & $2.08 E-03$ & $2.77 \mathrm{E}-02$ & $8.79 E+\infty$ & $4.12 E+\infty 0$ & $2.56 \mathrm{E}-01$ & $2.37 E+\infty$ & $7.86 E-01$ & $6.63 E-01$ & 3.94E-01 & 2.19E-01 & $2.68 E+01$ \\
\hline $241 \mathrm{Am}$, (Ci) & $5.98 E-01$ & $2.44 E+01$ & $2.95 E+02$ & $1.81 \mathrm{E}+01$ & 5.12E-01 & $2.21 E+\infty$ & $3.10 E+\infty$ & $3.94 \mathrm{E}+00$ & $2.63 E+01$ & $1.60 \mathrm{E}+01$ & $1.11 E+02$ \\
\hline Volume, (ㄴ) & $3.58 E+06$ & $2.11 E+06$ & $2.10 E+06$ & $4.21 \mathrm{E}+06$ & $4.18 E+06$ & $2.96 E+06$ & $3.65 E+06$ & $4.21 E+06$ & $4.13 E+06$ & $2.48 E+06$ & $4.24 E+06$ \\
\hline $\mathrm{Na}$ (M) & $6.33 E+\infty$ & $4.41 E+\infty 0$ & $4.00 \mathrm{E}+00$ & $6.44 E+\infty$ & $5.82 E+00$ & $5.91 E+\infty$ & $5.29 E+00$ & $6.07 E+\infty 0$ & $4.39 E+\infty)$ & $4.21 E+\infty$ & $4.99 E+00$ \\
\hline SpG & $1.30 E+\infty$ & $1.21 \mathrm{E}+\infty$ & $1.17 E+\infty$ & $1.31 E+\infty$ & $1.28 E+\infty$ & $1.27 \mathrm{E}+\infty$ & $1.29 E+00$ & $1.29 E+\infty 0$ & $1.19 E+\infty$ & $1.18 E+\infty$ & $1.21 \mathrm{E}+\infty$ \\
\hline Proc. Time (days) & 278 & 114 & 103 & 333 & 298 & 215 & 237 & 313 & 222 & 128 & 259 \\
\hline Corrosion Spec Met? & -7 & $\mathrm{Y}^{4}$ & $\mathrm{Y}$ & $\mathrm{Y}$ & $\mathrm{Y}$ & $\mathrm{Y}$ & $Y$ & $y$ & $\mathrm{Y}$ & $\mathrm{Y}$ & $Y$ \\
\hline
\end{tabular}


WHC-SD-WM-RPT-210, Rev. 0

\begin{tabular}{|c|c|c|c|c|c|c|c|c|c|c|c|}
\hline Contractor & C2 & C2 & $\mathrm{C} 2$ & C2 & C2 & $\mathrm{C2}$ & C2 & C2 & C2 & C2 & C2 \\
\hline Batch & 1 & 2 & 3 & 4 & 5 & 6 & 7 & 8 & 9 & 10 & 11 \\
\hline Process Start Date & 1-Jun-02 & 2Apr-03 & EAug-03 & $21-D e C-03$ & 1-Dec-04 & 9 -sep-06 & $24 \mathrm{Apr}-06$ & 31Dec-06 & 17+Nov-07 & 10-Jul-08 & $6 \mathrm{Feb-09}$ \\
\hline Cherrical & MT & MT & MT & MT & MI & MT & MI & MI & $\mathrm{MT}$ & MT & MT \\
\hline $\mathrm{Al}(\mathrm{OH}) 4$ & $270 E+02$ & $5.75 E+01$ & $9.07 E+00$ & $3.55 E+02$ & $1.33 E+02$ & $1.86 \mathrm{E}+02$ & $1.91 \mathrm{E}+\infty$ & $3.45 \mathrm{E}+02$ & $8.17 \mathrm{E}+01$ & $1.04 E+01$ & $9.17 E+01$ \\
\hline$B a+2$ & $5.52 E-07$ & $1.01 \mathrm{E}-04$ & $4.54 E-06$ & $1.22 \mathrm{E}-05$ & $1,81 E-03$ & $8.32 E-05$ & 4.11E-06 & $1.10 E-07$ & $3.92 E-03$ & $1.85 E-04$ & $7.25 \mathrm{E}-06$ \\
\hline $\mathrm{Ca}+2$ & 4.41E-05 & $3.49 \mathrm{E}-03$ & $4.38 E-01$ & $4.56 E-02$ & 1.91E-01 & $8.75 E-\infty$ & $6.06 \mathrm{E}-02$ & 1.47E-01 & $1.62 \mathrm{E}-01$ & $8.80 E-01$ & $3.16 E-01$ \\
\hline $\mathrm{Cd}+2$ & $1.86 E-06$ & $11 \mathrm{E} .04$ & $9.49 E-06$ & 4.41E-07 & $5.05 E-03$ & $2.32 \mathrm{E}-04$ & $1.14 \mathrm{E}-0 \mathrm{~S}$ & $2.69 E-02$ & $4.72 \mathrm{E}-03$ & $2.08 E-04$ & $7.96 \mathrm{E}-06$ \\
\hline Cr(OH)4- & 2.11E-01 & $4.49 E+\infty$ & 5.15E-01 & $3.18 E+\infty 0$ & $1.37 \mathrm{E}+00$ & $2.19 E+\infty 0$ & $8.20 \mathrm{E}-01$ & $3.31 E+00$ & $5.80 \mathrm{E}-01$ & $6.54 \mathrm{E}-01$ & $1.19 E+\infty$ \\
\hline $\mathrm{Fe}+3$ & $1.73 E-03$ & 4.97E-04 & $1.19 E+\infty$ & 1.74E-01 & $2.56 E-02$ & $1.63 E-02$ & $1.06 E-03$ & $1.18 E-01$ & 2.6E-02 & $2.41 E+\infty$ & $1.26 \mathrm{E}-01$ \\
\hline $\mathrm{Hg}+2$ & $0.00 E+\infty$ & $0.00 E+\infty 0$ & $0.00 E+\infty$ & $0.00 E+\infty$ & $0.00 E+\infty$ & $0.00 E+\infty$ & $0.00 E+\infty$ & $2.606-02$ & $1.25 E-03$ & 4.40E-0S & $1.53 \mathrm{E}-06$ \\
\hline $\mathrm{K}+$ & $3.83 E-02$ & $5.88 \mathrm{E}+\infty$ & $1.95 E+\infty$ & $1.39 E+01$ & $8.83 E+01$ & $138 E+01$ & $7.69 E+01$ & $2.76 E+01$ & $5.28 E+01$ & $5.87 \mathrm{E}+\infty$ & $7.10 E+00$ \\
\hline $\mathrm{La+3}$ & $\mid 0.00 E+\infty$ & $9.96 E-04$ & 4.48E-05 & $2.08 E-06$ & $4.85 E-08$ & 1.12E-09 & $3.68 \mathrm{E}-11$ & 9.85E-13 & $3.69 E-02$ & $1.74 E-03$ & $6.82 E-05$ \\
\hline Nat & $5.46 E+02$ & $2.14 E+02$ & $1.93 E+02$ & $6.21 \mathrm{E}+02$ & $5.02 E+02$ & $4.00 E+02$ & $4.44 E+02$ & $5.76 \mathrm{E}+02$ & $4.1 \mathrm{EE}+\infty$ & $3.76 E+02$ & $4.85 E+02$ \\
\hline$\overline{N i+3}$ & $1.30 E-06$ & $1.10 E-03$ & $3.596-01$ & $3.37 \mathrm{E}-02$ & $3.20 \mathrm{E}-02$ & $1.45 E-03$ & $7.14 E-05$ & $4.03 E-02$ & $4.58 E-02$ & $7.23 E-01$ & $6.52 E-01$ \\
\hline $\mathrm{Pb}+4$ & 3.28 & -04 & $2.63 E-01$ & $2.47 \mathrm{E}-02$ & $1.61 \mathrm{E}-02$ & $7.28 E-04$ & 5.51E-01 & $1.36 E-01$ & $1.37 \mathrm{E}-02$ & $5.30 E-01$ & $2.77 \mathrm{E}-02$ \\
\hline$\overline{U g}$ & & $E+\infty$ & $7.37 E-02$ & $2.06 E-02$ & 1.24E-01 & 5.69E-03 & $4.08 E-01$ & $2.17 \mathrm{E}-01$ & 5.19E-01 & $2.43 E-02$ & $9.52 \mathrm{E}-04$ \\
\hline $\cos -2$ & $7.27 E+01$ & $4.45 E+01$ & $6.26 E+01$ & $5.50 E+01$ & $6.63 E+01$ & $4.17 E+01$ & $2.70 E+\infty$ & $1.51 \mathrm{E}+01$ & $9.35 E+01$ & $1.25 E+02$ & $1.24 E+02$ \\
\hline CL- & $2.83 E+01$ & $1.22 E+\infty$ & $2.85 E+\infty 0$ & $1.97 \mathrm{E}+01$ & $7.60 E+\infty 0$ & $1.06 E+01$ & $1.01 E+01$ & $1.64 E+01$ & $2.81 E+\infty$ & $5.09 E+\infty$ & $7.07 \mathrm{E}+\infty$ \\
\hline$F$ & $2.02 E+01$ & $4.02 E+00$ & $4.13 E-01$ & $2.92 E+\infty$ & $4.45 E+\infty 0$ & $2.03 E-01$ & $9.98 E-03$ & $1.24 E+\infty$ & $1.14 E+01$ & $5.37 \mathrm{E}-01$ & $3.67 \mathrm{E}+\infty$ \\
\hline SO4-2 & & $E+01$ & $1.29 \mathrm{E}+01$ & $1.58 E+01$ & $7.62 E+00$ & $9.29 \mathrm{E}+\infty$ & $2.48 E+\infty 0$ & $2.75 E+\infty$ & $1.12 \mathrm{E}+01$ & $2.25 E+01$ & $2.63 E+01$ \\
\hline NO3- & $4.25 E+02$ & $E+02$ & $2.00 E+02$ & $4.59 E+02$ & $4.88 E+02$ & $2.85 E+02$ & $4.08 E+02$ & $279 E+02$ & $3.34 E+02$ & $3.95 E+02$ & $4.07 \mathrm{E}+02$ \\
\hline NO2- & $2.11 E+02$ & $1.19 E+02$ & OOE+01 & $2.63 E+02$ & $1.49 E+02$ & $27 E+02$ & $E+02$ & $2.37 E+02$ & $1.33 E+02$ & $8.52 E+01$ & $1.51 E+02$ \\
\hline POA 3 & $1.07 E+01$ & $30 E+\infty$ & 49E-01 & $4.98 E+\infty 0$ & $1.50 \mathrm{E}+\infty$ & $3.88 E+\infty$ & $4.00 E+00$ & $1.67 E+\infty$ & $7.29 \mathrm{E}+\infty 0$ & $1.19 E+\infty$ & $8.68 E+\infty$ \\
\hline $\mathrm{OH}$ & & $1 \mathrm{E}+01$ & $1.68 E+01$ & $1.38 E+02$ & $1.59 E+02$ & $1.02 \bar{E}+02$ & $1.64 E+02$ & $1.68 E+02$ & $5.59 \mathrm{E}+01$ & $3.12 \mathrm{E}+01$ & $2.03 E+01$ \\
\hline TOC & 1.125 & $+\infty$ & $3 . \overline{44 E+01}$ & $1.23 E+01$ & $8.31 \mathrm{E}+\infty$ & $6.67 \bar{E}+\infty$ & $4.91 E+\infty$ & $1.25 E+01$ & $3.64 E+01$ & $7.05 E+01$ & $4.96 E+01$ \\
\hline $14 \mathrm{C}, 10$ & & $O E-03$ & $9.01 E-05$ & $4.20 E-06$ & 6.15E-01 & $2.83 \mathrm{E}-02$ & $2 E-01$ & $1 E+\infty$ & $2.26 \mathrm{E}-01$ & $4 E-03$ & $3.20 \mathrm{E}+01$ \\
\hline $90 \mathrm{sr}$, & $=+01$ & $D E+03$ & $4.50 E+04$ & $6.86 E+03$ & $7.23 E+02$ & $7.04 E+03$ & $E+03$ & $2 E+\infty 4$ & $1.08 E+04$ & $07 \mathrm{E}+04$ & $1.02 E+05$ \\
\hline $90 \mathrm{Y}, \mathrm{C}$ & +01 & $=+\infty 3$ & $0 E+04$ & $6.86 E+03$ & $7.23 E+02$ & $7.04 E+\infty 3$ & $1.59 E+03$ & $1.23 E+04$ & $1.08 E+04$ & $8.07 E+04$ & $1.02 \mathrm{E}+05$ \\
\hline 99Tc, & & & $9 E+02$ & $8 E+\infty 2$ & $2.15 E+02$ & $2.56 E+02$ & $2.91 \mathrm{E}+02$ & $2.88 E+02$ & $1.16 E+02$ & $8.07 \mathrm{E}+02$ & $5.84 E+02$ \\
\hline $137 \mathrm{C}$ & & $+\infty$ & $3.10 E+05$ & $8.96 E+05$ & $5.99 E+05$ & $9.22 \mathrm{E}+05$ & $7.90 E+05$ & $1.00 E+06$ & $1.38 E+05$ & $3.23 E+05$ & $4.67 \mathrm{E}+05$ \\
\hline & +04 & $3.22 E+06$ & $2.95 E+05$ & $8.52 E+05$ & $5.69 E+05$ & $\mathrm{EE}+\infty$ & $1 E+05$ & $1.04 E+06$ & $1.31 \mathrm{E}+0 \mathrm{E}$ & $3.07 \mathrm{E}+05$ & $4.43 E+05$ \\
\hline $154 \mathrm{E}$ & $6-04$ & 7E-02 & $1.21 E+03$ & $1.14 E+02$ & $4.02 E+\infty 0$ & $E-01$ & OE-03 & $1.36 E-04$ & $2.89 E+\infty$ & $2.44 E+03$ & $1.52 \mathrm{E}+03$ \\
\hline $236 \mathrm{U}, 1$ & $E+\infty$ & $E+\infty$ & $0.00 E+\infty$ & $0.00 E+\infty 0$ & $0.00 E+\infty$ & $+\infty$ & $E+\infty$ & $0.00 E+\infty$ & $0.00 E+\infty$ & $0.00 E+\infty$ & $0.00 E+\infty$ \\
\hline 2380,16 & $E+\infty$ & & $0.00 E+\infty$ & $\overline{O E+00}$ & $0.00 E+\infty$ & $0.00 E+00$ & $0.00 E+\infty$ & $0.00 E+\infty$ & $0.00 E+00$ & $0.00 E+\infty$ & $0.00 E+00$ \\
\hline $237 \mathrm{~Np},(\mathrm{Ci})$ & & -05 & $2.78 E-05$ & SE-04 & 1.44E-DS & S6E-07 & 17E-08 & 5.81E-10 & $7.55 E-04$ & $3.56 E-05$ & $1.40 E-06$ \\
\hline $238 \mathrm{Pu}$ (C) & & $E-02$ & $5.21 \mathrm{E}-04$ & B1E-01 & $1.31 \mathrm{E}-02$ & 51E-04 & $1.98 E-06$ & 5.29E-07 & $6.92 \mathrm{E}-01$ & $3.26 E-02$ & $1.28 \mathrm{E}-03$ \\
\hline $239 \mathrm{Pu}, 1 \mathrm{C}$ & $E-\infty$ & 3E-01 & $2.99 E+01$ & $36 E+01$ & $1.52 E+\infty 0$ & $1.43 E+01$ & $3.73 E+\infty$ & $3.23 E+\infty$ & $4.97 E+\infty$ & $6.03 E+01$ & $1.20 \mathrm{E}+02$ \\
\hline 240Pu। & $E-04$ & GE-01 & $7.59 E+\infty$ & $3.91 \mathrm{E}+\infty$ & 2.43E-01 & $2.19 \mathrm{E}+\infty$ & $5.73 \mathrm{E}-01$ & 4.96E-01 & $1.21 \mathrm{E}+\infty$ & $1.53 E+01$ & $3.05 E+01$ \\
\hline $241 \mathrm{Pu}$ & $E-02$ & $4.02 E+\infty$ & $1.37 E+01$ & $1.07 \mathrm{E}+01$ & $6.89 E-01$ & $.47 E+\infty$ & $1.2 E+\infty$ & $1.47 E+\infty$ & $9.69 E-01$ & $2.73 E+01$ & 5.44E+01 \\
\hline $241 \mathrm{Am},(\mathrm{Ci})$ & $6.20 E-06$ & $2.43 E+01$ & $2.96 E+02$ & .07E+01 & $2.26 E+\infty 0$ & $16 E+00$ & $.08 E+\infty 0$ & $3.84 E+\infty$ & $2.63 E+01\}$ & $5.93 E+02$ & $1.39 E+02$ \\
\hline Volume, (L) & $4.13 E++6$ & $2.12 E+06$ & $2.10 E+06$ & $0 E+06$ & $4.19 E+\infty 6$ & $2.96 E+06$ & $3.65 E+06$ & $4.21 \mathrm{E}+06$ & $4.13 E+\infty 6$ & $3.74 E+06$ & 4.23E+06 \\
\hline $\mathrm{Na}(\mathrm{M})$ & $74 E+\infty$ & $4.39 E+\infty)$ & $4.00 E+\infty$ & $43 E+\infty 0$ & $5.21 \mathrm{E}+\infty$ & $5.87 \mathrm{E}+00$ & $5.20 E++0$ & $5.95 E+\infty$ & $4.38 E+\infty$ & $4.37 \mathrm{E}+\infty$ & $4.98 E+00$ \\
\hline SPG & $1.28 E+\infty 0$ & $1.21 E+\infty$ & $1.17 E+\infty$ & $1.31 E+\infty 0$ & $1.26 \mathrm{EE}+\infty$ & $1.27 \mathrm{E}+\infty$ & $1.29 E+\infty$ & $1.28 E+\infty$ & $1.19 E+\infty$ & $1.18 E+\infty 0$ & $1.21 \mathrm{E}+\infty$ \\
\hline Proc. T & 291 & 114 & 103 & 331 & 268 & 213 & 237 & 307 & 222 & 201 & 25 \\
\hline Corrosion Spec M & $\mathrm{Y}$ & & $\bar{Y}$ & $\mathrm{Y}$ & & & & & $\gamma$ & $\mathrm{Y}$ & \\
\hline
\end{tabular}




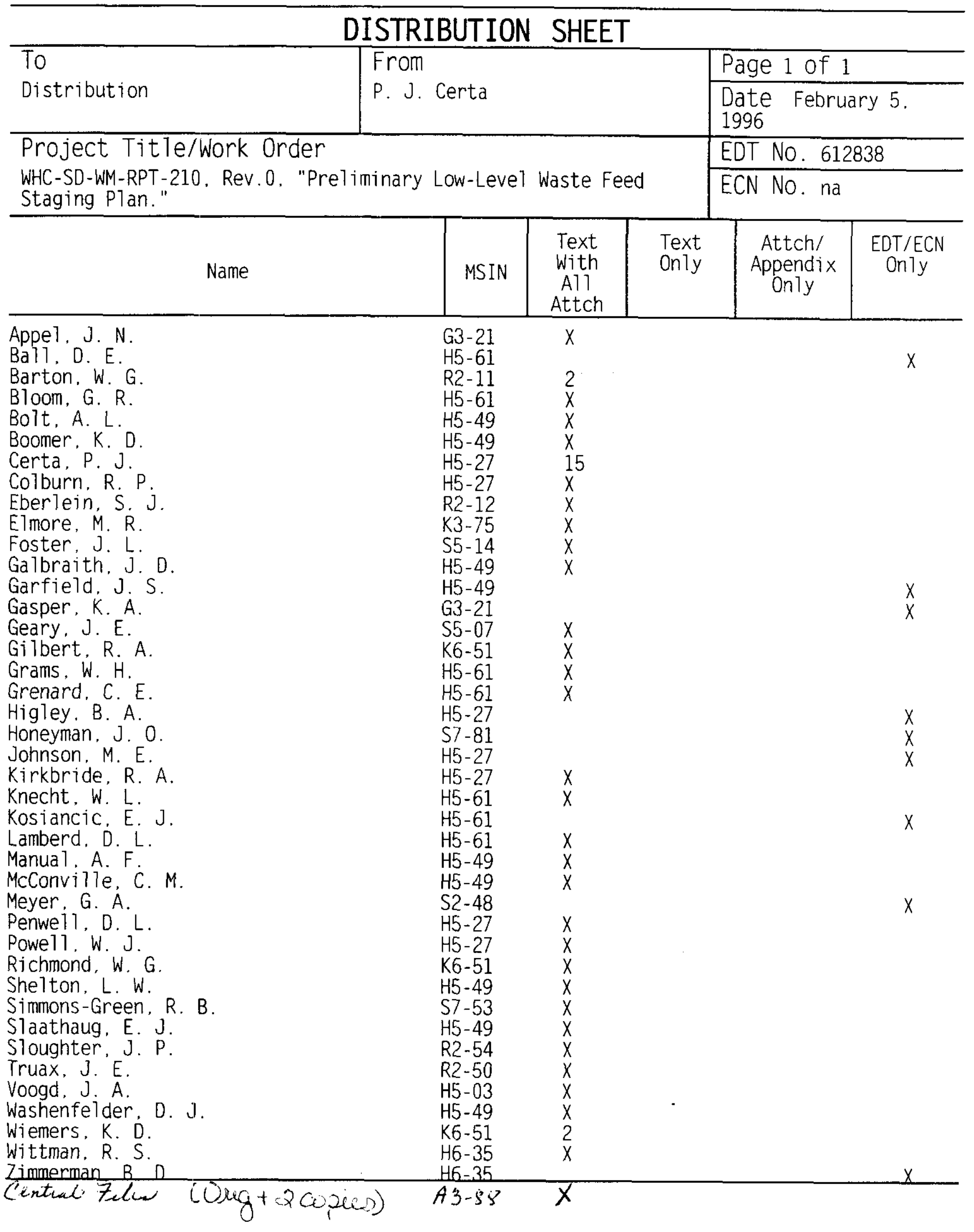

